\section{ORAL PRESENTATION ABSTRACTS}

\section{OP-001 \\ ANALYTICAL PERFORMANCE ASSESSMENT OF BIOCHEMISTRY ANALYSER}

Fevziye Burcu Șirin $^{1}$, Halil İbrahim Büyükbayram¹, Duygu Kumbul Doğuç', Ayşenur Atay

${ }^{1}$ Department of Medical Biochemistry, Faculty of Medicine, Suleyman Demirel University, Isparta

${ }^{2}$ Department of Medical Biochemistry, Atatürk Trainning and Research Hospital, Katip Celebi University, Izmir

OBJECTIVES: The aim of the study was to asses analytical performance of biochemistry analyser with two different TEa values which were determined by the Turkey Ministry of Health-Medical Laboratory Services Standardization Harmonization Working Group and Clinical Laboratory ImprovementAmendments (CLIA). The comparison of sigma values calculated with these TEa was aimed also. MATERIALS and METHODS: The study was conducted by using the internal quality and external quality control data of Beckman AU 5800 autoanalyzer (November 2017 - April 2018). Two levels of internal quality control data were used to calculate the $\mathrm{CV} \%$. Bias \% values were obtained from the data of external quality control results for 6 months period. Monthly TE and sigmametrics were calculated for each parameter. RESULTS: The total analytical error values of all 15 parameters were below the values determined by the Turkey Ministry of Health. However creatinine, albumin and urea tests were above CLIA-TEa limits only once. Urea and albumin were Sigma $<3$ according to both criteria. In these tests, low sigma values were more frequently observed with CLIA-TEa. The sigma of creatinine test was $<3$ for one month. Sigma levels of triglyceride were Sigma $<3$ only by using Turkey-TEa. CONCLUSIONS: Calculation of the total analytical error may may not be sufficient as an analytical quality indicator. It should be calculated together with the sigma metrics at the same time. Sigma metric calculation can be affected by a random high bias value from external quality control. Selection of appropiate TEa value for calculation is very determinative. Keywords: Total allowable error, sigma metric, analytical quality indicator

\section{OP-002 \\ EVALUATION OF THE STABILITY OF THE COMPENSANTORY JAFFE METHOD WITHIN THE DAY}

Ayla Yildiz, Esma Yücetaş, Cihan Coșkun, İbrahim Yılmaz, Yasemin E. Doventas, Macit Koldas

H.S.U. Haseki Education and Research Hospital Medical Biochemistry Laboratory, Istanbul

OBJECTIVES: The Jaffe method is the most commonly used method for the measurement of creatinine and is influenced by components such as proteins, glucose, ascorbic acid, ketone bodies, etc. Kinetic Jaffe (compensatory) method which is traceable according to Isotope Dilution Mass Spectroscopy (IDMS) is used in our laboratory. With atmospheric $\mathrm{CO} 2$ absorption, the calibration stability of the Jaffe reagent may deteriorate. Therefore daily calibrations are applied in our laboratory. There is no information about any deviation within the day. We decided to do this work in response to occasional feedback from clinics. MATERIALS and METHODS: Creatinine measurements were performed on two autoanalyzers ( AU2700 Biochemstry Autoanalyzer, BeckmanCoulter). Daily calibrations and internal quality controls were studied. Creatinine levels of the patients were measured at 10:00, 13:00 and 16:00 (twice) and the averages were taken and compared. The possible variables were excluded by using the same calibration and control lots RESULTS: When the averages of creatinine measurements within the day were compared, and there was no significant difference $(\mathrm{p}=$ 0.259). Also, a CV of 6 measurements made for the same sample was calculated and observed to be within acceptable limits. Similarly, there was no significant difference between the eGFR values $(p=0.196)$. CONCLUSIONS: The creatinine test is one of the most requested tests. In addition, the accuracy of creatinine-based assays (creatinine clearance, eGFR, urine creatinine, etc.) is dependent on reliable measurement of creatinine. This preliminary study demonstrates that there is no deviation in creatinine measurements with the Jaffe method during the day by daily calibration. Keywords: Creatinine, Jaffe, IDMS

\section{OP-003}

EVALUATION OF SYSMEX UF-5000 AUTOMATED URINE SEDIMENT ANALYZER PERFORMANCE

Zeynep Arıkan ${ }^{1}$, Müjgan Ercan Karada $\breve{g}^{2}$

${ }^{1}$ Ceyhan State Hospital, Biochemistry Laboratory,Adana

${ }^{2}$ Harran Faculty of Medicine, Department of Biochemistry, Sanliurfa in clinical laboratories. Automated urine analysis is usually preferred for laboratories with intensive workload. The aim of this study was to evaluate the performance of the automated urine analyser Sysmex UF-5000 MATERIALS and METHODS: A total of 337 first morning urine samples were studied by both UF-5000 and manual microscopy concurrently. The degree of concordance (Kappa coefficient) were evaluated. The sensitivity and specificity for the UF-5000 compared to manual microscopic examination were assessed. Carry over studies was also performed. RESULTS: The degree of concordance of erythrocyte and leukocyte counts in microscopy of 337 urine specimens with manual microscopy was found to be 0.53 and 0.73 respectively (kappa coefficient). The sensitivity and specificity values of RBC and WBC were calculated for UF-5000 as \%97.5, \%88.88, \%92.18, \%96.65, respectively. The results of carry over analysis for both RBC and WBC were $\% 0$. CONCLUSIONS:Thesedimentmicroscopyanalysisoferythrocytesandleukocytes with UF-5000 presented moderate and good correlation with manual microscopy. Keywords: Sediment,Urine,UF 500

\section{OP-004 \\ COMPARISON OF TEST RESULTS OBTAINED FROM LITHIUM HEPARIN GEL TUBES AND SERUM GEL TUBES}

\section{Serif Ercan}

Lüleburgaz State Hospital, Department of Medical Biochemistry, Kırklareli

OBJECTIVES: Serum is the most commonly used sample in biochemical analysis. However, there is currently trend that plasma might be alternative to serum due to some of its advantages. This study aimed to compare test results obtained from lithium heparin gel tubes and serum gel tubes. MATERIALS and METHODS: A total of 40 participants (20 healthy, 20 hemodialysis patients) were included to the study. Blood samples were drawn into serum gel tubes with clot activator (Greiner-Bio-One) and lithium heparin gel tubes (Greiner-Bio-One). 28 analytes analyzed frequently in clinical biochemistry laboratory were measured in serum and plasma samples on Cobas c501 (Roche Diagnostics) analyzer. To determine whether there was significant difference among test results, total error (TE) was calculated and compared total allowable error (TEa) limits based on Republic of Turkey Ministry of Healthy. For tests whose TEa limits have not been defined by this reference, limits based on CLIA and biological variation were used RESULTS: TE of below 5\% was calculated for sodium, calcium, chloride, amylase, urea, LDL-measured, glucose, magnesium, cholesterol, uric acid, AST and HDL. LDH, CK, iron, total bilirubin, total protein, CRP, potassium, albumin and triglyceride had TE of 5-7\%. TE of 7-10\% were determined for ALT, lipase, creatinine, phosphorus, LDL-calculated, direct bilirubin, GGT and ALP. CONCLUSIONS: It was concluded that test results of 28 analytes measured in lithium heparin gel tubes are comparable to those of serum gel tubes. It is thought that several advantages including reduced turnaround time might be provided by using plasma instead of serum in analysis of these tests. Keywords: gel separator, lithium heparin, plasma, sample types, serum

\section{OP-005 \\ DATA LOSS FROM INSTRUMENT RESULT PAGE TO THE LABORATORY RESULT PRINT}

Özgür Aydın

Kepez Public Hospital, Biochemistry, Antalya

OBJECTIVES: Hematology instruments in our laboratory analyze patient samples; send the results of selected parameters to the laboratory information system, and finally we report the results in a format designed according to the instructions of the government. The two data media were searched for composition and content. MATERIALS and METHODS: On 24 July 2018, 100 consequent patient results were viewed on the instrument results screen and recorded. Then, laboratory results of the patients were printed. The two results were compared, especially concerning the flags and histograms. RESULTS: 40 results in 100 , contained at least 1 flag. 18 in 40 results with flags were "Hypochromia", "Microcytosis" and "Anisocytosis". These 3 flags were considered to be estimated by the quantitative results of the patients. In the remaining 22, "Immature neutrophils", "Blasts", "Cellular interference", "Giant platelets", "Platelet clusters", "Variant lymphocytes", "NRBC" and "Eosinophilia"' were flags. Except "Eosinophilia", they were considered to have no counterpart in the laboratory results prints. CONCLUSIONS: Flags related to hypochromic microcytic anemia composed the majority of the flags. Absence of these flags may be clinically harmless. The others on the contrary, necessitate a peripheral smear evaluation, which might contribute to important clinical decision. Clinicians did not request a peripheral smear for any of patients in 15 days of follow-up. The missing flags, as present in the instrument result page but absent on the laboratory result page is a data loss, that has a potential impact on clinical decision. I suggest, they necessitate a peripheral smear evaluation as a reflex test. Keywords: flags, hemogram, peripheral smear, result report 


\section{OP-006 \\ RELATIONSHIP AMONG INTERNAL QUALITY CONTROL, EXPONENTIALLY WEIGHTED MOVING AVERAGES, PATIENTS RESULTS}

\section{Hikmet Can Cubukçu, Erdinç Devrim \\ Ankara University Faculty of Medicine Department of Medical Biochemistry}

OBJECTIVES: This study set out to investigate the efficiency of normal and high-level internal quality control results and exponentially weighted moving averages (EWMA) for reflecting analytic error affecting patient results. MATERIALS and METHODS: Three months of data of internal quality control results and averages of daily patient results belongs to free thyroxine(fT4), thyroid stimulating hormone(TSH) were obtained from the laboratory information system. The relationship between daily internal quality control results, EWMAs and daily patient results were analyzed by Pearson correlation test. The highest correlations between EWMA and patient results average was determined by changing the weighting factor " $\lambda$ value" which is used for EWMA calculation. RESULTS: When the relationship with the patient results averages is examined; the correlation coefficients ( $\mathrm{r}$ ) for fT 4 were found to be 0.26 and 0.37 , respectively $(\mathrm{p}<0,05)$. The highest $r$ values belong to EWMA were found to be 0.34 $(\lambda=0.15)$ and $0.42(\lambda=0.6)$ for the normal and high levels, respectively $(p<0,05)$. The $r$ values of normal and high internal quality control results for TSH were found be $0.14(p=0,222)$ and $0.30(p<0,05)$ respectively. The highest $r$ values belongs to EWMA were $0.17(\lambda=0,55 \mathrm{p}=0,125)$ and $0.36(\lambda=0.55, \mathrm{p}<0,05)$ for the normal and high levels.

CONCLUSIONS: The results of high-level quality control tests were found to be more effective in detecting analytical errors of fT4 and TSH tests. This efficiency can be increased by selecting the appropriate $\lambda$ value for EWMA calculation. Keywords: internal quality control, exponentially weighted moving average, analytical error, fT4, TSH

\section{OP-007 \\ THE IMPORTANCE OF NECTIN2 AND NECTIN4 ADHESION MOLECULES IN BREAST TUMORS}

Murat Serilmez ${ }^{1}$, Ceren Tilgen Yasasever ${ }^{1}$, Elif Bilgin Doğru ${ }^{1}$, Süleyman

Bademler $^{2}$, Hasan Karanlık ${ }^{2}$, Sezai Vatansever

${ }^{1}$ I.U Oncology Institute Department of Basic Oncology

${ }^{2}$ Istanbul University Oncology Institute Department of Clinical Oncology

OBJECTIVES: Breast cancer is still the leading cause of cancer deaths in women.Nectins, which are CAM, play a role in several intercellular junctions. close follow-up of patients with primary breast cancer increases the feasibility of effective treatments. We aimed to investigate both protein and mRNA levels of nectin-2,4, which are considered to be diagnostic and prognostic in these cancers, in serum material. The results obtained will be compared with healthy controls and the possible differences between the two groups will be determined statistically.

MATERIALS and METHODS: Serum levels of nectin-2 and nectin-4 molecules to be studied will be determined by ELISA and mRNA levels by RT PCR. cDNA synthesis is performed from total RNAs.GAPDH is used as the internal control and SYBR Gren as the fluorescence molecule to determine the expression in serum. Measurement of expression levels will be performed on RT PCR System. The present work was supported by the Research Fund of Istanbul University. Project no: 24745

RESULTS: 60 cases of breat cancer were enrolled in the study. Serum nectin-2 and nectin-4 protein levels were significantly lower in patients with lung cancer than the healthy contorls. The obtained nectin gen expression data and conclusions of this study will be presented oral presentation.

CONCLUSIONS: Nowadays breast cancer, diagnosis and development of new effective treatment methods, cancer is associated with an understanding of the biochemical and molecular characteristics of the cell. Different transcription in tumor cells, changes in signal transduction, know the balance of factors affecting proliferation new treatment in future breast cancer options.

Keywords: nectin2,4, adhesion molecule, breast cancer

\section{OP-008 \\ EVALUATING THE ANTI-TUMOROGENIC POTENTIAL OF MEMANTINE IN 4T1 MICE BREAST CANCER TUMOR MODEL}

Gülşah Albayrak ${ }^{1}$, Elif Burcu Bali ${ }^{2}$, Funda Demirtaş Korkmaz ${ }^{3}$,

Selen Güçlü Durgun ${ }^{3}$, Emin Ümit Bağrıaçık ${ }^{4}$

${ }^{1}$ Ufuk University, Faculty of Medicine, Department of Medical Biology, Balgat Ankara

${ }^{2}$ Gazi University, Vocational School of Health Services, Department of Medical Services and Techniques, Programme of Medical Laboratory Techniques,

Gölbașı, Ankara

${ }^{3}$ Gazi University, Faculty of Medicine, Department of Medical Biology and Genetics, Beşevler, Ankara

${ }^{4}$ Gazi University, Faculty of Medicine, Department of Immunology, Beșevler,

Ankara
Memantine, is one of the most commonly used drugs for the treatment of Alzheimer's disease. Despite many studies investigate its clinical and therapeutic usage, its in vivo effect on cancer cells has not been investigated yet. In this study, it is aimed to reveal the potential in vivo usage of Memantine as an anti-cancer agent on the 4T1 mouse breast cancer tumor model. MATERIALS and METHODS: $30 \mathrm{Balb} / \mathrm{c}$ female mice were subcutaneously inoculated with 4T1 cells to form a breast cancer tumor and 5 and $10 \mathrm{mg} / \mathrm{kg}$ doses of Memantine were injected intraperitoneally after palpable tumor formation. Tumor growth was measured using calipers every $2-3$ days. Total protein isolation from tumor tissues was done when the experimental procedure is over. The effects of memantine on tumor progression were assessed by western blotting. RESULTS: It was concluded that Memantine does not impact the tumor size whereas it affects cell energetics related (mTOR, GSK3beta ve PGC1a) and metastasis (E-kaderin, Vimentin ve B-Katenin) related protein expressions. CONCLUSIONS: This is the first study that investigates the anti-cancer effect of Memantine in vivo as a repositioned drug candidate. We strongly belive that after more detailed investigation of Memantine's molecular mechanism over cancer cells, its potential usage as a therapeutical option would be assessed better. (This research was supported by Gazi University BAP Number: 64 / 2018-01). Keywords: Memantine, 4T1, breast cancer, in vivo

\section{OP-009 \\ WWOX KNOCKOUT CELLS EXHIBIT CHROMOSOMAL ALTERATIONS AND COPY NUMBER VARIATIONS}

Bahadır Batar $^{1}$, Kay Huebner ${ }^{2}$

${ }^{1}$ Department of Medical Biology, Namik Kemal University School of Medicine, Tekirdag

${ }^{2}$ Department of Cancer Biology and Genetics, The Ohio State University Wexner Medical Center, Columbus, OH, USA

OBJECTIVES: Our aim is to determine if Wwox contributes to genome stability. MATERIALS and METHODS: Karyotype and copy number variation (CNV) analyseswerecarriedoutusingWwox-knockoutandWwox-wildtypeMEFcelllines. CNVs were detected through array comparative genomic hybridization (aCGH) RESULTS: Karyotype analysis of three cell lines (two knockout and one wild type, established from Wwox-knockout mouse models) showed near tetraploidy with chromosomal losses and gains. Both knockout MEFs exhibited two structural abnormalities not present in the wild-type cell line: $\operatorname{del}(7)$ and $\operatorname{del}(4)$ Loss of the distal arm of chromosome 4 encompasses the murine Cdkn2a gene, encoding p16, a locus frequently deleted in human cancers and in cultured cells. CNVs were assessed in DNAs of MEFs from two distinct Wwox-knockout mouse models and compared with DNAs from corresponding wild-type littermates (cell line pairs, KO5/WT4 from Wwox-knockout and Wwox5/Wwox3 from a different Wwox-knockout mouse model). Three distinct deletions were observed in the two knockout MEF lines at chromosome locations 1, 4, and 8 . CONCLUSIONS: The karyotype and CNV results suggest that Wwox participates in protecting the genome from damage.

Keywords: Wwox, genome stability, copy number variation, deletion

\section{OP-010}

ESCULETIN ENHANCES CASPASE-DEPENDENT APOPTOTIC CELL DEATH AND INSULIN SECRETION IN INS-1 CELLS

\section{Ayse Karatug Kacar \\ Istanbul University, Faculty of Science, Department of Biology, Istanbul}

OBJECTIVES: Insulinoma INS-1 cells are pancreatic tumors that have been shown importantcharacteristics of pancreaticbetacells. Esculetinisacompoundofcoumarin and has shown inhibitory effect on other cancer cell lines. The aim of this study was to investigate occurred cellular death and molecular mechanism in INS-1 cells. MATERIALS and METHODS: We have used INS-1 cell line in this study. The cell viability was assessed with WST-1 assay. The cell proliferation was indicated with Cell Proliferation ELISA, BrdU (colorimetric) kit. Apoptosis fold increase was determined using Cell Death Detection ELISA Kit. Necrosis was determined by ELISA using LDH Kit. The heat shock protein 70 (HSP70) levels, full caspase-3 levels and Beclin-1 levels were showed by Western Blotting. Reactive oxygen species were measured by using dichlorofluorescein diacetate. Insulin levels were analyzed by ELISA method. RESULTS: Cell viability and cell proliferation decreased with esculetin given in increasing doses in INS-1 cells. Apoptotic cell death was 32 fold increased by the administration of $3000 \mathrm{uM}$ esculetin compared to the control group. Full caspase-3 levels decreased in given $3000 \mathrm{uM}$ esculetin group according to control group. There was no difference between control group and experimental group at levels of necrotic cell death, the cellular autophagy marker Beclin-1, HSP 70 and reactive oxygen species. Insulin levels were increased with given $3000 \mathrm{uM}$ esculetin. CONCLUSIONS: As a result, administration of esculetin to INS-1 cells caused caspase-dependent apoptotic cell death. Esculetin increases insulin secretion which is important for beta cells to protect the remaining cells during death. Keywords: Insulinoma, INS-1 cell line, apoptosis, insulin 


\section{OP-011 \\ THE RELATIONSHIP WITH APOPTOSIS OF BORTEZOMIB RESISTANCE IN MULTIPLE MYELOMA CELL LINES}

Emine Öksüzoğlu, Gül Kozalak

Moleculer Biology Division, Department of Biology, Faculty of Science and

Letter, Aksaray University, Aksaray

OBJECTIVES: The most important problem in treatment of cancer is the development of resistance against cancer drugs. Multiple Myeloma (MM) is hematological cancer characterized by the accumulation of malignant plasma cells in bone marrow. Bortezomib is one of the most effective chemotherapeutic drugs used in treatment of MM. However, resistance against bortezomib in cancer treatment process is a frequent occurrence. For this reason, we were investitigated expression levels of bcl-2, bax, kaspas-3 and p-53 genes in apoptosis mechanism related to bortezomib resistance in multiple myeloma. MATERIALS and METHODS: Bortezomib-resistant(KMS20) and bortezomibesensitive(KMS28) cell lines were provided for this study. MTT assay was performed to confirm that the cell lines were resistant/sensitive and IC50 values of bortezomib were determined. RNA was isolated from both cell lines and cDNAs were obtained. Expression levels of studying genes were analyzed by qRT-PCR. RESULTS: In gene expression analysis results, the bcl-2/bax ratio was found to be 1.14 versus $5 \mathrm{nM}$ bortezomib in KMS20(resistant) cell line and 0.49 in KMS28(sensitive) cell line. For the $25 \mathrm{nM}$ bortezomib dose, the bcl-2/bax ratio was found to be 1.13 in KMS20 cell line, and 0.09 in KMS28 cell line. Expression of the kaspas-3 gene is decreased in KMS20 cell line while it increases in KMS28 cell line. CONCLUSIONS: Accordingly, apoptosis is suppressed in KMS20 cell line and cells are resistant to bortezomib, whereas apoptosis is induced in KMS28 cell line and cells become sensitive to bortezomib. Our results will allow to understand the molecular mechanisms causing drug resistance in cancer. Keywords: Apoptosis, Bortezomib, Cancer, Drug Resistance, Multiple Myeloma

\section{OP-012}

MDR TRANSPORTERS RESPONSIBLE FOR TIME-DEPENDENT EXTRUSION OF BORTEZOMIB FROM MULTIPLE MYELOMA CELLS

Gül Kozalak, Emine Öksüzoğlu

Moleculer Biology Division, Department of Biology, Faculty of Science and Letter, Aksaray University, Aksaray

OBJECTIVES: Cancer is the most common causes of death in world. Multiple Myeloma (MM) is hematological cancer characterized by accumulation of plasma cells. Bortezomib is the most effective chemotherapeutic drug used in treatment. However, resistance to bortezomib affects MM treatment negatively. Therefore, changes in gene expression of drug resistanceassociated proteins [MDR-1(P-gp), MRP-1, MRP-2, MRP-3, MRP-6, MRP-7 and GSTP-1] depending on time were investigated in MM cell lines. MATERIALS and METHODS: IC50 values of bortezomib were determined by MTT assay in KMS20 (resistant) and KMS28 (sensitive) MM cell lines. Both cells were exposed to doses of 5 and $25 \mathrm{nM}$ bortezomib for 24 and 48 hours to RNA isolation. Then cDNAs were obtained and expression levels of genes were analyzed by qRT-PCR. RESULTS: qRT-PCR results showed that MDR1, MRP1 and MRP7 genes increased in KMS20 for 24 and 48 hours. In KMS28; MRP1, MRP2, MRP7 and GSTP1 genes were increased, MDR1 gene was not detected. MRP6 gene was decreased, MRP3 gene was not observed in both cell lines. CONCLUSIONS: In this study which we performed by exposing MM cells to higher doses of bortezomib for long-term, MDR1, MRP1 and MRP7 gene overexpressions were observed in KMS20. This increase in MRP1 gene expression different from our previous study, was due to long-term exposure of cell to high doses of bortezomib. The reason of increase in expression GSTP1, MRP1, MRP2 and MRP7 gene in KMS28 is also long-term exposure to high doses of bortezomib. Conclusively, the use of these gene expression inhibiting agents together with bortezomib, may allow to show expected effects on MM cells. Keywords: Bortezomib, Cancer, Drug Resistance, MDR, Multiple myeloma.

\section{OP-013 \\ CURATIVE EFFECTS OF B-GLUCAN AGAINST TCDD-INDUCED OXIDATIVE KIDNEY DAMAGE IN RATS}

Kürșat Kaya ${ }^{1}$, Osman Ciftçi ${ }^{2}$

${ }^{1}$ Adiyaman University Faculty of Pharmacy, Department of Biochemistry,

Adiyaman

${ }^{2}$ Pamukkale University Faculty of Medicine, Department of Medicinal Pharmacology, Denizli

OBJECTIVES: 2,3,7,8-Tetracholorodibenzo-p-dioxin (TCDD) is an environmental contaminant and it is formed in the manufacture of chlorinated hydrocarbons, incineration processes, paper and pulp bleaching and emissions from steel foundries and motor vehicles. $\beta$-glucan $(\beta \mathrm{g})$ is natural polysaccharide that have pharmacological activities such as immunomodulation and antioxidant activity. The aim of this study was to investigate the effectiveness of $\beta \mathrm{g}$ on TCDD-induced oxidative kidney damage in rats.
MATERIALS and METHODS: Rats (n:32) were divided randomly into 4 equal groups. One group was kept as control and given corn oil as carrier. In second group, TCDD dissolved in corn oil was orally applied at the dose of $2 \mu \mathrm{g} / \mathrm{kg}$ / week for 30 days. In third group, $\beta \mathrm{g}$ was orally applied at the dose of $50 \mathrm{mg} / \mathrm{kg}$ day by gavages. In fourth group, TCDD and $\beta$ g were given together at the same doses. At the end of 30 days, the rats were euthanized under ether anesthesia. RESULTS: TCDD administration significantly increased TBARS levels, a marker of lipid peroxidation and significantly reduced SOD, CAT, GSH, and GPx levels which are members of the antioxidant defense system. However, $\beta \mathrm{g}$ treatment significantly improved TCDD-induced oxidative damage in the rat kidney tissue. CONCLUSIONS: As a result, the oxidative stress caused by TCDD has been removed by the $\beta \mathrm{g}$ in rats in a time-dependent manner. Thus, $\beta \mathrm{g}$ may be useful for the prevention and treatment of renal damage due to TCDD.

Keywords: 2,3,7,8 TCDD, Beta-glucan, Nephrotoxicity

\section{OP-014 \\ BLOOD MDA AND GSH LEVELS IN GASTRITIS AND CANCER PATIENTS}

Aysel Güven ${ }^{1}$, Samet Kisaçam²

${ }^{1}$ Pathology Laboratory Technicians, Vocational School of Healthcare Services, Baskent University, Ankara.

${ }^{2}$ Department of Biyology, Faculty of Science and Arts. Kafkas University, BiologyKars.

OBJECTIVES: To determine the role of increasing lipid peroxidation and declining GSH's on cancer and gastritis; despite the fact that the role of antioxidant systems on cancer and gastritis is still unknown.

MATERIALS and METHODS: Blood MDA and GSH levels of gastritis and cancer patients was determined by comparting the control group, 13 healthy individuals, with the total of 25 experimental groups, which consisted of 13 gastritis patients and 12 cancer patients, who applied to the Research and Application Center of Kafkas University to be in the research. RESULTS: GSH values for healthy group was $1.65 \pm 0.43 \mathrm{~mol} / \mathrm{ml}, 1.89 \pm 0.24 \mathrm{~mol}$ $/ \mathrm{ml}$ in the gastritis group and $1.51 \pm 0.28 \mathrm{~mol} / \mathrm{ml}$ in the gastric cancer patients. In the control group the MDAvalue was $0.67 \pm 0.66 \mathrm{nmol} / \mathrm{ml}$, gastritis group value was 2.97 $\pm 1.77 \mathrm{nmol} / \mathrm{ml}$ and $3.65 \pm 2.46 \mathrm{nmol} / \mathrm{ml}$ was the result in the gastric cancer patients. MDA levels in gastritis and gastric cancer patients were statistically significant ( $p$ $<0.05$ ) compared to the control group

CONCLUSIONS: Although the etiology of gastric cancer in humans is not fully known, according to this study it is possible to say that antioxidant defense system, increased oxidative stress and lipid peroxidation plays an important role in gastric carcinogenesis.

Keywords: Malondialdehyde (MDA), Reduced Glutathione (GSH), Cancer Gastritis

\section{OP-015 \\ THE ROLE OF COAGULATION PROTEASES IN REGULATION OF ENOS UNCOUPLING IN DIABETIC NEPHROPATHY}

İbrahim Söğüt

T.C. Istanbul Bilim University, Vocational School of Healty Services, Istanbul

OBJECTIVES: Diabetic nephropathy (dNP) is caused by extracellular matrix accumulation in mesangium after primary alterations in glomerulus and podocytes. Activated Protein C (aPC), being a coagulation protease, inhibits coagulation, apoptosis, and inflammation in intact endothelia cells. In this study, we tried to identify the mechanisms through which coagulation-protease-dependent signaling regulates eNOS activity. MATERIALS and METHODS: We used high-glucose-exposed mouse podocytes (mp-HG) as well as diabetic models (wild type; WT-D and high-level actived protein $\mathrm{C}$ synthesizing transgenic mice; APChigh-D) that were formed by streptozotocin (STZ) administration. aPC was administered as a therapeutic group. PLA was conducted to the mp test groups. BUN levels were measured in experimental groups. In addition to this, PAR-1,2,3,4, eNOS, Arjinaz-2, Caveolin-1, DHFR, Akt total protein levels were determined by immunoblotting. PAS and WT-1 staining were also carried out as pathohistochemical markers. RESULTS: Increased interaction between Arg-2 and eNOS following high glucose administration to $\mathrm{mp}$ was lowered with aPC administration $(\mathrm{p}<0.01)$. While PAR2 levels decreased, PAR-3 total protein levels increased $(\mathrm{p}<0.001)$ in experimental groups. Increased BUN levels, eNOS, Arg- 2 and Cav-1 total protein levels in diabetic groups were decreased with aPC administration (respectively $\mathrm{p}<0.05$ $\mathrm{p}<0.05, \mathrm{p}<0.001$ ve $\mathrm{p}<0.05$ ). Decreased DHFR and Akt total protein levels in diabetic groups were increased with aPC administration (respectively $\mathrm{p}<0.05$ and $\mathrm{p}<0.01)$. The rate of glomerular mesengial accumulation increased with diabetic conditions were decreased with aPC administration $(\mathrm{p}<0.001)$. The decreased cell viability with diabetes were increased with aPC administration $(\mathrm{p}<0.001)$. CONCLUSIONS: In conclusion, aPC, known as an important element in coagulation cascade, also mediates eNOS activity in dNP. Keywords: Activated protein C, arginase-2, diabetic nephropathy, Dihydrofolate reductase, eNOS, PAR-3 


\section{OP-016}

THE PROTECTIVE AND ANTIOXIDANT EFFECTS OF ASTAXANTHIN AGAINST CISPLATIN-INDUCED TOXICITY IN RATS

Saniye Ada ${ }^{1}$, Dilek Özbeyli ${ }^{2}$, Sezen Gizem Aydoğan ${ }^{3}$, Canan Hürdağ $\breve{g}^{3}$, Meral Yüksel ${ }^{4}$, Mustafa Baki Cekmen

${ }^{1}$ Department of Biochemistry, School of Medicine, Medeniyet University, İstanbul

${ }^{2}$ Department of Pathology Laboratory Technicianship, Vocational School of Health Related Services, Marmara University, İstanbul

${ }^{3}$ Department of Histology and Embryology, School of Medicine, Istanbul Bilim University, İstanbul

${ }^{4}$ Department of Medical Laboratory Technicianship, Vocational School of Health Related Services, Marmara University, İstanbul

OBJECTIVES: Cisplatin (Cis) is a platinum-based drug,which is used as a chemotherapeutic agent.Cis has several side effects such as ototoxicity,nephrotoxicity and neurotoxicity.Astaxanthin (Ast) is a carotenoid pigment with antioxidant and anti-inflammatory effects. The aim of this study is to determine the possible protective and antioxidant effects of astaxanthin against cisplatin-induced toxicity in rats MATERIALS and METHODS: Sprague-Dawley rats were included in the study $(\mathrm{n}=32)$.Cis was given i.p. at a dose of $8 \mathrm{mg} / \mathrm{kg} /$ day for three days.Ast group received additionally $100 \mathrm{mg} / \mathrm{kg} / \mathrm{day}$ via gavages for 10 days. Control received olive oil at the same dose.Rats were sacrificed,blood was collected for determination of BUN, creatinine, ALT, AST, hsTNI, TNF- $\alpha$, IL-6 and liver, kidney and heart tissues were removed for determination of oxidative stress parameters such as malondialdehyde(MDA),glutathione(GSH) levels and myeloperoxidase (MPO) activity.

RESULTS: The BUN,creatinine, ALT, AST, hsTNI, TNF- $\alpha$, IL- 6 levels are $(p<0.001)$ increased in Cis group to the control group.Cis +ast group reversed TNF- $\alpha$, ALT and hsTNI levels. MDA levels were higher in liver and heart tissues in Cis group, because kidney MDA levels were not different. GSH levels in kidney tissues were different higher in Cis group $(\mathrm{p}<0.001)$. MPO activity,which shows inflammation, is increased in all tissues of Cis treated rats.Ast treatment reverses the effects of Cis via reducing MPO activity,because the antioxidant effects to MDA and-or GSH levels in kidney,heart and liver tissues were not changed. CONCLUSIONS: Our findings suggested that Cis treatment induced damage in liver,heart and kidney tissues.Inflammation is the major mechanism which can be reduced with Ast treatment.Results of oxidative stress parameters show that Cis treatment reveals with "Cisplatin resistance" with increasing GSH levels in these groups.

Keywords: : Astaxhantin, Oxidative Stress, Cisplatin, Toxicity

\section{OP-017 \\ EFFECTS OF GENDER AND GLUCOSE-BASED NUTRITION ON REDOX HOMEOSTASIS IN DROSOPHILA MELANOGASTER}

Karolin Yanar

Department of Medical Biochemistry, Cerrahpașa Faculty of Medicine, Istanbul University-Cerrahpaşa, Istanbul

OBJECTIVES: Currently, Drosophila melanogaster has been used as a model organism in various experimental studies such as aging-lifespan, nutrition, disease models. In our study, we aimed to evaluate effects of high sucrose and protein-based nutrition on redox homeostasis in Drosophila melanogaster according to gender. MATERIALS and METHODS: Drosophila melanogaster colonies were divided into 4 groups as female and male flies feeding with low glucosehigh protein based medium and female and male flies feeding with high glucose high protein based-medium. Protein oxidation biomarkers such as protein carbonyl (PCO), dityrosin (DT), formylkynurenin (FKYN), $\mathrm{N}$-formylkynurenine (NFKYN), lipid peroxidation marker lipid hydroperoxide (LHP), glyoxidative stress marker; advanced glycation end products (AGE) levels and antioxidant enzyme; $\mathrm{Cu}, \mathrm{Zn}$-superoxide dismutase activity ( $\mathrm{Cu}, \mathrm{Zn}$ SOD) were analyzed by spectrophotometric or spectrofluorometric methods. RESULTS: Higher levels of PCO, DT, KYN, NFKYN, LHP, AGE levels and reduced activity of $\mathrm{Cu}, \mathrm{Zn}-\mathrm{SOD}(\mathrm{p}<0.001)$ were found in flies- feeding with high glucose-protein based medium as compared to low glucose based medium. Higher oxidative damage levels and conversely, higher $\mathrm{Cu}, \mathrm{Zn}-\mathrm{SOD}$ activity were found in male flies than females $(p<0.001$ for each parameter). CONCLUSIONS: Our results shows that nutrition type plays important role in maintenance of redox homeostasis. Low oxidative damage biomarker levels were shown in females. These data represent similar result with female mammals which are more sheltered against oxidative damage than males. On the other hand, elevated activity of $\mathrm{Cu}, \mathrm{Zn}$-SOD may be considered as compensatory mechanism. Further studies need to clarify possible mechanisms and relationship between signal pathways, lifespans and oxidative damage triangle. Keywords: Nutrition,Gender, Drosophila melanogaster, Redox homeostasis

\section{OP-018}

CAN AVANAFIL AND ZAPRINAST CHANGE SOME SELECTED CYTOKINE LEVELS İN OVARIECTOMIZED RAT'S LIVER?

Zübeyir Huyut ${ }^{1}$, Nuri Bakan², Erdem Çokluk ${ }^{3}$, Halil İbrahim Akbay ${ }^{1}$, Hamit Hakan Alp

${ }^{1}$ Department of Medical Biochemistry, Faculty of Medicine, Van Yuzuncu Y11 University, Van

${ }^{2}$ Department of Medical Biochemistry, Faculty of Medicine, Ataturk University, Erzurum

${ }^{3}$ Department of Medical Biochemistry, Faculty of Medicine, Sakarya University, Sakarya

OBJECTIVES: Itwas reported thatpostmenopausal-period, aphysiological process in women, is associated with increasing bone resorption and oxidative stress due to acute estrogen-deficiency. Studies reported that phosphodiesterase-5 inhibitors positively contribute to bone-mineral-density and thickness, and decrease levels of malondialdehyde, coenzyme Q10 and 8-hydroxy-2-deoxyguanosine, which are associated with oxidative stress. We investigated the changing levels of some selected-proinflamatuar cytokines and TNF- $\alpha$ in the liver of rats with ovariectomy, which have the same condition with postmenapozal period, and effect of Zaprinast and Avanafil (phosphodiesterase-5 inhibitors) on the experimental parameters MATERIALS and METHODS: 24 albino female rats ( 8 months) and weighing 250-350g were used and 4 groups of equal-number were randomly assigned. First group: abdomen region (about $2 \mathrm{~cm}$ ) was opened and again closed (sahm-group). Second group: abdominal region was opened and was performed ovariectomy (OVX). Groups 3 and 4 : the same procedure with OVX group was performed to them and were administered $10 \mathrm{mg} / \mathrm{kg}$ zaprinast and avanafil for 60 days, respectively. IL-1 $\beta$, IL-6, IL- 8 , IL-10 and TNF- $\alpha$ levels were measured by commercially available ELISA kits in liver of rats that were anesthetized after 60 days. RESULTS: IL-1 $\beta$, IL-6, IL-8 and TNF- $\alpha$ levels were increased in groups with OVX compared to sahm group, while they were decreased in zaprinast and especially avanafil-treated groups with OVX and were similar to sahm group values. However, this difference was only significant for IL-1 levels $(p<0.05)$. CONCLUSIONS: The data showed that zaprinast and especially avanafil decreased IL-1 $\beta$ levels. This may support the opinion that phosphodiesterase-5 inhibitors inhibit bone demineralization by inhibiting oxidative stress. Keywords: Avanafil, phosphodiesterase-5 inhibitors, interleukin, ovariectomy, zaprinast

\section{OP-019}

\section{DIRECT BILIRUBIN TEST OVERUSE; AN APPROACH OF RATIONAI} LABORATORY USE

Muammer Yücel, Mehmet Hicri Köseoğlu, Figen Narin Kâtip Celebi University, Atatürk Training and Research Hospital, Medical Biochemistry Laboratory, İzmir

OBJECTIVES: The direct bilirubin analysis is one of the most common tes in clinical biochemistry laboratories. It has been requested together with total bilirubin test by clinicians. We want to investigate unnecessary use of direct bilirubin testing for the last year within the principles of rational laboratory use. MATERIALS and METHODS: The direct bilirubin test is performed by the diazo method on the Architect c16000 (Abbott) autoanalyzer in our laboratory. We investigated the tests in which total and direct bilirubin analyses were ordered together from the patients who had a normal total bilirubin level $(<1.2 \mathrm{mg} / \mathrm{dL})$ between the days of 01.05 .2017 and 30.04 .2018 . Besides, we searched that direct bilirubin results were higher than $0.5 \mathrm{mg} / \mathrm{dL}$ in this group. RESULTS: The number of direct bilirubin analyses, in which total bilirubin results were between reference values, were 181,551 in the last year. Of these results only $1.58 \%(2,876)$ of direct bilirubin test were higher than reference level CONCLUSIONS: Unnecessary tests in clinical biochemistry laboratories lead to labor and financial loss. Direct bilirubin test orders with normal total bilirubin levels should be restricted within the framework of Rational Laboratory Practices. The mild elevations of direct bilirubin with normal total bilirubin levels are not clinically significant. Direct bilirubin should be analyzed as a reflex test in the patients with high total bilirubin levels. In addition, if the total bilirubin is normal, direct bilirubin can also be studied as a reflective testing in accordance with diagnosis. With this application, each laboratory can save cost considerably. Keywords: Direct Bilirubin, Rational Laboratory, Reflex Test

\section{OP-020}

\section{EVALUATION OF SIX SIGMA WITH DIFFERENT QUALITY GOALS;} NEED OF HARMONIZATION AND OTHER PROBLEMS

Murat Keles

Bursa Public Health Laboratory, Bursa

OBJECTIVES: Six Sigma Methodology; is a quality management tool that focuses on process variables and provides information about process performance. This methodology is widely used in clinical laboratories to evaluate analytical process performance and traditionally combines three components: tolerance limits (total allowable error), bias and impression. However, some defects have occurred during the adaptation of this industry-based methodology to clinical laboratories. 
CONCLUSIONS: Downregulation of miR-29b-2 caused overexpression of LOXL2 and HSP47 in hypertrophic scar. Overexpression of these genes enhances the aggresiveness of this disease. The identification of novel pathways regulated by the downregulation of miRNA may lead to a better understanding of molecular pathogenesis in fibrotic diseases. Keywords: hypertrophic scar, HSP47, LOX, miR-29 family, calculation has been performed analyte-based goals which was determinated to the quality expectations of our laboratory in line with Milan hierarchy. MATERIALS and METHODS: Sigma values were calculated using CLIA, Ricos, RCPA and Turkey TEa goals for 15 parameters. The benchmark performance was accepted $3 \sigma$. RESULTS: In our study, RCPA goals are the most stringent, followed by the Ricos BV Desirable, CLIA, and finally the Turkey TEa goals coming in last. According to RCPA goals, seven analytes failed to reach the required sigma level. In contrast, all analytes have met required quality level for Turkey TEa. In analyte-based goals only albumin showed borderline performance when electrolytes were excluded. CONCLUSIONS: It is important to ensure harmonization of tolerance limits for objectively international comparison. Furthermore, it is considered that the utilization of analyte-based goals is the most reasonable way, up to international consensus on tolerance limits. Keywords: Six Sigma, Quality management, Harmonization

\section{OP-021 \\ RATIONAL USE OF LABORATORY TEST REQUEST PROCEDURE: 25-HYDROXY VITAMIN D}

Habib Özdemir, Zeki Arı, Cevval Ulman

Manisa Celal Bayar University Faculty of Medicine, Department of Medical

Biochemistry, Manisa

OBJECTIVES: Rational Use of Laboratory Rational Test Request Procedure released by Ministry of Health, Republic of Turkey on 06 March 2018 recommends 90 day request interval for 25-Hydroxy-Vitamin-D. In this study we aimed to determine the rate of recurrent testing for Vitamin D. MATERIALS and METHODS: Numbers of Vitamin D test requests for year 2017 were obtained from laboratory information system. Patients were divided into two groups as adult and pediatric. Requests were evaluated based on Vitamin D test per patient in 90 days and also as low and normal based on reference range. RESULTS: There were 22580 Vitamin D tests requested in year 2017 and $4290(19 \%)$ of them were repeated test request in 90 days. Among the 4290 repetition of tests for Vitamin D, 4104(95.7\%) of them were requested from adult and $186(4.3 \%)$ test from pediatric patients. The most frequent repetitions were from Internal Medicine inpatient and outpatient clinics $(80 \%)$ within adult patients. It is noteworthy that Vitamin D test results from $2342(56.2 \%)$ adult patients were low if repeated in the last 90 days. CONCLUSIONS: Although the Ministry of Health recommends 90 days testing interval in the procedure, we observed $19 \%$ of repeat rate. Laboratory tests should answer a specific question and be performed only if their results can have an impact on patient care. Because most of our repetitions were from low reference range patients, we believe an exception of 90 days limit for those in needs, could have an impact on patient care. Keywords: Rational Use of Laboratory Test Request Procedure, 25-Hydroxy Vitamin D, Appropriate Test Request

\section{OP-022 \\ MIR-29B-2 REGULATES LYSYL OXIDASE-LIKE 2 AND HEAT SHOCK PROTEIN 47 IN HYPERTROPHIC SCAR}

Duygu Harmanc1 ${ }^{1}$, Ayşe Koçak ${ }^{1}$, Cenk Demirdöver ${ }^{2}$, Gül Güner Akdoğan ${ }^{1}$ Department of Molecular Medicine, Graduate School of Health Sciences, Dokuz Eylul University, İzmir

${ }^{2}$ Department of Plastic Reconstructive and Aesthetic Surgery, School of Medicine, Dokuz Eylul University, İzmir

${ }^{3}$ Department of Medical Biochemistry, School of Medicine, Izmir University of Economics, İzmir

OBJECTIVES: Hypertrophic scars are characterized by erythematous and raised fibrous lesions predominantly composed of excessive amounts of collagen deposits. Despite many studies that have examined the pathophysiology of hypertrophic scars, the underlying causes and the best treatment modalities are still unknown. The miR29 family in humans includes four different members. The particular interest of miR29 family members is due to their ability to inhibit the synthesis of extracellular matrix (ECM) proteins, especially collagens. The aim of this study was to investigate the role of miR-29 family on collagen maturation in primary hypertrophic scar cells. MATERIALS and METHODS: Tissue specimens were collected and established primary normal and hypertrophic scar fibroblast cell cultures. Evaluation of miR-29 familymembers'gene expression was determinedbyusing qPCR.Aftertransfection, extracellular LOX activity was measured using LOX activity kit in supernatants. LOX and HSP47 protein expressions were determined by using Western Blotting. RESULTS: The significant decrease in miR-29b-2 gene expression in skin hypertrophic scar tissue was determined in comparison to healthy control skin. After miR-29b-2 transfection, extracellular LOX activity decreased in transfected hypertrophic scar fibroblast cells compared to non-transfected scar cells. Transfection of primary hypertrophic scar cells with miR29b-2 led to a significant increase HSP47 and LOXL2 protein expression.

\section{OP-023}

\section{MGLU2 MGLU3 EXPRESSION LEVELS AT DIFFERENT} L-GLUTAMATE DOSES IN SCHIZOPHRENIA MODEL

Duygu Vardagli ${ }^{1}$, Muhsin Öztürk ${ }^{2}$, Emel Ulakoğlu Zengin ${ }^{3}$

${ }^{1}$ Medical Laboratory Techniques Program, Istanbul Esenyurt University,

İstanbul

${ }^{2}$ Department of Nutrition and Dietetics, Faculty of Health Sciences, Istanbul Esenyurt University, İstanbul

${ }^{3}$ Cerrahpaşa Medical School, Department of Biochemistry, Istanbul University, İstanbul

OBJECTIVES: Glutamate and glutamate receptors which are widely to serve in the brain synapses, suggesting that the brain main glutamate pathways in the etiology of many diseases hosting psychosis.Although a narrower range as a group of diseases using the diagnostic criteria of psychosis, schizophrenia is one of the diseases in this scale. In this research, we planned a ketamine induced NMDA antagonism in Wistar rats, in order to examine the role of metabotropic glutamatergic receptors modulation and expression in schizophrenia pathology. MATERIALS and METHODS: Ketamine which is an anesthetic is treated daily in $30 \mathrm{mg} / \mathrm{kg}$ for 5 days.On the day when the injections are completed, brain tissues of the animals will immediately be removed under phenobarbitale $(50 \mathrm{mg} / \mathrm{kg})$ anesthesia and these tissues are maintained under $-80^{\circ} \mathrm{C}$ until the laboratory research time. Receptors expression levels are detected by western blotting method in kontrol and ketamine groups and also in the experiment groups generated by different L-glutamate doses. We evaluate the statistical significance of the data, SPSS 20 program. RESULTS: According to the statistical results we obtained in our study; metabotropic glutamate receptor levels (mGlu2, mGlu3 ) in both brain regions prefrontal cortex and striatum were decreased in high concentrations of L-glutamate, whereas no significant changes in the metabotropic glutamate receptor expressions in lower concentrations of L-glutamate. CONCLUSIONS: Decreasing expression level of metabotropic glutamate receptor at high concentrations of L-glutamate suggests that if intracellular calcium concentration state is primary related with autoreceptor function. Keywords: Ketamine, Schizophrenia, mGlu2, mGlu3, Glutamate

\section{OP-024 \\ DETERMINING OF NIS GENE EXPRESSION IN GASTRIC TISSUE OF MORBID OBESE INDIVIDUALS}

Deniz Mıhçıoğlu ${ }^{1}$, Filiz Özbaș Gerçeker ${ }^{2}$, Başar Aksoy $^{3}$, Nimet Yılmaz Süleyman Nezih Hekim

${ }^{1}$ Department of Medical Biology, School of Medicine, SANKO University, Gaziantep

${ }^{2}$ Department of Biology, Faculty of Art and Science, Gaziantep University, Gaziantep

${ }^{3}$ Department of General Surgery, School of Medicine, SANKO University, Gaziantep

${ }^{4}$ Department of Gastroenterology, School of Medicine,SANKO University, Gaziantep

${ }^{5}$ Department of Medical Biochemistry, School of Medicine, Cumhuriyet University, Sivas

OBJECTIVES: Obesity is seen as one of the top ten (10) illness's listed by World Health Organization (WHO). Sodium Iodide Symporter (NIS) gene is a plasma membrane glycoprotein that mediates iodide uptake in thyroid glands, stomach, salivary glands, lactating mammary glands and intestine. The aim of the study is to determine the Sodium Iodide Symporter (NIS) gene expression level between morbid obese and non-obese individuals in gastric tissue. MATERIALS and METHODS: In this study, 33 individuals diagnosed with obesity and control group consisted of gastric tissue of 21 subjects with normal BMI were collected. RNA isolation, cDNA synthesis and qRT-PCR analyses were performed on the samples to determine NIS gene expression. TSH levels of morbid obese patients were compared to non-obese group RESULTS: Demographic data of obese and control groups had significant differences $(\mathrm{p}=0,001)$ in age, weight and BMI. TSH levels of obese patients were compared to non-obese group. Statistically significant difference was found between preoperation of morbid obese and control groups $(\mathrm{p}=0,015)$ and between preoperation and postoperation of obese group $(\mathrm{p}=0,001)$. No significant difference $(\mathrm{p}>0.05)$ was observed between the obese and control groups in NIS gene expression levels. CONCLUSIONS: Because of the interaction between NIS and the other ion pumps, new studies are needed for better understanding the ion channel mechanisms. Additionally, as the obesity is influenced by genetic factors, the research will also contribute to the question of the familial transition while the samples are collected from the obese individuals. Keywords: Gene Expression,NIS, Obesity; 


\section{OP-025 \\ NOVEL NOBOX GENE C. 1841C $>$ T VARIANT IN A CASE WITH PREMATURE OVARIAN FAILURE}

Hande Küçük Kurtulgan

Department of Medical Genetics, Faculty of Medicine, Cumhuriyet University, Sivas

OBJECTIVES: Premature ovarian failure is characterized by secondary amenorrhea and elevations of gonadotropin levels before age 40. In some cases, the first referral complaint may be primary amenorrhea. In the case of premature ovarian failure presenting with primary amenorrhea, it was aimed to share in the accompaniment of the literature due to the first detection of $\mathrm{c} .1841 \mathrm{C}>\mathrm{T}$, a novel variant in the NOBOX gene. MATERIALS and METHODS: A 26-year-old female patient with no systemic diseasehistory and nodysmorphic findings admitted tomedicalgenetic polyclinic for the complaint of primary amenorrhea. The patient was assessed for hormone levels and ultrasonographic findings. Chromosome analysis and molecular karyotyping were performed to exclude numerical and structural chromosomal anomalies for genetic diagnosis. Next generation sequencing method was used to detect variations in the FSHR gene and genes associated with premature ovarian failure. RESULTS: Karyotype and molecular karyotype evaluations were normal. In NOBOX (heterozygous c. $1841 \mathrm{C}>\mathrm{T}$ ) and FSHR (homozygous p.S680N and heterozygous p.A307T), some variants were detected. Bioinformatic analysis showed that the variant in the NOBOX gene was a «damaging) according to SIFT and a spossibly damaging) according to PolyPhen. Genetic analysis was planned for the parents and elder sister of the case. CONCLUSIONS: NOBOX gene variants cause autosomal dominant premature ovarian failure type 5 . In conclusion, we believe that this case should be considered as a premature ovarian failure type 5 due to the c.1841C $>\mathrm{T}$ variant detected in the NOBOX gene, and variants in the FSHR gene also contributed to the clinic. Keywords: primary amenorrhea, premature ovarian failure, NOBOX, gene

\section{OP-026 \\ SINGLE-VARIANT ANALYSIS AND POLIGENIC RISC SCORE OF GENETIC TRAITS ASSOCIATED WITH WHEEZING FENOTYPE}

Nazente Atçeken $^{1}$, Şefayet Karaca ${ }^{2}$, Mehmet Karaca $^{3}$, Ersoy Cïvelek ${ }^{4}$, Bülent Enis Şekerel $^{5}$, Renato Polïmanti

${ }^{1}$ Aksaray University, Institute of Science and Technology, Aksaray

${ }^{2}$ Aksaray University, Faculty of Health Scence, Department of Nutrition and

Dietetics, Aksaray

${ }^{3}$ Aksaray University, Faculty of Science and Arts, Department of Biology,

Aksaray

${ }^{4}$ Ankara Child Health And Diseases Hematology Oncology Research Hospital,

Pediatric Allergy and Immunology Clinic, Ankara

${ }^{5}$ Hacettepe University, Faculty of Medicine, Pediatric Allergy and Asthma Unit, Ankara

${ }^{6}$ Department of Psychiatry, Yale University School of Medicine and Va Ct

Healthcare Center, West Haven, Ct, United States

OBJECTIVES: The complex nature of pediatric respiratory diseases are attributed to the effect of numerous genetic features. In this study, association of GWAS confaunding risk alleles with different asthma phenotypes was investigated in Turkish pediatric patients. MATERIALS and METHODS: Five different genetic loci (GSDMB rs2305480, IL33 rs928413, RAD50 rs6871536, IL1R1 rs1558641, CDHR3 rs6967330) were genotyped in 919 Turkish children assessed by ISAAC (International Study of Allergy and Asthma in Childhood) Phase II questionnaire. Single variant and PRS (polygenic risk score) analysis were considered to dissect the role of risk alleles with respect to 42 traits related to respiratory diseases and their comorbidities. RESULTS: PRS based on the combined effects of the five investigated variants resulted association with the risk of waking up with wheezing (Beta $=0.94, p=1.49 * 10-3)$. In the single-variant analysis, RAD50 rs $6871536 * \mathrm{C}$ allele was associated with a $52 \%$ increased risk of bronchitis diagnosis $(\mathrm{OR}=1.52, \mathrm{p}=1.01 * 10-3)$. We observed a suggestive association between GSDMB rs $2305480 * \mathrm{G}$ and the risk of eczema: children carriers of the $\mathrm{G}$ allele have a $45 \%$ increased risk ( $O R=1.45, \mathrm{p}=3.32 * 10-3)$. Finally, we tested the association of the variants with expression of the corresponding genes, detecting significant associations for all alleles analyzed. CONCLUSIONS: Present investigation contributed to a greater understanding of the genetics of respiratory diseases in non-European individuals and provided novel dataregarding the genetics of childhood respiratory diseases and theircomorbidities. *This study was partly supported by Aksaray University Scientific Research Projects Unit with the project numbered 2017-024.

Keywords: Respiratory Diseases, Allergy, Polygenic Risk Score

\section{OP-027 \\ EFFECTS OF RS1169289 \& RS55834942 MUTATIONS OF HNF1A ON BIOCHEMICAL PARAMETERS IN MODY PATIENTS}

Deniz Kanca Demirci ${ }^{1}$, Nurdan Gül ${ }^{3}$, Oğuz Öztürk ${ }^{2}$, İlhan Satman ${ }^{3}$, Feyza Darendeliler ${ }^{4}$, Hülya Yilmaz Aydoğan ${ }^{2}$

${ }^{1}$ Halic University, Faculty of Art and Science, Department of Molecular Biology and Genetics, Istanbul

${ }^{2}$ Istanbul University, Aziz Sancar Institute of Experimental Medicine, Department of Molecular Medicine, Istanbul

${ }^{3}$ IstanbulUniversity, Istanbul Faculty of Medicine, Department of Internal Medicine, Division of Endocrinology and Metabolic Diseases, Istanbul. ${ }^{4}$ Istanbul University, Istanbul Faculty of Medicine, Department of Pediatrics, Division of Pediatric Endocrinology, Istanbul

OBJECTIVES: In this study, we investigated the effect of rs1169289 $(\mathrm{C}>\mathrm{G})$ and rs55834942 $(\mathrm{G}>\mathrm{A})$ mutations of HNF1A gene (MODY3) on the clinical and biochemical parameters in patients with maturity onset diabetes mellitus of the young (MODY). MATERIALS and METHODS: HNF1A rs1169289 and rs55834942 mutations have been analyzed with next generation sequencing in 79 controls and 75 patients with MODY prediagnosed. RESULTS: There was no significant difference in the genotype frequencies of the rs55834942 mutation between the study groups ( $>0.05)$, however, the rs1169289 mutant-G allele was found to be more frequent in patients with MODY than controls (Control:36.1\% vs. MODY:53.3\%, p=0.029). The rs1169289-CC genotype showed significantly higher triglyceride (TG), VLDL-K, ALT levels and lower HDL-C, sT4 and Creatinine levels $(\mathrm{p}<0.05)$ than the mutant-G allele in the controls. In addition, mutant-GG genotype was associated with high sT3 and low urea levels $(\mathrm{p}<0.05)$ when compared with Callele. In the MODY group, rs1169289-CC genotype was associated with higher VLDL-C and Creatinine levels $(\mathrm{p}<0.05)$ compared to mutant-G allele. Furthermore, control subjects with mutant-GG genotype had lower ALT and AST levels $(p<0.05)$ than those with $C$ allele. Serum total-cholesterol, TG, LDL-C and VLDL-C levels were significantly lower $(\mathrm{p}<0.05)$ in MODY subjects with the rs55834942 mutant-A allele than those with the GG genotype. Also, the control subjects with mutant A allele showed a higher insulin, AST and ALT levels $(p<0.05)$ than those with the CC genotype. CONCLUSIONS: Our findings indicate that rs 1169289 and rs55834942 mutations of HNF1A gene may affect both the risk of MODY and liver and kidney function. Keywords: MODY3, HNF1A, rs116928, rs55834942

\section{OP-028 \\ IN VITRO INVESTIGATION OF PEG-TiO-PTX NANOTARGETED DRUG EFFECT ON BREAST CANCER}

Ayça Taș ${ }^{1}$ Erkan Gümüş̧ ${ }^{2}$ Neşe Keklikçioğlu Çakmak ${ }^{3}$, Mustafa Atabey ${ }^{4}$, Yavuz Siliğ

${ }^{1}$ Cumhuriyet University, Faculty of Health Sciences, Department of Nutrition and Dietetics, Sivas, aycatas@cumhuriyet.edu.tr

${ }^{2}$ Cumhuriyet University, Faculty of Medicine, Department of Histology Embryology, Sivas

${ }^{3}$ Cumhuriyet University,Engineering Faculty, Chemical Engineering, Sivas ${ }^{4}$ Sivas Medicana Hospital, General Surgery Clinic, Sivas

${ }^{5}$ Cumhuriyet University, Faculty of Medicine, Department of Biochemistry, Sivas

OBJECTIVES: Breast cancer is one of the leading causes of mortality among women worldwide due to various factors such as aggressive invasion, early metastasis, resistance to existing chemotherapeutic drugs and high mortality. The aim of this study is 1) to increase the biocompatibility of the TiO2 nanoparticle by activating with PolyEthylene Glycol (PEG) to develop a new nanostructure system and 2) to determine anticancer activity of Paclitaxel (PTX) loaded PEG-TiO2 on MDA-MB-231 cell lines. MATERIALS and METHODS: TiO2 nanoparticles used in this study were synthesized, coated with PEG, and PEG-TiO2 nanostructure system was loaded with PTX. SEM, EDX, XRD, UV, Zeta Potential analyses of suspensions prepared at different concentrations of TiO2, PEG-TiO2, DOX, and PEG-TiO2DOX nanostructured system were performed. The synthesized drugs were applied to the MDA-MB-231 breast cancer cell line and cytotoxic effect of these drugs were determined by using MTT method. The MDA-MB-231 cells were treated with different concentrations of $\mathrm{TiO} 2(5-100 \mu \mathrm{M})$ for 24,48 and 72 hours. Apoptosis and necrosis were determined by fluorescence microscopy using the Hoechst 33258 (HO)/propidium iodide (PI) double staining. RESULTS: The effects of TiO2, PEG-TiO2, PTX, and PEG-TiO2PTX on the MDA-MB-231 cell line were compared with the control group and IC50 values were determined for 24,48 and 72 hours. CONCLUSIONS: In this study, it was shown that the effect of PEG-TiO2-PTX nanostructured system on MDA-MB-231 cell line was inhibitory to growth in cancer cells and induced apoptosis when compared with control group and PTX. Keywords: Breast Cancer, MDA-MB-231, PEG-TiO2, PTX 
Introduction

Breast cancer is the leading type of cancer in women worldwide [1]. Several therapeutic strategies including hormone blocking therapy, chemotherapy, and monoclonal antibodies, are used to treat breast cancer [2]. Paclitaxel, as the standardized first-line chemotherapeutics with platinum and anthracycline compounds, is bind to $\beta$-tubulin to reinforce the microtubule stabilization [3]. Unfortunately, the efficacy of paclitaxel therapy is limited by the development of paclitaxel resistance [4]. Drug resistance is, however, a major obstacle to successful chemotherapy. It has been reported that most initially responsive patients acquire a multidrug resistance (MDR) phenotype, and some patients Show MDR even with their first treatment regimen [5]. The treatment of cancer involves different therapies based on alkylating agents, antimetabolites, biological agents, etc.; but one of the principal problems is the side effects due to difficulties in differentiating between cancerous and normal cells, which produces systemic toxicity [6]. When exploring new strategies for the treatment of cancer, one possibility is the use of nanomaterials. For more than 30 years, nanomaterials have been used as pharmaceutical carriers to enhance the in vivo antitumor efficacy of drugs. The first studies in the 1970s used nanoscale drug carriers, such as liposomes entrapping antitumor pharmaceuticals. The development of nanostructured devices for drug delivery and controlled release constituted new antitumor chemotherapies [7]. The efficient carrier properties of NPs have enhanced their use in cancer treatment. NPs can be used to treat cancer by either passive or active processes. Photocatalyzed TiO2 NPs have been shown to eradicate cancer cells. TiO2 NPs can be maintained for a long time in the body, and they are nontoxic and stable without light irradiation [8]. Polyethylene glycol (PEG) is used in targeted drug delivery system because it is non-toxic, nonimmunogenic and non-antigenic. PEGylated nanocarriers have the ability to evade the reticulo endothelial system (RES) and extend the circulation time of encapsulated drugs in the bloodstream [9]. Our primary goal in this study is; To increase the biocompatibility of the $\mathrm{TiO} 2$ nanoparticle, it is necessary to activate it with PEG to develop a new nanostructure system. Secondly, the PTX drug is loaded onto this nanostructure system and applied to the MDA-MB-231 cell line to determine anticancer activity and the present study was to identify the paclitaxel binding PEG-TiO2 that are associated with MDR by using a newly developed line of MDA-MB-231 cell line.

Materials and Methods

$\mathrm{TiO} 2$ nanoparticles synthesize and Synthesize of PEGylated TiO2 nanoparticles: In this study, $\mathrm{TiO} 2$ were used as the nanoparticles. $\mathrm{TiO} 2$ nanoparticles were produced by a sol-gel process [9]. Titanium iso-propoxide (TIP) was used as the starting precursor to synthesize TiO2-nanoparticles using the sol-gel method. Polyethylene glycol was used to increase the stability of the TiO2 NPs and to coat the nanoparticles. $20 \mathrm{~mL}$ of TiO2 NP $(0.5 \mathrm{mg} / \mathrm{ml})$ was added to the PEG solution and stirred for 24 hours. The TiO2-PEG NPs were centrifuged at $12500 \mathrm{rpm}$ for 30 minutes and were dispensed in $20 \mathrm{ml}$ of ultrapure water.

Paclitaxelin binding to nanostructuring systems: PTX loaded onto TiO2-PEG was mixed with $0.5 \mathrm{mmol} / \mathrm{L} \mathrm{pH} 8$ overnight with TiO2-PEG solutions $(\sim 0.2 \mathrm{mg}$ $/ \mathrm{mL}$ ). The unbound PTX was filtered through a $100 \mathrm{kDa}$ filter and the washing procedure was repeated. The resulting TiO2-PEG-PTX was stored at $4{ }^{\circ} \mathrm{C}[10]$. $\mathrm{TiO} 2$ nanoparticles and TiO2-PEG-PTX characterization: The morphologies of TiO2 were characterised by the XRD pattern. The UV-visible absorption of TiO2, TiO2-PEG and TiO2-PEG-PTX NPs was determined using a UV-visible spectrophotometer (UV-1280, Shimadzu, Japan).

Cell Culture: Cell lines including MDA-MB-231 cells were maintained in DMEM medium, containing $10 \%$ fetal bovine serum (FBS), penicillin (100 U/ $\mathrm{mL})$ and streptomycin $(10 \mathrm{mg} / \mathrm{L})$. Cells were grown in at $37{ }^{\circ} \mathrm{C}, 5 \% \mathrm{CO} 2$ and 95 $\%$ air in a humidified incubator. For each cell line, $70-80 \%$ confluent cell culture flask was trypsinized and cells were seeded in 96 well plates.

Cytotoxic effect of $\mathrm{TiO} 2$ targeted drug in and MDA-MB-231 cells: The in vitro cytotoxicity of the TiO2, TiO2-PEG, TiO2-PEG-PTX and PTX against MDAMB-231 cell lines was performed with the MTT 3-(4,5-dimethylthiazol-2-yl)2,5-diphenyltetrazolium bromide) assay according to the Skehan's method [11]. Briefly, cells were trypsinized and plated into 96-well plates (Corning, USA) in $0.1 \mathrm{~mL}$ of complete culture medium at a density of $1 \times 105$ cells per well and allowed to attach for $24 \mathrm{~h} .1 \mu \mathrm{L}$ of test substance at concentrations ranging between $5-100 \mu \mathrm{g} / \mathrm{ml}$ were added into each well containing the cells. Test substance was diluted with sterilized water into the desired concentrations from the stock. The plates were incubated at $37^{\circ} \mathrm{C}$ with an internal atmosphere of $5 \% \mathrm{CO} 2$. After 24 , 48 and $72 \mathrm{~h}$ incubation, with different concentrations of compounds, MTT (5 mg/ $\mathrm{ml}$ dissolved in PBS) $10 \mu \mathrm{l} /$ well was added directly to all the wells and incubated for 2 hours at $37^{\circ} \mathrm{C}$. The supernatant was carefully removed from each well and $100 \mathrm{~mL}$ of DMSO was added to each well to dissolve the formazan crystals. After mixing with a mechanical plate mixer for $15 \mathrm{~min}$, the absorbance of plates were recorded at $570 \mathrm{~nm}$ on a microplate reader (Bio-Tek, USA). All drug doses were parallel tested in triplicate and were performed at least 3 times; control samples were run with $1 \%$ sterilized water.

Hoechst 33258 (HO; Sigma) /propidium iodide (PI; Sigma) staining: The quantitative measurement of cell death was performed by Hoechst $33258(\mathrm{HO}) /$ propidium iodide (PI) staining for apoptosis and necrosis. The IC50 concentrations determined by MTT measurement of each of the PTX, TiO2, TiO2-PEG, TiO2PEG-PTX drugs on the MDA-MB-231 cell lines implanted on the lamella in six well plates were washed with PBS after 48 hours and fixed with formaldehyde solution. MDA-MB-231 cells were again washed with PBS, incubated in 10 min darkness with addition of HO and PI. Finally, the cells were washed again with PBS and then the lamella mounting media was added and sealed. Results of cell morphology changes were visualized by fluorescence microscopy. In the fluorescence microscope, 5 different regions were photographed from the preparations examined in the appropriate wave length on the $40 \mathrm{X}$ objective. At least 200 cells were counted for each group and apoptotic and necrotic cell ratios were calculated [12].

Results and Discussion

Synthesis and characterization of TiO2 and TiO2-PEG-PTX nanoparticles: XRD in Figure 1 illustrated that the as-prepared TiO2 sample was in the anatase phase. XRD spectra indicated the presence of the main peaks at $2 \theta$ values of 25.420 $(101), 37.890,48.120,55.160,62.790$ that are typical of the anatase phase of $\mathrm{TiO} 2$. The average crystallite size of $\mathrm{TiO} 2$ nanoparticles was calculated from XRD patterns (Fig. 1) using Scherrer's equation, and was found that the average crystallite size of TiO2 nanoparticles is around $12 \mathrm{~nm}$

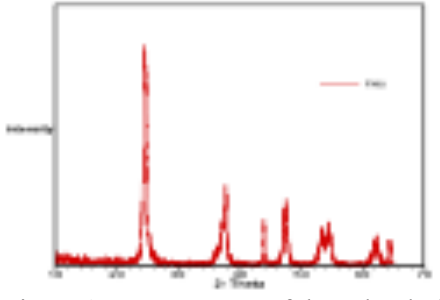

Figure 1. XRD pattern of the sol-gel TiO2 nanoparticles.

The characteristic peak of PTX occurred at about $250 \mathrm{~nm}$. These results indicated that PTX is successfully loaded onto the TiO2-PEG NPs.

Cytotoxic effect of TiO2, TiO2 -PEG, PTX and TiO2-PEG-PTX targeted drug in and MDA-MB-231 cells:The cytotoxicity was estimated by MTT assay against both cell lines, since MTT assay can accurately measure metabolic activity of living cells via MTT reaction with mitochondrial dehydrogenases Figure 2 shows changes in cell inhibition for 24,48 and 72 hours versus increasing concentrations of MDA-MB-231 cell lines. $x$-axis shows cell types and varying time points, while the y-axis shows the inhibition rates of cancer cells relative to the control. As you can see in Fig. 3 in parallel with the increase in TiO2, PEGTiO2, PEG- TiO2-PTX and PTX concentration, there has been an increase also in the mortality rates of MDA-MB-231 breast cancer cells. The low IC50 value "the high concentration of complex required for killing $50 \%$ of breast cance cells" indicates that high cytotoxicity. Despite the time and dose dependent increase in the cytotoxicity of TiO2, PEG- TiO2, PEG- TiO2-PTX and PTX in MDA-MB-231 cells, IC50 values was observed for 24, 48 and 72 hours in the working range. TiO2-PEG-PTX, PEG-TiO2, TiO2, and PTX drugs on MDAMB-231 cells were the most active for $72 \mathrm{~h}$ of incubation. In addition, the most active TiO2-PEG-PTX and IC50 values for 24,48 and 72 hours were $46,58 \mu \mathrm{g}$ $\mathrm{ml}, 33,06 \mu \mathrm{g} / \mathrm{ml}$ and $28,34 \mu \mathrm{g} / \mathrm{ml}$ respectively (Table 1 ).

Table 1: Comparison of IC50 values between TiO2-PEG-PTX, PEG- TiO2, TiO2, and PTX on MDA-MB-231 after $24 \mathrm{~h}, 48 \mathrm{~h}$ and $72 \mathrm{~h}$ of incubation.

\begin{tabular}{lccc} 
& \multicolumn{3}{c}{$\mathrm{IC} 50(\mu \mathrm{g} / \mathrm{ml})$} \\
Drugs & $24 \mathrm{~h}$ & $48 \mathrm{~h}$ & $72 \mathrm{~h}$ \\
TiO2-PEG- PTX & 46,58 & 33,06 & 28,34 \\
TiO2-PEG & 76,26 & 67,97 & 56,53 \\
TiO2 & 64,06 & 45,15 & 37,23 \\
PTX & 55,52 & 41,73 & 30,74
\end{tabular}

Hoechst 33258 (HO; Sigma) /propidium iodide (PI; Sigma) stainin: In this present study, morphological alterations of apoptotic cell death were detected by fluorescence microscope using $\mathrm{HO}$ and PI staining. The apoptosis rates of MDAMB-231 cells treated with TiO2-PEG-PTX and PTX were found to be $68 \%$ and $57 \%$, respectively. Whereas the necrosis rates of MDA-MB-231 cells treated with TiO2-PEG-PTX and PTX were found to be $5.8 \%$ and $4.3 \%$, respectively. In addition, TiO2-PEG-PTX caused more apoptotic death than PTX, although it was not statistically significant.

Conclusion

In summary, modified PEGylated TiO2 drug carriers (TiO2-PEG-PTX) were developed to target drug delivery and treatment. This study demonstrates the possibility of using TiO2-PEG-PTX to inhibit the growth of breast cancer (MDA-MB-231) cells with therapeutic treatments. Apoptosis rate of TiO2-PEGPTX were not found to be statistically significant, although an increased rate of apoptosis was detected after treatment with TiO2-PEG-PTX. Based on the results of this study, further in vitro and in vivo studies are needed. As a result, it may be a novel method of developing targeted drugs based on this molecule for cancer treatment.

Acknowledgements: This study was carried out at Cumhuriyet University's Advanced Technology Application and Research Center (CUTAM).

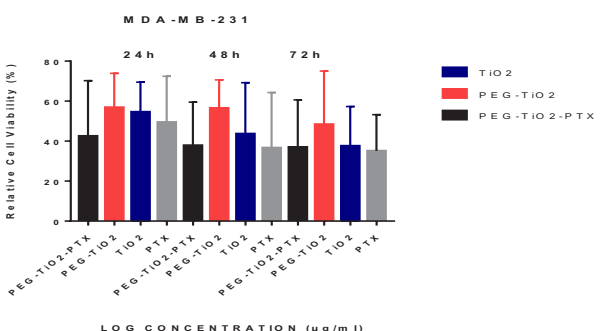


Figure 2. Cytotoxity activities of of TiO2-PEG-PTX, PEG- TiO2, TiO2, and PTX drugs on MDA-MB-231 cell line

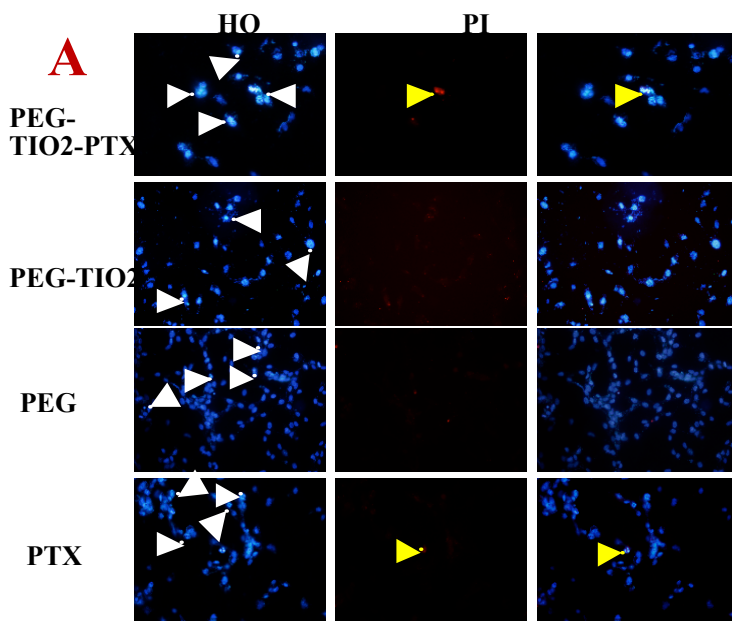

B

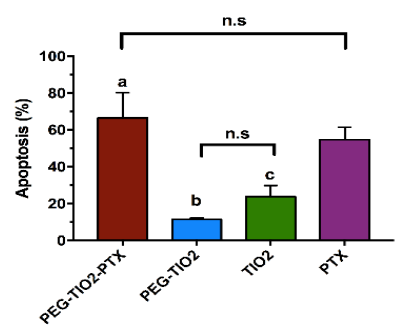

C

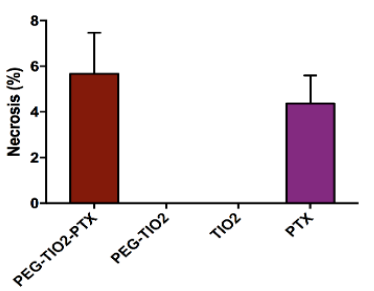

Figure 4. Representative HO/PI staining of MDA-231 cells (A). White and yellow arrows indicate apoptotic and necrotic cells, respectively. Percentage of apoptotic (B) and necrotic cells (C) according to drug types. Data are presented mean \pm SD from 200 cells for each group. a,b,cp $<0.05$. n.s: not significant References

1.Torre LA, Bray F, Siegel RL, Ferlay J, Lortet Tieulent J and Jemal A: Global cancer statistics, 2012. CA Cancer J Clin 65: 87 108, 2015.

2.Crown J, O'Leary M and Ooi WS: Docetaxel and paclitaxel in the treatment of breast cancer: A review of clinical eperince. Oncologist 9 (Suppl 2): S24 S32, 2004.

3.Moscow JA, Cowan KH: Multidrug resistance. J Natl Cancer Inst 1988; 80: $14-20$.

4.Bedard PL, Di Leo A, Piccart-Gebhart MJ (2010). Taxanes: optimizing adjuvant chemotherapy for early-stage breast cancer. Nat Rev Clin Oncol, 7, 22-36.

5.Saloustros E, Mavroudis D, Georgoulias V: Paclitaxel and docetaxel in the treatment of breast cancer. Expert Opin Pharmacother 2008; 9: $2603-2616$. 6.Rasmussen, J.W. Martinez, E.; Louka, P.; Wingett, D.G. Zinc oxide nanoparticles for selective destruction of tumor cells and potential for drug delivery applications. Exp. Opin. Drug Deliv. 2010, 7, 1063-1077.

7.Felice, B.; Prabhakaran, M.P.; Rodríguez, A.P.; Ramakrishna, S. Drug delivery vehicles on a nano-engineering perspective. Mater. Sci. Eng. C 2014, 41, $178-$ 195

8.Thevenot, P. Cho, J. Wavhal, D.; Timmons, R.B. Tang, L. Surface chemistry influences cancer killing effect of $\mathrm{TiO} 2$ nanoparticles. Nanomedicine 2008, 4 , $226-236$.

9.Mahbubul I.M. Elcioglu E.B. Saidur R. Amalina M.A., Ultrasonics Sonochemistry, "Optimization of ultrasonication period for better dispersion and stability of TiO2-water nanofluid", 37, 360-367, 2017.

10.Sun, X. Z. Liu, K. Welsher, J. T. Robinson, A. Goodwin, S. Zaric, and H. Dai. 2008. "Nano-graphene oxide for cellular imaging and drug delivery", Nano research, 13:203-12.

11.Skehan P, Storeng R, Scudiero D, Monks A, McMahon J, Vistica D, Warren JT, Bokesch H, Kenney S, Boyd MR. New colorimetric cytotoxicity assay for anticancer-drug screening. J Natl Cancer Inst. 1990; 82(13):1107-1112.

12.Syed Abdul Rahman, S. N., N. Abdul Wahab, and S. N. Abd Malek. 2013. "In vitro morphological assessment of apoptosis induced by antiproliferative constituents from the rhizomes of Curcuma zedoaria", Evidence-Based Complementary and Alternative Medicine, 2013.

\section{OP-030}

ORGANOTOXIC EFFECTS OF DEGUELIN AND DOCETAXEL IN EXPERIMENTAL LUNG CANCER MODEL

Hakan Cengiz ${ }^{1}$, Mehmet Ali Koçdor ${ }^{2}$, Seda Özbal ${ }^{3}$, Nilgün Yener ${ }^{4}$,

Meral Karaman ${ }^{5}$, Asuman Argon ${ }^{6}$, Tarık Salman ${ }^{7}$, Emine Çağnur Ulukuş ${ }^{8}$,

Hilal Koçdor ${ }^{9}$

${ }^{1}$ Department of Molecular Medicine, Institute of Health Science, Dokuz Eylul University, Izmir

${ }^{2}$ Department of Molecular Medicine, Institute of Health Science, Dokuz Eylul University, Izmir; Deparment of General Surgery, Faculty of Medicine, Dokuz Eylul University, Izmir

${ }^{3}$ Department of Histology\&Embryology, Faculty of Medicine, Dokuz Eylul University, Izmir

${ }^{4}$ Department of Medical Biochemistry, Faculty of Medicine, Dokuz Eylul

University, Izmir

${ }^{5}$ Department of Medical Microbiology, Faculty of Medicine, Dokuz Eylul University, Izmir; Department of Laboratory Animal Science, Institute of Health Science, Dokuz Eylul University, Izmir

${ }^{6}$ Department of Medical Pathology, Bozyaka Training\&Research Hospital, Izmir ${ }^{7}$ Department of Molecular Medicine, Institute of Health Science, Dokuz Eylul University, Izmir; Department of Medical Oncology, Ataturk Training\&Research Hospital, Katip Celebi University, Izmir

${ }^{8}$ Department of Medical Pathology, Faculty of Medicine, Dokuz Eylul University, Izmir

${ }^{9}$ Department of Molecular Medicine, Institute of Health Science, Dokuz Eylul University, Izmir; Department of Basic Oncology, Institute of Oncology, Dokuz Eylul University, Izmir

OBJECTIVES: In the experimental in vivo metastatic lung cancer model,it is the investigation of organotoxic effects of Docetaxel which are used in standard treatment,and chemotherapeutic candidate molecule Deguelin. MATERIALS and METHODS: Experimental design;Control,Cancer Cancer+DMSO, Cancer+Deguelin, Cancer+Docetaxel, Cancer+Combination. A metastatic lung cancer model was established with LewisLungCarcinoma cell line in 42adult C57BL/6 mice(f). After the injection (7days) of cancer cell lines, the doses set in the cell lines were applied 6 times in advance to the groups every day and sacrification was performed on the determined day. Heart, spleen, kidney, liver tissues were homogenized in buffer solution with Bullet Blender device. Oxidative stress index (OSI) and superoxide dismutase (SOD) enzyme activity were measured using colorimetric method to determine organotoxiceffects. Tissue sections (heart, spleen, kidney, liver and stomach) of all groups were stained with Hematoxylin\&Eosin and examined for ischemia and necrosis.Significance among the groups was determined byANOVA, and Holme-Sidak analysis for post-hoc comparisons. Statistical significance was accepted as $\mathrm{p}<0.05$. RESULTS: Tumor development in the treatment group with Deguelinwas statistically significant lower than the other groups. Allsubjects had macroscopically abnormal appearance inthe heart tissues.There was involvement inGIS in the cancer group. In the Docetaxel group, slowing and weakness were observed inthe treatment-induced movements and hemorrhage was seen in some subjects. OSI and SOD enzyme activity analyzes on tissue homogenates showed no statistically significant difference between groups in tissues other than kidney and spleen tissues $(p>0,05)$. Histochemical analysis showed noischemia or necrosis inany group CONCLUSIONS: Thedosesof Deguelin, achemotherapeutic candidatemolecule and Docetaxel whichis appliedin standard therapy inlung cancer have been identifiedfortheexperimental animal.Intheexperimentalmodel inwhichthese determineddoseswereapplied, it was observed that the agentsused by looking at this tochemicalandoxidativestressmarkerswerenotsuperiortoeachotherintermsof organotoxic effects. Although alone or combination as in vivo usage of Deguelin does not result in an additional organotoxic load,it maybe an agent candidate for thetreatment of lungcancer. Keywords: Deguelin, Docetaxel, Organotoxic Effect, Experimental Metastatic Model of Lung Cancer, C57BL, Lewis Lung Carcinoma Cell Line (LLC)

OP-031

THE EFFECT OF COMBINED TREATMENT OF FK506 AND AKT INHIBITORY ON PDGF-INDUCED PC3 CELLS INVASION

Harun Ün

Department of Biochemistry, Faculty of Pharmacy, Agri Ibrahim Cecen University, Agri

OBJECTIVES: We aimed to show the effects of Tacrolimus (FK506) and Akt inhibitory (Akti) on the PC3 cells invasion that induced with Platelet Derived Growth Factor (PDGF) which has important role on cancer cell proliferation. MATERIALS and METHODS: Doses of drugs were determined as PDGF $(100 \mathrm{ng} / \mathrm{ml})$, Akt inhibitörü $(5 \mu \mathrm{M})$ ve FK506 $(1 \mu \mathrm{M})$. Wound Healing assay and matrigel transwell chamber assay were used to show the invasion of PC3 cells. Experimental groups were determined as; Control, PDGF, Akti, FK506, PDGF+Akti, PDGF+FK506, Akti+FK506 and PDGF+Akti+FK506. The Results were obtained by imaging with a light microscope (Leica, DMIL LED, Germany) RESULTS: Looking at the Wound Healing assay results, it was shown that Akti and FK506 treatment reduced the invasion while PDGF promoted the PC3 cells invasion. Combined treatment of FK506 with Akt inhibitory had effective results 
against to invasion. According to transwell invasion results, it was shown that combined treatment of FK506 and Akti blocked the PC3 cells invasion and these results supported the Wound Healing assay results. It was also shown that there were less number of invasive cells in FK506+Akti treated group than other groups. CONCLUSIONS: As a result of this study, PDGF-induced PC3 cells invasion can inhibited by Akt inhibitor and FK506 and also it is understood that combined treatment of these two drugs will give effective results against invasion. Keywords: PDGF, FK506, Akt inhibitory, invasion, PC3

\section{OP-032 \\ THE EFFECTS OF PHENOTHIAZINE DYES ON GAG-MODIFIED APLP2 AND $\beta$-SECRETASE 1 LEVELS IN HS766T CELLS}

Kevser Biberoglu, Melike Yuksel, Seda Onder, Ozden Tacal

Department of Biochemistry, School of Pharmacy, Hacettepe University, Ankara

OBJECTIVES: Amyloid precursor-like protein 2 (APLP2) and its glycosaminoglycan (GAG)-modified form are highly expressed in pancreatic cancer cell lines. Evidences have shown that inhibition of APLP2 and its cleavage enzyme, $\beta$-secretase decrease the growth of pancreatic cancer cells. In present study, the inhibitory effects of two phenothiazine dyes [toluidine blue O (TBO) and methylene blue (MethB)] were determined on $\beta$-secretase (BACE1 and BACE2) activity in pancreatic cancer cells (Hs766T). Also, the effects of both dyes were investigated on GAG-modified APLP2 and BACE1 levels in Hs766T cells. MATERIALS and METHODS: Hs766T cells were treated with TBO or MethB $(0-40 \mu \mathrm{M})$ for 24 hours. The inhibitory effects of both dyes on $\beta$-secretase activity were evaluated with a fluorometric BACE assay kit in cell lysates. Also, the levels of GAG-modified APLP2 and BACE1 were analyzed using Western blot. The results were compared to those obtained with control cells. RESULTS: $\beta$-secretase activity was significantly inhibited by $30 \%$ and $44 \%$ at $10 \mu \mathrm{M}$ and $20 \mu \mathrm{M}$ MethB, respectively. GAG-modified APLP2 level was reduced by $34 \%$ at $20 \mu \mathrm{M}$ MethB. However, BACE1 levels were not significantly changed by MethB. On the other hand, GAG-modified APLP2 level was reduced by $35 \%$ while BACE1 level was decreased by $44 \%$ at $20 \mu \mathrm{M}$ TBO. $\beta$-secretase activity was not significantly altered by TBO. CONCLUSIONS: TBO and MethB may show useful effects in the treatment of pancreas cancer treatment.

Supported by the grants from the Hacettepe University Scientific Research Projects Coordination Unit(HUBAB, TSA-2017-13929) and TUBITAK(SBAG-113S256). Keywords: APLP2, $\beta$-secretase, Phenothiazine dyes, Pancreas cancer

\section{OP-033 \\ INVESTIGATION OF SINERGIC EFFECT OF RHO KINASE INHIBITOR AS 1892802 AND PACLITAXEL ON BREAST CANCER}

Mustafa Ergül

Department of Biochemistry, Faculty of Pharmacy, Sivas Cumhuriyet University, Sivas

OBJECTIVES: Cancer is one of the most important health problems in worldwide and the treatment approaches are still not at desirable levels. Conventional anti-cancer agents may cause systemic toxicity and drug resistance; to overcome these hurdles, drug combinations have been widely employed in therapy. In this study, to determine whether AS 1892802 can enhance chemosensitivity to paclitaxsel, the combined effects of AS 1892802 with paclitaxel on MDA-MB-231 cells were investigated. MATERIALS and METHODS: MDA-MB-231 cells were treated with Paclitaxel and AS 1892802 alone at $0.01,0.1,1,10$ and $100 \mu \mathrm{M}$ concentrations. Next, the effect of inhibitor and Paclitaxel on cell viability was evaluated by XTT method. Based on the IC50 values, increased concentrations of AS $1892802(0.005,0.05,0.5,5$ and $50 \mu \mathrm{M})$ were applied to the cells in combination with a constant concentration of $7.5 \mu \mathrm{M}$ Paclitaxel. In addition, the effects of paclitaxel, inhibitors and their combinations on the apoptosis have been investigated using flow cytometry. RESULTS: Experimental results exhibited that the combination of AS 1892802 and Paclitaxel showed significant cytotoxic and apoptotic effects on MDA-MB-231 cells. While IC50 values of AS 1892802 and Paclitaxel were calculated as 89 and $9.55 \mu \mathrm{M}$ for $48 \mathrm{~h}$ respectively, the IC50 value of their combination was calculated as $2.17 \mu \mathrm{M}$. Total apoptosis was also measured as $12.39 \%, 45.88 \%$ and $55.7 \%$ for $1 \mu \mathrm{M}$ AS $1892802,1 \mu \mathrm{M}$ Paclitaxel and $0.5 \mu \mathrm{M}$ their combination, respectively. CONCLUSIONS: Experimental data indicate that AS 1892802 significantly enhances the chemotherapeutic effect of paclitaxel on breast cancer cells. Keywords: Breast Cancer, Rho Kinase inhibitör, Synergic Effect, Apoptosis

Introduction

Today, cancer is a very serious disease and the second-leading cause of death all over the world (1). Among these, breast cancer is one of the most commonlydiagnosed type of cancer among women. Although there have been significant advances in the diagnosis and treatment of breast cancer in recent years, treatment-related problems still continue and survival is not at the desired level (2). Chemotherapy is an important option in the treatment of breast cancer and taxanes, especially PTX, have widely been used in early and metastatic breast cancer therapy since the 1990s. However, resistance to PTX may develop some patients especially advanced cases during treatment and limits its clinical application (3). Hence, novel therapeutic strategies for breast cancer treatment are urgently needed to overcome chemoresistance. Combined treatment by using some sensitizing agents is an important strategy to overcome the drug resistance and there are numerous combination studies in the literature $(3,4,5)$.

Rho-kinases (ROCKs) play key roles in various biological processes such as formation of stress fibers, regulation of calcium sensitivity of smooth muscle contraction, cell proliferation, and cell migration. Therefore, ROCK inhibition may be used as a potential treatment strategy in many disease including cancer (4). The anti cancer effect of ROCK inhibition has been shown in many studies, especially in recent years $(6,7)$. Hence, in this study, we aimed to evaluate the effect of PTX combined with Rho kinase inhibitor AS 1892802 on MDAMB-231 cells in an attempt to establish effective novel combination. To the best of our knowledge, this is the first study to have exhibited the efficacy of AS $1892802+$ PTX combination on breast cancer cells

Material and Methods

In-vitro cytotoxicity assay, Cell culture: The cytotoxicity of the AS 1892802 alone and combine with PTX was tested against human breast cancer MDAMB-231 cell line (Manassas, VA, USA). The cells were cultured in DMEM (Gibco Thermo Fisher Scientific) containing 10\% FBS, 1\% L-glutamine, 100 $\mathrm{IU} / \mathrm{mL}$ peni-cillin and $10 \mathrm{mg} / \mathrm{mL}$ streptomycin (Gibco Thermo Fisher Scientific) in $25 \mathrm{~cm} 2$ polystyrene flasks and maintained in a humidified atmosphere with $5 \% \mathrm{CO} 2$ at $37^{\circ} \mathrm{C}$. Growth and morphology were moni $\neg$ tored and the cells were passaged when they had reached almost $85-90 \%$ confluence.

Cell viability assay: Cell viability was evaluated using the XTT (2,3-bis-(2methoxy-4-nitro-5-sulfophenyl)-2H-tetrazolium-5-carboxanilide) assay (Roche Diagnostic, Germany) against the MDA-MB-231 cells. AS 1892802 and PTX were dissolved in DMSO and stock solutions were prepared. Then these stocks were diluted in DMEM and various concentrations were prepared prior to treatment. The MDA-MB-231 cells were seeded in 96-well plates at a density of $1 \times 104$ cells per well in $100 \mu \mathrm{L}$ whole DMEM and were allowed to attach overnight before treatment. Next day, the cells were either allowed to grow in media alone or in media containing increasing concentrations of AS 1892802 , PTX, or the combination of the two agents and incubated for $48 \mathrm{~h}$. At the end of the incubation period, for cytotoxicity, $50 \mu \mathrm{L}$ XTT labeling mixture were added to each well and then the plates were incubated at $37^{\circ} \mathrm{C}$ for four h. Finally, the absorbance of XTT-formazan was measured using a microplate (ELISA) reader at $450 \mathrm{~nm}$ against the control. All experiments were performed in three independent experiments and the cell viability was expressed in \% related to control $(100 \%$ of viability).

Apoptosis assay: The extent apoptosis was examined using the Muse Annexin V/Dead Cell (Merck Millipore) assay, as described in the manufacturer's instructions. Briefly, MDA-MB-231 cells were treated with AS $1892802(1 \mu \mathrm{M})$, PTX $(1 \mu \mathrm{M})$ and their combination $(0.5 \mu \mathrm{M}+0.5 \mu \mathrm{M})$ for $48 \mathrm{~h}$

After that, the cells were collected, diluted with PBS containing 1\% FBS and incubated with $100 \mu \mathrm{L}$ Muse ${ }^{\mathrm{TM}}$ Annexin V \& Dead Cell reagent (Merck Millipore) for $20 \mathrm{~min}$ at room temperature in the dark. The events for live, dead, early and late apoptotic cells were analyzed by Muse ${ }^{\mathrm{TM}}$ Cell Analyzer. Data of apoptosis induction by AS 1892802, PTX and the combination of the two agents were calculated from three independent experiments.

Statistical Analyses: Statistical analysis was carried out using IBM SPSS Statistic 25 version. All data are expressed as mean \pm SEM. Groups were compared statistically using general linear models of analysis of variance (ANOVA) followed by Tukey test and t-test when appropriate. Also, Kruskal-Wallis and Mann-Whitney U tests have been used when the parametric test assumptions have been violated. $\mathrm{P}<0.05$ was considered statistically significant.

Results and Discussion

Inhibition of Cell Proliferation: In the present study, XTT cell proliferation assay was performed to assess antiproliferative effects of AS 1892802 alone and combined with PTX on MDA-MB-231 cells for $48 \mathrm{~h}$. Firstly, to determine the cytotoxicity of AS 1892802 alone, growing cells were treated with increasing concentrations of AS 1892802 and incubated for $48 \mathrm{~h}$. Then, to determine the IC50 value of PTX on MDA-MB-231 cells, PTX was administrated on MDAMB-231 cells at various concentrations and incubated for $48 \mathrm{~h}$. According to experimental results, AS 1892802 alone did not show significant antiproliferative effect except for high concentrations againist MDA-MB-231 cells. Moreover, we were interested if AS 1892802 might affect the sensitivity of MDA-MB-231 cells towards frequently used antineoplastic drug PTX. We hence treated MDAMB-231 cells with AS $1892802(0.005,0.05,0.5,5$ and $50 \mu \mathrm{M})$ and PTX $(7.5 \mu \mathrm{M}$ constant concentration) combination for $48 \mathrm{~h}$. As presented in Fig 1., an important loss of viability was observed in AS $1892802+$ PTX combination at $48 \mathrm{~h}$. The IC50 values calculated as $89,9.55$ and $2.17 \mu \mathrm{M}$ for AS 1892802, PTX and their combination, respectively for $48 \mathrm{~h}$. These results suggested that when compared with PTX treatment alone, AS 1892802 combination significantly enhanced the cytotoxicity of PTX in MDA-MB-231 cells. In the literature, various Rho kinase inhibitors alone or combine with some agents have already been found to be cytotoxic on various cancer cells such as, servical and non-small cell lung cancer $(8,9)$

AS 1892802-PTX Combination Induced Apoptosis of MDA-MB-231 Cells Synergistically: In this study, it was also investigated whether the AS 1892802 PTX combination induce apoptosis in MDA-MB-231 cells. Prior to apoptosis experiments, the cells were treated with the AS $1892802(1 \mu \mathrm{M}), \operatorname{PTX}(1 \mu \mathrm{M})$ and AS $1892802+\operatorname{PTX}(0.5+0.5 \mu \mathrm{M})$ combination for $48 \mathrm{~h}$. Afterwards, Annexin $\mathrm{V}$ binding assay was performed to evaluate the effects of the combination on apoptosis of breast cancer cells. In this assay, four populations of cells can be distinguished, namely non-apoptotic cells, Annexin V (-) and 7-AAD (-), early apoptotic cells, Annexin V (+) and 7-AAD (-), late stage apoptotic cells, Annexin V $(+)$ and 7-AAD $(+)$ and necrotic cells, Annexin V (-) and 7-AAD (+). As seen 
in Fig. 2, when compared to 0.1\% DMSO-treated control, AS 1892802 and PTX alone groups, the statistically significant apoptotic effects were observed from combination group $(\mathrm{p}<0.05)$. Percent of total apoptotic cells were $10.45 \%$, $34.67 \%$, and $39.53 \%$ for AS 1892802 , PTX and their combination at $48 \mathrm{~h}$ respectively. These data indicate that when compared to AS 1892802 and PTX alone, their combination is able to induce as mainly early and late apoptosis in MDA-MB-231 cells. Moreover, this result consistent with the data obtained from cell proliferation assay in Fig.1.

Conclusion: In conclusion, our results show that AS 1892802 combined with PTX may be an effective and feasible strategy to enhance the effects of chemotherapy in patients with breast cancer. However, further studies are needed to verify these anti cancer effects.

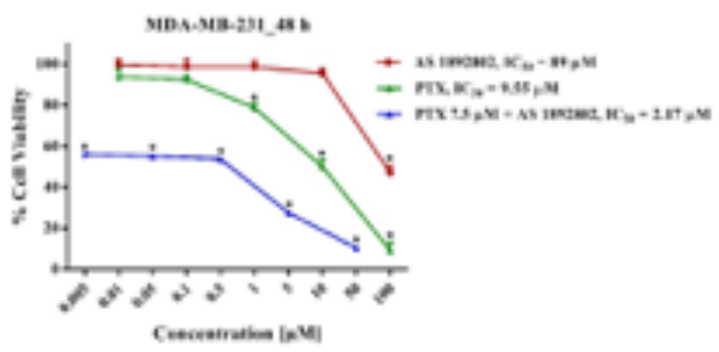

Figure 1. AS 1892802 enhances the cytotoxic effect of PTX on MDA-MB-231 cells.

(A)

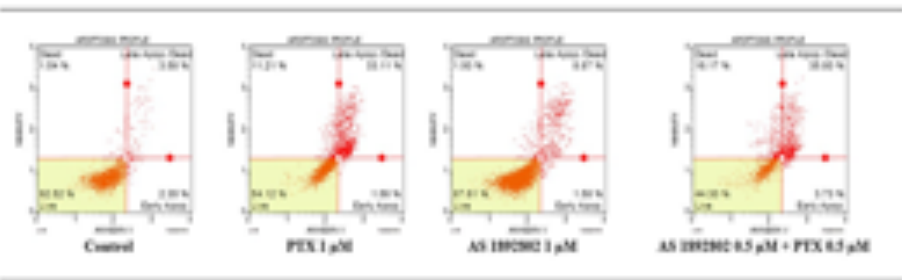

Figure 2. (A) Apoptotic effects of AS 1892802, PTX and their combination on MDA-MB-231 cells.

Figure 2. (B) Percentages of early and late apoptotic cells following the treatments. Statistically significant differences are \&, *, \# p < 0.05, ** p >0.05 from values compared to AS 1892802 and PTX group.

(B)

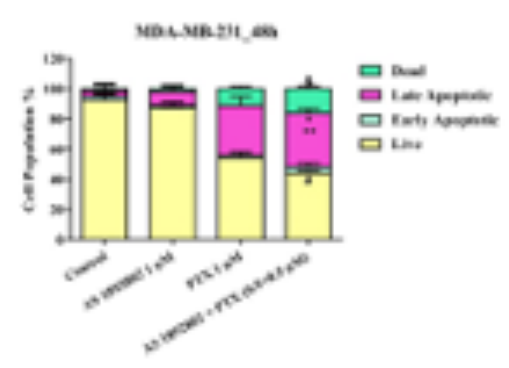

References

1.Torre LA, Bray F, Siegel RL, Ferlay J, Lortet-Tieulent J, et al. Global cancer statistics, 2012. CA Cancer J Clin. 2015; 65(2):87-108.

2.Szostakowska M, Trębińska-Stryjewska A, Grzybowska EA, Fabisiewicz A. Resistance to endocrine therapy in breast cancer: molecular mechanisms and future goals. Breast Cancer Res Treat. 2018; [Epub ahead of print].

3.Němcová-Fürstová V, Kopperová D, Balušíková K, Ehrlichová M, Brynychová $\mathrm{V}$, et al. Characterization of acquired paclitaxel resistance of breast cancer cells and involvement of ABC transporters. Toxicol Appl Pharmacol. 2016; 310:215228.

4.Ergul M, Turgut NH, Sarac B, Altun A, Yildirim S, et al. Investigating the effects of the Rho-kinase enzyme inhibitors AS1892802 and fasudil hydrochloride on the contractions of isolated pregnant rat myometrium. Eur J Obstet Gynecol Reprod Biol. 2016; 202:45-50.

5.Bakar F. Cucurbitacin B Enhances the Anticancer Effect of Imatinib Mesylate Through Inhibition of MMP-2 Expression in MCF-7 and SW480 Tumor Cell Lines. Anticancer Agents Med Chem. 2016; 16(6):747-54.

6.Rath N, Munro J, Cutiongco MF, Jagiełło A, Gadegaard N et al. Rho Kinase Inhibition by AT13148 Blocks Pancreatic Ductal Adenocarcinoma Invasion and Tumor Growth. Cancer Res. 2018;78(12):3321-3336.

7. Zhang X, Wu N. Fasudil inhibits proliferation and migration of Hep-2 laryngeal carcinoma cells. Drug Des Devel Ther. 2018;12:373-381.

8.Zhang W, Liu K, Pei Y, Ma J, Tan J, et al. Mst1 regulates non-small cell lung cancer A549 cell apoptosis by inducing mitochondrial damage via ROCK1/ F-actin pathways. Int J Oncol. 2018; 53: 2409-2422.

9.Dong J, Wang M, Ni D, Zhang L, Wang W, et al. MicroRNA-217 functions as a tumor suppressor in cervical cancer cells through targeting Rho-associated protein kinase 1. Oncol Lett. 2018; 16(5):5535-5542.

\section{OP-034 \\ DETECTION OF CIRCULATING TUMOR CELLS (CTCS) IN VARIOUS TYPES OF CANCER}

Emine Terzi, Ender Șimşek, Beyza Ecem Öz Bedir, Tuğba Kevser Uysal, Elif Ercan, Ahmet Carhan, Özen Özensoy Güler

Department of Medical Biology, Faculty of Medicine, Ankara Yildirim Beyazit University, Ankara

OBJECTIVES: Cells that are found in the circulation during tumor metastasis are called circulating tumor cells (CTCs). The counting and characterization of CTCs are promising for personalized therapies. Due to CTCs are the initiators of metastasis, they have potential to alter the course and outcome of the disease. In this study, it was aimed to evaluate whether CTCs could be used as tumor markers in various types of cancer (bladder, larynx, lung, prostate).

MATERIALS and METHODS: In this study, the detection of CTCs was performed with our modified method. $7.5 \mathrm{~mL}$ peripheral blood sample was obtained from bladder, larynx, lung, prostate cancer patients and healthy volunteers. We performed a density based ficoll gradient centrifugation and an immunomagnetic enrichment (with CD45-negative selection). A flow cytometer based on the expression of the epithelial cell adhesion molecule (EpCAM) and CK 14,15,16,19 were used for the detection of CTCs.

RESULTS: According to the results of our study, CTCs were detected in the samples of bladder, larynx, lung and prostate cancer patients. 13 CTCs in bladder cancer, 7 CTCs in laryngeal cancer, 13 CTCs in lung cancer and 9 CTCs in prostate cancer were detected. However, no CTCs were detected in healthy volunteers.

CONCLUSIONS: This study shows us CTCs might be used as a predictive biomarker of some cancer types. With further studies, the metastatic process can be better understood and new approaches can be developed for cancer diagnosis. Keywords: Cancer, CTC(s), Flow cytometry

\section{OP-035 \\ DETERMINATION OF CIRCULATING TUMOR CELLS BY FLOW CYTOMETRY IN THE BLADDER CANCER PATIENTS}

Elif Ercan, Ender Șimșek, Özen Özensoy Güler, Ahmet Çarhan Department of Medical Biology, Faculty of Medicine, Ankara Yildirim Beyazit University, Ankara

OBJECTIVES: The current study aimed to detect of circulating tumor cells (CTCs) in $7.5 \mathrm{~mL}$ blood samples of bladder cancer patients by flow cytometry. MATERIALS and METHODS: Fresh venous blood was taken from patients before and after surgery and the peripheral blood mononuclear cells were isolated with the density-gradient centrifugation method. Direct immunofluorescence assay was performed using monoclonal antibodies against cell surface markers. Sorting was carried out with BD FACS AriaTM III Cell Sorter. markers. Sorting was carried out with BD FACS Aria were evaluated on controls. Median CTC count before the operation was 6.0 (min$\max : 4.0$ to 21.0 ) and after the operation was calculated as 0.0 (min-max: $0.0-5.0$ ). CONCLUSIONS: The results are promising in terms of CTC detection in bladder cancer by flow cytometry. Pre- and post-operative CTC counts as predictive and prognostic biomarker dramatically change in this study. Keywords: Bladder Cancer, Circulating Tumor Cells, Flow Cytometry

\section{OP-036}

\section{COMPARISON OF INDUCTION OF PROTOPORPHYRIN IX SYNTHESIS IN 2D AND 3D CELL CULTURE}

\section{S. Sibel Erdem}

Istanbul Medipol University, International School of Medicine, Medical Biochemistry, Istanbul

OBJECTIVES: To understand complex tumor biology, three dimensional multicellular tumor spheroids (3D MTS) are advantageous compared to 2D cell culture models. The aims of this study are to induce synthesis of Protoporphyrin IX, which is an endogenous porphyrin and photosensitizer, via incubation of MCF-7 cells with $\delta$-aminolevulonic acid and to compare phototoxicity based cell viability in 2D and 3D models after photodynamic therapy (PDT) application. MATERIALS and METHODS: By employing liquid top layer method, MCF-7 cell line is grown to MTS having 100-150 $\mu \mathrm{m}$ diameters at the end of the 4th day. MTS were incubated with different concentration of ALA $(0.5 \mathrm{mM}-2 \mathrm{mM})$ and then were exposed to near-IR light $(>630 \mathrm{~nm}, 10 \mathrm{j}$ $\mathrm{cm} 2$ ). Following $24 \mathrm{~h}$ incubation period, MTS' cell viability is tested. The same procedure is applied to MCF7 cells that are grown in 2D cell culture. 
RESULTS: Cell uptake of ALA and consequently, synthesis of Protoporhyrin IX greatly varied in two distinctive (2D and 3D) models. Phototoxicity, which is generated as a result of exposure to same amount of light dose, and cell viability were greatly different in two models. CONCLUSIONS: As a result of complex structural organization of MTS, diffusion of ALA to the MTS structure as well as cell uptake of it is fairly low. Due to structural obstacles to deliver light to the hypoxic center of MTS, cell viability of MTS in 3D was higher than 2D model. Obtained results could be used to acquire valuable information regarding tumor structure and biology, drug delivery systems, drug diffusion and distribution into the tumor. Keywords: Protoporhyrin IX, 3D cell culture, $\delta$-aminolevulonic acid (ALA), Heme synthesis, Photodynamic Therapy (PDT)

\section{OP-037 \\ DRUG CARRYING NANOPARTICLES PREPARED WITH GREEN SYNTHESIS METHOD FOR TARGETED CANCER THERAPY}

Güliz Ak, Tuğba Karakayalı, Ayșe Nur Cin, Senay Sanlıer

Department of Biochemistry, Faculty of Science, Ege University, Izmir

OBJECTIVES: Doxorubicin is an anticancer agent and have lots of side effects. Curcumin can act as an inducer for p53-dependent apoptosis and enhance the activity of doxorubicin. Drugs can be addressed to target area with magnetic nanoparticles thus increases bioavailability and decreases side effects. Green synthesis method enables nanoparticle production utilizing vegetable extracts. The aim of this work is development of doxorubicin and curcumin loaded magnetic nanoparticles through green nanotechnology. MATERIALS and METHODS: Magnetic nanoparticles were prepared using Camellia sinensis extract and $\mathrm{FeCl} \square$ solution at different ratios. These structures were characterized with XRD, SEM, EDX and FTIR. Doxorubicin and curcumin solutions at varying concentrations were added into nanoparticles for encapsulation and loaded drug amounts were determined spectrophotometrically. The resulting nanoparticles were investigated with SEM and FTIR. In vitro drug release from nanoparticles was performed using dialysis membrane tubings at $\mathrm{pH} 7.4$ and $37^{\circ} \mathrm{C}$. RESULTS: It was found that nanoparticles have ideal morphology $(\sim 50-60$ $\mathrm{nm}$ ), magnetite core and capped with flavanoids. Encapsulation efficiency of doxorubicin and curcumin were $73 \%$ and $95 \%$ respectively. Almost no change was dedected in morphology of drug loaded nanoparticles. In addition controlled drug release profile $(\sim \% 10$ release at $24 \mathrm{~h})$ was achieved. CONCLUSIONS: Flavonoids provides the reduction of $\mathrm{Fe}^{3} \square$, formation of magnetites and coating of nanoparticles. This green synthesis method are low cost. Obtained nanoparticles could be thought as magnetically targeted drug delivery system for cancer therapy. It can be suggested that nanoparticles could have cytotoxicity on especially lung and ovarian cancer and this activity could increase with synergistic effect of curcumin. Keywords: Cancer, targeted therapy, magnetic nanoparticle, doxorubicin, curcumin, green synthesis

\section{OP-038}

\section{ANTICANCER EFFECT OF CUCURBITACIN B LOADED HYBRID NANOCARRIERS ON HUMAN BREAST CANCER CELLS}

Filiz Bakar Ateș ${ }^{1}$, Erva Özkan ${ }^{1}$, Ceyda Tuba Sengel Türk ${ }^{2}$

${ }^{1}$ Department of Biochemistry, Faculty of Pharmacy, Ankara University, Ankara ${ }^{2}$ Department of Pharmaceutical Technology, Faculty of Pharmacy, Ankara University, Ankara

OBJECTIVES: Breast cancer is an important health problem in recent years, and the studies including anticancer effects of natural derived compounds have great importance as well as the researches based on the investigations of mechanisms of cancer development. Cucurbitacin B is a triterpenoid derived natural compound which is present in plants and the studies report that this compound display antiproliferative effciency in various cancer cells. The aim of this research is to develop various nanoparticle formulations loaded with cucurbitacin B, and to investigate their antiproliferative effects on human breast cancer cells. MATERIALS and METHODS: Lipid polymer hybrid nanoparticles as drug carrier systems of cucurbitacin B were prepared by using Design of Experiment approach and optimum formulation were selected based on the $3^{2}$ factorial design. The anticancer activity of the optimum hybrid nanoparticles in MCF-7 and MDA-MB-231 cells were evaluated.

RESULTS: Optimum hybrid formulation was selected according to its desired particle size and highest encapsulation efficiency. The results showed that hybrid formulation significantly inhibited cancer cell proliferation in a dose dependent manner. The annexin V-binding studies performed through flow cytometry and fluorescence imaging have also showed that the hybrid formulation induced apoptosis of breast cancer cells.

CONCLUSIONS: The hybrid nanocarriers developed in this research were observed as promising drug carriers for the delivery of cucurbitacin B against breast cancer treatment. The strong anticancer effects against breast cancer cells indicated that these nanocarriers may be potential candidates for cancer treatment. Acknowledgments: This study is supported by The Scientific and Technological Research Council of Turkey (Tübitak) with 117S131 project number.

Keywords: Cucurbitacin B, MCF-7, MDA-MB-231, Lipid Polymer Hybrid
Nanoparticles, Anticancer, Apoptosis

OP-039

\section{INVESTIGATION OF THE CYTOTOXIC, GENOTOXIC \&} APOPTOTIC EFFECTS OF CAPSAICIN ON GASTRIC CANCER

Eray Metin Güler ${ }^{1}$, Mustafa Kesmen ${ }^{2}$, Abdurrahim Koçyiğit ${ }^{1}$ ${ }^{1}$ Bezmialem Vakif University School of Medicine Department of Medical Biochemistry, Istanbul

${ }^{2}$ Istanbul Pendik Veterinary Control Institute, Pendik - Istanbul

OBJECTIVES: Gastric cancer is the first in the world for both men and women. Today, the search for alternative treatments continues because current drugs and combinations are inadequate in the treatment of cancer. In our country, it is reported that Isot(Capsicum annuum), especially grown in the ŞanliurfaRegion and used as a spice, has antioxidant, anti-inflammatory, antimicrobial and anticancer effects. The aim of our research; investigation of cytotoxic, genotoxic and apoptotic effects of different concentrations of capsaicin and isot extracts on gastric cancer.

MATERIALS and METHODS: In our study, Isot collected from Şanliurfaregion were extracted with ethanol and methanol. The total phenol-flavonoid anthocyanin\&antioxidant levels of the extract were measured. The amount of capsaicin, the active ingredient in the extracts, was determined by HPLC. Different doses of Capsaicin and Isot extracts were applied to gastric adenocarcinoma cells(AGS) and normal-epithelial-cells(CCD1079Sk). After incubation for $24 \& 48 \mathrm{~h}$, cytotoxic, genotoxic, apoptotic and ROS activities were analyzed. RESULTS: Cytotoxicity was enhanced by extracts and capsaicin in AGS\&CCD1079Sk cells in a dose-dependent-manner. Extracts and capsaicin also induced apoptosis, DNAdamage, and increased ROS. Extracts and capsaicin inhibited some apoptotic proteins, resulting in apoptosis through regulation of proapoptotic and antiapoptotic proteins. It has been found that ethanol extract has more cytotoxic genotoxic and apoptotic effects than methanol extract and capsaicin that this effect is probably associated with their pro-oxidant and ROS production capacity.

CONCLUSIONS: As a result, it has been found that high doses of Isot\&Capsaicin on cancer\&ealthy cells have cytotoxic, genotoxic\&apoptotic effects with pro-oxidant effect. Cancer cells are more-sensitive than healthycells. Thus may have cancer potential.

Keywords: Gastric Cancer, Capsaicin, Isot Pepper, Apoptosis

\section{OP-040 \\ DETECTION OF MT-ND5 AND MT-CYB MUTATIONS IN THE HT25 AND HCT 116 COLON CANCER CELL LINES}

Gamze Turna ${ }^{1}$, Serap Yalçın ${ }^{2}$

${ }^{1}$ Department of Medical Biochemistry, Faculty of Medicine, Kirsehir Ahi Evran University, Kirsehir

${ }^{2}$ Department of Molecular Biology and Genetics, Faculty of Art and Sciences,

Kirsehir Ahi Evran University, Kirsehir

OBJECTIVES: Human mitochondrial DNA (mtDNA) is a circular, doublestranded DNA molecule that containing 37 genes. It has been determined that tumor development is related with mtDNA mutations. Recent studies have identified the presence of mtDNA mutations in many types of cancer, including colon cancer. In this study, we aimed to determine the presence of variations of mitochondrial NADH dehydrogenase 5 (MT-ND5) and mitochondrial cytochrome $\mathrm{b}$ (MT-CYB) genes in the mtDNA of HT25 and HCT 116 colon cancer cell lines MATERIALS and METHODS: mtDNA was isolated from HT25 and HCT 116 colon cancer cell lines and MT-ND5 and MT-CYB genes were amplified by polymerase chain reaction (PCR). DNA direct sequencing was done using forward and reverse primers. RESULTS: The mutational analysis of the mtDNA revealed the presence of A15366G, C15367G, T15567d, T15573d variations in CYB gene, T12574C T12575C, A12579C, A12584d, A12587G, C12588G, T12643C, T12650C T12706C, T12881C, A12909d, A12926d, G12940C variations in ND5 gene in HT25 cell line. In the mutational analysis of mtDNA in the HCT 116 cell line determined the presence of T15609C, A15610AT variations in the CYB gene. In contrast, no mutation was detected in the ND5 gene. CONCLUSIONS: It was concluded that novel MT-ND5 and MT-CYB mutations could be found in colon cancer cell lines. Thus, these mutations might play an important role in colon cancer prognosis. However, whether the mitochondria dysfunction contribute to colon cancer needs to be further investigated. Keywords: Colon cancer, mtDNA, MT-ND5, MT-CYB

\section{OP-041 \\ ROLE OF ENDOT}

Rüstem Anıl Uğan

Department of Biochemistry, Faculty of Pharmacy, Ataturk University 25240

Erzurum

OBJECTIVES: The aim of this study is to explore the role of ET- 
in HCT116 proliferation and invasion. Anti-proliferative and antiinvasion effects of the non-selective dual ETA/ETB receptor antagonist Bosentan was determined on HCT116 cell line in vitro MATERIALS and METHODS: Cells were seeded into the plates and 24 $\mathrm{h}$ after the cells were incubated with or without 10-4M BOS for 1-4 days. The wound healing, MTT and Crystal Violet Assays were performed. RESULTS: Bosentan exert anti-proliferative and anti-invasion effect on HCT116. Important inhibitory effects on invasion and wound healing of HCT116 cells were showed by the Bosentan group compared to the Control group. CONCLUSIONS: The major findings of current study were that critical role of Bosentan on proliferation and invasion of HCT116 cells. Keywords: Bosentan, HCT116, invasion, proliferation

\section{OP-042 \\ THE EFFECT OF N-ACETYLCYSTEINE ON OXIDATIVE STRESS INDUCED BY CCL4 HEPATOTOXICITY IN THE RATS}

Elif Azize Özșahin Delibaș ${ }^{1}$, Kader Köse' $^{1}$, Cevad Yazıc1 ${ }^{1}$, Kemal Deniz ${ }^{2}$ ${ }^{1}$ Department of Medical Biochemistry, Faculty of Medicine, Erciyes University, Kayseri

${ }^{2}$ Department of Pathology, Faculty of Medicine, Erciyes University, Kayseri

OBJECTIVES: This study was performed to form an oxidative stress model by hepatotoxic agent carbon tetrachloride (CCl4) and to investigate the effects of $\mathrm{N}$-acetylcysteine (NAC), a powerful antioxidant, on the oxidative stress induced by hepatotoxicity, through myeloperoxidase (MPO) activity and protein oxidation. MATERIALS and METHODS: Wistar albino male rats were divided into four groups as $\mathrm{CCl} 4$, NAC, $\mathrm{CCl} 4-\mathrm{NAC}$ and Control, each of ten rats. $\mathrm{CCl} 4$ $(1,0 \mathrm{~mL} / \mathrm{kg}$ rat weight/per day, ip $)$ as a single dose and NAC $(200 \mathrm{mg} / \mathrm{kg}$ rat weight/per day, ip) as three doses were applied to corresponding groups. Hepatotoxicity was identified with histopatologic methods. MPO activity was determined in plasma and protein carbonyl compounds (PCC), one of the indicator of protein oxidation, were measured in serum samples. RESULTS: There was no significant difference between Control and NAC groups, in terms of measured plasma MPO activity or serum PCC levels. When compared to these groups, MPO activity and PCC levels were found to be higher in the $\mathrm{CCl}$ 4roup. In the $\mathrm{CCl} 4-\mathrm{NAC}$ group, $\mathrm{CCl}$-induced hepatotoxic lesions such as steatosis, inflammation and necrosis were remarkably improved in the presence of NAC, and also NAC significantly lowered MPO activity and PCC levels, so that the values were reached to those of Control and NAC groups. CONCLUSIONS: As reflected by higher MPO activity and PCC levels, oxidative stress, induced by $\mathrm{CCl} 4$ hepatotoxicity, may be prevented by the presence of NAC. Thus, NAC addition may be offered to the treatment protocols of several diseases, in the pathogenesis of which oxidative stress exist. Keywords: Carbon Tetrachloride, Myeloperoxidase, N-acetylcysteine, Protein Carbonyl Compounds, Rat.

\section{OP-043 \\ HORMETIC STRESS RESPONSE OF DIETARY PHYTOCHEMICALS IN HEALTHY AGING}

\section{Ceren Gezer}

Department of Nutrition and Dietetics, Faculty of Health Sciences, Eastern Mediterranean University, Famagusta, North Cyprus

OBJECTIVES: Hormesis is defined as any circumstance in which chemical and environmental factors give beneficial effect to the cells at low doses while causing harm for them at high doses. The stress responses observed in mammalian cells can be classified as heat shock, unfolded protein, autophagic, DNA damage, antioxidant and sirtuin responses at the intracellular and molecular levels. Factors which strengthen the hemodynamic structure causing low-level molecular damage and activating one or several stress response pathways are called hormetin. Dietary phytochemicals are potential nutritional hormetins. Resveratrol, curcumin, epicatechin, isothiocyanates, ferulic acid can form stress responses causing the stimulation of kinases and transcription factors. MATERIALS and METHODS: This presentation will focus on the increasing quantity and content of the related literature in the last 10 years. We did a Google Scholar research for articles published between 2008-2018 years with the keywords of "hormesis", "nutrition", "dietary phytochemicals" and "aging". The search revealed 1,860 articles (nearly $48 \%$ of these were in the last 3 years) RESULTS: We throughly investigated the literature with the aim to explain the stress response effect mechanisms of the dietary phytochemicals as nutritional hormetins and as important components that affect the delay of age-related diseases, thus provide healthy aging and increase the lifespan.

CONCLUSIONS: Our search results indicate that these phytochemicals are related to nuclear factor erythroid 2 and sirtuin pathway, heat shock response activation and nuclear factor kappa-B down regulation. The mechanisms of action of important phytochemicals and stress response pathways will be discussed in the light of data obtained in recent years

Keywords: hormesis, dietary phytochemicals, healthy aging

\section{OP-044 \\ TAU PROTEIN AND 8-ISO-PROSTAGLANDIN IN CHILDREN WITH ATTENTION-DEFICIT HYPERACTIVITY DISORDER}

Filiz Atalay Cubuk ${ }^{1}$, Ergül Belge Karutaş ${ }^{2}$, Hatice Altun ${ }^{3}$

${ }^{1}$ Akdeniz University, Institute of Science, Department of Biotechnology, Antalya

${ }^{2}$ Kahramanmaras Sutcu Imam University Faculty of Medicine, Department of Biochemistry, Kahramanmaras

${ }^{3}$ Kahramanmaras Sutcu Imam University, Medicine Faculty, Department of Child and Adolescent Psychiatry, Kahramanmaras

OBJECTIVES:Attention-deficit hyperactivity disorder (ADHD) is a common childhood neur obehavioural disorder. No specific etiology has been identified for ADHD. Tau protein contributes to the proper function of neuron 8-isoprostaglandin F2 $\alpha$ (8-iso-PGF2 $\alpha$ ) is an indicator of oxidative stress biomarkers Up to now, no studies have been conducted on the concentrations of Tau protein and 8 -iso-PGF $\alpha$ in children with ADHD. The aim of this study is to evaluate the concentrations of Tau protein and 8-iso-PGF2 $\alpha$ in children with ADHD.

MATERIALS and METHODS: The present study included 35 children with ADHD diagnosed by DSM-V criteria. Controls included 35 age, gender-matched healthy children. Children and adolescents were evaluated using the Schedule for Affective Disorders and Schizophrenia for school-age children, lifetime version (KSAD-L). The IQ was assessed by using the manual for the Weschler Intelligence Scale for Children-Revised. The concentrations of Tau protein, 8-iso-PGF2 $\alpha$ in serum samples were measured with enzyme-linked immunosorbent assay. RESULTS: There was no significant difference between the groups in terms of age, sex $(p>0.05)$. The results indicated that the concentrations of 8 -iso-PGF2 $\alpha$ increased in patients with ADHD compared to control $(\mathrm{p}<0.05)$. However, there were no change in tau protein concentrations as statistically between groups. In the ROC analysis, there was good diagnostic value for 8 -iso-PGF2 $\alpha$

CONCLUSIONS: This is the first report to investigate the association between serum 8-iso-PGF2 $\alpha$, tau protein concentrations in ADHD patients. Our results indicated that 8-iso-PGF2 $\alpha$ may play a role in the etiology of ADHD Also, with $99 \%$ sensitivity and specificity, it is thought that 8-iso-PGF2 $\alpha$ could be important for the diagnosis and treatment.

Keywords: ADHD, 8-iso-PGF2 $\alpha$, Tau protein

\section{OP-045}

\section{EVALUATION OF THE POST-ANALYTICAL PHASE IN MEDICAL} LABORATORIES

Zeliha Gunnur Dikmen ${ }^{1}$, Oytun Portakal' ${ }^{1}$, Suat Hayri Küçük ${ }^{2}$, Ferhan Girgin Sağın ${ }^{3}$, Doğan Yücel ${ }^{4}$

'Hacettepe University, Faculty of Medicine, Department of Medical Biochemistry, Ankara

${ }^{2}$ Health Sciences University, Bagcilar Health Training and Research Center, Department of Medical Biochemistry, İstanbul

${ }^{3}$ Ege University Medical Faculty, Department of Medical Biochemistry, İzmir ${ }^{4}$ Health Sciences University, Ankara Health Training and Research Center,

Department of Medical Biochemistry, Ankara

OBJECTIVES: Post-analytical phase is very important in medical laboratory management and standardization of the post-analytical phase is required for accreditation of the laboratories. In this study, we aimed to evaluate the post-analytical phase in laboratories in Turkey. MATERIALS and METHODS: Post-analytical phase working group has prepared a questionnaire including 24 questions on postanalytical practices. Then the responses from 104 medical laboratories were examined to identify current post-analytical phase practices. RESULTS: $60 \%$ of the test results were approved both by laboratory technician and specialist, $40 \%$ by only laboratory technician, autoverification is used only in $7.4 \%$ of the laboratories. $54 \%$ of the patients receive their reports from the clinician and $31 \%$ from the laboratory secretary. Reference intervals suggested by the companies are used in $78 \%$ of the laboratories, $15 \%$ use literature based ranges, $6 \%$ use their own ranges. The comment of the laboratory specialist is added to $\% 16.5$ of the reports, $8.7 \%$ of the patients ask questions to the laboratory specialist about their results. When necessary, $56.4 \%$ of the clinical chemists give consultation to the clinician. Critical values are reported in $\% 96$ of the medical laboratories, $\% 75$ by phone call and $23 \%$ by text messages. Laboratory tecnician is responsible of critical value notification in $46 \%$ of the laboratories and $73 \%$ of the clinical services are informed about the results in 30 minutes. The most common reported critical values are electrolytes $(\% 91.8)$, creatinine $(\% 77.5)$ glucose $(\% 96.9)$ and troponin $(\% 75.5)$ levels. The analysis of critical value notification statistics are performed by $87 \%$ of the laboratories, monthly. CONCLUSIONS: Laboratory professionals should focus on standardization of the post-analytical phase; dealing with abnormal test results, informing the clinicians about critical values, adding interpretative comments to laboratory test results. Keywords: postanalytical phase, critical value notification 


\section{OP-046 \\ CRITICAL VALUE EVALUATION IN HACETTEPE UNIVERSITY HOSPITALS}

Emine Nilay Bakır, Furkan Yıldız, Zeliha Günnur Dikmen, İncilay Lay, Oytun Portakal, Aslı Pınar

Hacettepe University, Faculty of Medicine, Department of Medical

Biochemistry, Ankara

OBJECTIVES: A critical value (CV) is defined as 'a test result that is significantly outside the normal range and may represent lifethreatening values'. CV notification is one of the main quality indicators of the post-analytical phase to improve patient safety. MATERIALS and METHODS: In our study, test results reported from Hacettepe University Hospitals (Pediatric, Adult and Oncology) in 2018 between January and June have been evaluated in terms of CVs. 11 tests including glucose, sodium, potassium, magnesium, phosphorus, total calcium, total bilirubin, ammonia, hemoglobin, thrombocyte count and hematocrit were selected from our CV list. CV ratios for the selected tests were calculated according to the hospitals. CVs below the lower limits and above the upper limits were also analyzed. RESULTS: Our laboratory has obtained $10,614 \mathrm{CVs}$ in total $1,655,713$ selected test results $(0.64 \%)$. Pediatric, Adult and Oncology hospitals contributed to the total CVs with a $18 \%, 71 \%$ and $11 \%$, respectively. The most common CVs were thrombocyte $(25 \%)$, hemoglobin $(22 \%)$ and total calcium $(15 \%)$ overall. The most common CVs in Pediatric Hospital were hemoglobin, thrombocyte and total bilirubin while thrombocyte, hemoglobin and total calcium were most common CVs in Adult and Oncology Hospitals. CVs for total calcium and magnesium were evidently below the lower limit in all hospitals. Hypoglycemia was significant in pediatric patients $(79 \%)$ whereas hyperglycemia was remarkable $(64 \%)$ in adult patients. CONCLUSIONS: Upper and lower limits of CVs should be determined for each hospital. Laboratory professionals should revise their CV list in communication with clinicians to provide a safer and higher quality patient care. Keywords: Critical value, post-analytic, lower limit, upper limit

\section{OP-047 \\ THE EFFECTS OF HIGH FRUCTOSE DIET ON ENDOPLASMIC RETICULUM STRESS, CELL DEATH AND OXIDATIVE DAMAGE}

Zeynep Mine Coskun, Melike Ersoz, Zehra Yaren Dönmez, Esma Nur Demir, Berin Sena Arslan, Aynur Acar

Department of Molecular Biology and Genetics, Faculty of Arts and Sciences, Istanbul Bilim University, Istanbul

OBJECTIVES: Total consumption of refined fructose has increased amazingly in the last 30 years. Many studies showed that high fructose intake induced diseases such as insulin resistance, metabolic syndrome. This study was designed to investigate the effects of high fructose diet on endoplasmic reticulum (ER) stress, cell death and, oxidative damage statutes in rat pancreas. MATERIALS and METHODS: Male Sprague Dawley rats (8-10 weeks-old) were divided into two groups. Control group $(\mathrm{n}=7)$ was fed standard pellet and tap water and Fructose group $(n=7)$ was drank $20 \%$ fructose in drinking water for 8 weeks. The blood and pancreas tissues were collected from rats. Total antioxidant and oxidant statuses in plasma were measured, spectrophotometrically. Glucose regulated protein 78 (Grp78), Inositol Requiring Kinase 1 (IRE1), Protein Kinase-like ER Kinase (PERK), Activating Transcription Factor 4 and 6 (ATF4 and 6), C/EBP Homologous Protein (CHOP), Caspase -3, -8, -9 and -12 mRNA expression in pancreas tissue were determined by the qRT-PCR. RESULTS: It was observed that high fructose diet increased the mRNA expression levels of Grp78, IRE1, PERK, ATF 4, ATF 6 and Caspase -3, -8, -9 and -12 in rat pancreas of the Fructose group as compared to control group. The high fructose diet significantly reduced plasma antioxidant levels in the Fructose group when compared to Control group. However, the levels of total oxidant in plasma showed an increase with fructose diet, non-significantly. CONCLUSIONS: Our findings were shown that high fructose diet may cause ER stress and cell death in pancreas tissue, and disruptions of the oxidant/antioxidant balance in plasma. Keywords: Cell death, ER stress, Fructose, Oxidative stress

\section{OP-048 \\ A NOVEL IRON CHELATING LIGAND FOR IRON OVERLOAD DISEASES}

Gülüzar Özbolat ${ }^{1}$, Arash Alizadeh Yegani $^{2}$

${ }^{1}$ Cukurova University, Faculty of Medicine, Department of Medical Biochemistry, 01330 Adana

${ }^{2}$ Mustafa Kemal University, Faculty of Veterinary, Department of

Pharmacology,31060 Hatay

OBJECTIVES: Iron overload is a serious clinical condition for humans and is a key target in drug development. The aim of this study was to investigate the cytotoxic and antioxidant activities of Fe (III) ions with curcumin ligand that may be used in the treatment of iron overload.

MATERIALS and METHODS: In this study, Fe(III) complex of curcumin was synthesized and structurally characterized in its solid and solution state by FT-IR, UV-Vis, elemental analysis, and magnetic susceptibility. The cytotoxic activities of the ligand and the Fe (III) complex were evaluated by the MTT assay. Superoxide dismutase activity of the complex was tested using an indirect method. The catalytic activity of Fe(III) complex in DMSO against the disproportionation of hydrogen peroxide was also each tested.

RESULTS: Curcumin formed a brown-red complex with Fe(III). Data regarding magnetic susceptibility showed that the complexes with a $1: 2$ (metal/ligand) mole ratio had octahedral geometry. The complex showed higher antioxidant activity against HUVEC cell lines at an IC50 value of 5.3. Superoxide dismutase activity of the complex was tested. The results indicated that the complexes show increased SOD activity, suggesting that the iron complex is capable of removing free radicals. The catalytic activity of Fe (III) complex also showed catalytic activity.

CONCLUSIONS: Our study results revealed that the Fe(III) complex of curcumin with an appropriate potential drug may act as a protector against oxidative stress and the observed cytotoxicity could be pursued to obtain a potential drug. Further studies investigating the use of curcumin for this purpose are needed. Keywords: Curcumin, iron overload, catalase, Fe(III), Superoxide dismutase, cytotoxic activities

\section{OP-049}

\section{PLATELET LEVELS AND NEUTROPHIL/LYMPHOCYTE RATIO IN} THYROID NODULES WITH AND WITHOUT CANCER DIAGNOSIS

Soycan Mizrak ${ }^{1}$, Şirin Küçük ${ }^{2}$

Department of Medical Biochemistry, Faculty of Medicine, Usak University, Usak

${ }^{2}$ Department of Medical Patology, Faculty of Medicine, Usak University, Usak

OBJECTIVES: Nodular formation of thyroid tissue is a very common endocrinologic pathology. Approximately $5 \%$ of thyroid nodules can prove to be cancerous. The usefulness of mean platelet volume(MPV) and neutrophil to lymphocyte count(NLO) is determined as an indicator of immunological response and subclinical inflammation in recent years. In this study we evaluate the association of thyroid stimulating hormone(TSH), platelet, MPV and NLO levels between the thyroid nodules that turn into cancer and do not convert. MATERIALS and METHODS: Our study consisted of patients with thyroid nodules that converted to thyroid cancer $(n=100)$ and didn't convert to thyroid cancer $(n=100)$. These patients were selected retrospectively using Hospital Information System. The TSH, NLO, platelet and MPV levels were recorded preoperatively and the difference between them was evaluated statistically with SPSS 21. Differences between groups were examined with using Mann Whitney U Test. $\mathrm{P}<0.05$ were considered significant RESULTS: Platelet, TSH and neutrophil values were significantly higher in the nodular group which convert to thyroid cancer $(p<0,05)$. In addition, the likelihood of being thyroid cancer increased 1.47 times with a unit increase in the NLO variable, and 1.008 times with a unit increase in the Platelet variable. CONCLUSIONS: High levels of platelet and neutrophil in thyroid cancer may be due to increased cytokine level changes. It can be shown that data obtained from total blood count, which is an easy, inexpensive and reproducible assay, can be used as a marker in predicting prognosis with further studies. Keywords: neutrophil, platelet, thyroid nodule

\section{OP-050 \\ LOCALIZATION OF TISSUE REQUIRING SURGERY IN HYPERPARATHYROIDISM: CASE REPORT}

Elif Değirmen İsen ${ }^{1}$, Taner Demirci ${ }^{2}$, Selçuk Akın ${ }^{1}$, Bülent Adar ${ }^{3}$ ${ }^{1}$ Department of Clinical Biochemistry, Batman State Hospital, Batman ${ }^{2}$ Department of Endocrinology \& Metabolism, Batman State Hospital, Batman ${ }^{3}$ Department of Clinical Biochemistry, University of Health Sciences Van Education and Research Hospital, Van

OBJECTIVES: Parathyroid adenomas is the most common cause of Primer hyperparathyroidism (PHP). Adenomas usually have elevated levels of serum parathyroid hormone $(\mathrm{PTH})$ and calcium. The only alternative in the treatment of parathyroid adenomas is the surgeon. Determination of adenomal localization provides great convenience for minimally invasive parathyroidectomy. Laboratories help diagnose of many diseases. We want to share with you a case that we have seen this contribution clearly. MATERIALS and METHODS: Parathormone level was measured from the tissue that evaluated as parathyroid preoperative by ultrasound-guided fine needle aspiration biopsy (FNAB). by ultrasound-guided fine needle aspiration biopsy (FNAB).
RESULTS: Parathyroid Adenoma in the right lobe was detected with thyroid ultrasonography. Patient's blood PTH level was $138.7 \mathrm{pg} / \mathrm{mL}(18.5-88)$. Parathyroid adenoma suspicious lesion PTH level was measured as $>2000 \mathrm{pg}$ $\mathrm{mL}$ in FNAB aspirate. Patient was operated on these findings pathology report was reported as parathyroid adenomas. Postoperatively measured control blood calcium level was $9.6 \mathrm{mg} / \mathrm{dL}$, PTH level was $25.9 \mathrm{pg} / \mathrm{mL}$ at normal levels. CONCLUSIONS: The success of minimally invasive parathyroidectomy is based on the localization of the abnormal gland preoperatively. The sensitivity of the ultrasonographic scan to detect the parathyroid adenoma is $\% 70-80$, sensitivity to localization of abnormal parathyroid gland by scintigraphic 
method is reported as $\% 85-95$. As current developments have increased interest in minimally invasive parathyroid surgery, more sensitive methods for localization are being investigated. When FNAB in the presence of preoperative ultrasonography is a highly sensitive method of localization of parathyroid tissue in addition the parathyroid level measurement in tissue aspiration confirms the diagnosis. Keywords: Parathormone, minimally invasive parathyroidectomy, aspirate,

\section{OP-052 \\ PROTECTIVE EFFECT OF NUTRACEUTICALS ON OXIDANT- ANTIOXIDANT LEVELS IN THE RAT BREAST CANCER}

Hüseyin Fatih Gül, Necip Ilhan, Nevin Ilhan

Firat University Faculty of Medicine Department of Medical Biochemistry, Elazıg

OBJECTIVES: The aim of this study was to investegate the potential chemoprevention effects of Pomegranate (P) and Tangeretin (T), both alone and in combination, on the oxidant-antioxidant status in 7,12-dimethylbenz [a] anthracene (DMBA)-induced rat breast cancer model. MATERIALS and METHODS: A total of 56 Sprague Dawley female rats, 8-10 weeks old, were randomly divided into 8 groups. The first 4 groups were designed as controls of cancer and treatment groups and were composed of Control, P $(5 \mathrm{~g} /$ $\mathrm{kg}$ every day for the first 30 days), $\mathrm{T}(50 \mathrm{mg} / \mathrm{kg}$ every day for the first 30 days) and $\mathrm{P}+\mathrm{T}$ groups. The other 4 groups were designed as cancer and treatment groups and were composed ofDMBA(D; $60 \mathrm{mg} / \mathrm{kg}$ single dose on the 15 th day of the study) and $\mathrm{D}+\mathrm{P}, \mathrm{D}+\mathrm{T}, \mathrm{D}+\mathrm{P}+\mathrm{T}$ groups, respectively. At the end of 23 weeks, MDA levels were measured in order to evaluate oxidative stress and lipid peroxidation from breast tissue samples, and for antioxidant status SOD, CAT, GSH-Px enzyme activities and GSH levels were measured spectrophotometrically by appropriate methods. RESULTS: While tissue MDA levels significantly increased in the DMBA group compared to the control group, SOD, CAT, GSH-Px activities and GSH levels significantly decreased. When the DMBA group and the treatment groups were compared, MDA levels significantly decreased only in the $\mathrm{D}+\mathrm{P}+\mathrm{T}$ while only the GSH levels of antioxidant parameters significantly increased in all treatment groups. CONCLUSIONS: It was observed that combined application of nutraceuticals affected oxidative stress and lipid peroxidation, moreover, it was found to act chemopreventively by activating the antioxidant defense system over non-enzymatic pathways in DMBA-induced breast cancer Keywords: Breast Cancer, DMBA, Nutraceuticals, Oxidant-Antioxidant Levels

\section{Introduction}

Breast cancer, which is the most common type of cancer in women in Turkey as well as in the world, is still one of the most important health problems.

7,12-dimethylbenz [a] anthracene (DMBA), is considered as potential mutagenic and carcinogenic agents that play important roles in the development of oxidative stress-induced cancers, by leading to the production of free radicals in vivo. These radicals are highly toxic to cell membranes and cellular organelles and also interact with many macromolecules and lead to the deterioration of their structure and functions $(1,2)$.

The organism develops antioxidant defense systems against such damaging agents; they can be separated as enzymatic or non-enzymatic. In addition, it has recently been found that fruits and vegetables (nutraceuticals) containing various natural antioxidant phytochemical agents in the human diet have a significant positive contribution to this antioxidant system in our organism and thus benefit in the treatment of various diseases including as cancer $(3,4)$.

Pomegranate fruit (Punica granatum L), peel and extract contain many natural bioactive phytochemical agents. These include flavonoids such as Luteolin Kaempferol, Quercetin, hydrolyzable tannins such as punicalagin, ellagic acid, caffeic acid, gallic acid, and polyphenolic (acid) compounds, etc. $(5,6)$. It has been reported that pomegranate derivetes contains valuable phytochemicals which can be used therapeutically, has antiproliferative, antiangiogenic, antiinvasive and proapoptotic effects in some cancer cells in vitro and in vivo, and has strong antioxidant and anti-inflammatory properties (7).

Tangeretin is a polymethoxyflavone (PMF) compound with $5,6,7,8,4^{\prime}$-pentamethoxy flavone abundant in the peels of citrus fruit such as mandarin, lemon, orange, and grapefruit. In the literature, the bioactivity of citrus flavonoids has included the treatment of metabolic disorders, antiatherosclerotic, antidiabetic, anti-inflammatory, neuroprotective, antimicrobial and antioxidant regulation. PMFs' cancer preventive and / or anticancer activities contain various complex mechanisms. Furthermore, the use of these bioactive PMFs for chemopreventive and therapeutic purposes in the treatment of various diseases, especially cancer, has been the subject of many studies and attracts great attention nowadays $(8)$.

Based on these considerations, it was aimed to investigate the chemopreventive effects of the administration of nutraceutical agents, alone or in combination, such as Pomegranate extract and Tangeretin on the oxidant-antioxidant condition in DMBA-induced rat breast cancer.

Materials and methods

This study was carried out in Firat University Experimental Research Center (FÜDAM) in accordance with the ethical principles of standard experimental applications and by obtaining Firat University Animal Experiments Local Ethics Committee (Approval Meeting Date: 06.0.4.2016, Number of Meeting: 2016/07, Decision No: 73, Protocol No: 2016/48).

Sprague Dawley female rats aged 8-10 weeks and weighing 205-220 g were used in the study. The rats were homogeneously, randomly divided into 8 groups. The first 4 groups were designed as the controls of cancer and treatment groups, and they were called as the Control group ( $\mathrm{K}: \mathrm{n}=7$ : fed with standard pellet feed and water ad libitum), Pomegranate group ( $P: n=7$ : from the beginning of the study

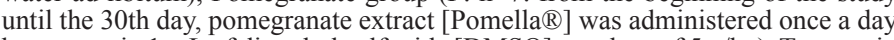
by gavage in $1 \mathrm{~mL}$ of dimethyl sulfoxide [DMSO] at a dose of $5 \mathrm{~g} / \mathrm{kg}$ ), Tangeretin group (T: $n=7$ : from the beginning of the study until the 30th day, Tangeretin was administered once a day by gavage in $1 \mathrm{~mL}$ of DMSO at a dose of $50 \mathrm{mg} / \mathrm{kg}$ ) and the Pomegranate+Tangeretin group $(P+T: n=6$ : Pomella $\AA+$ Tangeretin was administered in combination in the same way as mentioned above), respectively. Furthermore, on the 15 th day of the study, the animals in the first 4 groups were administered with $1 \mathrm{~mL}$ of olive oil only once by gavage. The other 4 groups were designed as the cancer and chemopreventive groups, and they were called as the DMBA/Cancer group (D: $n=7$ : on the 15th day of the study, DMBA was administered in $1 \mathrm{~mL}$ olive oil once by gavage at a dose of $60 \mathrm{mg} / \mathrm{kg}$ ) and $\mathrm{D}+\mathrm{P}$ group $(\mathrm{n}=8), \mathrm{D}+\mathrm{T}(\mathrm{n}=7), \mathrm{D}+\mathrm{P}+\mathrm{T}(\mathrm{n}=7)$, respectively. DMBA administrations in the last 3 chemopreventive groups were performed in the same dose and in the same way as DMBA administered in the previous group (Group 5), and phytotherapy agents were administered in the same dose and in the same way as the above-mentioned $2 \mathrm{nd}$, 3rd, and 4th sham groups.

In the study, the in-vivo breast cancer generation protocol with DMBA was determined as follows; the rats were administered with DMBA with a sterile oralgastric catheter at a dose of $60 \mathrm{mg} / \mathrm{kg}$ live weight by a single dose oral gavage under mild ether sedation. Approximately 100 days (16 weeks) after DMBA was administered on the 15th day of the study, the first mass formation was observed in the breast tissue. At the end of the $23 \mathrm{rd}$ week of the experiment, the rats were sacrificed by using sterile instruments under appropriate anesthetic conditions, and the experimental part was terminated.

A part of the breast tissue excised to cover the tumorous tissue was homogenized for 3 minutes at $16000 \mathrm{rpm}$ with the help of a homogenizer (Ultra TurraxType T25-B, IKA Labortechnic, Germany) in 0.15M KCI $(1 ; 9, \mathrm{w} ; \mathrm{v})$ solution $(+40 \mathrm{C})$ to be used in biochemical analyses. The total protein levels were determined according to the Lowry method (9) in clear supernatants obtained after the centrifugation of homogenates at $5000 \mathrm{xg}$ for 1 hour $\left(+4^{\circ} \mathrm{C}\right)$. MDA levels for the evaluation of oxidative stress and lipid peroxidation, and SOD, CAT, GSH-Px enzyme activities and GSH levels for the evaluation of the antioxidant status were measured using appropriate spectrophotometric methods (10-14).

The Mann-Withney U test was used for the statistical difference between the control and DMBA groups to reveal the formation of cancer in the data obtained as a result of biochemical analyses. In order to reveal the chemopreventive activity of drugs, the Kruskal-Wallis test was first used to show the statistical difference between the $\mathrm{D}, \mathrm{D}+\mathrm{P}, \mathrm{D}+\mathrm{T}, \mathrm{D}+\mathrm{P}+\mathrm{T}$ groups, and then Dunn's test was used to show from which group this difference originated. $\mathrm{p}<0.05$ was accepted for the lowest statistical significance, and the results were presented in Median (Min-Max). Furthermore, the statistical evaluation of all data obtained from this study was performed using IBM SPSS Statistics 22 which is licensed to Frrat University.

The analytical purity of DMBA (Tokyo Chemical Industry Co., Ltd. (TCI), Portland, USA) used in the study to generate the cancer model was $>98 \%$ (by GS). The pomegranate extract used as a chemopreventive agent in the study was the commercial whole pomegranate extract in powder with a natural polyphenolic ratio of standardized at least $95 \%$ purity (by HPLC) 'Pomella ${ }^{\circledR}$ ' (Verdure Sciences ${ }^{\circledR}$, Noblesville, USA). Tangeretin (AvaChem Scientific, San Antonio, U.S.A.) used as a chemopreventive agent in the study was in powder form and with $98 \%$ analytical purity (by HPLC). In the study, $0.1 \%$ DMSO (Fisher scientific, Leicestershire, UK) was used to dissolve therapeutic agents. Results

The tissue oxidant and antioxidant levels of animals in all groups are summarized in the table.

Table 1. Comparison of Oxidant and Antioxidant levels for all groups

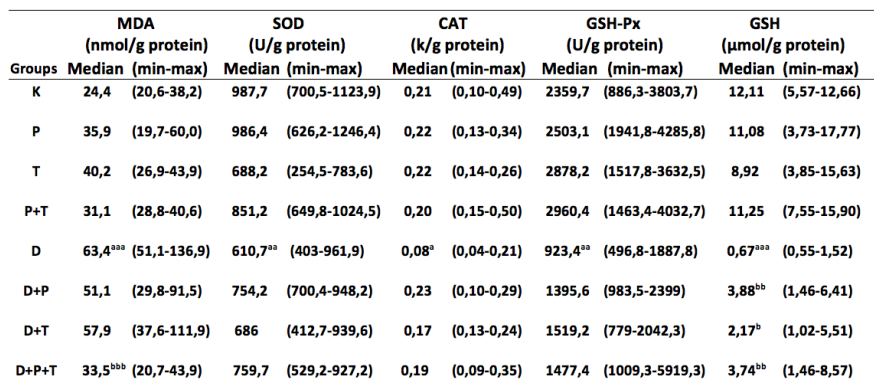

a $p<0,05$; aa $p \leq 0,005$; aaa $p=0,001$ : Compared to the Control (K) group, (Mann-Withney $U$ test) b $p<0,05$; ${ }^{b} p<0,01$; bb $p \leq 0,005$ : Compared to the DMBA (D) group (Kruskal-Wallis, Dunn test)

Discussion

In the study, the fact that breast tissue MDA levels of the rats in the cancer group showed a statistically significant increase $(p=0.001)$ compared to the control group. This condition, in cancer cells that proliferated with DMBA; It was interpreted as lipid peroxidation is induced and ultimately contributes to the progression of cancer. The fact that MDA levels were lower in all treatment groups compared to those in the cancerous group in our study is compatible with the literature $(8,15-17)$. However, the statistically significant decrease close to the control $(\mathrm{p} \leq 0.005)$ was observed in the group in which only two therapeutic agents were administered $(\mathrm{D}+\mathrm{P}+\mathrm{T})$ combinally. This can be interpreted that bioactive 
polyphenol compounds in pomegranate extract administered as a nutraceutical agent (punicalagin, gallic acid, and ellagic acid polyphenols) and Tangeretin with a flavonoid structure showed a synergistic effect to prevent DMBA-induced lipid peroxidation.

In our study, in accordance with some literature (15-18), it was determined that tissue SOD, CAT, GSH-Px activities and GSH levels of the rats with DMBA induced breast cancer significantly decreased $(\mathrm{p} \leq 0.005 ; \mathrm{p} \leq 0.05 ; \mathrm{p} \leq 0.005$ and $\mathrm{p}=0.001$ ) compared to the control group. Increases were determined in tissue SOD, CAT and GSH-Px activities in all phytotherapy groups compared to the DMBA group. However, only significant effective increases were found in GSH levels. Although some of the results of our study seem to support the aforementioned studies, it can be interpreted that the oral treatments of pomegranate and tangeretin alone or in combination showed an anticarcinogenic effect through nonenzymatic antioxidant pathways rather than enzymatic pathways in activating the antioxidant defense system to deal with lipid peroxidation and oxidative stress resulting from DMBA.

In conclusion, especially the combined administration of Pomegranate extract and Tangeretin appears to be more useful in preventing the development of DMBA-induced breast cancer. However, we believe that further molecular studies are needed.

Acknowledgements

This study (Project No: TF16.37) was supported by Firat University Scientific Research and Projects Unit (FÜBAP) and OYP Coordinatorship. We thank FÜBAP and OYP Coordinatorship for its support.

References

1. Kosenko E, Kaminsky Y, Lopata O, Muravyov N, Kaminsky A, Hermenegildo $C$, et al. Nitroarginine, an inhibitor of nitric oxide synthase, prevents changes in superoxide radical and antioxidant enzymes induced by ammonia intoxication. Metab Brain Dis 1998;13: 29-41.

2. Schliess F, Gorg B, Fischer R, Desjardins P, Bidmon HJ, Herrmann A, et al. Ammonia induces MK-801-sensitive nitration and phosphorylation of protein tyrosine and residues in rat astrocytes. FASEB J 2002;16:739-41.

3. Kalra EK. Nutraceutical - Definition and Introduction. AAPS PharmSci 2003;5(3):27-28.

4. Sghaiera MB, Skandrani I, Nasra N, et al. Flavonoids and sesquiterpenes from Tecurium ramosissimum promote antiproliferation of human cancer cells and enhance antioxidant activity: A structure-activity relationship study. Environmental Toxicology and Pharmacology AAPS 2011:32:336-48.

5. Bishayee A, Mandal A, Bhattacharyya P, Bhatia D. Pomegranate exerts chemoprevention of experimentally induced mammary tumorigenesis by suppression of cell proliferation and induction of apoptosis. Nutr Cancer 2016;68(1):120-130

6. Turrini E, Ferruzzi L, Fimognari C. Potential effects of pomegranate polyphenols in cancer prevention and therapy. Oxid Med Cell Longev 2015; Article ID 938475 doi:10.1155/2015/938475.

7. Negi PS, Jayaprakash GK, Jena BS. Antioxidant and antimutagenic activities of pomegranate peel extracts. Food Chemistry 2003;80(3);393-97.

8. Gao Z, Gao W, Zenga SL, L1 P, Liu EH. Chemical structures, bioactivities and molecular mechanisms of citrus polymethoxyflavones. Journal of Functional Foods 2018;40:498-509.

9. Lowry OH, Rosenbrough NJ, Farr AL, Randall RJ. Protein Measurements with the Folin Fenol Reagent J Biol Chem 1951:193(1):265-75.

10. Ohkawa H, Ohishi N, Yagi K. Assay for Lipid Peroxides in Animal Tissues by Thiobarbituric Acid Reaction Anal Biochem 1979;95(2):351-58.

11. Sun Y, Oberley LW, Li Y. A simple method for clinical assay of superoxide dismutase. Clinical Chemistry 1988;34(3):497-500.

12. Aebi H. Catalase İn: Buergmeyer U (eds). Method of enzymatic analysis. New York and London Academic Press 1974:673-677.

13. Paglia DE, Valentine WN. Studies on the quantitative and qualitative characterization of erythrocyte glutathione peroxidase. J Lab Clin Med 1967:70:158-169.

14. Fairbanks V, Klee GG. Biochemical aspects of hematology. In: Burtis CA, Ashwood ER editors. Textbook of Clinical Chemistry 2nd edition. Philadelphia, Saunders Press, 1994:2026-27.

15. Periyasamy K, Baskaran K, Ilakkia A, et al. Antitumor efficacy of tangeretin by targeting the oxidative stress mediated on 7,12-dimethylbenz(a) anthraceneinduced proliferative breast cancer in Sprague-Dawley rats. Cancer Chemother Pharmacol 2015;75(2):263-72

16. Lakshmi A, Subramanian S. Chemotherapeutic effect of tangeretin, a polymethoxylated flavone studied in 7,12-dimethylbenz(a)anthracene induced mammary carcinoma in experimental rats. Biochimie 2014:99:96-109.

17. Dassprakash MV, Arun R, Abraham SK, Premkumar K. In vitro and in vivo evaluation of antioxidant and antigenotoxic potential of Punica granatum leaf extract. Pharm Biol 2012; 50(12): 1523-30.

18. Rice-Evans CA, Miller NJ, Paganga G. Structure-antioxidant activity relationships of flavonoids and phenolic acids. Free Radic Biol Med 1996;20(7):933-956.

\section{OP-053 \\ INVESTIGATION OF PHOSPHOLIPASE A2 AND MATRIX METALLOPROTEINASE-9 WITH CORONAR PLAQUE STRUCTURE}

Neslihan Sungur, Hümeyra Acıkan, Sabahattin Muhtaroğlu, Didem Barlak Keti Department of Medical Biochemistry, Faculty of Medicine, Erciyes University, Kayseri

OBJECTIVES: Coronary computed tomography angiography (CCTA ) evaluate the presence of coronary plaques and stenosis, coronary bypass graft patency, and the origin and course of congenital coronary anomalies. Lipoprotein-associated phospholipase A2 (Lp-PLA2) is a promising new marker of atherosclerotic plaque destabilization, which plays a key role in the metabolism of pro-inflammatory phospholipids and in the generation of pro-atherogenic metabolites. Matrix metalloproteinase (MMP)-9 degrades extracellular matrix (ECM)proteinsandactivatescytokinesandchemokinestoregulatetissueremodeling. This study was performed to investigate whether combined use of LpPLA2 and MMP-9 levels and coronary computed tomography angiography (CCTA) results have additional prognostic value for predicting cardiovascular events in patients with suspected coronary artery disease (CAD). MATERIALS and METHODS: Serum Lp-PLA2 and MMP-9 levels were studied by ELISA method. In the study groups, serum routine biochemical parameters were analyzed.

RESULTS: A total of 54 patients with suspected CAD who were underwent both CCTA and serum Lp-PLA2 and MMP9 measurements were evaluated. Stenosis and plaque percentile were $20.4 \%$ and 24.1 respectively. Patient with steonsis/ plaque group had significantly higher level of LpPLA2 and MMP-9 than control. Both Lp-PLA2 positively associated with MMP-9 and also MMP-9 with nonHDL. SdLDL associated not only with CRP and Lp-PLA2 but also with all assayed parameters.

CONCLUSIONS: Measurement of Lp-PLA2, MMP-9, and sdLDL-C levels in atherosclerosis may be correlated with the presence of atherosclerotic plaque and or stenosis.

Keywords: Coronary CT angiography, Lp-PLA2, MMP-9, sdLDL, Coronary Plaque

\section{OP-055 \\ COMPARISON OF APOPTOTIC RESPONSE IN PARKINSON'S DISEASE IN VITRO MODELS}

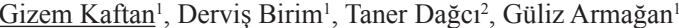
Department of Biochemistry, Faculty of Pharmacy, Ege University, Izmir ${ }^{2}$ Department of Physiology, Faculty of Medicine, Ege University, Izmir

OBJECTIVES: Apoptosis is a programmed cell death that plays a major role in the regulation of intercellular and intracellular homeostasis under physiological conditions. In this study, it is aimed to compare the apoptotic responses of four neurotoxins that are widely used to induce Parkinson's Disease model. MATERIALS and METHODS: Human neuroblastoma cell line (SH-SY5Y) was used in this study. Cell viability analysis were performed following MPP+, 6 -OHDA, rotenone and paraquat treatments at three different time points $(12$, 24,48 hours) and IC50 values for each neurotoxin were calculated. Pro- and anti-apoptotic (bax, bad, bak, bcl-2, bcl-x1) and total caspase-3 protein levels were measured by western blot following treatments. Comparisons of means between groups were performed by ANOVA followed by Tukey's post hoc test. RESULTS: All neurotoxins triggered apoptosis in cells. Rotenone and paraquat significantly altered the expression of bax, bcl-2, bcl-xl; MPP + significantly altered the expression of bcl-2, bcl-xl and 6-OHDA significantly altered the expression of bad and bcl-xl proteins $(p<0.05)$. Each neurotoxin was found to enhance and/or reduce different proteins associated with apoptosis. CONCLUSIONS: It can be concluded that before the decision of a neurotoxin inducing Parkinson's disease model, it is necessary to determine the target proteins for screening newly synthesized drugs. It is considered useful to demonstrate the efficacy of the drug with a number of protein-binding assays prior to cell culture studies and to select the most effective neurotoxin accordingly. This study was supported by TÜBİTAK 2209-A Supporting Program for Domestic Research Projects of University Students. Keywords: Parkinson's disease, apoptosis, MPP+, Rotenone, Paraquat, 6-OHDA

\section{OP-056}

\section{AN UNCOMMON HEMOGLOBIN VARIANT: HEMOGLOBIN MOABIT}

Hülya Ünal ${ }^{1}$, Ayssenur Atay ${ }^{1}$, Muammer Yücel ${ }^{1}$, Figen Narin ${ }^{1}$, Duran Canatan ${ }^{2}$ ${ }^{1}$ Katip Celebi University, Izmir Ataturk Training and Research Hospital, Department of Clinical Biochemistry, Izmir.

${ }^{2}$ Antalya Genetic Diseases Diagnosis Center, Antalya

OBJECTIVES: $\mathrm{Hb}$ variants can be faced to various clinical and laboratory findings. Hb Moabit is an unstable $\mathrm{Hb}$ variant with slightly reduced oxygen affinity. Arginine exchange (Leu $\rightarrow$ Arg) was detected at 86 th position in the alpha chain instead of leucine. In this study we presented a case with $\mathrm{Hb}$ Moabit or -like variant, which was firstly detected in our country. MATERIALS and METHODS: Blood sample of a 14-year-old male patient with the preliminary diagnosis of abnormal hemoglobin was 
studied by HPLC method (Variant II, Bio RAD). Beta gene and alpha gene analyzes were also performed for definitive diagnosis. RESULTS: HbA0: $71.9 \%$, HbA2: $1.3 \%$, HbF: $0.2 \%$ and an unidentified peak: $18.1 \%$ (retention time: 3.93 ). Hb:14.6 g/dL, Hct: $43.4 \%$, RBC: $5.5 \mathrm{M} / \mathrm{mm} 3$, MCV:78.9 fL, and MCH:26.6 pg. When the data library was examined, this peak could not be identified. Blood sample was analysed on the other HPLC system (Trinity, Biotech). The patient was thought to have the Hb Moabit variant. No mutation was detected in beta gene sequence analysis. Upon the absence of any deletions or mutations identified in the alpha strip analysis, the MLPA test and Alpha1-Alpha2 sequence analysis were progressed to detect other deletions and mutations. MLPA analysis was normal. In the analysis of the sequence, a signal like Hb Moabit was obtained. Sequence analysis is being continued. CONCLUSIONS: Abnormal hemoglobins are common seen in our country, located in the Mediterranean zone. It is very important to carry out molecular genetic analysis studies of unidentified peaks in HPLC. Keywords: Abnormal hemoglobin variant, Hb Moabit, alpha chain mutation

\section{OP-057 \\ THE CHANGES IN CELLULAR RESPONSES AFTER NRF2 GENE SILENCING IN PARKINSON'S DISEASE}

Elvin Sevgili Gïrșen ${ }^{1}$, Fadïme Aydin Köse ${ }^{1}$, Taner Dağci², Gülïz Armağan ${ }^{1}$ ${ }^{1}$ Department of Biochemistry, Faculty of Pharmacy, Ege University, 35100 , Bornova, Izmir

${ }^{2}$ Department of Physiology, School of Medicine, Ege University, 35100, Bornova, Izmir

OBJECTIVES: Recently, in addition to nuclear translocation and stability of Nrf2, GSK-3 $\beta$ inhibition has gained increasing attention in the prevention of oxidative stress and oxidative-stress related disorders. The present study was aimed to

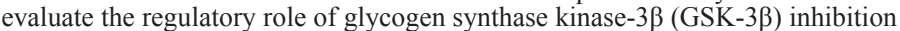
on oxidative stress through Nrf2 pathway in in vitro model of Parkinson's disease. MATERIALS and METHODS: siRNA-mediated gene silencing technique was used to examine the responses of Nrf2-target genes including HO1 , NQO1 to siRNA depletion of Nrf2 in MPP+-induced dopaminergic neuronal loss in SH-SY5Y cells. Nrf2 and its downstream regulated genes and proteins were analyzed using Real-time PCR and Western Blotting techniques, respectively, following GSK-3 $\beta$ inhibition by tideglusib. RESULTS: The cell viability was increased following GSK-3 $\beta$ enzyme inhibition against MPP+. Moreover, tideglusib significantly induced HO-1, NQO1 mRNA/ protein expressions and nuclear translocation of $\mathrm{Nrf2}(\mathrm{p}<0.05)$. Nrf2 knockdown by siRNA abolished the protection exerted by tideglusib pre-treatment. CONCLUSIONS: GSK-3 $\beta$ enzyme inhibition may modulate endogenous cellular antioxidant defense systems including Nrf2/ARE pathway in Parkinson's disease. This study was supported by TÜBITTAK (The Scientific and Technical Research Council of Turkey) (Project Number: 215S528) and the Ege University Scientific Research Foundation (Project Numbers: 15/ECZ/012 and 16/BIL/004). Keywords: Parkinson's disease, glycogen synthase kinase-3 $\beta$, Nrf2 pathway

\section{OP-058 \\ A CASE OF FLOATING-HARBOR SYNDROME WITH A NOVEL MUTATION}

Malik Ejder Yıldırım

Cumhuriyet University, Faculty of Medicine, Department of Medical Genetics, Sivas

OBJECTIVES: Floating-Harbor Syndrome (FHS) is a rare autosomal dominant genetic condition characterized by speech defect, short stature with delayed bone mineralization, skeletal malformations and dysmorphic facial appearance such as triangular face, prominent nose, long eyelashes, short philtrum and deep-set eyes. SRCAP gene mutations cause this syndrome.. We aimed to report a male patient with Floating-Harbor syndrome who had novel mutation from Sivas in this study. MATERIALS and METHODS: After the physical examination, $x$-ray imaging was performed on the patient's bone structure (head, vertebral column, upper and lower extremities). Chromosome analysis and array comparative genomic hybridization (aCGH, Affymetrix / Thermo Fisher Scientific, US) were applied. Next-Generation Sequencing (NGS, Illumina, US) was done for mutation analysis. RESULTS: Physical examination of the patient revealed mental retardation, short stature, triangular face, mandibular prognathism, large nose, speech impairment, hearing loss and esotropia. The patient had been operated due to cleft palate and lip. A mild scoliosis and dental disorder was detected in $\mathrm{x}$-ray. Chromosome analysis (46XY) and aCGH were normal. As a new mutation, c.7300G $>$ T (Exon 34) was detected in SRCAP gene by NGS. CONCLUSIONS: We diagnosed a 16 year old boy as Floating-Harbor Syndrome with classical features of the disease such as short stature, triangular face, large nose, speech defect, mental retardation. He had disease-specific, heterozygous SRCAP gene mutation. There was no family history of the patient. It was a novel mutation. Keywords: Floating-Harbor Syndrome, short stature, novel mutation, NGS.

\section{OP-059 \\ A PRACTICAL APPROACH FOR IDENTIFYING HBS OR HBD VARIANTS IN ELECTROPHORESIS: THE SOLUBILITY TEST}

Cihan Coşkun ${ }^{1}$, Fatih Özçelik², Emrah Kılıçaslan

${ }^{1}$ University of Health Sciences, Haydarpaşa Numune Training and Research Hospital, Medical Biochemistry, Istanbul

${ }^{2}$ University of Health Sciences, Sultan Abdülhamid Han Training and Research Hospital, Medical Biochemistry, Istanbul

${ }^{3}$ University of Health Sciences, Sultan Abdülhamid Han Training and Research Hospital, Department of Hematology, Istanbul

OBJECTIVES: The most common hemoglobin variant in our country after hemoglobin $\mathrm{S}(\mathrm{HbS})$ is HbD-Punjab (Punjab). HbD disease usually does not give clinical symptoms unlike $\mathrm{HbS}$ disease having genetic origin which is often seen in the Mediterranean region of Turkey and characterized by severe hematological crisis. Therefore, similar electrophoretic behavior of the two variants may cause clinical anxiety until differential diagnoses are made. In our study, we aimed to discuss a practical method used to differentiate $\mathrm{HbD}$ and $\mathrm{HbS}$ variants known by clinical biochemistry laboratories.

MATERIALS and METHODS: Firstly, the records of 400 patients with $\mathrm{Hb}$ electrophoresis in the last 6 months were evaluated retrospectively. Al patient results performed by "Sebia Hydrasys electrophoresis device with alkaline cellulose acetate method were again reviewed. Then, it was evaluated clinical diagnosis and evaluation of the patients who were thought to be $\mathrm{HbS}$ or $\mathrm{HbD}$ variants and their solibility test results using sodium dithionite and saponin solution were evaluated. In addition, these results were also confirmed by high performance liquid chromatography (HPLC).

RESULTS: As a result of our evaluation, it was found that there is a migration compatible with $\mathrm{HbS}$ or $\mathrm{HbD}$ variants in five patients. When the clinical diagnosis and anamnesis of these patients were examined, it was thought that only two patients might have Hbs variant.

When the resolution test results using sodium dithionite and saponin solution for differentiation of $\mathrm{HbS}$ and $\mathrm{HbD}$ variants were examined, it was determined that $\mathrm{Hb}$ variant of the 3 patients who were thought to be HbD was dissolved in solution and $\mathrm{Hb}$ variant of 2 patients who were thought to be $\mathrm{HbS}$ was insoluble. In addition, the results were also consistent with the HPLC method results. CONCLUSIONS: Differentiation of $\mathrm{HbS}$ and $\mathrm{HbD}$ variants showing the same electrophoretic migration in the alkaline electrophoresis can be made practically with the solubility test using sodium dithionite and saponin solution. Keywords: $\mathrm{HbS}, \mathrm{HbD}$, The Solubility Test

\section{OP-060 \\ INHIBITION EFFECT OF ARYLIDENE INDANONES DERIVATIVES ON ACETYLCHOLINESTERASE ENZYME ACTIVITY}

Halide Edip Temel ${ }^{1}$, Belgin Sever ${ }^{2}$, Mehlika Dilek Altıntop ${ }^{2}$, Ahmet Özdemir ${ }^{2}$ ${ }^{1}$ Anadolu University, Faculty of Pharmacy, Department of Biochemistry, Eskişehir

${ }^{2}$ Anadolu University, Faculty of Pharmacy, Department of Pharmaceutical Chemistry, Eskișehir

OBJECTIVES: Alzheimer's disease (AD) is the leading cause of dementia in elderly people. The main physio pathologies are oxidative stress, inflammation and apoptosis that leads to neuronal loss and decrease at acetylcholine (ACh) levels. Nowadays, for symptomatic treatment of $\mathrm{AD}$, acetylcholinesterase inhibitors are used for increment of decreased ACh levels. Acetylcholinesterase (AChE) is a highly viable target for the design and development of potent anti-AD agents. The aim of this study is to investigate the inhibitory activity of arylidene indanone derivate's on AChE. MATERIAL-METHODS: In the present study, 5-chloro-6-methoxy-2 [4-(substituted)benzylidene]-2,3-dihydro-1H-inden-1-one derivatives (1-10) were evaluated for their ability to inhibit AChE by a modified Ellman's method. Besides, molecular docking studies that were performed for compound 4 in the active site of human $\mathrm{AChE}$ (PDB code: 4EY7), some different pharmacokinetic parameters of all compounds were in silico predicted by Schrödinger's Maestro Molecular modelling package. RESULTS: The most potent AChE inhibitor was found as N-[4-[(5-chloro-6methoxy-1-oxo-1,3-dihydro-2H-inden-2-ylidene)methyl]phenyl]-acetamide (4) $(\mathrm{IC} 50=5.93 \pm 0.29 \mu \mathrm{g} / \mathrm{mL})$. Docking results indicated that compound 4 presented $\pi-\pi$ stacking bonds with Trp286 and Tyr337 residues and formed H-bond with Phe295 residue in the active site of AChE. Besides, in silico pharmacokinetic results showed that all compounds were within the acceptablerange intended for human use. CONCLUSIONS: According to both in vitro andin silico studies, compound 4 stands out as a promising orally bioavailable anticholinesterase agent for further studies. Keywords: Acetylcholinesterase, Arylidene Indanones, Docking Studies 


\section{OP-062 \\ THE EFFECT OF SUBEROYLANILIDE HYDROXAMIC ACID ON FIBROSIS MARKERS IN HUMAN HEPATIC STELLAT CELL LINE}

Merve Özel $^{1}$, Gülden Başkol ${ }^{2}$, Mevlüt Başkol ${ }^{3}$

${ }^{1}$ Erciyes University Institute of Health Sciences Medical Biochemistry, Kayseri ${ }^{2}$ Erciyes University Faculty of Medicine, Medical Biochemistry

${ }^{3}$ Erciyes University Faculty of Medicine, Department of Gastroenterology,

Kayseri

OBJECTIVES: Hepatic stellate cells (HSCs) are a major cell type responsible for liver fibrosis. Its functions are; the synthesis of extracellularmatrix (ECM) components, synthesis of matrix metalloproteinases (MMP) which play a role in the degradation of ESM, metallopeptidase inhibitors (TIMP) and liver regeneration. The activation of HSCs increases the release of certain chemicals and the accumulation of the proteins in the ECM damages the connective tissue so that the fibrosis process begins. Histone modifications allow control of gene expression at the transcriptional level. Histone deacetylase (HDAC) enzymes affect significant cellular processes, compounds that inhibit these enzymes have been defined. Suberoylanilide hydroxamic acid (SAHA) is a potent reversible HDAC inhibitor. It has been reported that SAHA inhibits the activation of hepatic stellate cells. In this study, it was aimed to investigate the effect of SAHA on MMP2, MMP9, TIMP (1-3) gene expression levels in human hepatic stellate cell line (LX-2). MATERIALS and METHODS: Gene expression was analyzed by Real Time PCR RESULTS: SAHA statistically reduced MMP2 and MMP9 gene expression levels in LX-2 cell line $(\mathrm{p}<0.001, \mathrm{p}<0.001)$. There was no significant difference in TIMP (1-3) gene expression levels $(\mathrm{p}<0.069, \mathrm{p}<0.303, \mathrm{p}<0.092)$. CONCLUSIONS: Liver fibrosis is characterized by increased expression of MMPs and TIMPs. In our study, we think that SAHA inhibits the activation of hepatic stellate cells by reducing the level of MMP2 and MMP9 gene expression in LX-2 cells, therefore SAHA have a positive effect in inhibiting fibrosis, but further study of this issue is needed for better interpret Keywords: Insan hepatik stellat hücre hatt1, Fibrozis, SAHA

\section{OP-063 \\ PHAGE DISPLAY DERIVED ANTIBODIES ENRICH ALIPHATIC RESIDUES IN ANTIGEN BINDING REGIONS}

Murat Karadağ, Nazlı Eda Kaleli, Sibel Kalyoncu Uzunlar Izmir Biomedicine and Genome Center (IBG), Izmir

OBJECTIVES: Therapeutic monoclonal antibodies are discovered/optimized with either in vivo or in vitro techniques. One of the most commonly used in vitro technology is phage display where antibody libraries are displayed on the surface of bacteriophages for screening of antigen binding. Although phage display has lots of advantages, antibodies might show polyreactivity and self-interaction which should be further improved. In this project, we aim to understand the difference between phage and non-phage derived antibodies. MATERIALS and METHODS: We use a database consisting of 137 antibodies which are either approved or on phase II/III clinical trials. Complementary determining regions (CDRs) of those antibodies are analysed based on physicochemical characteristics of residues. Statistical analysis based on sequence features are conducted and structural case studies based on two approved antibodies (adalimumab and infliximab) are presented. RESULTS: According to Pearson's and Spearman's correlation analysis of biophysical characterization results, phage-derived antibodies show more polyreactivity and self-interaction. We find that the reason behind these undesired attributes are aliphatic residues enriched in 2 particular CDR regions of antibodies. Also, we find some other significant factors related to the rest of CDR regions which probably contribute to self-interaction and polyreactivity of antibodies. CONCLUSIONS: We conclude that aliphatic residues enrich in the CDR regions of phage-derived antibodies. This might contribute to nonspecificity and self-interaction of antibodies. Our results would help developing better library design approaches for further phage display studies. Keywords: Antibody, Complementary Determining Regions, Phage Display, Polyreactivity, Self-Interaction

\section{OP-064 CHILDREN-WHO-STUTTER}

$\underline{\text { Seher Kara Öngel }}^{1}$, Ergül Belge Kurutaş ${ }^{1}$, Nagihan Bilal ${ }^{2}$

${ }^{1}$ Department of Medical Biochemistry, Faculty of Medicine, Kahramanmaras Sutcu Imam University, Kahramanmaras

${ }^{2}$ Department of Otorhinolaryngology, Faculty of Medicine, Kahramanmaras Sutcu Imam University, Kahramanmaras

OBJECTIVES: Stuttering is a speech disorder. There is known to be a close relationship between stress severity and stuttering. Up to now, no studies have been conducted on the concentrations of 8-iso-prostaglandin F2 $\alpha$ (8-iso-PGF2 $\alpha)$ as oxidative stress biomarkers in stuttering pediatric patients. In this study, it was aimed to compare the concentrations of 8-isoPGF $2 \alpha$ in stutterers and control groups and to evaluate the relationship between 8 -iso-PGF2 $\alpha$ concentrations and the severity of stuttering.
MATERIALS and METHODS: The study included a total of 80 individuals, comprising a study group of 40 and a control group of 40 . The severity of the stutter in the patient group was evaluated with the Stuttering Severity Instrument 3 (SSI). Blood samples were taken from both the patient and control groups and 8 -iso-PGF2 $\alpha$ concentrations were mesured by ELISA. RESULTS: In the stuttering patients, 8 -iso-PGF2 $\alpha$ concentrations were determined to be statistically significantly higher than those of the control group $(p<0.05)$. In the ROC analysis, there was good diagnostic value for 8 -iso-PGF $2 \alpha$, with the area under the curve as 1.0. A direct, positive, statistically significant correlation was determined between SSI points and 8-iso-PGF2 $\alpha$ values $(r=0.420, p=0.037)$. CONCLUSIONS: The results of the study showed that 8-iso-PGF2 $\alpha$ concentrations of the stuttering patients were higher than those of the control group. With $99 \%$ sensitivity and specificity, it is thought that 8-iso-PGF2 $\alpha$ in particular could be important for the diagnosis and treatment of these patients. As the severity of the stutter increased, so there was an increase in 8 -iso-PGF2 $\alpha$, suggesting that 8 -iso-PGF $2 \alpha$ is importantin stuttering. Keywords: 8 -iso-PGF2 $\alpha$, oxidative stres, stuttering

\section{OP-065 \\ THE RELATIONSHIP BETWEEN VITAMIN D LEVELS AND RESPIRATORY AND FOOD ALLERGY}

Sibel Kulaksizoğlu

Antalya Research and Training Hospital, Clinical Biochemistry Laboratory, Antalya

OBJECTIVES: In recent years, the prevalence of allergic diseases has increased significantly. The association of allergic diseases with other diseases has been shown in many studies. Another parameter associated with allergic diseases is vitamin D. There are studies showing that allergic diseases increase in vitamin D deficiency. The purpose of our study is to investigate the relationship between allergy tests and vitamin D in patients who applied to Antalya Training and Research Hospital. MATERIALS and METHODS: Between January 2017 and August 2018, allergy tests and vitamin D results were assessed retrospectively in the Antalya Training and Research Hospital.

RESULTS: Vitamin D levels were $27.1 \pm 14.1 \mathrm{ng} / \mathrm{ml}$ in 788 patients with negative food allergy test in total 1176 patients, while vitamin Dlevels were $28,6 \pm 12.9 \mathrm{ng} / \mathrm{ml}$ in 388 patients with food allergy test positive. Vitamin D levels were $23.8 \pm 10.1 \mathrm{ng}$ / $\mathrm{ml}$ in 243 patients with positive respiratory allergy test, while vitamin D levels were $29.6 \pm 13.9 \mathrm{ng} / \mathrm{ml}$ in 933 patients with negative respiratory allergy test $(\mathrm{p}<0.01)$ CONCLUSIONS: There was a significant relationship between vitamin D levels and respiratory allergies. The relationship between the presence of vitamin D deficiency and allergic diseases is clinically important in Antalya province. Keywords: Vitamin D, Food Allergy, Respiratory Allergy

\section{OP-066}

\section{ANTI-CANCER ACTIVITY OF PACLITAXEL LOADED NGO} NANOTHERAPY SYSTEMS ON MDA-MB-231 CELL LINES

\section{Neșe Keklikcioğlu Çakmak ${ }^{1}$, Erkan Gümüş ${ }^{2}$ Ayça Taş ${ }^{3}$, Ömer Topcu ${ }^{4}$, Yavuz Siliğ $\breve{~}^{5}$}

${ }^{1}$ Cumhuriyet University,Engineering Faculty, Chemical Engineering, Sivas ${ }^{2}$ Cumhuriyet University, Faculty of Medicine, Department of Histology Embryology, Sivas

${ }^{3}$ Cumhuriyet University, Faculty of Health Sciences, Department of Nutrition and Dietetics, Sivas

${ }^{4}$ Cumhuriyet University, Faculty of Medicine, Department of General surgery, Sivas

${ }^{5}$ Cumhuriyet University, Faculty of Medicine, Department of Brain and Neurosurgery, Sivas

OBJECTIVES: The aim of this study is 1)to increase the biocompatibility of the Nano Grafen Oxide (NGO) nanoparticle by activating with PolyEthylene Glycol (PEG) to develop a new nanostructure system and 2) to determine the cytotoxic effect of Paclitaxel (PTX) loaded with this drug on MDA-MB-231 cell lines. MATERIALS and METHODS: NGO nanoparticles used in this study were synthesized by Hummers method, coated with PEG, and NGO-PEG nanostructure system was loaded with PTX. SEM, EDX, XRD, UV, Zeta Potential analyses of suspensions prepared at different concentrations of NGO, NGO-PEG, PTX, and NGO-PEG-PTX nanostructured system were performed. The synthesized NGO, NGO-PEG, PTX, and NGO-PEG-PTX were applied to the MDA-MB-231 breas cancer cell line and cytotoxic effect of these drugs were determined by using MTT method. The MDA-MB-231 cells were treated with different concentrations of NGO, NGO-PEG, PTX, and NGO-PEG-PTX (5-100 $\mu \mathrm{M})$ for 24, 48 and 72 hours. Apoptosis and necrosis were determined by fluorescence microscopy using the Hoechst 33258 (HO)/propidium iodide (PI) double staining. RESULTS: In this study, the characterization analyzes of NGO, NGOPEG, PTX, and NGO-PEG-PTX nanostructured system are in accordance with the literature data. The effects of NGO, NGO-PEG, PTX, and NGO-PEG-PTX on the MDA-MB-231 cells were compared with the control group and IC50 values were determined for 24,48 and 72 hours. CONCLUSIONS: In this study, it was shown that the effect of NGO-PEGPTX nanostructured system on MDA-MB-231 cells was inhibitory to growth in cancer cells and induced apoptosis when compared with control group and PTX. 


\section{Keywords: Breast Cancer, MDA-MB-231, PEG-NGO, PTX}

UV-vis spectra were employed to examine the drug loading behavior of NGOPEG (Figure 2). The characteristic absorption peak of PTX $(250 \mathrm{~nm})$ appeared in the sample of NGO-PEG-PTX, indicating successful formation of NGO-PEGPTX conjugates. This peak indicating efficient loading of PTX by NGO-PEG. Keywords: Breast Cancer, MDA-MB-231, PEG-NGO, PTX

\section{Introduction}

Cancer is one of the principal causes of mortality worldwide and represents a serious health problem [1]. Breast cancer is the most common malignancy in women and is the second most common cause of cancer-related death in women worldwide [2]. Various therapeutic strategies including hormone inhibitors, chemotherapy and monoclonal antibodies are used in breast cancer treatment [3]. Chemotherapy has become more and more important in the treatment of breast cancer, and is considered to be a key part of the treatment needed to avoid the recurrence of cancer after surgery [4]. However, the biggest obstacle to chemotherapy is drug resistance [5]. Paclitaxel (PTX) is one of the chemotherapeutic agents with antitubulin activity used in the treatment of breast cancer patients [6]. However, the efficacy of paclitaxel treatment is limited to the development of drug resistance [7]. In recent years, scientists have focused on nanoparticles to develop more effective chemotherapy treatment methods. Nanostructing systems can show better synergistic effects and are widely used in targeted treatment of tumors in the clinic [8]. Nanopolymer material has become a novel type of carrier due to its unique hydrophilic carbon atom structure and satisfactory physical-chemical properties [9]. Graphene oxide (GO) is a new generation of polymers, such as polyethylene glycol (PEG) or hydroxyl graphene-PEG, can be used as the carrier for antitumor drugs to improve the treatment efficacy of loading drugs [10]. Therefore, it is necessary to reduce PTX adverse effects by binding with drug carrier, and enhance treatment efficiency. In this study, we generated NGO-PEGPTX complex, whose cytotoxicity and antitumor efficiency were evaluated in human MDA-MB-231 breast cancer cells.

Materials and Methods

Synthesis of PEGylated Graphene Oxide: Graphene oxide (GO) was prepared from expandable graphite flake according to the modified Hummer's method [11-13]. To obtain NGO, GO was cracked by ultrasonic probe at $570 \mathrm{~W}$ for 2 h. For pegylation, $\mathrm{NaOH}(1.2 \mathrm{~g})$ and $\mathrm{ClCH} 2 \mathrm{COOH}(1.0 \mathrm{~g})$ were added to $\mathrm{NGO}$ aqueous suspension $(10 \mathrm{~mL}, 2 \mathrm{mg} / \mathrm{mL})$ and sonicated at $500 \mathrm{~W}$ for $3 \mathrm{~h}$ to convert $\mathrm{OH}$ groups to $\mathrm{COOH}$ via conjugation of acetic acid moieties resulting in NGO$\mathrm{COOH}$. The NGO-COOH solution was neutralized, and purified by repeated rinsing and filtrations, producing well dispersed $\mathrm{NGO}-\mathrm{COOH}$ aqueous solution. $\mathrm{N}$-(3-dimethylaminopropyl-N'-ethylcarbodiimide) hydrochloride (EDC) was added to the NGO-COOH suspension $(10 \mathrm{~mL}, 1 \mathrm{mg} / \mathrm{mL})$ at $\mathrm{pH} 5.6$ and the mixture was sonicated for $5 \mathrm{~min}$ PEG $(2 \mathrm{mg} / \mathrm{mL})$ was then added to the above suspension and stirred for $24 \mathrm{~h}$ at room temperature. The final product (NGOPEG) was washed by repeated centrifugation and filtration, first with $5 \% \mathrm{HCl}$ aqueous solution, and then distilled water for several times [14,15]

Characterization: The morphologies of NGO and NGO-PEG-PTX were characterized using XRD and ultraviolet-visible (UV-VIS) spectrometer. X-ray diffraction (XRD) data were obtained by a diffractometer (Rigaku DMAX IIIC). UV-Vis spectrophotometer (UV-1280, Shimadzu, Japan) was utilized to record the spectra of prepared samples range from 200 to $800 \mathrm{~nm}$.

Drug loding on NGO-PEG: PTX loading onto NGO-PEG was done by simply mixing $0.4 \mathrm{mg} / \mathrm{mL}$ of PTX with NGO-PEG solution $(0.2 \mathrm{mg} / \mathrm{mL})$ at $\mathrm{pH} 8$ overnight. Unbound PTX was removed by repeated washing and filtration through a $100 \mathrm{kDa}$ filter (Millipore). The resulting NGO-PEG-PTX complexes were resuspended and stored at $4{ }^{\circ} \mathrm{C}$.

Cell Culture: MDA-MB-231 cells were maintained in DMEM medium, containing $10 \%$ fetal bovine serum (FBS), penicillin $(100 \mathrm{U} / \mathrm{mL})$ and streptomycin $(10$ $\mathrm{mg} / \mathrm{L}$ ). Cells were grown in at $37{ }^{\circ} \mathrm{C}, 5 \% \mathrm{CO} 2$ and $95 \%$ air in a humidified incubator. For each cell line, $70-80 \%$ confluent cell culture flask was trypsinized and cells were seeded in 96 well plates.

Cytotoxic effect of NGO targeted drug in and MDA-MB-231 cells: Cytotoxicity of the NGO, NGO-PEG, NGO-PEG- PTX and PTX against MDA-MB-231 cell lines was performed with the MTT 3-(4,5-dimethylthiazol-2-yl)-2,5diphenyltetrazolium bromide) assay according to the Skehan's method. Briefly, cells were trypsinized and plated into 96-well plates (Corning, USA) in $0.1 \mathrm{~mL}$ of complete culture medium at a density of $1 \times 105$ cells per well and allowed to attach for $24 \mathrm{~h} .1 \mu \mathrm{L}$ of test substance at concentrations ranging between 5-100 $\mu \mathrm{g} / \mathrm{ml}$ were added into each well containing the cells. Test substance was diluted with sterilized water into the desired concentrations from the stock. The plates were incubated at $37^{\circ} \mathrm{C}$ with an internal atmosphere of $5 \% \mathrm{CO}$. After 24,48 and $72 \mathrm{~h}$ incubation, with different concentrations of compounds, MTT $(5 \mathrm{mg} /$ $\mathrm{ml}$ dissolved in PBS) $10 \mu \mathrm{l} / \mathrm{well}$ was added directly to all the wells and incubated for 2 hours at $37^{\circ} \mathrm{C}$. The supernatant was carefully removed from each well and $100 \mathrm{~mL}$ of DMSO was added to each well to dissolve the formazan crystals. After mixing with a mechanical plate mixer for $15 \mathrm{~min}$, the absorbance of plates were recorded at $570 \mathrm{~nm}$ on a microplate reader (Bio-Tek, USA). All drug doses were parallel tested in triplicate and were performed at least 3 times; control samples were run with $1 \%$ sterilized water.

Results and DiscussionSynthesis and characterization of NGO-PEG and NGOPEG-PTX

NGO was obtained by oxidation of graphite following the modified Hummers method and then modified with PEG to improve the biocompatibility and enhance blood circulation of graphene $[16,17,18]$. The distances between the sheets as well as their folding and structural disruptions in graphite and its functionalized derivatives are highly different. Therefore, the graphite, NGO and carboxylated functionalized samples were characterized by XRD for more structural analysis. The XRD patterns confirmed the chemical oxidation of the exfoliated graphite and formation of NGO (Fig. 1). Graphite demonstrate a very strong and sharp peak at $2 \theta=26.40^{\circ}$, which corresponds to the diffraction of the (002) plane. After graphite oxidation to NGO, the (002) reflection of graphite disappears and a diffraction peak at $2 \theta=10.21^{\circ}$ is present, which matchs to the diffraction of the $(001)$ plane indicative of the successful oxidation of graphite $[19,20]$. Further carboxylation process under basic conditions resulted in a more dispersion and exfoliation of nano-sheets probably due to the addition of the chloroacetic acid residue $(-\mathrm{O}-\mathrm{CH} 2-\mathrm{COOH})$. As a result, the carboxylated sample showed a much weaker and broader diffraction peak at $2 \theta=9.82^{\circ}$ as compared to the NGO which indicates an increase in the interlayer spacing.

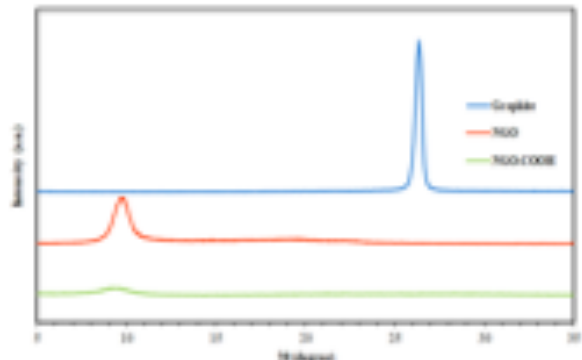

Figure 1. The XRD patterns of graphite, $\mathrm{NGO}$ and $\mathrm{NGO}-\mathrm{COOH}$.

UV-vis spectra were employed to examine the drug loading behavior of NGOPEG (Figure 2). The characteristic absorption peak of PTX $(250 \mathrm{~nm})$ appeared in the sample of NGO-PEG-PTX, indicating successful formation of NGO-PEGPTX conjugates. This peak indicating efficient loading of PTX by NGO-PEG.

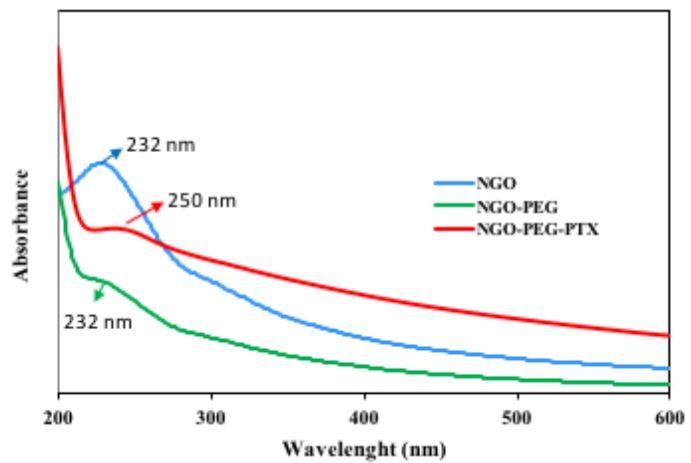

Figure 2. UV-vis absorbance spectra of NGO, NGO-PEG and NGO-PEG-PTX. Cytotoxicity activities of NGO, NGO-PEG, NGO-PEG-PTX and PTX drugs on MDA-MB-231 cells: Figure 3 shows changes in cell inhibition for 24,48 and 72 hours versus increasing concentrations of MDA-MB-231 cell lines. $\mathrm{x}$-axis shows cell types and varying time points, while the y-axis shows the inhibition rates of cancer cells relative to the control. Compared to the control group, NGO-PEG-PTX treated MDA-MB-231 breast cancer cells showed significantly decreased tumor survival rate after $24 \mathrm{~h}, 48 \mathrm{~h}$ and $72 \mathrm{~h}$ of incubation. Compared to the PTX group, the NGO-PEG-PTX group had significantly reduced survival rate after $24 \mathrm{~h}, 48 \mathrm{~h}$ and $72 \mathrm{~h}$ of incubation. Cell survival rates in all groups after $24 \mathrm{~h}, 48 \mathrm{~h}$ and $72 \mathrm{~h}$ of incubation were significantly decreased than those in the control group. With elongated treatment time, the survival rate of tumor cells was significantly reduced. NGO, NGO-PEG, NGO-PEG-PTX and PTX drugs on MDA-MB-231 cells was the most active for $72 \mathrm{~h}$ of incubation. In addition, the most active NGO-PEG-PTX and IC50 values for 24, 48 and 72 hours were 28,58 $\mu \mathrm{g} / \mathrm{ml}, 39,16 \mu \mathrm{g} / \mathrm{ml}$ and $31,24 \mu \mathrm{g} / \mathrm{ml}$ respectively (Table 1 ).

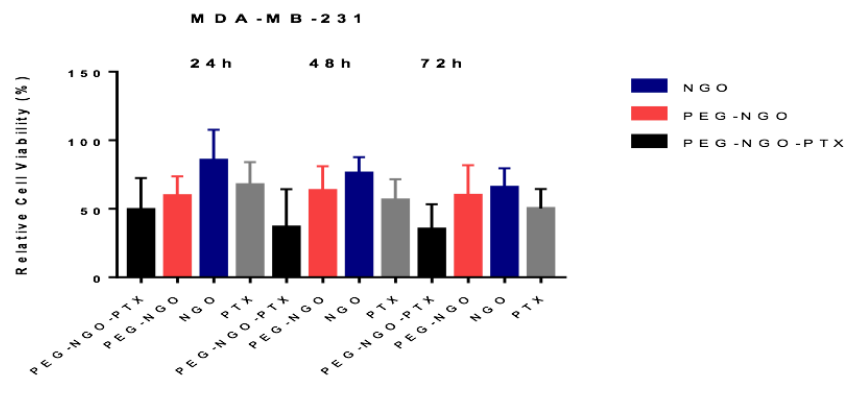

Figure 3. Cytotoxity effect of NGO, NGO-PEG, NGO-PEG- PTX and PTX drugs on MDA-MB-231 cell line. 
Table 1: Comparison of IC50 values between NGO, NGO-PEG, NGO-PEG-PTX and PTX on MDA-MB-231 after $24 \mathrm{~h}, 48 \mathrm{~h}$ and $72 \mathrm{~h}$ of incubation.

Drugs

$$
\begin{aligned}
& \mathrm{IC} 50(\mu \mathrm{g} / \mathrm{mL}) \\
& \mathrm{MDA}-\mathrm{MB}-231
\end{aligned}
$$

$\begin{array}{lccc} & 24 \mathrm{~h} & 48 \mathrm{~h} & 72 \mathrm{~h} \\ \text { NGO-PEG-PTX } & 28,58 & 39,16 & 31,24 \\ \text { NGO-PEG } & 66,72 & 51,39 & 50,52 \\ \text { NGO } & 59,38 & 44,78 & 43,95 \\ \text { PTX } & 55,52 & 41,73 & 30,74\end{array}$

$1.1 \quad$ Hoechst 33258 (HO; Sigma) /propidium iodide (PI; Sigma) stainig In our study, morphological alterations of apoptotic cell death were detected by fluorescence microscope using HO and PI staining. The apoptosis rates of MDAMB-231 cells treated with NGO-PEG-PTX and PTX were found to be $59.8 \%$ and $56.3 \%$, respectively. Whereas the necrosis rates of MDA-MB-231 cells treated with TiO2-PEG-PTX and PTX were found to be $6.9 \%$ and $4.1 \%$, respectively. In addition, NGO-PEG-PTX caused more apoptosis than PTX, although it was not statistically significant.

Conclusion

In summary, NGO, NGO-PEG and NGO-PEG-PTX were successfully synthesized and characterization analyzes were shown. The synthesized nanomaterials retained their stability over days or even months. This study demonstrates the possibility of using NGO-PEG-PTX to inhibit the growth of breast cancer (MDA-MB-231) cells with therapeutic treatments. Apoptosis rate of NGO-PEGPTX was not found to be statistically significant, although an increased rate of apoptosis was detected after treatment with NGO-PEG-PTX. As a result, NGOPEG-PTX had more apoptotic death than PTX in the MDA-MB-231 cells.

Acknowledgement: This study was carried out at Cumhuriyet University's Advanced Technology Application and Research Center (CUTAM).

References

1.Siegel, R. Miller, K.D. Jemal, A. Cancer Statistics, 2018.CA CANCER J CLIN 2018: 68(1):7-30.

2.Ottewell, P. D.; Woodward, J. K.; Lefley, D. V.; Evans, C. A.; Coleman, R. E.; Holen, I. Anticancer Mechanisms of Doxorubicin and Zoledronic Acid in Breast Cancer Tumor Growth in Bone. Mol. Cancer Ther. 2009, 8, 2821-2832.

3. Crown J, O'Leary M and Ooi WS: Docetaxel and paclitaxel in the treatment of breast cancer: A review of clinical experience. Oncologist 9 (Suppl 2): S24-S32, 2004.

4.Carrick S, Parker S, Thornton CE, et al: Single agent versus combination chemotherapy for metastatic breast cancer. Cochrane Database Syst Rev 2009; 15: CD003372.

5.Moscow JA, Cowan KH: Multidrug resistance. J Natl Cancer Inst 1988; 80: $14-20$.

6.Gradishar WJ: Taxanes for the treatment of metastatic breast cancer. Breast Cancer (Auckl) 6: 159-171, 2012.

7.Saloustros E, Mavroudis D, Georgoulias V: Paclitaxel and docetaxel in the treatment of breast cancer. Expert Opin Pharmacother 2008; 9: 2603 - 2616.

8.Qiu S, Xing W, Mu X, et al. A 3D nanostructure based on transition-metal phosphide decorated heteroatom-doped mesoporous nanospheres interconnected with graphene: Synthesis and applications. ACS Appl Mater Interfaces 2016; 8:32528.

9. Qiu S, Xing W, Mu X, et al. A 3D nanostructure based on transition-metal phosphide decorated heteroatom-doped mesoporous nanospheres interconnected with graphene: Synthesis and applications. ACS Appl Mater Interfaces 2016; 8:32528.

10.Liu J, Liu K, Feng L, et al. Comparison of nanomedicinebased chemotherapy, photodynamic therapy and photothermal therapy using reduced graphene oxide for the model system. Biomater Sci 2017;5:331.

11.Zhang L, Xia J, Zhao Q, Liu L, Zhang Z. Functional graphene oxide as a nanocarrier for controlled loading and targeted delivery of mixed anticancer drugs. Small 2010; 6:537-44

12.Hummers WS, Offeman RE. Preparation of graphitic oxide. J Am Chem Soc 1958; 80:1339.

13. Stankovich S, Piner RD, Nguyen ST, Ruoff RS. Synthesis and exfoliation of isocyanate-treated graphene oxide nanoplatelets. Carbon 2006; 44:3342-7.

14. Zhang, Wen, et al. "Synergistic effect of chemo-photothermal therapy using PEGylated graphene oxide.” Biomaterials 32.33 (2011): 8555-8561.

15. Sun, X., Liu, Z., Welsher, K., Robinson, J. T., Goodwin, A., Zaric, S., \& Dai, H. (2008). Nano-graphene oxide for cellular imaging and drug delivery. Nano research, 1(3), 203-212.

16.Hummers WS, Offeman RE. Preparation of graphitic oxide. J Am Chem Soc 1958; 80:1339.

17. Zhang, L., Wang, Z., Lu, Z., Shen, H., Huang, J., Zhao, Q., ... \& Zhang, Z. (2013). PEGylated reduced graphene oxide as a superior ssRNA delivery system. Journal of Materials Chemistry B, 1(6), 749-755.

18. Yang, K., Zhang, S., Zhang, G., Sun, X., Lee, S. T., \& Liu, Z. (2010). Graphene in mice: ultrahigh in vivo tumor uptake and efficient photothermal therapy. Nano letters, 10(9), 3318-3323.

19.Pradhan, S. K., Xiao, B., Mishra, S., Killam, A., \& Pradhan, A. K. Resistive switching behavior of reduced graphene oxide memory cells for low power nonvolatile device application. Scientific reports, 6, 26763, 2016.

20.Angelopoulou, A., Voulgari, E., Diamanti, E. K., Gournis, D., \& Avgoustakis, $\mathrm{K}$. Graphene oxide stabilized by PLA-PEG copolymers for the controlled delivery of paclitaxel

\section{OP-067 \\ RELATION BETWEEN RED BLOOD CELL DISTRIBUTION WIDTH (RDW) AND INFLAMMATORY BIOMARKERS}

Arzu Kösem, Turan Turhan

Ankara Numune Training and Research Hospital, Biochemistry Laboratory

OBJECTIVES: Recent studies have demonstrated that red cell distribution width (RDW) is associated with inflamatuar markers.

MATERIALS and METHODS: We retrospectively analyzed results of RDW,hemoglobin, C-reactive protein (CRP), mean corpuscular volume (MCV), ferritin, erythrocyte sedimentation rate (ESR), mean platelet volum (MPV). RESULTS:Atotal of 591 randomly selectedpatientsadmitted to ourhospitalbetween 01.01.2018 and 31.06.2018 were retrospectively analyzed through the hospital information system. Patients were divided into two groups in terms of their RDW levels as follows: first group: $<14.5 \%$; second group: $\geq 14.5 \%$. Second group were had higher ferritin and lower values of MCV, hemoglobin than first group values. CONCLUSIONS: RDW, may be a useful diagnostic and prognostic marker of inflamation, with treatment monitoring.

Keywords: Inflammation, red blood cell distribution width (RDW), MPV,Hemoglobin

\section{OP-068 \\ ANALYSIS OF PREANALYTIC ERRORS BY DIFFERENT AUTOANALYZER AND SAMPLE TYPES}

Cuma Mertoglu

Clinical Biochemistry, Erzincan University Faculty of Medicine, Erzincan

OBJECTIVES: It is aimed to determine the causes of preanalytical errors according to different autoanalyzer and sample types. MATERIALS and METHODS: In this retrospective study, rejected biological samples were analyzed in the laboratory information system of Mengucek Gazi Training and Research Hospital between 01.01.2017 - 31.12.2017. According to device types, reasons for rejection and rejection rates were identified. RESULTS: At the indicated dates, 748758 samples were reached in the laboratory, of which $4245(0.56 \%)$ were rejected. The number of rejected samples and the percentage of the total number of samples in their group; biochemistry $597(0.289 \%)$, hormone $743(0.504 \%)$, hemogram $930(0.460 \%)$, coagulation $456(0.977 \%)$, blood gas $1137(6.050 \%)$, nephelometer $227(0.316 \%)$ and sedimentation $155(\%$ 0.277) were found. Most reasons for rejection; incorrect test request $(\%$ 53.6) and hemolysis $(\% 22.6)$ in the biochemistry samples, inadequate sample $(61.5 \%)$ and incorrect test request $(30.2 \%)$ in hormone samples, clotted samples $(76.9 \%)$ and incorrect sample container (7.9) in hemogram samples, level error $(38.5 \%)$ and clotted sample $(31.3 \%)$ in coagulation samples, clotted sample $(89.1 \%)$ and inadequate sample $(5.7 \%)$ in the blood gas samples, incorrect sample container (\% 53.7) and incorrect test request $(\% 21.1)$ in the nephelometer specimens, incorrect sample container $(37.4 \%)$ and clotted samples $(34.1 \%)$ in the sedimentation samples were identified. CONCLUSIONS: The preanalytical error sources vary according to the sample types and autoanalyzers. These results should be stated in personnel trainings and necessary precautions should be taken. Keywords: Preanalytical error, hemolysis, clotted samples, insufficient sample, incorrect test request, incorrect sample container

\section{OP-069 \\ EVALUATION OF IODINE LEVELS IN LAST THREE YEARS; RETROSPECTIVE STUDY}

Hümeyra Acıkan, Neslihan Sungur, Sabahattin Muhtaroğlu, Didem Barlak Keti Department of Medical Biochemistry, Faculty of Medicine, Erciyes University, Kayseri

OBJECTIVES: Iodine is a basic trace element, required for the production of thyroid hormone. Iodine deficiency impairs thyroid hormone production and has many adverse effects. Approximately 2.2 billion people live in regions with iodine deficiency and are at risk for the complications of iodine deficiency. In this study, iodine values measured in urine specimens from biochemistry laboratory between 2015-2017 were retrospectively screened; gender age groups and seasonal distribution of low iodine levels were examined. MATERIALS and METHODS: In our laboratory, the iodine spot urine was assayed by Sandell-Klothoff method. From the iodine results between 2015-2017, the lower ones were identified and the variation between years was compared by creating different groups. RESULTS: When the years 2015-2017 were examined, it was observed that the iodine deficiency was increasing $(43.5 \%, 47 \%$ and $64 \%$, respectively). When the gender percentage of those with low iodine levels is examined, more women were seen (female and male, respectively, $56 \%$ and $45.5 \%$ respectively). Considering the age range from 0 to 18 years, it was found that iodine lowering was the most adolescent period and increased over the years (55\% in 2015 and $75 \%$ in 2017). When seasonal variation was observed, it was found to be generally difference. CONCLUSIONS: Iodine deficiency remains an important public health problem. In this regard, community awareness and continuity of education are important. Keywords: Iodine deficiency, Retrospective,Trace element 


\section{OP-070}

\section{FASTING AND NON-FASTING LIPOPROTEINS ARE NOT THE SAME}

Betül Özbek İpteç, Ahmet Rıfat Balık, Fatma Meriç Yılmaz, Gülsen Yılmaz Atatürk Training and Research Hospital, Ankara Yıldırım Beyazıt University, Faculty of Medicine, Department of Medical Biochemistry, Ankara

OBJECTIVES: Lipid panel tests are requested in 10-12 hour fasting however, recent studies have demonstrated that especially low-density lipoprotein (LDL) cholesterol do not significantly change with food intake and this difference is attributed to hemodilution effect caused from fluid intake. In addition, those studies claimed that non-fasting LDL cholesterol is better indicator to show cardiovascular disease (CVD). Aim of this study is to compare the fasting and non-fasting LDL values of the same individuals and discuss whether non-fasting and fasting LDL results can be used in place of each other, directly or after applying hemodilution correction models. MATERIALS and METHODS: A total of 248 apparently healthy participants were collected and fasting and non-fasting blood samples of the same individual were withdrawn in same day. All samples were analyzed for hemoglobin, albumin, triglyceride, total cholesterol, high-density lipoprotein (HDL), and LDL concentrations. Results are evaluated before and after adjusting the fasting and non-fasting samples with two different correction factors calculated by using fasting and non-fasting albumin and hemoglobin concentrations. Concordance of fasting and non-fasting risk group for developing CVD were calculated according to the National Cholesterol Education Program classification. RESULTS: Fasting and non-fasting LDL and non-high density lipoprotein cholesterol (non-HDL) concentrations were significantly different in every model $(\mathrm{p}<0.001)$. Concordance results of fasting and non-fasting LDL and non-HDL risk groups were $63.8 \%$ and $77.9 \%$ respectively. CONCLUSIONS: Our results demonstrated that fasting and non-fasting LDL and non-HDL concentrations could not be used in place of each other even when the results were adjusted for elimination of the hemodilution effect. Keywords: Low-density lipoprotein cholesterol (LDL), non-fasting, fasting, cardiovascular risk

\section{OP-071 \\ PERFORMANCE WITH DIFFERENT EQUATIONS FOR LDL-C ESTIMATION BETWEEN HEALTLY POPULATION IN TURKEY}

Mehmet Fatih Alpdemir, Medine Alpdemir

Balıkesir State Hospital, Clinical Biochemistry Laboratory, Balıkesir

OBJECTIVES: In rutine, low-density lipoprotein cholesterol (LDL-C) is estimated using Friedewald equation. However, several new formulas have been proposed for estimation LDL-C for recently years but have not verified in different populations. The aim of this study compare LDL-C estimations using various formulas with directly measured LDL-C in among the Turkish population. MATERIALS and METHODS: A total of 1478 participants who were aged between 18 and 65 were classified into five groups according to serum triglycerides (TG) concentration as follows: $<100(n=292), 100-199(n=262), 200-299(n=304), 300-$ $399(n=254)<400-1000(n=366) \mathrm{mg} / \mathrm{dL}$. Serum lipid profile concentrations were measured with Cobas 6000 c501 ( Roche Diagnostic). D- LDL-C concentrations were measured by a homogenous direct assay using reagents. We used results of the D- LDL-C measurement as the reference value. We investigated the accuracy ten equations (Friedewald, De Cordova, Ahmadi, Anandaraja, Teerakanchana, Chen, Hattori, Vujovic, Puavillai, Hatta) for estimating LDL-C in this study. RESULTS: In group 1, Anandaraja formula correlated best with D- LDL-C ( $\mathrm{r}=$ $0.367)$, but this correlation is weakly. In group 2 and group 4, Teerakanchana formula correlated best with D- LDL-C (respectively; $r=0.931, r=0.950$ ). In group 3 . Friedewald and Teerakanchana formulas correlated best with D- LDL-C ( $r=$ $0.935)$. In group 5, Anandaraja formula correlated best with $\mathrm{D}-\mathrm{LDL}-\mathrm{C}(\mathrm{r}=0.792)$. CONCLUSIONS: We observed suitable correlation of the Teerakanchana at TG range 100-400 mg/dL. Anadaraja formula showed the best correlation in high TG concentrations. Consequently, it is necessary to determine the formula selection for LDL-C according to the TG concentration. Keywords: Friedewald Formula, Low-Density Lipoprotein Cholesterol, Cholesterol, Triglyceride, Estimation Low-Density Lipoprotein Cholesterol

\section{OP-072 \\ COMPARISON OF EMERGENCY BIOCHEMISTRY TESTS WITH LI- HEPARIN (BARRICOR TM) AND GEL TUBES}

Bilal İlanbey ${ }^{1}$, Kenan Güclü ${ }^{2}$

${ }^{1}$ Department of Medical Biochemistry, Faculty of Medicine, Kırşehir Ahi Evran University, Kırşehir

${ }^{2}$ Kırşehir Ahi Evran University Training and Research Hospital Biochemistry

Laboratory, Kırșehir

OBJECTIVES: Reliable and rapid test results requested by the ED are important for the patient to receive early treatment, as well as to shorten the LOS. Since use of plasma needs no clothing time and shortness the centrifugation, we compared BD Vacutainer ${ }^{\circledR}$ Barricor TM lithum heparin tubes with mechanical separator for the chemistry parameters with our current tubes; Greiner bio-one VACUETTE $®$ serum gel tubes.
MATERIALS and METHODS: Blood samples taken from randomly selected 42 ED patients collected to lithium heparin (Barricor ${ }^{\mathrm{TM}}$ ) and serum gel tubes (VACUETTE $®$ ). Barricor TM tubes were centrifuged for 3 minutes at $2360 \mathrm{xg}$, and serum gel tubes were centrifuged for 10 minutes at $1500 \mathrm{xg}$. Twelve chemistry parameters were analysed. Dependent $t$ test was used for normal distirbution tests and Wilcoxon sign test was used for non-normal distribution. Total error, bias and $\%$ bias were applied for clinical significancy level. RESULTS: Considering for ALT, albumin, calcium, potassium, urea, total bilirubin and direct bilirubin results were statistically significant. No significant difference found for the other parameters. Statistically significant results, tested for clinically significancy and bias and total error checked. No clinically significant difference was detected for any parameters. CONCLUSIONS: As a result, there were statistically significant differences in several parameters between the BD Vacutainer $(\mathrm{B}$ Barricor TM plasma tube with mechanical seperator and the serum gel tubes. However, this difference was not clinically significant. The BD Vacutainer ${ }^{\circledR}$ Barricor TM plasma tube can be an alternative to serum gel tubes to shorten the TAT and improve sample quality. Keywords: Barricor, Li-heparin, serum gel tube, mechanical separator, plasma tube.

\section{OP-073}

\section{ANALYSIS OF OXIDATIVE STRESS DEPENDED PEROXIDE AND FREE FATTY ACIDS OF MICROALGAL LIPID}

Nurcan Vardar Yel

Altinbas University

OBJECTIVES: Schizochytrium sp. is widely studied microalgae to obtain high content of polyunsaturated fatty acids especially docosahexaenoic acid (DHA). They contain various bioactive compounds that can be used as pharmaceutical raw material, food additive, aquaculture and animal feed.Schizochytrium sp. which is grown rapidly and produced high amount of DHA can be used as an alternative to fish oils. The aim of this study is to analyze the lipid peroxide and free fatty acids due to the oxidative stress of microalgae oil with high DHA ratio. MATERIALS and METHODS: : PUFAs are prone to autoxidation (oxidative rancidity) because of double bonds in their structure. Generally, autoxidation is determined by the peroxides which are intermediates in the autoxidation reaction. Free radical is formed in the autoxidation reaction that leads to form off-flavours. Acedic asid-chloroform method was used for peroxide value determination in this study. The free fatty acids (FFAs) and the non-polar components are separately recovered and measured with phenolphthalein assay. RESULTS: Microalgal lipid free fatty acid $0.1 \mathrm{ppm}$, Anisidine value $20 \mathrm{mg} \mathrm{KOH} \mathrm{/} \mathrm{gr,} \mathrm{peroxide} \mathrm{value} 5 \mathrm{meg} / \mathrm{kg}$ were found. Free fatty acid, anisidin, peroxide and unsaponifiable matter values were determined below the limit when it is compared to fish oil. CONCLUSIONS: Fish can accumulate toxins such as mercury, dioxins, and polychlorinated biphenyls (PCBs), and spoiled fish oil may produce peroxides. Because of LC-PUFAs are more prone to oxidation, it was suggested to add antioxidant solution to algal culture Keywords: Lipid, oxidative stress, peroxide, free fatty acid

\section{OP-074 \\ THE EFFECT OF ACRYLAMIDE ADMINISTRATION ON LARGE INTESTINE AND BLADDER FUNCTIONS IN RATS}

Rıfat Ertekin, Rıdvan Bağcı, Sedat Kaçar, Dilek Burukoğlu Dönmez, Varol Sahintürk

Eskisehir Osmangazi University, Faculty of Medicine, Department of Histology and Embryology

OBJECTIVES: Acrylamide, a water-soluble vinyl monomer, is widely used in various industrial fields. The toxic effects of acrylamide on rats have been shown in many studies. However, the effect of acrylamide on organs such as the bladder and large intestine has not been investigated much. In this study, we examined how acrylamide influences the functions of the large intestine and bladder MATERIALS and METHODS: 13-week-old $\mathrm{m}$ ale Sprague-Dawley rats were used for this study. Rats were assigned into two groups as control and acrylamide groups. The control group was fed with standard rat diet and drinking water. The rats of acrylamide group were administered acrylamide at a daily dose of $40 \mathrm{mg} / \mathrm{kg}$ for 21 days, once a day and by gavage. At the end of 21 days, the rats were sacrificed by being fasted for 12 hours. RESULTS: The rats were undergone to laparotomy and it was seen th at the rats of acrylamide group had distention in their large intestines and they had urinary retention (glob vesica) in their bladder. It was observed that their large intestine and bladder were tense and full despite they had fasting for 12 hours. CONCLUSIONS: Acrylamide causes distension of large intestine and urinary retention in the bladder. This may result from neurotoxic effect of acrylamide on the spinal level and the intestinal and bladder smooth muscle dysfunction which occurs depending on this effect. Keywords: Acrylamide, neurotoxicity, large intestine, bladder 


\section{OP-075 \\ PROMINENT AUTOFLUORESCENCE WAS OBSERVED IN FORMALDEHYDE-FIXED, PARAFFIN.EMBEDDED LIVER TISSUE SAMPL}

Sedat Kacar, Rıdvan Bağcı, Rıfat Ertekin, Dilek Burukoğlu Dönmez, Varol Şahintürk

Eskisehir Osmangazi University, Basic Medical Science, Department of Histology and Embryology

OBJECTIVES: Histological techniques are indispensable scientific methods based on microscopic examination. In histology, specific stainings are as common as non-specific stainings. Specific stainings are called as immunohistochemistry staining, which is based on protein antibody interaction. Immunofluorescence is one of those techniques, in which fluorophores are bound to the end of a secondary antibody and emit fluorescent when exposed to respective wavelength of ultraviolet. In this study, our goal is to examine the specificity of immunofluorescence technique in, paraffin-embedded tissue sections. MATERIALS and METHODS: In our study, formaldehyde-fixed and paraffin-embedded rat liver blocks were used. Routine immunohistochemical procedures were performed to the tissue sections. After removed the paraffins, the tissue sections were treated with both primer ( Nrf2) and secondary antibodies (goat anti-rabbit), treated with only secondary antibody or treated with no antibodies and then examined under fluorescence microscopy. We employed FITC fluorophore, which emits green colored light. RESULTS: According to the results, green autofluorescent was observed over whole liver tissue, especially in vascular parts of liver, in the tissue sections to which no primary and secondary antibodies were applied. The cytoplasmic part of cells considered to be immunopositive were also observed in tissue sections in which no primer antibody was used. CONCLUSIONS: In conclusion, formaldehyde-fixed liver tissue sections emitted excessive autofluorescence. Under these conditions, it is very difficult to examine immunofluorescenctly-labelled tissue. It is therefore necessary to examine the tissue sections under fluorescent microscope with different filters before starting the experiment. Keywords: Liver, formaldehyde, autofluorescent, immunofluorescent

\section{OP-076}

\section{GLUT 2 PROTEIN CHANGE IN HEPATOCYTES AFTER ACRYLAMIDE EXPOSURE: AN IMMUNOCYTOCHEMICAL \\ EXAMINATION}

Sedat Kaçar, Ezgi Bektur, Rıfat Ertekin, Rıdvan Bağcı, Varol Şahintürk Eskisehir Osmangazi University, Faculty of Medicine, Histology and Embryology Department, Eskisehir

OBJECTIVES: Acrylamide is a chemical, the neurotoxic, genotoxic, mutagenic effects of which is well-known on living organisms. Glucose transporter 2 (GLUT 2 ) is an important transmembrane carrier protein which assists the glucose intake into cell. In literature, to our best knowledge, there is a gap about the impact of acrylamide on GLUT 2 proteins. Thus, in the present study, our purpose was to examine the effct of acrylamide on GLUT 2 proteins of clone 9 hepatocyte cells. MATERIALS and METHODS: Initially, the amount of acrylamide toxic to half of the cells was determined by MTT assay. Then, one group of cells was treated with acrylamide for $24 \mathrm{~h}$, while one group of cells was used as control. $24 \mathrm{~h}$ later, the cells' media were removed and cells were fixed with ice-cold methanol. Then, cells were treated with triton X, primary antibody and secondary antibody, respectively. The samples stained with Immunocytochemistry and hematoxylin-eosin staining were observed under a microscope. RESULTS: The IC50 value of acrylamide for clone 9 cells was determined to be $5.44 \mathrm{mM}$ by MTT test. According to immunocytochemistry results, GLUT 2 expressions were detected to increase in acrylamide-treated groups when compared to untreated group. Hematoxylin eosin staining showed that acrylamide caused degenerative changes such as cellular shrinkage and nuclear condensation. CONCLUSIONS: To sum up, to our knowledge, we, for the first time, examined GLUT 2 expressions in acrylamide-treated hepatocytes. Further studies are needed to enlighten the exact mechanism of acrylamide-induced GLUT 2 alteration. Keywords: Acrylamide, MTT, GLUT 2, immunocytochemistry

\section{OP-077 \\ CORRELATION BETWEEN PHENOLIC INGREDIENTS AND LIFE SPAN EFFECTS OF ASPARAGUS OFFICINALIS L}

Hasan Kilıçgün

Erzincan Binali Yıldırım University, Faculty Of Health Sciences, Nutrition and Dietetics Department, Erzincan

OBJECTIVES: Asparagus officinalis L. is native for northern Africa, Europe, western Asia and Mongolia. The aim of this study was to determine dosedependent relations between phenolic ingredients and life span effect and fertility of Asparagus officinalis in Caenorhabditis elegans which was accepted as useful experimental model organism for examination on longevity. MATERIALS and METHODS: In this study, five experimental groups (1, 2, $45,10, \mathrm{mg} / \mathrm{mL}$ Asparagus officinalis infusions and one control group) were used to determine the most effective dose of Asparagus officinalis in terms of life span and fertility properties. For fertility effect of Asparagus officinalis, quantitation of constitutive egg-laying was performed according to the standard protocol described by Michael Koelle. Briefly, after mature nematodes were paleced in dishes, the number of eggs is determined by the end of each 30-minute X 20-lens microscop. Also, the life span analysis experiments were performed according to the standard protocol described by Sutphin and Kaeberlein RESULTS: It was observed that, Asparagus officinalis infusions of 1,2 and $4 \mathrm{mg} / \mathrm{mL}$, had the potential to promote for the longevity and fertility properties of Caenorhabditis elegans although higher (5 and10) $\mathrm{mg} / \mathrm{mL}$ concentrations did not promote on those parameters CONCLUSIONS: These results indicated that Asparagus officinalis may be used as a supplement to prolong life span and fertility properties for the other living organisms and human beings, but the dose should be carefully considered to avoid unfavorable effects. Keywords: Asparagus officinalis L, Caenorhabditis elegans, Life span, Fertility, Phenolics

\section{OP-078 \\ HYPERTYROIDISM INCREASES TRPV1 ACTIVITY IN RAT BRAIN AND CEREBELLUM}

Ezgi Bektur, Erhan Șahin, Sedat Kaçar, Varol Şahintürk Department of Histology and Embryology, Faculty of Medicine, Eskișehir Osmangazi University, Eskisehir

OBJECTIVES: In hyperthyroidism,the thyroid gland produces excess thyroxine hormone and increases reactive oxygen radicals.Oxidative stress changes antioxidant levels of various tissues,including brain regions. Transient receptor potential vaniloid 1 (TRPV1) is a non-selective cationic channel whose activity is affected by various pathological conditions and oxidative stress.There is insufficient study of how TRPV1 channels are affected by hyperthyroidism.In this study,it was aimed to investigate the relationship between oxidant and antioxidant levels of TRPV1 in brain tissue of hyperthyroid rats. MATERIALS and METHODS: A total of 20 adult male Wistar albino rats were divided into two groups (control and hyperthyroidism) in our study.In order to establish hyperthyroidism model,12 $\mathrm{mg} / \mathrm{L}$ thyroxine hormone was added to the drinking water of rats for 4 weeks. At the end of the experiment, T3, T4, $\mathrm{TSH}$,total antioxidant capacity and total oxidant levels were measured by ELISA. Total antioxidant capacity (TAC) and total oxidant levels (TOS) of the brain and cerebellum tissues were measured by ELISA method.In addition,TRPV1 expressions were examined by immunohistochemistry and western blot methods. RESULTS: TSH and TAC levels decreased;T3,T4 and TOS levels increased in hyperthyroidism group.According to immunohistochemistry results, while the control group showed weak staining in brain and cerebellar cortex neurons,TRPV1 expression was intense positive hyperthyroidism group.There is no reaction in hippocampal neurons in both control and hyperthyroidism groups.Western blot analysis showed that TRPV1 expression was higher in brain and cerebellum tissues of hyperthyroidism group than control. CONCLUSIONS: Hyperthyroidism increases the expression of TRPV1 in brain and cerebellum cortex neurons and is probably due to oxidative stress. Keywords: Hyperthyroidsm, brain, cerebellum, TRPV1.

\section{OP-079}

\section{THE ROLE OF PROSTAGLANDIN E2 IN DIABETIC NEPHROPATHY}

Emre Avci, Gamze Cagatay, Gulcin Alp Avci

Department of Molecular Biology and Genetics Department, Faculty of Arts and Science, Hitit University, Corum

OBJECTIVES: Diabetic nephropathy (DN) is a microvascular complication characterized by the presence of relatively common urinary albumin expression, diabetic glomerular-lesions, and pathologic quantities of glomerular filtration rate (GFR)'s loss in patients with type I and II diabetes mellitus.Several factors play a role, especially on the DN, such as vascular pressure.Although prostaglandins (PG) are mainly vasodilator-effective, they do not play an essential role in the regulation of renal hemodynamics in normal humans. However, if the underlying glomerular disease is renal insufficiency, PGE2 is one of the factors that maintain the renal blood flow and GFR by decreasing the preglomerular resistance. We aimed to evaluate the efficacy of PGE2 values in DN patients treated with hemodialysis treatment in our study. MATERIALS and METHODS: Patients who had undergone an old and new diagnosis, taking oral-antidiabetic and insulin-treatment and whose renal function was impaired were included in the study dialysis centers.Patients were composed of 22-patients in the nephropathy group and 17-patients in the healthy control group. The serum PGE2 values were determined by ELISA. RESULTS: PGE2'serum concentrations in DN group were significantly higher than control group.

CONCLUSIONS: Recent studies have investigated the effects of PGE2 on changes related to immunodeficiency, inflammation and oxidative stress, cardiovascular diseases, diabetes andmetabolic syndrome.Results suggest thatinsulininsufficiency and high blood glucose in DN patients may disrupt supply of cytokine-gammalinolenic acid cis-linoleic acid and decrease prostaglandin formation. In this case feedback regulation can increase PGE2 production. The altered PG metabolism may be responsible for the development and progression of vascular complications. Keywords: Diabetic nephropathy, prostaglandin, PGE2 


\section{OP-080 \\ EVALUATION OF PROTEIN OXIDATION IN STREPTOZOTOCIN INDUCED DIABETIC RATS}

Meltem Demir

Medicalpark Hospital

OBJECTIVES: Diabetes mellitus (DM) is a chronic disorder.Methylglyoxal (MGO), a precursor of advanced glycation endproducts (AGE), is detoxified in the organism by Glyoxalase through Glyoxalese I (GLO I) and GLO II.This study was aimed to investigate AGE formation in a diabetic rat model induced by streptozotocin (STZ) and the possible role of melatonin MEL. MATERIALS and METHODS: Four study groups, each containing ten Sprague Dawley rats, were defined as control, MEL, STZ and STZMEL. STZ and STZ-MEL groups were given a single $50 \mathrm{mg} / \mathrm{kg}$ dose of STZ to induce diabetes. MEL, $25 \mathrm{mg} / \mathrm{kg}$ was given intraperitoneally to MEL and STZ-MEL groups. At the end of study, the levels of MGO, GLO I and GLO II enzymes were also determined in only tissue samples. RESULTS: Blood and urine glucose levels were found to be high in rats. STZ group had been shown to have higher tissue MGO levels and lower GLO I and GLO II activities, MEL treatment had suppressed high levels of MGO and increased enzymatic activities in STZ-MEL group. CONCLUSIONS: This study, we have shown that reducing MGO tissue levels in chronic diabetes to almost normal level and that the GLO system suppressed in diabetic rats are preserved with MEL,GLO I and GLO II activities increased. It has been shown that STZ induced diabetic rats had high MGO levels and the supression of GLO detoxification system indicates that AGE formation in diabetes is inevitable. Therefore, the usage of antioxidants such as MEL may be suggested to prevent daibetic complications. Keywords: protein oxidation, diabetes, methylglyoxal

\section{OP-081 \\ EFFECTS OF BORIC ACID ON HEART TISSUE DAMAGE CAUSED BY RENAL ISCHEMIA/REPERFUSION}

Yakup Kara $^{1}$, Ceyhan Hacığ $l^{1}{ }^{1}$, Fatih Kar ${ }^{1}$, Ezgi Kar ${ }^{1}$, Hakan Şentürk², Güngör Kanbak

${ }^{1}$ Eskisehir Osmangazi University, Faculty of Medicine, Department of Medical Biochemistry, Eskisehir

${ }^{2}$ Eskisehir Osmangazi University, Faculty of Arts and Sciences, Department of Biology, Eskisehir

OBJECTIVES: Ischemia/reperfusion(I/R) has an important place in various heart diseases. In this study, it was aimed to investigate the effects of boric acid(BA), which is known contribution to antioxidant defense system on heart tissue damage caused by renal 1schemia/reperfusion. MATERIALS and METHODS: In our study, 35 Spraque Dawley rats were randomly divided into five groups as sham, $\mathrm{I} / \mathrm{R}, \mathrm{I} / \mathrm{R}+50-\mathrm{mg} / \mathrm{kg}-\mathrm{BW}-\mathrm{BA}, \mathrm{I} /$ $\mathrm{R}+100-\mathrm{mg} / \mathrm{kg}-\mathrm{BW}-\mathrm{BA}, \mathrm{I} / \mathrm{R}+200-\mathrm{mg} / \mathrm{kg}-\mathrm{BW}-\mathrm{BA}$. Ischemia was performed at the $\mathrm{I} / \mathrm{R}$ groups for 45 -minutes from the left renal artery. After this procedure was performed 24-hour reperfusion. In the I/R+BA groups, BA was administered intraperitoneally 10 -min before reperfusion. Myeloperoxidase(MPO) and catalase(CAT) enzyme activities were measured in surgically taken heart tissues. RESULTS: MPO, increased significantly in the $I / R$ group compared to the sham group $(\mathrm{p}<0.01)$. There was statistically significant decrease in MPO level compared to I/R group in the group to which $50-\mathrm{mg} / \mathrm{kg}-\mathrm{BW}-\mathrm{BA}$ was applied in the BA applied groups $(\mathrm{p}<0.01)$. CAT, was significantly reduced in the $I / R$ group compared to the sham group $(\mathrm{p}<0.01)$. CAT levels were significantly elevated in the $50-\mathrm{mg} / \mathrm{kg}-\mathrm{BW}-\mathrm{BA}$ group compared to the $\mathrm{I} / \mathrm{R}$ group $(\mathrm{p}<0.01)$. CONCLUSIONS: In our study, inflammatory and antioxidant effects on the heart tissue were investigated as distant tissue damage resulting from renal $I / R$. Renal I/R may weaken the antioxidant system while increasing the inflammatory effect in the heart. One of the studies on the mechanisms of action of boric acid is the association with the inflammatory response. It has been shown in our study that boric acid may reduce increased inflammation. Also, we believe that the antioxidant properties of BA contribute to the antioxidant system. Keywords: Renal Ischemia/Reperfusion, Boric Acid, Heart, Inflammation, Oxidative Damage

\section{OP-082 \\ NEUROPROTECTIVE EFFECTS OF BORIC ACID ON BRAIN AGAIINST RENAL ISCHEMIA/REPERFUSION INJURY}

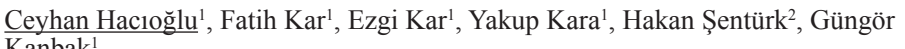
Kanbak

${ }^{1}$ Eskisehir Osmangazi University, Faculty of Medicine, Department of Medical Biochemistry, Eskisehir

${ }^{2}$ Eskisehir Osmangazi University, Faculty of Arts and Sciences, Department of Biology, Eskisehir

OBJECTIVES: Renal ischemia/reperfusion (I/R) may cause distant tissue damage. Boric acid (BA) with antioxidant properties is suggested to be a protective agent against I/R injury. The aim of this study was to investigate the neuroprotective effects of boric acid on brain against renal $I / R$ induced oxidative damage.
MATERIALS and METHODS: 35 rats were divided into five groups: sham, $\mathrm{I} / \mathrm{R}, \mathrm{I} / \mathrm{R}+50 \mathrm{mg} / \mathrm{kg} \mathrm{BA}, \mathrm{I} / \mathrm{R}+100 \mathrm{mg} / \mathrm{kg}$ BA and $\mathrm{I} / \mathrm{R}+200 \mathrm{mg} / \mathrm{kg}$ BA. Sham group was only subjected to surgical stress procedure. In $I / R$ group, left renal artery was isolated and ischemia was induced for 45 minutes with atraumatic vascular clamp, then followed by 24-hour reperfusion. In I/ R+BA groups, BA was administered intraperitoneally 10 minutes before reperfusion, unlike the $\mathrm{I} / \mathrm{R}$ group. In rat brain tissues MDA levels, GSH levels, SOD activities and NO levels were measured spectrophotometrically. RESULTS: Renal I/R caused a significant increase in MDA and NO levels as compared to the values of the control group $(\mathrm{P}<0.01)$, but caused a decrease in GSH levels and SOD activities.Conversely, rats treated with BA prior to reperfusion showed a significant reduction in the brain MDA and NO levels as compared to renal I/R group, on the other hand was an increase in GSH levels and SOD activities. CONCLUSIONS: This study showed protective effects of BA on brain tissue against renal I/R injury. BA treatment can decrease lipid peroxidation levels and increase antioxidant enzymes activities in brain hippocampus of renal $I / R$ induced rats. Our results indicate that BA is useful for brain function maintaining in renal $\mathrm{I} / \mathrm{R}$ induced rats.

Keywords: Renal Ischemia/Reperfusion, Brain, Boric Acid, Oxidative Damage, Neurodegeneration.

\section{Introduction}

Kidney have an important role in the maintenance of the body's hemostatic balance and in the elimination of toxic products [1]. Renal ischemia-reperfusion (IR) damage is a major cause of acute renal injury (AKI). The main cause of the high mortality rate in the case of AKI is due to distant organ damage [2,3]. Renal IR induces oxidative stress by increasing the production of reactive oxygen and nitrogen species (ROS and RNS, respectively) that lead to an increase in lipid peroxidation and reduce in antioxidant capacity (4). It has been demonstrated that renal IR caused a significant reduction in antioxidant levels in the hippocampus [5-9]. Boric acid (BA), which is mostly present in the form of compound in nature, is a trace mineral for livings [10]. Boric acid is rapidly absorbed by the gastrointestinal tract and is spreaded through the body by passive diffusion [11]. It has been reported that BA scavenged ROS and supported antioxidant mechanisms by increasing the levels of enzymatic and non-enzymatic antioxidant molecules [12-15]. It is not known precisely whether BA can prevent to brain damage in renal IR-induced rats. Therefore, in current study, we evaluated the possible neuroprotective effects of BA on brain in renal IR-induced rats.

Materials and Methods

Animals: This study was conducted with thirty five healthy Spraque Dawley adult female rats (weighing $250 \pm 30 \mathrm{~g}$ ) obtained from the Medical and Surgical Experimental Research Center, Eskisehir. Experimental procedures were carried out according to the decision of Animal Experiments Local Ethics Committee of Eskisehir Osmangazi University (Approval number: 657).

Study design: All surgical procedures were performed under anesthesia Anaesthetized all animals underwent right renal nephrectomy under sterile conditions. Following, each animal was placed separately in cages and allowed to heal for 15 days. In the experimental design, the rats were randomly divided into five groups (sham, IR, IR $+50 \mathrm{mg} / \mathrm{kg} \mathrm{BA}, I R+100 \mathrm{mg} / \mathrm{kg} \mathrm{BA}, I R+200 \mathrm{mg} / \mathrm{kg}$ BA groups) of seven animals in each group.

At the end of the 15-day recovery period, $0.5 \mathrm{~mL}$ saline or BA were injected intraperitoneally 10 minutes before the reperfusion period without ischemia. After 24 hours of reperfusion, the experimental animals were sacrificed under anesthesia. Brain tissues were removed quickly and stored at $-80^{\circ} \mathrm{C}$ until analysis. Biochemical assays: Malondialdehyde (MDA) levels were measured according to the method reported by Ohkawa et al [16]. The results were indicated as nmol/ mg protein.

Glutathione (GSH) levels were determined according to Srivastava and Beutler [17]. Brain GSH levels were expressed as $\mu \mathrm{mol} / \mathrm{mg}$ protein. Nitric oxide (NO) measurement was based on the measurement of nitrite and nitrate due to oxidation of nitric oxide. The amount of nitrite was measured precisely according to the method also known as the Griess reaction (18). The results were expressed as $\mu \mathrm{mol} / \mathrm{mg}$ protein. Superoxide dismutase (SOD) activity was measured according to the method of Sun et al [19].

The result were indicated as Unit/mg protein. Protein contents of brain was measured by the biuret method [20].

Histopathological examination: Brain tissues were washed in phosphate buffer at $\mathrm{pH} 7$, and then immediately placed in $10 \%$ neutral formaldehyde solution for histological analysis. Brain samples were embedded in paraffin and $4 \mu \mathrm{m}$ sections were obtained by using microtome (Leica RM 2025). Hematoxylin and eosin were applied to sections and they were closed with poly-L-Lysine coated slides. Histopathological examinations of stained brain sections were performed using light microscopy (Olympus CH40). The histopathological levels were graded according to changes observed as follows: no damage with 1, moderate damage with 2 , great damage with 3 . The mean of all numerical scores in each group was evaluated as the total histopathological score.

Statistical analysis: Results are stated as standard error of means $( \pm$ SEM). Data were analyzed by utilizing one-way analysis of variance (ANOVA) on the SPSS version 21.0 for Windows. Post hoc Tukey HSD and Tamhane's T2 tests were used for multiple comparisons. The value of $p<0.05$ was accepted to be significant.

Results

Effects of BA on GSH, SOD, MDA and NO levels in brain tissue: We found that renal IR caused significantly a $45 \%$ and $29 \%$ decrease in GSH and SOD levels compared with sham group, respectively (Table 1). BA treatment at doses of 50 and $100 \mathrm{mg} / \mathrm{kg}$ prior to reperfusion resulted in an improvement in GSH levels 
and SOD activities. Renal IR was found an increase in lipid peroxidation and a decrease in NO levels compared with sham group (40\% and $27 \%$, respectively). 50 and $100 \mathrm{mg} / \mathrm{kg}$ BA treatment caused a significant reduction in MDA and an increase in NO levels. On the contrary, high dose BA $(200 \mathrm{mg} / \mathrm{kg})$ treatment caused a decrease $43 \%$ in GSH, $24 \%$ in NO and $27 \%$ in SOD levels and an increase $55 \%$ in MDA levels.

Effects of BA on histological changes: Brain tissues were evaluated histopathologically for the presence of neuronal damage, dilated vascular structure and necrotic cells. In the sham group was observed a healthy brain appearance together with neurons and glial cells in the cortical aria (histological score, hs $=0$ ) (Figure 1, A1-A2). Intensive cellular damage, cortical area damage, dilated vascular structures and necrotic cells were detected in the brain tissues of IR group (hs=3***a ) (Figure $1, \mathrm{~B} 1-\mathrm{B} 2$ ). In IR $+50 \mathrm{mg} / \mathrm{kg} \mathrm{BA}$ group, a few dilated vascular structures and necrotic cells in the cortical area as well as normal appearance of neurons suggested that BA reduced ischemic damage in brain tissue (hs $=1.14 \pm 0.73 * * * b)$ (Figure $1, \mathrm{C} 1-\mathrm{C} 2$ ). In the IR $+100 \mathrm{mg} / \mathrm{kg} \mathrm{BA}$ group, several dilated vascular structures in the cortical area showed that BA improved tissue damage compared to the IR group and histologically provided neurons and glial cells similar to the sham group $(0.57 \pm 0.12 * * * b)$ (Figure 1, D1-D2). The dose of $200 \mathrm{mg} / \mathrm{kg} \mathrm{BA}$ was not as effective as the others against brain damage induced by renal IR (2.51 \pm 0.45 ) (Figure 1, E1-E2). All data are expressed as mean \pm SEM. a: As compared to sham group. B: as compared to IR group. ${ }^{* *} \mathrm{p}<0.001$.

Discussion

Renal IR injury is a serious issue affecting various physiological and biochemical processes such as multiple organ failure, remote organ injury and clinical operations [21]. Our results indicated that renal IR in rats induced the adverse effects on the brain as a remote organ. Histopathological examinations consistent with increased MDA and NO levels and reduced antioxidant capacity supported that brain damage in rats that may be related to renal IR-induced oxidative stress. This is the first reported study to display the neuroprotective effect of BA as a ROS scavenger on renal IR-induced brain injury. Oxidative stress is actually expressed as an increase in intracellular production of ROS resulting from the imbalance between pro-oxidant and antioxidant mechanisms [22].

Our results consistent with previous studies, after $45 \mathrm{~min}$ of ischemia followed by $24 \mathrm{~h}$ of reperfusion, significant decreases in brain GSH levels and SOD activities and an increase in MDA level were observed [23]. In addition, many studies have shown that renal IR leads to histologically organ damages such as congestion, necrotic cells, cellular infiltration and vascular endothelial damage [24].

Table 1. Effects of BA on some oxidative and antioxidant parameters on the brain tissue.

\begin{tabular}{|c|c|c|c|c|}
\hline Groups & $\begin{array}{c}\text { GSH Levels } \\
\text { ( } \mu \mathrm{mol} / \mathrm{mg} \text { protein) }\end{array}$ & $\begin{array}{c}\text { NO Levels } \\
(\mu \mathrm{mol} / \mathrm{mg} \text { protein })\end{array}$ & $\begin{array}{l}\text { SOD Activities } \\
\text { (Unit/mg protein) }\end{array}$ & $\begin{array}{c}\text { MDA Levels } \\
\text { (nmol/mg protein) }\end{array}$ \\
\hline Sham & $9.57 \pm 1.12$ & $143.68 \pm 13.84$ & $275.39 \pm 25.36$ & $12.26 \pm 3.51$ \\
\hline IR & $5.31 \pm 2.34 * * * a$ & $106.13 \pm 8.62 * * * a$ & $196.48 \pm 14.73 * * a \mathrm{a}$ & $17.21 \pm 2.68 * * * a$ \\
\hline $\mathrm{IR}+50 \mathrm{mg} / \mathrm{kg}$ BA & $6.35 \pm 1.16 * \mathrm{~b}$ & $134.08 \pm 15.37 * * * \mathrm{~b}$ & $208.95 \pm 12.31 * \mathrm{~b}$ & $15.72 \pm 1.24 * \mathrm{~b}$ \\
\hline $\mathrm{IR}+100 \mathrm{mg} / \mathrm{kg} \mathrm{BA}$ & $8.54 \pm 1.05 * * \mathrm{~b}$ & $128.61 \pm 13.72 * * \mathrm{~b}$ & $257.49 \pm 16.43 * * \mathrm{~b}$ & $14.39 \pm 1.62^{* * *} \mathrm{~b}$ \\
\hline $\mathrm{IR}+200 \mathrm{mg} / \mathrm{kg}$ BA & $5.46 \pm 1.07$ & $109.46 \pm 21.19$ & $201.03 \pm 22.47$ & $18.97 \pm 2.16$ \\
\hline
\end{tabular}

Post hoc Tukey HSD test was used for comparison among the experimental groups. All data are expressed as mean \pm SEM ( $n=7$ in each group). a: As compared to sham group. b: As compared to IR group. *p $<0.05, * * p<0.01, * * * p$ $<0.001$. BA: Boric acid. IR: Ischemia-reperfusion. GSH: Glutathione. MDA: Malondialdehyde. NO: Nitric oxide. SOD: Superoxid dismutase.

In the current study, BA treatment significantly increased GSH levels and SOD activities and decreased MDA and NO levels, which is showed that BA acts as a ROS scavenger. In addition, BA provided histological improvement by decreasing the number of necrotic cells and dilated vascular structures in the brain tissue. In accordance with the literature, we found that high-dose BA $(200 \mathrm{mg} / \mathrm{kg})$ treatment has been shown to have toxic effects by reducing antioxidant capacity and increasing lipid peroxidation [25].

Overall, renal IR causes damages in brain functions and structures which are important for continuity of neuronal processes. To date, no studies have been investigated the neuroprotective effect of BA against renal IR-induced brain damage. Our results indicate that renal IR injury causes changes in brain histological structure, and BA treatment in low doses $(50$ and $100 \mathrm{mg} / \mathrm{kg})$ may improve these disorders.
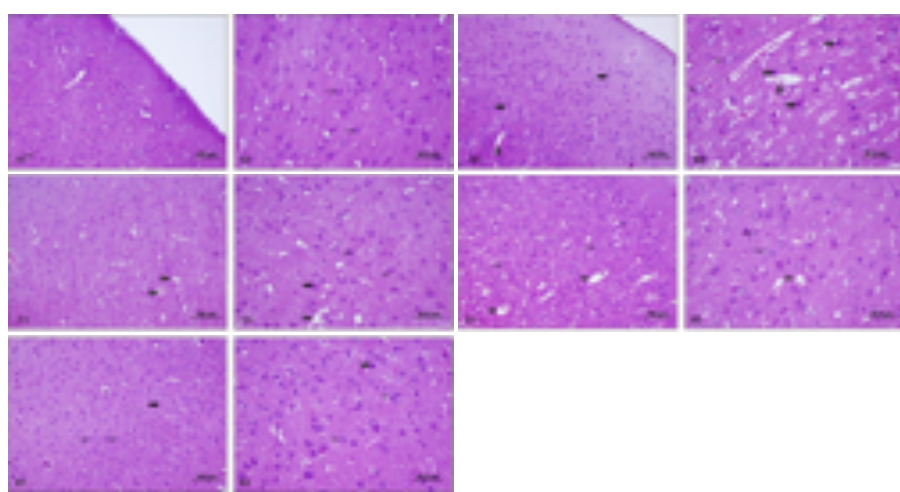

Figure 1. Effects of boric acid on renal IR-induced brain damage in rats. Representative sections of the brain stained with hematoxylin and eosin. Light microscopic images of the brain of rats from sham group (A1-A2), IR group (B1-B2), IR+50mg/kg BA group (C1-C2), IR+100mg/kg BA group (D1-D2) and $\mathrm{IR}+200 \mathrm{mg} / \mathrm{kg}$ BA group (E1-E2). $\rightarrow$ : Normal neurons. $\Delta:$ Dilated vascular structures. : Necrotic cells.

Acknowledgement: This study was supported by Eskişehir Osmangazi

University Scientific Research Projects Commission as a project (Project No: 2018-2035).

Ethical Considerations: This study was approved by the Animal Care and Use

Committee of the Eskișehir Osmangazi Universiy (Approval number: 2018/657)

Conflict of Interest: The authors report no conflict of interest. References

1. Golab F, Kadkhodaee M, Zahmatkesh M, Hedayati M, Arab H, Schuster R, et al. Ischemic and non-ischemic acute kidney injury cause hepatic damage. Kidney Int 2009; 75(8):783-792

2. Hassoun HT, Grigoryev DN, Lie ML, Liu M, Cheadle C, Tuder RM, et al. Ischemic acute kidney injury induces a distant organ functional and genomic response distinguishable from bilateral nephrectomy. Am J Physiol Renal Physiol 2007; 293(1):F30-40.

3.Doi K, Rabb H. Impact of acute kidney injury on distant organ function: recent findings and potential therapeutic targets. Kidney Int 2016; 89(3):555-564.

4. Kelly KJ. Distant effects of experimental renal ischemia/reperfusion injury. J Am Soc Nephrol 2003; 14(6):1549-58.

5.Kizilbash SJ, Kashtan CE, Chavers BM, Cao Q, Smith AR. Acute kidney injury and the risk of mortality in children undergoing hematopoietic stem cell transplantation. Biol Blood Marrow Transplant 2016; 22(7):1264-1270.

6. Woodman R, Lockette W. Alpha-methyltyrosine inhibits formation of reactive oxygen species and diminishes apoptosis in PC12 cells. Brain Research 2009; 1296:137-147.

7. Young IS, Woodside JV. Antioxidants in health and disease. J Clin Pathol 2001; 54(3):176-86.

8. Yu F, Liang H, Xin S. Renal ischemia reperfusion causes brain hippocampus oxıdative damage and inhibition effect. Afr J Tradit Complement Altern Med 2016; 13(5):61-66

9. Emre MH, Erdogan H, Fadillioglu E. Effect of BQ-123 and nitric oxide inhibition on liver in rats after renal ischemia-reperfusion injury. Gen Physiol Biophys 2006; 25(2):195-206.9.

10. Nielsen FH. Biochemical and physiologic consequences of boron deprivation in humans. Environ Health Perspect 1994; 102(7):59-63.

11. Murray FJ. A comparative review of the pharmacokinetics of boric acid in rodents and humans. Biol Trace Elem Res 1998; 66(1-3):331-41

12. Ince S, Kucukkurt I, Cigerci IH, Fatih Fidan A, Eryavuz A. The effects of dietary boric acid and borax supplementation on lipid peroxidation, antioxidant activity, and DNA damage in rats. J Trace Elem Med Biol 2010; 24(3):161-164. 13. Türkez H, Geyikoglu F, Tatar A, Keles S, Ozkan A. Effects of some boron compounds on peripheral human blood. Z Naturforsch C 2007; 62(11-12):889896.

14. Kucukkurt I, Ince S, Demirel HH, Turkmen R, Akbel E, Celik Y. The Effects of Boron on Arsenic-Induced Lipid Peroxidation and Antioxidant Status in Male and Female Rats. J Biochem Mol Toxicol 2015; 29(12):564-571.

15. Colak S1, Geyikoglu F, Keles ON, Türkez H, Topal A, Unal B. The neuroprotective role of boric acid on aluminum chloride-induced neurotoxicity. Toxicol Ind Health 2011; 27(8):700-710.

16. Ohkawa H, Ohishi N, Yagi K. Assay for lipid peroxides in animal tissues by thiobarbituric acid reaction. Anal Biochem 1979; 95(2):351-358.

17. Srivastava SK, Beutler E. Glutathione metabolism of the erythrocyte. The enzymic cleavage of glutathione-haemoglobin preparations by glutathione reductase. Biochem J 1970; 119(3):353-357.

18. Dejam A, Hunter CJ, Schechter AN, Gladwin MT. Emerging role of nitrite in human biology, Blood Cells Mol Dis 2004; 32(3):423-429.

19. Sun Y, Oberley LW, Li Y. A simple method for clinical assay of superoxide dismutase. Clin Chem 1988; 34(3):497-500.

20. Gornall AG, Bardawill CJ, David MM. Determination of serum proteins by means of the biuret reaction. J Biol Chem 1949; 177(2):751-766.

21. Yildirim A, Gumus M, Dalga S, Sahin YN, Akcay F. Dehydroepiandrosterone improves hepatic antioxidant systems after renal ischemia-reperfusion injury in rabbits. Ann Clin Lab Sci 2003; 33(4):459-464

22. Khastar H. Protective effects of vitamin E against liver damage caused by renal ischemia reperfusion. Ren Fail 2015; 37(3):494-496.

23. Khastar H, Kadkhodaee M, Sadeghipour HR, Seifi B, Hadjati J, Najafi A et al. Liver oxidative stress after renal ischemia-reperfusion injury is leukocyte dependent in inbred mice. Iran J Basic Med Sci 2011; 14(6):534-539.

24. Grams ME, Rabb H. The distant organ effects of acute kidney injury. Kidney Int 2012; 81(10):942-948.

25. Mohora M, Boghianu L, Muscurel C, Duta C, Dumitrache C. Effects of boric acid on redox status in the rat liver. Rom J Biophys 2002; 12(3-4):77-82. 


\section{OP-083 \\ RENAL ISCHEMIA-REPERFUSION EFFECT ON SPLEEN AS \\ REMOTE TISSUE DAMAGE AND ROLE OF BORIC ACID}

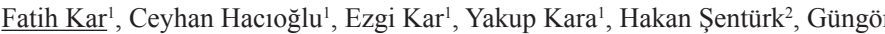
Kanbak

${ }^{1}$ Eskisehir Osmangazi University, Faculty of Medicine, Department of Medical Biochemistry, Eskisehir

${ }^{2}$ Eskisehir Osmangazi University, Faculty of Arts and Sciences, Department of Biology, Eskisehir

OBJECTIVES: Recent studies have shown the effects of distant tissue on renal ischemia/reperfusion $(\mathrm{I} / \mathrm{R})$ damage in some organs such as the brain, liver, pancreas and spleen. The aim of this study was to examine the therapeutic effect of Boric Acid (BA) due to the properties of different doses against distant tissue splenic injury, which is caused by oxidative stress induced by renal I/R. MATERIALS and METHODS: In the study, 35 Spraque Dawley rats were divided into five groups 7 animals in each group. Sham, I/R, I/R $+50 \mathrm{mg} / \mathrm{kg} \mathrm{BA}, \mathrm{I} /$ $\mathrm{R}+100 \mathrm{mg} / \mathrm{kg} \mathrm{BA}$ and $\mathrm{I} / \mathrm{R}+200 \mathrm{mg} / \mathrm{kg} \mathrm{BA}$. Ischemia was induced for 45 minutes, followed by 24 hours of reperfusion. In I/R+BA groups, BA was administered intraperitoneally 10 minutes before reperfusion, unlike the I/R group. MDA, GSH, and NO levels were measured spectrophotometrically in rat spleen tissues. RESULTS: Regarding the spleen tissue, there was statistically significant decrease in GSH levels and significant increase in MDA and NO levels in the renal $I / R$ group compared to the sham group and $B A$ groups $(P<0.01)$. In contrast, compared to the $\mathrm{I} / \mathrm{R}$ group treated with $\mathrm{BA}$ at different doses prior to reperfusion, $50 \mathrm{mg} / \mathrm{kg}$ BA administration showed significant decrease in MDA and NO levels, while an increase in GSH level was observed. CONCLUSIONS: In this study, it was concluded that $50 \mathrm{mg} / \mathrm{kg}$ BA is the most appropriate dose because Boric acid is a moderately toxic compound. BA demonstrates a protective effect against oxidative stress on the spleen as distant tissue damage in rats subjected to renal $I / R$ Keywords: Renal Ischemia/Reperfusion, Spleen, Boric Acid, Oxidative Damage

\section{Introduction}

Renal ischemia reperfusion (I/R) injury may occur in various clinical conditions such as multiple organ damage, inflammation, shock, and surgery [1]. As a result of distant tissue damage of renal $I / R$, it causes morbidity and mortality due to multiple organ failure. Although many studies have shown that kidney damage affects different distant organs such as the lungs, liver and pancreas but the effect on the spleen is still unclear [2]

Reactive oxygen species (ROS) and inflammation processes are the mechanisms used in the pathogenesis of remote organ injury [3]. Reactive oxygen species are highly unstable oxygen molecules that can cause cellular damage by affecting the inflammatory markers as well as by oxidizing lipids in the cell membrane structure [4]. The role of oxidative stress in spleen injury has been shown in several studies [5]. Endogenous antioxidants such as superoxide dismutase (SOD) and catalase (CAT) and glutathione (GSH) reduce ROS production in renal $\mathrm{I} / \mathrm{R}$-induced distant tissue damage. Therefore, new drugs and compounds known to have exogenous antioxidant properties are widely investigated in ischemia and reperfusion injury [5]. Renal I/R can induce inflammatory response with the synthesis of chemokines and cytokines affected by oxidative stress and activate the immune response. The synthesis of proinflammatory cytokines such as IL- 6 and TNF- $\alpha$ plays an important role in the development of inflammatory reaction and acute kidney injury (AKI) [6]

The regulation of inflammation occurring during renal I/R depends on the effect of the spleen, which is one of the most important immune organs in the body, on inflammatory mediators. The spleen appears to play an important role in cytokine production and disease progression, indicating a potential therapeutic target for a number of ischemia-related diseases [7]. More research is needed to clarify the role of the spleen in damage caused by ischemia-reperfusion and to develop new therapeutic strategies.

Boron, Boric acid (BA) and its compounds, which are considered as essential elements by the World Health Organization, regulate antioxidant system activity and immune system functions in human and animal metabolism [8]. Previous studies have shown that both boric acid and borate perform reversible interactions with biomolecules containing cis-hydroxyl groups and affect NAD+ functions [9]. There are limited studies on how boric acid reduces ROS effects by inducing antioxidant defense mechanisms and inflammation process $[10,11]$. The use of boron and its compounds (BA) in medicine is increasing day by day. Specifically, determining dose studies and explaining mechanisms are extremely important [12].

The purpose of this study is to investigate the effects of 50,100 and $200 \mathrm{mg} / \mathrm{kg}$ BA on the antioxidative activities and proinflammatory cytokines of the spleen tissue in renal I/R-induced Sprague Dawley (SD) rats. In addition, the histological effects of boron on the spleen tissue structure were studied.

Material and Methods

Animals and Surgical Procedure: The ethics committee for the study received 657 decision numbers from Eskisehir Osmangazi University Animal Experiments Local Ethics Committee (HADYEK). 3-4 months old SD female rats, weight between 180 to 220 grams, were used in this study. A total of thirty five rats were randomly divided into five groups $(n=7)$. The rats were maintained in rooms that had 12:12 light/dark illumination, heat $\left(22 \pm 2^{\circ} \mathrm{C}\right)$ and humidity $(45-50 \%)$ automatically adjusted during the experiment. Animals were allowed to adapt to ambient conditions for one week before starting the experiment.

Group 1 animals were determined as sham operation group. Nephrectomy was performed in this group of animals, and after 15 days of healing, $0.5 \mathrm{ml}$ saline was injected intraperitoneally without ischemia. Group 2 animals were determined as I/R group. Nephrectomy was performed in this group of animals, and after 15 days of healing, 45 -minute ischemia was performed to each animal. $0.5 \mathrm{~mL}$ of saline was injected intraperitoneally to the rats 10 minutes before the reperfusion time. Groups 3, 4 and 5 were determined as treatment groups with 50,100 and $200 \mathrm{mg} / \mathrm{kg} \mathrm{BA}$, respectively. Firstly, nephrectomy was performed to the animals in these groups and then the determined BA doses were administered intraperitoneally by dissolving in $0.5 \mathrm{ml}$ of saline after 15 days of recovery. All the animals were sacrificed by taken intracardiac blood under anesthesia at the end of 24-hour reperfusion.

At the end of the experimental procedures, intracardiac blood and spleen were collected from the animals for biochemical analysis. Blood samples were centrifuged at $3000 \mathrm{rpm}$ for $10 \mathrm{~min}$ to obtain serum. The spleen tissues and serum samples of each animal in the groups were stored in the $-80^{\circ} \mathrm{C}$ freezer until analysis time.

Biochemical Analyses of Spleen Tissues: The levels of malondialdehyde (MDA), glutathione (GSH) and nitric oxide (NO) were determined manually by using spectrophotometric methods with the obtained spleen tissue supernatants. In the measurement of oxidative stress markers in spleen tissues, lipid peroxidation was measured according to the method of MDA used by Ohkawa et al. [13]. GSH levels were measured in spleen tissue homogenate according to the method reported by Beutler et al. [14]. For the measurement of NO levels in tissue samples, the method reported by Cortas was applied [15] TNF- $\alpha$ and IL-6 levels from proinflammatory cytokines were measured according to the Quantikine manufacturer's instructions and guidelines using the enzyme-linked immunosorbent assay (ELISA) kit specific for rat cytokines. Protein contents of spleen tissues was measured by the biuret method mentioned in Gornall's study [16]

Histological Analyses of Spleen Tissues: Spleen tissues were obtained $24 \mathrm{~h}$ after reperfusion in all groups. Tissue specimens were fixed in $10 \%$ formalin and embedded in paraffin. Sections were cut $5-\mu \mathrm{m}$ thick and stained with hematoxylin-eosin for light microscope examination. The light microscopic images of the rat spleens of all experimental groups were evaluated at different magnifications.

Statistical Analyses: The results of the methods mentioned in this study were analyzed as mean \pm standard deviation (SD) and using SPSS 21.0 for Windows. The difference between the mean values between the groups was evaluated using one-way analysis of variance (ANOVA). In all reported $p$ values, $p<0.01$ was considered significant. All comparisons were made between the sham, I/R and BA treatment groups.

Results

MDA, NO, GSH and TNF- $\alpha$, IL-6 levels in splenic tissue samples of all groups: Statistical analysis using the data obtained from laboratory analysis is presented in this section. Proinflammatory cytokine levels (TNF- $\alpha$, IL-6) and oxidative stress parameters (MDA, GSH and $\mathrm{NO}$ ) were determined in rat spleen tissue. Our previous studies have shown the effects of serum BUN, creatinine levels and other biochemical and histological analyses on renal injury after I/R [17] This study has shown for the first time that different doses of BA may affect the various steps of renal I/R pathophysiological pathways and distant tissue spleen damage. The results of MDA, GSH and NO levels in spleen tissues are shown in Table 1

Table 1: The effects of 50,100 and $200 \mathrm{mg} / \mathrm{kg}$ boric acid (BA) treatments on MDA, NO, GSH and TNF- $\alpha$, IL- 6 levels in splenic tissue of rats induced by renal ischemia-reperfusion (I/R) (Means $\pm \mathrm{SD}$ ).

$\begin{array}{llllll}\text { Parameters } & \text { Group 1 }(\mathrm{n}=7) & \text { Group 2(n=7) } & \text { Group 3(n=7) } & \text { Group 4(n=7) } & \text { Group 5(n=7) } \\ \text { MDA (nmol/mg protein) } & 3.03 \pm 0.37 & 8.17 \pm 0.40 \mathrm{a} & 5.02 \pm 0.34 \mathrm{a}, \mathrm{b} & 6.58 \pm 0.40 \mathrm{a}, \mathrm{b} & 7.14 \pm 0.32 \mathrm{a}, \mathrm{b}, \mathrm{c} \\ \text { NO }(\mu \text { mol/mg protein }) & 26.23 \pm 1.67 & 35.49 \pm 1.77 \mathrm{a} & 29.45 \pm 0.94 \mathrm{a}, \mathrm{b} & 31.91 \pm 0.59 \mathrm{a}, \mathrm{b} & 33.0 \pm 0.69 \mathrm{a} \\ \text { GSH (nmol/mg protein }) & 11.78 \pm 0.97 & 6.59 \pm 0.84 \mathrm{a} & 8.97 \pm 0.54 \mathrm{a}, \mathrm{b} & 7.87 \pm 0.46 \mathrm{a} & 7.16 \pm 0.43 \mathrm{a} \\ \text { TNF- } \alpha(\mathrm{pg} / \mathrm{mg} \text { protein }) & 21.92 \pm 1.31 & 84.59 \pm 1.44 \mathrm{a} & 50.21 \pm 2.49 \mathrm{a}, \mathrm{b} & 75.66 \pm 3.50 \mathrm{a}, \mathrm{b}, \mathrm{c} & 81.48 \pm 1.64 \mathrm{a}, \mathrm{c} \\ \text { IL-6 }(\mathrm{pg} / \mathrm{mg} \text { protein) } & 14.28 \pm 1.53 & 59.71 \pm 2.18 \mathrm{a} & 36.68 \pm 1.03 \mathrm{a}, \mathrm{b} & 51.74 \pm 2.27 \mathrm{a}, \mathrm{b}, \mathrm{c} & 56.41 \pm 1.41 \mathrm{a}, \mathrm{c}\end{array}$

$\mathrm{a}: \mathrm{p}<0.01$ compared with Group 1, $\mathrm{b}: \mathrm{p}<0.01$ compared with Group 2 $\mathrm{c}: \mathrm{p}<0.01$ compared with Group 3

Compared to the sham group (Group 1), NO and MDA levels were significantly higher in splenic tissue of the I/R group (Group 2). NO and MDA levels were significantly lower in the BA groups (Group 3, 4 and 5) administered at differen doses compared to the I/R group. The GSH levels of the spleen tissues was significantly lower in the I/R group compared to the sham group. In addition, there was a significant increase in BA-treated groups compared to I/R group $(\mathrm{p}<0.01)$

The level of proinflamatuar cytokines TNF- $\alpha$ and IL-6 levels were increased in the $\mathrm{I} / \mathrm{R}$ groups compared to sham. While $50 \mathrm{mg} / \mathrm{kg}$ BA resulted in a moderate decrease in TNF- $\alpha$ and IL-6 levels compared to I/R group $(\mathrm{p}<0.01)$, no significant difference was observed in other 100 and $200 \mathrm{mg} / \mathrm{kg} \mathrm{BA}$ applications (Table 1). Histological analysis of spleen tissues : The light microscopic images of the rat spleens of all experimental groups are shown in Figure 1. The cortex and parenchymal tissue of the sham group rat spleen were normal. In the spleen of ischemia group, white pulp degeneration and red pulp contraction were observed with parenchymal tissue damage. It also drew attention to the thickened trabecular structures. It was observed that parenchymal tissue damage decreased and white pulp and red pulp structures were observed close to normal in rat spleen belonging to group 3 . Thickening was observed in trabecular structures. The parenchyma tissue damage decreased in the rat spleens belonging to the group 4 and white pulp, red pulp and trabecular structures were observed to be close to 
normal. Parenchyma tissue damage decreased in rat spleens belonging to group 5 , while some white pulp damage was observed to continue, but near-normal spleen structure was observed.
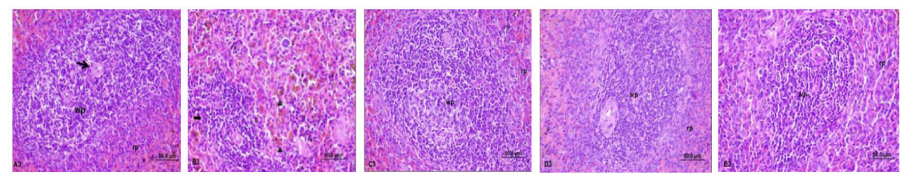

Figure 1: Light microscopic images of the rat spleens of different experimental

groups (HE, scale bar: $50.0 \mu \mathrm{m}$ ).
Discussion

The spleen plays an important role in maintaining the body's normal immune function. Oxidative stress and other processes caused by renal ischemia reperfusion may affect functional changes on the spleen and directly affect the immune and resistance of the body [18]. Boron is a necessary trace element with various functions for living organisms. Like many trace elements, because of high doses and long-term use, it can cause toxic effects on tissues and organs [19].

The most likely mechanism is the inactivation of ROS by acting as a ROS cleanser because BA increased glutathione levels in this study while decreasing MDA and NO levels. However, in the studies performed to determine the appropriate dose, better results were obtained in the groups given $50 \mathrm{mg} / \mathrm{kg} B A(\mathrm{p}<0.05) .5$ and $10 \mathrm{mg} / \mathrm{kg} \mathrm{BA}$ showed that serum MDA levels were significantly decreased and serum total antioxidant capacity (TAC) levels increased and this could lead to antioxidant activity by decreasing lipid peroxidation in Çakır et al. study [20]. In another study conducted, it has been shown that the appropriate amount of boron addition increases the activity of antioxidant enzyme and decreases lipid peroxidation by increasing free radical clearance of the spleen [21]. Therefore, low boron concentration may promote spleen development and functions during $\mathrm{I} / \mathrm{R}$. The addition of $80-640 \mathrm{mg} / \mathrm{L}$ boron in drinking water has been shown to seriously impair the development of the spleen and immune function. In addition, it has been shown that by adding $80 \mathrm{mg} / \mathrm{L}$ boron concentration, MDA content increases and antioxidant enzyme activities decrease, this concentration causes significant negative effects on spleen antioxidant function and oxygen [22]. New drug development and treatment strategies have been targeted on oxidative stress after RIR injury, including inhibition of superoxide formation or increased antioxidants. Some researchers have found that selective blocking of NO production sheds light on the underlying molecular mechanisms that cause oxidative stress due to I/R injury and its effects on other tissues. These results were consistent with the data we found in our previous and present study [17]. In a similar study, the use of high-dose boron decreased the spleen weight at different degrees and histopathological changes of the spleen were observed [21]. Reperfusion with activation of macrophages in tissue causes an increase in proinflammatory cytokine levels such as IL- 6 and TNF- $\alpha$. This results in damage to distant organs [23] In the study evaluating inflammation processes after I/R, BA has been shown to reduce the release of proinflammatory cytokines such as TNF- $\alpha$ and IL- 6 and protect against cell death caused by oxidative stress [24]. Our findings are consistent with the current literature, but dose studies on humans and animals should be continued.

In some experimental studies, the potential roles and some functions of spleen are shown in ischemic AKI. Ischemic preconditioning in the spleen has been shown to provide protection from AKI from splenocytes from mice after RIR. Studies have shown that the spleen has some etiology in the RIR and related AKI, but it has not shown that it has a one-way effect [25].

Different roles of the spleen before and after ischemia should be clarified and more research is needed on people. In the experimental studies conducted over many years, the possible signaling pathways and treatment strategies that connect the organs such as kidney, lung, heart, spleen and intestine have been examined not only for ischemia but also for some other diseases. In this study, we have focused on spleen as distant organ effects of RIR from a oxidative stress and preinflammatory perspective. Targeting remote tissue damage pathways and new drug substances identified as dose studies such as Boric acid should lead to new therapeutic strategies against AKI and reduce high mortality during AKI-related multiple organ failure.

Acknowledgement: This study was supported by Eskişehir Osmangazi University Scientific Research Projects Commission as a project (Project No: 2018-2035). Conflict of interest statement: The authors report no conflict of interest.

Ethical Considerations: This study was approved by the Animal Care and Use Committee of the Eskişehir Osmangazi Universiy (Project No: 2018/657).

References

1. Laura E, Heitham T. Inflammatory mechanisms of organ crosstalk during ischemic acute kidney injury. Intern J Nephrol 2012;505197.

2. Hussein A, Abd-Elkhabir A, Abozahra A, et al. Pancreatic injury secondary to renal ischemia/reperfusion (I/R) injury: possible role of oxidative stress. Physiol Res 2013;63:47-55

3. Marian V, Dieter L, Jan M, Mark T, Milan M, Joshua T. Free radicals and antioxidants in normal physiological functions and human disease. Intern $\mathrm{J}$ Biochem Cell Biol 2007;39:44-84.

4. Kinsey GR, Li L, Okusa MD. Inflammation in acute kidney injury. Nephron Exp Nephrol 2008;109:e102.

5. Abogresha NM, Greish SM, Abdelaziz EZ, Khalil WF. Remote effect of kidney ischemia-reperfusion injury on pancreas: role of oxidative stress and mitochondrial apoptosis. Archives of medical science: AMS, 2016;12.2:252.

6. Jang HR, Rabb H. The innate immune response in ischemic acute kidney injury. Clin Immunol 2009;130:41.
7. Xiangyu Z, Yingiian Z. A new hypothesis: the immunomodulatory effects of mesenchymal stromal cell derived extracellular vesicles in ischemic kidney injury partly through spleen. Nephrol Open J. 2015;1(2):25-29.

8. W.H. Organization, et al.Trace Elements in Human Nutrition and Health, WHO 1996;0-361.

9. Kim DH, Marbois BN, Faull KF, Eckhert CD. Esterification of borate with NAD (+) and NADH as studied by electrospray ionization mass spectrometry and B-11 NMR spectroscopy, J. Mass Spectrom 2003;38(6):632-640.

10. Uluisik I, Karakaya HC, Koc A. The importance of boron in biological systems. Journal of Trace Elements in Medicine and Biology 2018;45:156-162

11. Moseman RF. Chemical disposition of boron in animals and humans, Environ. Health Perspect. 1994;102;113-117.

12. Kane RC, Bross PF, Farrell AT, Pazdur R, Velcade R. USFDA approval for the treatment of multiple myeloma progressing on prior therapy, Oncologist 2003;8(6):508-513.

13. Ohkawa H, Ohisi N, Yagi K. Assay for Lipid Peroxides in Animal Tissues by Thiobarbituric Acid Reaction. Analytical Biohemistry, 1979;95:351-358.

14. Buetler E, Duron O, Barbara MK. Improved method for the determination of blood glutathione. Journal of Laboratory and Clinical Medicine 1963;61:882-888. 15. Cortas NK, Wakid NW. Determination of inorganik nitrate in serum and urine by a kinetik cadmium reaction method. Clinical Chemistry 1990;36:1440-1443. 16. Gornall AG, Bardawill CJ, David MM. Determination of serum proteins by means of the biuret reaction. J Biol Chem 1949; 177(2):751-766.

17. Sentürk H, Kar F, Hacioğlu C, Kanbak G. Renal İskemi-Reperfüzyon ile İndüklenmiş Oksidatif Stres Hasarının Pankreas Üzerine Etkisi: Doza Bağımlı Borik Asidin Rolü. KSU J. Agric Nat 2018;21(6):944-949.

18. Mebius RE, Kraal G. Structure and function of the spleen. Nat Rev Immunol 2005;5:606-616

19. Pahl MV, Culver BD, Vaziri ND. Boron and the kidney review. J Ren Nutr 2005;15(4):362-370

20. Cakir S, Eren M, Senturk M, Sarica ZS. The Effect of Boron on Some Biochemical Parameters in Experimental Diabetic Rats. Biol Trace Elem Res 2018;184(1):165-172.

21. Ince S, Keles H, Erdogan M, Hazman O, Kucukkurt I. Protective effect of boric acid against carbon tetrachloride-induced hepatotoxicity in mice. Drug Chem Toxicol 2012;35(3):285-292

22. Hu Q, Li S, Qiao E, Tang Z, Jin E, Jin G, Gu Y. Effects of boron on structure and antioxidative activities of spleen in rats. Biological trace element research, 2014; $158.1: 73-80$

23. Basbug M, Yıldar M, Yaman İ, Özkan ÖF, Akşit H, Cavdar F, et al. Effects of boric acid in an experimental rat model of hepatic ischemia-reperfusion injury. Acta Medica Mediterr 2015;31:1067-1073.

24. Yildar M, Aksit H, Korkut O, Ozyigit MO, Sunay B, Seyrek K: Protective effect of 2-aminoethyl diphenylborinate on acute ischemia-reperfusion injury in the rat kidney. J Surg Res 2014;187(2):683-689.

25. Wystrychowski W, Filipczyk L, Cierpka L, Obuchowicz E, Więcek A, Wystrychowski A. Splenectomy attenuates the course of kidney ischemiareperfusion injury in rats. In: Transplantation proceedings. Elsevier 2014;46(8):2558-2561

\section{OP-084 \\ THE VIEW OF THE STUDENTS ABOUT BIOCHEMISTRY COURSE FROM MIDDLE EAST COUNTRIES}

Rabia Semsi ${ }^{1}$, Erdal Ergünol ${ }^{2}$, Aylin Sepici Dinçel ${ }^{1}$

${ }^{1}$ Gazi University, Faculty of Medicine, Department of Medical Biochemistry, Ankara

${ }^{2}$ Cyprus Health and Social Sciences University, Faculty of Dentistry, TRNC

OBJECTIVES: This study was done to investigate the demographic background of incoming students from Middle Eastern countries and to evaluate their biochemistry education and academic success

MATERIALS and METHODS: The study included the students from Middle East countries Term I $(n=29)$ and Term II $(n=17)$ of Cyprus Health and Social Sciences University Faculty of Dentistry. Biochemistry is taught for 2 hours (lectures) every week in the curriculum (academically oriented, theoretically). Students' academic performance was evaluated with quizzes, midterm and final exams.

RESULTS: Overall, the study included 46 students $(58.7 \%, n=27$, male and $41.3 \%, \mathrm{n}=19$, female). The demographic background of students was: $30.43 \%$ from Iran, 23.91\% from Syria, 8.75\% from Iraq and 6.55\% from Egypt, $4.35 \%$ from Jordan. The rest, $2.17 \%$ came from other countries (Bahrain, Afghanistan, Pakistan, TC, USA, Germany, Lebanon and Palestine). The questions of main subjects were evaluated separately and as an example from the group of lipid questions about $57.89 \%$ of the students were successful. According to the final exam, $47.36 \%$ of these students in Term I were successful while $59.09 \%$ of the students in Term II were successful.

CONCLUSIONS: The main purpose of biochemistry course at universities is the association of the basic structure and functions of macromolecules to human metabolism. Instructors need to review their course content for the students and use new methods for the understanding of the lessons. Besides all, incoming students from Middle East countries have more problems with language or adaptation. This situation is reflected to their academic success. As a result, we thought that it would be appropriate to give basic theoretical knowledge in the biochemistry curriculum of the related faculty.

Keywords: Biochemistry, Health Science Education, Descriptive Analysis 


\section{OP-085 \\ TRANSITION TO GLUCOMETER INTEGRATED TO THE}

\section{INFORMATION MANAGEMENT SYSTEM: A SURVEY STUDY}

Levent Deniz, Merve Șenyüzlü, Hümeyra Öztürk Emre, Berrin Berçik İnal Istanbul Training and Research Hospital, Medical Biochemistry, Istanbul

OBJECTIVES: The Point of Care Testing is a test performed at or near the patient resulting in possible changes in patient care. In our 500-bed hospital, 40 manual glucose meters and 15.000 strips are used monthly in various clinics. However, our laboratory could not follow these tests thoroughly because of the high number of users. Therefore, as of 01.01 .2018 , the glucose meters was integrated to the Laboratory Management Information System (Accu-Check Inform II, Roche). Later, a survey study was conducted to observe the effects of this change in the clinics. MATERIALS and METHODS: Face to face interviews were conducted with 27 nurses and 27 physicians from Internal Medicine, Intensive Care, Physical Therapy, ENT and Emergency departments using 10 elective questions. RESULTS: According to the results, we were informed that our physicians and nurses were satisfied with the continuous training given by our laboratory, the results of the new system and the users' being registered into the system, and the fast and retrospective obtaining of the results. Besides, according to the survey result, there is a request to increase the number of devices and of the measurement of ketone level at the same time with that of the glucose. CONCLUSIONS: The results and following-up of the users through the information system will both raise user awareness and protect the employees legally. The advantages of the system are the reliability of the results, the central laboratory's easy following-up the internal quality controls, the names of the users, the quality indicators and the number of strips. Keywords: Glucometer, Point of Care Testing, Laboratory Management Information System

\section{OP-087 \\ EFFECT OF ANGIOTENSIN (1-7) TREATMENT ON OXIDATIVE STRESS PARAMETERS, IMA AND MPO LEVELS IN DIABETES}

Nazlı Otuzaltı1 ${ }^{1}$ İkbal Özen Küçükçetin ${ }^{2}$, Esra Akcabag $^{3}$, Sadi Satılmış Özdem³ Uğur Dalaman ${ }^{4}$, Nazmi Yaras ${ }^{4}$, Sebahat Özdem ${ }^{1}$

${ }^{1}$ Akdeniz University Medical Faculty, Departments of Medical Biochemistry ${ }^{2}$ Akdeniz University Faculty of Health Sciences, Department of Nutrition and Diethetics

${ }^{3}$ Akdeniz University Medical Faculty, Departments of Medical Pharmacology

${ }^{4}$ Akdeniz University Medical Faculty, Department of Biophysics

OBJECTIVES: In this study effect of chronic angiotensin (1-7) (Ang1-7), a novel peptide of renin-angiotensin system, treatment on ischemia-modified albumin, myeloperoxidase levels and oxidative stress parameters known to play a role in development of diabetic complications was investigated in diabetic rats. MATERIALS and METHODS: 3 months-aged male rats were grouped into 4: Experimental diabetes was induced with single i.p. streptozotocin (STZ) injection in Diabetes $(\mathrm{D}, \mathrm{n}=10)$ and Diabetes+Ang1-7 $(\mathrm{DA}, \mathrm{n}=6)$ and STZvehicle was administered to Control $(\mathrm{C}, \mathrm{n}=10)$ and Control+Ang1-7 (CA, $\mathrm{n}=8$ ) groups. Four weeks later, $576 \mu \mathrm{g} / \mathrm{kg} /$ day s.c. Ang1-7 for 4 weeks was administered to DA and CA, whereas Ang1-7-vehicle to C and D groups. Thenafter, serum levels of total oxidative stress (TOS, umol/L), total antioxidant capacity (TAS, mmol/L), total sulphydryl (umol/L), advanced protein oxidation products (AOPP, umol/L), ischemia-modified albumin (IMA, U/ $\mathrm{mL})$ and myeloperoxidase (MPO, U/L) were measured spectrophotometrically. RESULTS: TOS, AOPP and IMA levels increased $(14.69 \pm 4.77,11.19 \pm 1.40$, $10.85 \pm 1.30 ; 15.51 \pm 7.69,10.42 \pm 2.45,9.86 \pm 3.15 ; 122.20 \pm 36.70,91.40 \pm 13.45$, $84.60 \pm 4.47$, respectively) whereas TAS and sulfhydryl decreased significantly $(2.08 \pm 0.80,2.83 \pm 0.97,2.85 \pm 0.84 ; 743.10 \pm 338.30,1042.00 \pm 104.40,1046.00$ \pm 118.40 , respectively) in D compared to $\mathrm{C}$ and $\mathrm{A}$ groups with no significant differences between $\mathrm{C}$ and $\mathrm{A}$ groups. Although TOS, AOPP, IMA increased whereas TAS and sulfhydryl decreased in D compared to DA, only IMA levels differed significantly $(p=0,049)$. MPO levels differed significantly only between K and DA. CONCLUSIONS: It was concluded that decreament in certain oxidative stress parameters, especially IMA, and partial increament in antioxidantdefenses observed with chronic Ang 1-7 treatment may be useful in preventing diabetic complications. This study was supported by TUBITAK with the project number TUBITAKSBAG 1175066

Keywords: Angiotensin (1-7), Diabetes Mellitus, Oxidative Stress

\section{OP-088 \\ DETERMINATION OF URINARY PODOCIN AND PODOCALYXIN} LEVELS BY LIQUID CHROMATOGRAPHY-MASS SPECTROMETRY

Bilge Karatoy Erdem, Halide Akbas

Akdeniz University, Medical Faculty, Department of Biochemistry, Antalya

OBJECTIVES: The detection of podocyte injury is important for the evaluation of renal diseases. Urinary markers of podocyte injury could be defined by the measurement of podocin and podocalyxin in the urine. The aim of this study was to multiplex determinate of urinary podocytes, based on the detection of podocytespecifictrypticpeptidesbyliquidchromatography-massspectrometry(LC-MS/MS).
MATERIALS and METHODS: Recombinant human podocin, podocalyxin and synthetic stable isotope-labeled tryptic peptides were obtained. Peptide standard solutions were prepared at the following concentrations: $0,1.562,3.125,6.25$, $12.5,25$ and $50 \mathrm{ng} / \mu \mathrm{L}$. RapiGest ${ }^{\mathrm{TMSF}}$ were added to urine samples before digestion and the samples were incubated at $60^{\circ} \mathrm{C}$ for $40 \mathrm{~min}$. Urine samples were digested overnight at $37{ }^{\circ} \mathrm{C}$ by the addition of trypsin. The stable isotopelabeled internal standard peptides were added to each sample, then analyzed with positive electrospray ionization mode in a triple quadripole LC-MS/MS RESULTS: Inter/intra assay precisions and accuracies of the assay were below $10 \%$ and between $80 \%$ and $100 \%$, respectively. The values of r-squared (r2) were found for podocin 0,999, for podocalyxin as 0,994 in generated calibration curves. The time of the analysis was 12-13 minutes (min) for both parameters (Podocin: 11 min, Podocalyxin: 7 min). The accuracy of the test was also evaluated with ELISA methods. CONCLUSIONS: Our method is a reliable alternative for the simultaneously quantification of podocin and podocalyxin in urine samples. Determination of the urinary podocytes, based on the detection of podocyte-specific tryptic peptides by LC-MS/MS may provide diagnostic and prognostic information in renal diseases Keywords: podocin, podocalyxin, LC-MS/MS

\section{OP-089}

THE ROLE OF METHYLGLYOXAL LEVELS IN DIABETES DIAGNOSIS

Duygu Eryavuz ${ }^{1}$, Sedat Abuşoğlu ${ }^{1}$, Mehmet Nuri Atalar ${ }^{3}$, Süleyman Baldane ${ }^{2}$, Abdullah Sivrikaya $^{1}$, Oğuzhan Tok ${ }^{1}$, Mehmet Yıldırımel ${ }^{1}$, Ali Ünlü ${ }^{1}$

${ }^{1}$ Selcuk University Faculty of Medicine, Department of Biochemistry, Konya

${ }^{2}$ Selcuk University Faculty of Medicine, Department of Internal Medicine, Endocrinology, Konya

${ }^{3}$ Igdir University, Tuzluca Vocational School, Therapy and Rehabilitation Department, Igdir

OBJECTIVES: Diabetes Mellitus (DM) is a metabolic disorder characterized by the presence of chronic hyperglycemia accompanied by impairment in the metabolism of carbohydrates, lipids and proteins. The cause is either impaired insulin secretion or impaired insulin action or both. During chronic hyperglycaemia increased production of methylglyoxal occurs which may result in excessive production of advanced glycation end products (AGEs). Methylglyoxal (MG) is a reactive dicarbonyl intermediate and a precursor of advanced glycation end products (AGEs). Recent studies suggested a role for MG in insulin resistance and beta-cell dysfunction. Our goal in this study is to clarify MG's role in diabetes diagnosis, progression and treatment. MATERIALS and METHODS: 41 control, 34 prediabetic, 40 controlled type 2 diabetic, 34 uncontrolled type 2 diabetic subjects were enrolled to this study. MG levels were measured at $315 \mathrm{~nm}$ wavelength in a UV detector using a C18 column in ultra-performance liquid chromatography. RESULTS: Serum MG levels were significantly higher in patients with prediabetes $(8,34(3,48-16,42))$, controlled $(14,51(4,2-31,28))$ and uncontrolled $(15,81(2,44-33,64))$ type 2 diabetes than in controls $(4,29(1,86-7,78) ; \mathrm{p}<0.001)$ for all compared groups. There was no significant difference in serum MG levels between controlled and uncontrolled diabetic subjects $(\mathrm{p}=0.61)$. CONCLUSIONS: Our findings demonstrate hyperglycemia increased methylglyoxal and AGEs generation in prediabetic and diabetic patients. Thus MG playing an important role in the pathophysiology of diabetes mellitus. Briefly, we thinks of methylglyoxal levels monitoring in diabetic patients contribute for diabetes diagnosis and treatment. Keywords: Diabetes mellitus, insulin resistance, methylglyoxal

\section{OP-090 \\ EARLY POSTOPERATIVE CHANGES OF SPHINGOMYELINS AND CERAMIDES AFTER SLEEVE GASTRECTOMY}

Hakan Özer1, İbrahim Aslan², Mehmet Tahir Oruç ${ }^{3}$, Yaşar Cöpelci ${ }^{3}$, Ebru Afșar ${ }^{4}$, Sabriye Kaya ${ }^{4}$, Mutay Aslan $^{4}$

${ }^{1}$ Internal Medicine Clinic, Antalya Research and Education Hospital, University of Health Sciences, Antalya

${ }^{2}$ Endocrinology Clinic, Antalya Research and Education Hospital, University of Health Sciences, Antalya

${ }^{3}$ Surgery Clinic, Antalya Research and Education Hospital, University of Health Sciences, Antalya

${ }^{4}$ Department of Medical Biochemistry, Faculty of Medicine, Akdeniz

University, Antalya

OBJECTIVES: This study aimed to determine early postoperative changes of serum sphingomyelin (SM) and ceramide (CER) species following laparoscopic sleeve gastrectomy (LSG).

MATERIALS and METHODS: Twenty obese patients [mean body mass index (BMI) 45,64 $\pm 6,10 \mathrm{~kg} / \mathrm{m} 2$ ] underwent LSG and normal weight control patients (mean BMI 31,51 $\pm 6,21 \mathrm{~kg} / \mathrm{m} 2$ ) underwent laparoscopic cholecystectomy Fasting blood samples were collected prior to surgery, at day 1 and day 30 after surgery. Circulating levels of $\mathrm{C} 16-\mathrm{C} 24 \mathrm{SMs}, \mathrm{C} 16-\mathrm{C} 24 \mathrm{CERs}$ and sphingosine-1-phosphate (S1P) were determined by an optimized multiple reaction monitoring (MRM) method using ultra fast-liquid chromatography (UFLC) coupled with tandem mass spectrometry (MS/MS). Ceramide-1phosphate (C1P) levels were determined by enzyme-linked immunosorbent 
assay (ELISA). Lipid profile, routine biochemical and hormone parameters were assayed by standard kit methods. Insulin sensitivity was evaluated using homeostatic model assessment for insulin resistance (HOMA IR). RESULTS: A significant decrease was observed in serum levels of very-longchain C24 SM, very-long-chain C22-C24 CERs and C1P in LSG patients after postoperation day 1 and day 30 compared to preoperation levels. At 30 days postsurgery, BMI was reduced by $11 \%$, fasting triglycerides were significantly decreased, and insulin sensitivity was increased compared to presurgery values. A significant positive correlation was found between HOMA-IR and serum levels of C22-C24 CERs in LSG patients. CONCLUSIONS: We conclude that very long chain CERs may mediate improved insulin sensitivity after LSG.

Keywords: Laparoscopic sleeve gastrectomy, sphingomyelin, ceramide

\section{OP-091}

\section{OUR LAB EXPERIENCE IN ESTABLISHING ACYLCARNITINE-} AMINOACID CUTOFFS IN NEWBORN SCREENING BY TANDEM MS

Özlem Demirelce, Özkan Özdemir, Neslihan Yıldırım Saral, Fehime Benli Aksungar, Mustafa Serteser

Acibadem Labmed Clinical Laboratories, İstanbul, Türkiye

OBJECTIVES: To evaluate distribution of acylcarnitines and aminoacid levels of normal newborn population in Turkey and to determine, compare cutoffs of inherited metabolic disorders.

MATERIALS and METHODS: Newborn screening by tandem MS from 2016 to 2018 were reviewed retrospectively. Among total 17.076 newborns, 10.000 term newborn ( $>37$ week) metabolic screening data was included for obtaining the normal population percentile distribution. Study group include newborns born in our hospitals located in various regions of Turkey. Heel prick blood samples were obtained and spotted on filter paper from $>24$ hours of age. Low birth weights $(<2500 \mathrm{gr})$, newborns at NICU and with any disorder were excluded from normal population group. RESULTS: Taking into account the concentrations of our confirmed cases in some groups from 26 searched diseases we have extracted number of newborns flagged for each analyte by using P1, P99, 4SD, R4S and CDC cutoffs. Considering the Region 4 Stork validated disease range values we have analyzed our data and chose target cutoffs that laid within the recommended intervals and than editted according to the literature, estimated effect on clinical utility, recall rates, false negative and false positive rates. Our multiple SD cutoffs settled below, within, mostly above the R4S target ranges and all were below the CDC levels. Normal population 4SD values are consistent with R4S. CONCLUSIONS: It is planned to change the values of XLeu, Met $(\mathrm{L}, \mathrm{H})$, Tyr, C0, C4 and C5 when considering the valid values in order to eliminate false positive and false negative values in target intervals according to R4S. Keywords: Tandem MS, Newborn screening, acylcarnitine, aminoacid

\section{OP-092 \\ DETERMINATION OF ENOS GENE POLYMORPHISM AND PLASMA ADMA CONCENTRATIONS IN PATIENTS WITH LUNG CANCER}

Zafer Bayraktutan $^{1}$, Ahmet Kızıltunç ${ }^{1}$, Ebubekir Bakan ${ }^{1}$, Hamit Hakan Alp ${ }^{2}$ ${ }^{1}$ Department of Medical Biochemistry, Faculty of Medicine, Atatürk University, Erzurum

${ }^{2}$ Department of Medical Biochemistry, Faculty of Medicine, Yüzüncü Y1l University, Van

OBJECTIVES: Lung cancer is the most common cancer type in our worldwide. Smoking is the most important risk factor for lung cancer. Also, it is known that genetic factors take part in occurring and developing lung cancer. Many single nucleotide polymorpisms are defined for eNOS gene. Two of them are T-786C on the promoter region of gene and G894T polymorphism on exon 7 of gene. We aimed to investigate plasma ADMA levels and eNOS T-786C and G894T polymorphisms on lung cancer patients. MATERIALS and METHODS: Blood samples of 100 patients and 100 controls were taken for polymorphism analyses with PCR method based on reversed hybridization technique. Plasma ADMAlevels were measured by HPLC technique. RESULTS: There was no significant difference between the polymorphisms of patients and control groups $(\mathrm{p}>0.05)$. Plasma ADMA levels of patients were significantly higher than those of controls $(p<0.05)$. Plasma ADMA levels were significantly higher in the patients and control groups with $\mathrm{CC}$ and TT polymorphisms on eNOS T-786C and G894T gene regions, respectively. Additionally, $\mathrm{CC}$ polymorphisms were found higher on small cell lung cancer patients compared with non-small cell lung cancer patients. In small cell lung cancer patients, ADMA levels were found high. CONCLUSIONS: Our findings show that there was no significant difference in terms of the polymorphisms between lung cancer patients and control groups. However, plasma ADMA levels were significantly higher in patient group than controls. All these findings suggest that high plasma ADMA levels and CC genotypes are associated with small cell lung cancer. Keywords: Nitric Oxide, Endothelial Nitric Oxide synthase, polymorphism

Introduction

Lung cancer is the most common and the highest mortality type in the world as it is in our country. Smoking is the first cause of lung cancer. Although smoking is the most important cause of lung cancer formation, it is a known fact that many other known and unknown causes leads to the formation of lung cancer. NOS catalyzes the production of nitric oxide (1). eNOS is an endothelial celloriginating NOS form. Two of the SNPs in the eNOS gene (single nucleotide polymorphism) are the G894T polymorphism in the exon 7 region with the T-786C polymorphism in the promoter region of the gene. Nitric oxide (NO); is a free radical consisting of two atoms. Besides its role in normal physiology, nitric oxide is responsible for patogenesis of diseases, such as coronary artery disease, hypertension, and various types of cancer. In 1992, Vallance et al. first described Asymmetric Dimethyl Arginine (ADMA) as the endogenous inhibitor of nitric oxide synthase in human plasma and urine (2). In this study we measured plasma ADMA levels in patients with lung cancer and investigated their association with NO and polymorphisms and examined whether the two SNPs were effective in the development of lung cancer.

Materials and Methods

Selection of Patient and Control Group: This study was approved Atatürk Univ Faculty of Medicine ethic commite (22.05.2009/64). 100 patients with lung cancer (male: 78, female: 22) who were hospitalized at Süleyman Demirel Research Hospital, Atatürk University Medical School were included. Collection of Samples:For the detection of polymorphism in the patient and healthy control group one time, $6 \mathrm{~mL}$ of venous blood was collected and aliquotted with EDTA containing anticoagulant as $3 \mathrm{~mL}$. Aliquot samples were stored at $-80^{\circ} \mathrm{C}$ until the working day.

Methods: The eNOS T-786C and eNOS G894T polymorphisms were detected in blood samples taken from the patient and control group. A commercially available CVD strip assay kit (Viennalab Diagnostics; Vienna, Austria) was used for this. Polymorphism Analysis, DNA Isolation

For DNA isolation, EDTA venous blood samples previously stored at $-80^{\circ} \mathrm{C}$ were used. One day before the work started, the samples were transferred to the $-20^{\circ} \mathrm{C}$ cabin and It was dissolved in the $+4{ }^{\circ} \mathrm{C}$ cabinet in the working day. The supernatant was obtained by treating the samples according to the kit description. The supernatant containing DNA to be used in PCR was stored at $2-8^{\circ} \mathrm{C}$ until PCR. DNA Purity Determination and Concentration Calculation: DNA concentrations and purity ratings were determined by absorbance measurements at 260 and 280 $\mathrm{nm}$ wavelengths, with quartz tube as $195 \mu \mathrm{L}$ pure water $+5 \mu \mathrm{L}$ supernatant. The A260 / A280 ratio of 1.7-1.8 was accepted as the purity level that could be used in PCR analysis.

In Vitro Amplification (PCR): In PCR, all steps were performed on ice until the thermal cycle program was started, and DNA samples were kept frozen with PCR reagents. In Taq Dilution Buffer, a fresh diluent sample of Taq DNA Polymerase was prepared $(0.2 \mathrm{U} / \mu \mathrm{L})$. For each sample to be amplified, a reaction tube was placed on ice and treated according to the protocol.Analysis of Amplification Products in Agarose Gel Electrophoresis A 3\% agarose gel was prepared with appropriate protocols. The $1 / 2$ x TBE (Tris, Boric acid, EDTA) buffer was added to the electrophoresis tank to cover the top of the gel. DNA specimens and amplification products with $6 \mathrm{X}$ loading buffer were placed on wells on the gel, and the samples were run on the gel.

Hybridization:Test strips, color formers wash solution B, DNAT and conjugate solutions for the hybridization process were expected to reach room temperature. Hybridization was performed according to the standard procedure. After hybridization, standard wash and staining protocols were applied.

Evaluation of Strips: Following the staining process, wild type and / or mutation bands appeared in the striplines. Only wild type band formation is normal in the stripes; both the wild type and the formation of the mutation band heterozygote; only the occurrence of the mutation band was evaluated as a homozygote genotype.

NO Measurement: The NO amount of the samples was measured spectrophotometrically with the Griess reaction (3).

ADMA Analysis: ADMA analysis was performed with a kit based on commercially available high-pressure liquid chromatography (HPLC) method. Evaluation was made with a fluorescence detector.

Statistical analysis: Statistical analysis of data in our study was made using the IBMSPSS 19.0 statistical program. The distributions of the variables were examined by the Kolmogorov Smirnov test. As the numerical variables were normally distributed, the difference between the two groups was assessed by using the Sample-T test. To assess the difference between 3 or more groups, the ONEWAY-ANOVA test was used. X2 (Chi-square) test was used for the analysis of the catagoric data. A statistically significant difference of $\mathrm{P}<0.05$ was considered.

Results

Gene Polymorphisms:The distribution of TT, TC, CC polymorphisms in the eNOS T-786C promoter gene region and GG, GT, and TT polymorphisms in the eNOS G894T exon 7 gene region between the patients and the control group in our study are given in Table 1. No statistical difference was found in the distribution of these polymorphisms among the groups $(p>0.05)$.

ADMA and NO levels: ADMA and NO levels measured in patients with lung cancer and in the control group are given in the Table 2 . A statistically significant difference was found between the groups for both parameters $(p<0.05)$. Based on the classification of patients with lung cancer, statistical analysis of ADMA and NO levels is given in the Table 3. ADMA levels were statistically significantly higher in SCLC compared to NSCLC. Comparison of ADMA and NO levels with eNOS gene polymorphisms. The distributions of ADMA and NO levels according to the polymorphisms in the eNOS T-786C promoter gene region are given in the Table 4. The distribution of the ADMA and NO levels according to the polymorphisms found in the eNOS G894T exon 7 gene region of the eNOS gene is given in the Table 5. Distribution of eNOS gene polymorphism is seen according to classification of patients with lung cancer below. A statistically 
significant difference was found between the individuals in the genotypes TT, TC and CC in terms of polymorphisms in the eNOS T-786C promoter gene region according to classification in the analysis performed $(\mathrm{p}=0.041)$. However, no statistically significant difference was found in the classification of the individuals in the GG, GT and TT genotypes in terms of polymorphisms in the eNOS G894T exon 7 gene region $(\mathrm{p}=0.107)$.

Discussion

After the discovery of NO in 1987, much work has been done on cancer and NO relationship, and it is thought that NO may be effective both in cancer development and in the growth and development of cancer that has developed. In our study, 100 patients with lung cancer and 100 control groups were studied. There was a statistically significant difference in the levels of NO in the patient group compared to the control group. NO levels were found high in the patient group. Similarly, Obara H at all. (4) have found NO levels significantly higher in mycoplasma hyorhinis study on stomach cancer seen in infected people. Nam KT at all. (5) investigated the role of iNOS in Helicobacter pyloriassociated carcinogenesis. As a result, iNOS has contributed to the formation of Helicobacter-related cancers and they found NO levels high in cancer-induced mice. We hypothesized that expression of eNOS at the gene level and plasma ADMA levels might contribute to formation of lung cancer and progression in the elucidation of these complex relationships between NO and cancer. In our study, 100 lung cancer patients and 100 control group evaluated in terms of TT, TC, CC polymorphisms in the eNOS T-786C promoter gene locus, and GG, GT, TT polymorphisms in the eNOS G894T exon 7 gene region. TT distribution in patients with lung cancer in the eNOS T-786C promoter gene region was $42 \%$, compared with $53 \%$ in the control group. TC distribution was $47 \%$ in lung cancer, $39 \%$ in control group, and CC distribution was $11 \%$ in lung cancer and $8 \%$ in control group. There was no statistically significant difference in polymorphisms between the lung cancer patients and the control group in the eNOS T-786C promoter gene region. In the eNOS G894T exon 7 gene locus, the GG distribution was $56 \%$ in patients with lung cancer, while it was $60 \%$ in the control group. GT distribution was $34 \%$ in lung cancer, $31 \%$ in control group and $10 \%$ in TT distribution in lung cancer, while it was $9 \%$ in control group. There was no statistically significant difference in polymorphisms between eNOS G894T exon 7 gene locus and lung cancer patients. In 1992, Vallance et al. First described ADMA as an endogenous inhibitor of NO synthase in human plasma and urine (6). ADMA is an amino acid naturally found in the plasma. ADMA is a posttranslational modification of arginine (6). Yoshimatsu et al. (7) have studied serum ADMA levels in stomach, breast, hematopoietic, and lung cancer cases with a total of 118 subjects (33 of these cancer cases were lung cancer) and found to be significantly higher than the control group. They have linked ADMA elevation to overexpression of PRMT1(protein arginine methyltransferase) by measuring PRMT1 in the same cancer types. However, they said there was a need for further studies to explain this expression increase and the regulation of ADMA levels in cancers. Szuba et al. (8) investigated plasma ADMA levels in hematological malignancies of different types and found to be significantly higher than the control group. Phebe $\mathrm{L}$ at all study showed a significant inverse correlation between ADMA and NO. This study emphasizes the correlation between ADMA and NO (9). Karthik Reddy at all have studied that the elevated DDAH1(Dimethylarginine dimethylaminohydrolase-1) results in enhanced NO production and its downstream VEGF and HIF1 expression due to reduced tumor ADMA (10). Andrzej Szuba at al. report that a substantial increase of plasma ADMA in the population of patients with different hematological malignancies. They say that increased protein turnover, oxidative stress and impaired dimethylarginine dimethylaminohydrolase activity,which degraded ADMA, occurring in hematological malignancies may lead to increased dimethylarginines production (11). ADMA in hematological patients could be a result of increased degradation of intracellular proteins (12). Zheng at al. reveals that the plasma ADMA level is elevated in colon cancer patients, which can attenuate serum starvation-induced apoptosis in LoVo cells.(13). All these studies have shown to increase ADMA levels in many different tissue-derived cancer cases. In our study, parallel to these studies, we found that plasma ADMA levels were statistically higher in patients with lung cancer than control group. We determined plasma ADMA levels by HPLC method. We also investigated the relationship between eNOS T-786C and G894T polymorphisms in 100 lung cancer patients and 100 control groups and plasma ADMA and NO levels of both groups in our study. As a result, we could not find any statistically significant difference between the polymorphisms and NO levels in both groups. However, we found that the ADMA levels were significantly higher in patients with CC and TT polymorphism, in terms of gene regions above. This table suggests that eNOS gene expression in individuals in the $\mathrm{CC}$ genotype is affected in a way that increases $\mathrm{NO}$ levels and in this cases eNOS may increases plasma ADMA levels, the endogenous inhibitor of eNOS. In terms of eNOS T-786C and G894T polymorphisms in these data, the individuals with CC and TT genotypes, respectively, suggest that plasma ADMA levels are highly dependent on plasma NO levels. Hovewer, they may dependent on this level for other reasons. In addition, there was no statistically significant difference in our study between NSCLC and SCLC with respect to NO levels whereas ADMA levels in SCLC were statistically higher than those of NSCLC. There was no statistical difference in G894T polymorphisms in both groups when evaluating SCLC and NSCLC for polymorphisms. However, there was a statistically significant difference when evaluated for T-786C polymorphism. CC genotype was higher in SCLC than in NSCLC. Our study suggest that the $\mathrm{CC}$ genotype is more likely to be observed in SCLC. Therefore, If individuals carrying this genotype get lung cancer they may be more likely to have SCLC. In our view, the pathophysiological mechanism underlying this and its relation to ADMA should be explored further in a wider range of patient groups. In our study, there was no statistically significant difference between the age of the patient group and the control group when the patient and control group were examined for their demographic characteristics. There was a statistically significant difference in favor of the patient group in terms of smoking. It was a result that we expected to have a high drinking level in the patient group of the cigarette, which was obviously accused of lung cancer etiology.

Conclusion and recommendations

In our study, we investigated TT, TC, CC polymorphisms in the eNOS T-786C promoter gene region and GG, GT, TT polymorphisms in eNOS G894T exon 7 gene locus in 100 lung cancer patients and 100 control groups. There was no statistically significant difference between the lung cancer patients and the control group in terms of these polymorphisms. Plasma ADMA and NO levels in lung cancer patients were statistically higher than control group. Plasma ADMA levels of patients in the $\mathrm{CC}$ and TT genotypes and patients in the control group were significantly higher than the other polymorphic groups in terms of eNOS T-786C and G894T polymorphisms, respectively. In addition, there was no statistically significant difference in our study compared to in NSCLC NO levels and in SCLC NO levels, whereas ADMA levels in SCLC were statistically significantly higher than in NSCLC. When assessed for polymorphisms, there was no statistical difference in G894T polymorphism in both groups. However, there was a statistically significant difference when evaluated for T-786C polymorphism. The CC genotype was higher in SCLC than in NSCLC. As a result, it is clea that more genetic studies are needed in lung cancer disease, which is complicated by the interaction of genetic and environmental factors. In patients with lung cancer, eNOS T-786C and G894T polymorphisms and plasma ADMA levels may be added to other parameters in much wider patient and control groups to clarify these dark associations that have been studied and can not be explored. Thus, in these studies, significant contributions can be made to both the etiology and the development of lung cancer.

References

1.Tsutsui M, Tanimoto A, Tamura M, Mukae H, Yanagihara N, Shimokawa H, Otsuji Y. Significance of nitric oxide synthases: Lessons from triple nitric oxide synthases null mice. J Pharmacol Sci. 2015;127(1):42-52.

2.Vallance P, Leone A, Calver A, Collier J, Moncada S. Accumulation of an endogenous inhibitor of nitric oxide synthesis in chronic renal failure. Lancet. 1992;339(8793):572-5

3.Tsikas D. Analysis of nitrite and nitrate in biological fluids by assays based on the Griess reaction: appraisal of the Griess reaction in the L-arginine/nitric oxide area of research. J Chromatogr B Analyt Technol Biomed Life Sci. 2007;851(1-2):51-70. 4.Obara H, Harasawa R. Nitric Oxide Causes Anoikis through Attenuation of E-Cadherin and Activation of Caspase-3 in Human Gastric Carcinoma AZ-521 Cells Infected with Mycoplasma hyorhinis. J Vet Med Sci. 2010;72(7):869-74.

5.Nam KT, Oh SY, Ahn B, Kim YB, Jang DD, Yang KH, Hahm KB, Kim DY. Decreased Helicobacter pylori associated gastric carcinogenesis in mice lacking inducible nitric oxide synthase. Gut. 2004;53(9):1250-5.

6.Calver A, Collier J, Leone A, Moncada S, Vallance P. Effect of local intra-arterial asymmetric dimethylarginine (ADMA) on the forearm arteriolar bed of healthy volunteers. J Hum Hypertens. 1993;7(2):193-4.

7.Yoshimatsu M, Toyokawa G, Hayami S, Unoki M, Tsunoda T, Field HI, Kelly JD, Neal DE, Maehara Y, Ponder BAJ, Nakamura Y, Hamamoto R. Dysregulation of PRMT1 and PRMT6, Type I arginine methyltransferases, is involved in various types of human cancers. International Journal of Cancer. 2011;128(3):562-73.

8.Szuba A, Chachaj A, Wrobel T, Dzietczenia J, Mazur G, Antonowicz-Juchniewicz J, Kuliczkowski K, Andrzejak R. Asymmetric dimethylarginine in hematological malignancies: a preliminary study. Leukemia Lymphoma. 2008;49(12):2316-20.

9.Abdel-Messeih PL, Nosseir NM, Bakhe OH. Evaluation of inflammatory cytokines and oxidative stress markers in prostate cancer patients undergoing curative radiotherapy. Cent Eur J Immunol. 2017;42(1):68-72.

10.Reddy KRK, Dasari C, Duscharla D, Supriya B, Ram NS, Surekha MV, Kumar JM, Ummanni R. Dimethylarginine dimethylaminohydrolase-1 (DDAH1) is frequently upregulated in prostate cancer, and its overexpression conveys tumor growth and angiogenesis by metabolizing asymmetric dimethylarginine (ADMA). Angiogenesis. 2017.

11.Szuba A, Chachaj A, Wrobel T, Dzietczenia J, Mazur G, Antonowicz-Juchniewicz J, Kuliczkowski K, Andrzejak R. Asymmetric dimethylarginine in hematological malignancies: a preliminary study. Leuk Lymphoma. 2008;49(12):2316-20.

12.Wu G, Morris SM, Jr. Arginine metabolism: nitric oxide and beyond. Biochem J. 1998;336 ( Pt 1):1-17.

13.Zheng N, Wang K, He J, Qiu Y, Xie G, Su M, Jia W, Li H. Effects of ADMA on gene expression and metabolism in serum-starved LoVo cells. Sci Rep. 2016;6:25892.

Table 1: Distribution of eNOS T-786C and G894T polymorphisms in the patient and control group.

\begin{tabular}{llll} 
& $\begin{array}{l}\text { Lung cancer patients } \\
\mathrm{N}=100\end{array}$ & $\begin{array}{l}\text { Healthy control group } \\
\mathrm{N}=100\end{array}$ & P value \\
\hline eNOS T-786C & & & \\
TT & $42(\% 42)$ & $53(\% 53)$ & \multirow{2}{*}{0.288} \\
TC & $47(\% 47)$ & $39(\% 39)$ & \\
CC & $11(\% 11)$ & $8(\% 8)$ & \\
\hline Allel Frekansi & & 0.725 & \\
T allel & 0.655 & 0.275 & 0.848 \\
C allel & 0.345 & $60(\% 60)$ & \\
\hline eNOS G894T & & $36(\% 56)$ & \\
GG & $34(\% 34)$ & $9(\% 9)$ & \\
GT & $10(\% 10)$ & 0.755 & \\
TT & 0.73 & 0.245 & \\
\hline Allele Frequency & 0.27 & & \\
G allel & & & \\
T allel & & & \\
& & &
\end{tabular}


TBS International Biochemistry Congress 2018 - 29 $9^{\text {th }}$ National Biochemistry Congress

Table 2: ADMA and NO levels in patients with lung cancer and control group.

$\begin{array}{llll} & \begin{array}{l}\text { Lung cancer } \\ \text { patients } \\ \mathrm{N}=100\end{array} & \begin{array}{l}\text { Healthy } \\ \text { control group } \\ (\mathrm{X}=100\end{array} & \text { P value } \\ & 1.72 \pm 1.27 & \begin{array}{l}\mathrm{X} \pm \mathrm{SD}) \\ 0.94 \pm 0.45\end{array} & 0.000 \\ \begin{array}{l}\mathrm{ADMA} \\ (\mu \mathrm{mol} / \mathrm{L})\end{array} & 30.95 \pm 18.20 & 24.03 \pm 12.61 & 0.011 \\ \mathrm{NO} & & & \end{array}$

$(\mu \mathrm{mol} / \mathrm{L})$

Table 3: Distribution of ADMA and NO levels according to histopathological classification.

Classification

$\begin{array}{llll} & \begin{array}{l}\mathrm{KHAK}(\mathrm{N}=24) \\ (\mathrm{X} \pm \mathrm{SD})\end{array} & \begin{array}{l}\mathrm{KHDAK}(\mathrm{N}=76) \\ (\mathrm{X} \pm \mathrm{SD})\end{array} & \mathrm{p} \text { value } \\ \text { ADMA }(\mu \mathrm{mo} & 2.51 \pm 1.68 & 1.47 \pm 1.01 & 0.01 \\ & & & \\ \mathrm{NO}(\mu \mathrm{mol} / \mathrm{L}) & 30.65 \pm 19.25 & 31.04 \pm 17.99 & 0.93\end{array}$

Table 4: ADMA and NO levels in groups according to eNOS T-786C polymorphisms

\begin{tabular}{|c|c|c|c|c|c|c|c|c|}
\hline \multirow{3}{*}{$\begin{array}{r}\text { eNOS } \\
\text { T-786C }\end{array}$} & \multirow{2}{*}{\multicolumn{2}{|c|}{$\begin{array}{l}\text { Akciğer Kanserli } \\
\text { Hastalar } \\
\mathrm{N}=100\end{array}$}} & \multicolumn{3}{|c|}{ Sağlıklı Kontrol } & \multicolumn{3}{|c|}{ Toplam } \\
\hline & & & & 100 & & & $\mathrm{~N}=$ & \\
\hline & & $\begin{array}{l}\mathrm{NO} \\
(\mu \mathrm{mol} / \mathrm{L})\end{array}$ & $\begin{array}{l}\mathrm{ADMA} \\
(\mu \mathrm{mol} / \mathrm{L})\end{array}$ & & $\begin{array}{l}\mathrm{NO} \\
(\mu \mathrm{mol} / \mathrm{L})\end{array}$ & $\begin{array}{l}\text { ADMA } \\
(\mu \mathrm{mol} / \mathrm{L})\end{array}$ & & $\begin{array}{l}\mathrm{NO} \\
(\mu \mathrm{mol} / \mathrm{L}\end{array}$ \\
\hline & $\mathrm{N}$ & & & $\mathrm{N}$ & & & $\mathrm{N}$ & \\
\hline TT & 42 & $31.45 \pm 17.22$ & $1.51 \pm 1.18$ & 53 & $24.35 \pm 12.98$ & $0.84 \pm 0.35$ & 95 & $27.49 \pm 1$ \\
\hline $\mathrm{TC}$ & 47 & $32.76 \pm 19.73$ & $1.45 \pm 1.05$ & 39 & $23.2 \pm 12.41$ & $0.84 \pm 0.35$ & 86 & $28.42 \pm 1$ \\
\hline $\mathrm{CC}$ & 11 & $21.29 \pm 12.44$ & $3.62 \pm 0.89 *$ & 8 & $25.96 \pm 9.09$ & $2.06 \pm 0.37 *$ & 19 & $23.26 \pm 1$ \\
\hline
\end{tabular}

*: The ADMA levels of carriers with CC alleles were statistically significantly higher than the other two types $(\mathrm{p}<0.05)$

Table 5: ADMA and NO levels in groups according to eNOS G894T polymorphisms

\begin{tabular}{|c|c|c|c|c|c|c|c|}
\hline \multirow{2}{*}{\multicolumn{2}{|c|}{$\begin{array}{l}\text { ung cancer } \\
\text { 'atients } \\
\mathrm{J}=100\end{array}$}} & \multirow{2}{*}{\multicolumn{3}{|c|}{$\begin{array}{l}\text { Healthy control } \\
\mathrm{N}=100\end{array}$}} & & \multicolumn{2}{|c|}{ Total } \\
\hline & & & & & & $\mathrm{N}=2$ & \\
\hline & $\begin{array}{l}\text { NO } \\
(\mu \mathrm{mol} / \mathrm{L})\end{array}$ & $\begin{array}{l}\text { ADMA } \\
(\mu \mathrm{mol} / \mathrm{L})\end{array}$ & & $\begin{array}{l}\text { NO } \\
(\mu \mathrm{mol} / \mathrm{L})\end{array}$ & $\begin{array}{l}\mathrm{ADMA} \\
(\mu \mathrm{mol} / \mathrm{L})\end{array}$ & & $\begin{array}{l}\text { NO } \\
(\mu \mathrm{mol} / \mathrm{L})\end{array}$ \\
\hline & & & $\mathrm{N}$ & & & $\mathrm{N}$ & \\
\hline & $31.01 \pm 17.4$ & $1.44 \pm 0.92$ & 60 & $23.55 \pm 13.6$ & $0.87 \pm 0.32$ & 116 & $27.15 \pm 15.93$ \\
\hline & $31.18 \pm 18.82$ & $1.78 \pm 1.52$ & 31 & $24.02 \pm 11.06$ & $0.85 \pm 0.38$ & 65 & $27.77 \pm 15.9$ \\
\hline & $29.77 \pm 22.02$ & $3.06 \pm 1.32 *$ & 9 & $27.23 \pm 8.29$ & $1.69 \pm 0.76^{*}$ & 19 & $28.57 \pm 16.69$ \\
\hline
\end{tabular}

*: The ADMA levels of the TT allele carriers were statistically significantly higher than the other two types $(\mathrm{p}<0.05)$

Table 6: Distribution of eNOS T-786C and eNOS G894T polymorphisms according to histopathological classification in the patient group

\begin{tabular}{lll}
\multicolumn{3}{c}{ Lung cancer patients } \\
\hline eNOS T-786C & KHAK & KHDAK \\
TT & $9(\% 37.5)$ & $33(\% 43.4)$ \\
TC & $9(\% 37.5)$ & $38(\% 50)$ \\
CC & $6(\% 25)$ & $5(\% 6.6)$ \\
\hline Allel Frequency & & \\
T allele & 0.562 & 0.684 \\
C allele & 0.437 & 0.315 \\
\hline eNOS G894T & & \\
GG & $13(\% 54.2)$ & $43(\% 56.6)$ \\
GT & $6(\% 25)$ & $28(\% 36.8)$ \\
TT & $5(\% 20.8)$ & $5(\% 6.6)$ \\
\hline Allele Frequency & & \\
G allele & 0.666 & 0.75 \\
T allele & 0.333 & 0.25
\end{tabular}

\section{OP-093 \\ RELATIONSHIP BETWEEN SERUM NO AND ADMA LEVELS WITH ACUTE EXACERBATION OF COPD}

Pelin Uysal

Mehmet Ali Aydınlar University, Faculty of Medicine, Atakent Hospital,

Department of Chest Diseases, Istanbul

OBJECTIVES: Asymmetric dimethylarginine (ADMA), a metabolite of protein turnover throughout the body, is considered as a signifcant factor in nitric oxide(NO) homeostasis that may interfere with several processes related to the evolution of infammatory airway diseases. The aim of the study was to compare the serum levels of ADMA and NO between patients with stable chronic obstructive pulmonary disease (COPD) and those with acute exacerbation of COPD. The serum levels of ADMA and NO in patients with acute exacerbation of COPD also establish whether their levels vary in relation to forced expiratory volume in 1s (FEV1). MATERIALS and METHODS: This study involved 55 patients with exacerbated COPD, 50 patients with stable COPD and 30 healthy subjects. Serum ADMA and NO levels were measured using ELISA and the colorimetric method, respectively. RESULTS: Serum ADMA levels were significantly higher, however, NO levels were lower in patients with COPD compared with controls. Serum ADMA levels in patients with exacerbated COPD were significantly higher than in those with stable COPD; NO levels were decreased compliant with progression of COPD stages. ADMA levels were inversely correlated with NO levels. Serum ADMA levels were significantly negative correlated with FEV1, while NO were significantly positive correlated with FEV1. CONCLUSIONS: Our study indicates that circulating ADMA levels as the marker of nitrosative stress increase during exacerbated COPD. The measurement of serum ADMA and NO levels may be useful in the evaluation of exacerbated COPD. ADMA may be a novel therapeutic target for the treatment of COPD. Keywords: Acute exacerbation, Asymmetric dimethylarginine, Chronic obstructive pulmonary disease, Nitric oxide

\section{OP-094}

\section{INCREASED SERUM ASYMMETRIC DIMETHYLARGININE LEVELS IN WORKERS WITH LEAD EXPOSURE}

Saadet Celik ${ }^{1}$, Lütfiye Tutkun², Servet İ́ritaş ${ }^{3}$, Meside Gündüzoz ${ }^{4}$, Sedat Abuşoğlu ${ }^{5}$, Ali Ünlü̈5, Vugar Ali Türksoy ${ }^{6}$, Serdar Deniz ${ }^{7}$, Hüseyin İlter ${ }^{8}$ ${ }^{1}$ Bilecik Public Health Laboratory, Bilecik

${ }^{2}$ Department of Biochemistry, School of Medicine, Bozok University, Yozgat

${ }^{3}$ Council of Forensic Medicine

${ }^{4}$ Department of Toxicology, Ankara Occupational and Environmental Diseases Hospital

${ }^{5}$ Department of Biochemistry, Selcuk University Faculty of Medicine, Konya ${ }^{6}$ Department of Public Health, Bozok University

${ }^{7}$ Public Health Directorate, Malatya

${ }^{8}$ General Directorate of Public Health, Ministry of Health

OBJECTIVES: A growing body of epidemiological research associates lead exposure with adverse cardiovascular health. Our aim was to determine the relation between serum asymmetric dimethyl arginine levels and lead-exposure. MATERIALS and METHODS: Serum ADMA was analyzed with the Shimadzu LC-20AD system coupled with Applied Biosystems MDS SCIEX (USA) API 3200 mass spectrometry in electrospray ionization (ESI) positive mode by Phenomenex Luna C18 column with a modified method. Briefly, 100 microliters $(\mu \mathrm{L})$ of internal Standard (d7-ADMA) in methanol were added to $200 \mu \mathrm{L}$ of serum and centrifuged at $13.000 \mathrm{rpm}$ for 10 minutes to remove the precipitated proteins. The supernatant was collected and dried under a nitrogen gas flow at $600 \mathrm{C}$. The derivatization step was performed dissolving the dried extract in 200 $\mu \mathrm{L}$ of a freshly prepared butanol solution containing $5 \%(\mathrm{v} / \mathrm{v})$ acetyl chloride and kept at $60 \mathrm{oC}$ for 20 minutes. The solvent was removed by evaporation under nitrogen flow at $60 \mathrm{oC}$. The derivatized samples were dissolved in $100 \mu \mathrm{L}$ of water-methanol $(90: 10, \mathrm{v} / \mathrm{v})$ containing $0.1 \%(\mathrm{v} / \mathrm{v})$ formic acid and $40 \mu \mathrm{L}$ was injected into the ultra pressure liquid chromatography (UPLC) analytical column. RESULTS: Serum asymmetric dimethylarginine (ADMA) $(0.22 \pm 0.09$ $\mu \mathrm{mol} / \mathrm{L}$ vs $0.17 \pm 0.03 \mu \mathrm{mol} / \mathrm{L}, \mathrm{p}<0.001)$ were higher in lead-exposed group compared to controls. There was a statistically positive significant correlation between serum ADMA and whole blood lead levels $(r=0.326, p<0.001)$ CONCLUSIONS: ADMA has been suggested as a parameter for endothelial dysfunction and coronary heart disease.Lead toxicity might be a risk factor by inhibition of nitric oxide synthase ezyme. Keywords: Asymmetric dimethylarginine, Cardiotoxicity, Battery Workers, Lead, Exposure

\section{OP-095 \\ DETECTION OF B-THALASSEMIA CD44 MUTATION BY USING PIEZOELECTRIC BIOSENSOR FOR NON-INVASIVE DIAGNOSIS}

Umut Kökbaș, Kezban Kartlaşmış, Ebru Dündar Yenilmez, Abdullah Tuli, Levent Kayrın

Department of Medical Biochemistry, Faculty of Medicine, Çukurova University, Adana

OBJECTIVES: $\beta$-Thalassemia is one of the most monogenic autosomal recessive disorder characterized by defective production of the hemoglobins $\beta$-chain. Definition of the $\beta$-globin genotype is necessary for genetic counselling in the carriers, and for predicting prognosis and management options in the patients with thalassemia. DNA-based prenatal diagnosis of $\beta$-thalassemias routinely relies on polymerase chain reaction (PCR) and gel electrophoresis. The aim of this study is to develop a new procedure, a DNA-based piezoelectric biosensor, for the detection of $\beta$-thalassemia CD-44 mutation fetus' cell free DNA from maternal blood. MATERIALS and METHODS: Cell-free fetal DNA taken from maternal whole blood. Bioactive layer was constituted by binding 2 -HidroxymetacrilateMeta 
criloamidoscystein(HEMA-MAC) nanoploymers on the electrode's surface. Single oligonucleotide probes specific for CD-44 mutation of $\beta$-thalassemia were attached to the nanopolymer. The measurements were executed by piezoelectric resonance frequency which is caused by binding of the cell free fetal DNA in media with single oligonucleotide probe on the electrode surface. The results were confirmed by the conventional molecular method as ARMS. RESULTS: The piezoelectric resonance frequencies obtained by hybridization of the cell free fetal DNA on bioactive layer were found $246 \pm 21,293 \pm 16$ ve $384 \pm 18 \mathrm{~Hz}$ for the samples of normal $\beta$-globin, heterozygote, and homozygote of CD-44 mutation, respectively. CONCLUSIONS: The developed biosensor serves as a specific result to Cd-44 mutation. It could accurately discriminate between normal and CD-44 mutation samples. Becauseoflow costs, fastresults, specificity andhighdetection/information effectiveness as compared with conventional prenatal diagnosis methods,we can be offered this techique as an alternative to conventional molecular methods. Keywords: Genosensor, Non-invasive, Prenatal diagnosis, Cd-44

\section{OP-096 \\ A NEW ENZYME BIOSENSOR DESIGN FOR RAPID SCREENING OF CONGENITAL ADRENAL HYPERPLASIA IN NEWBORN}

Ebru Dündar Yenilmez

Çukurova University Faculty of Medicine Department of Medical Biochemistry

OBJECTIVES: Congenital Adrenal Hyperplasia (CAH) is a family of autosomal recessive disorders characterized by deficiency in one or another of the enzymes of cortisol biosynthesis. The most prevalent form of the disorder is 21-hydroxylase $(21 \mathrm{OH})$ deficiency which is the most frequent inborn metabolism error and 17-Alpha-OHP is secreted in abundant excess. Measurement of 17-Alpha-OHP is therefore valuable in the initial diagnosis of CAH. Newborn screening procedures for $\mathrm{CAH}$ are still suboptimal because of low specificity, particularly in premature infants. The aim of this study was to design a biosensor for detection 17-Alpha-OHP; a new method for CAH screening in newborn. MATERIALS and METHODS: The electrochemical measurements were performed using a gold electrode coated with Au-Poly HemaMac, combined with the reference $\mathrm{Ag} / \mathrm{AgCl}$ electrode and the auxiliary $\mathrm{Au} / \mathrm{Pd}(98 / 2 \%)$ electrode. UV immobilization performed with 17-Alpha-OHP-horseradish peroxidase on the modified gold electrode surface with anilin $(20 \mu \mathrm{L}$ enzyme and $20 \mu \mathrm{L}$ anilin). RESULTS: Optimization studies determine the most suitable working conditions for using the biosensor. Polymerization time was $2 \mathrm{~h}$, the enzyme concentration used $0.5 \mathrm{mg} / \mathrm{mL}$, temperature was $35^{\circ} \mathrm{C}$, pH was 6.5 with phosphate buffer. After the characterization studies of the biosensor the detection limit was $0.015 \mathrm{ng} / \mathrm{mL}-7.5 \mathrm{ng} / \mathrm{mL}$, repeatability was $2.98 \pm 0.04$. CONCLUSIONS: The demonstrated method for 17-Alpha-OHP detection in newborn is useful and can be carry out rapidly in clinical diagnosis. Using automated biosensors are reproducible, quick and results can be generated within a few minutes compared to the traditional tests in use. Keywords: Biosensor, enzyme, 17- Alpha-OHP, CAH

\section{OP-097 \\ DEVELOPMENT OF MOLECULARLY IMPRINTED POLYMER BASED BIOENSOR SYSTEM FOR DETERMINATION OF PREDNISOLON}

\section{Erhan Canbay ${ }^{1}$, Erol Aky1lmaz ${ }^{2}$}

${ }^{1}$ Ege University Faculty of Medicine, Medical Biochemistry Department, Izmir ${ }^{2}$ Ege University Faculty of Science, Biochemistry Department, Izmir

OBJECTIVES: Prednisolone is one of the most widely used synthetic corticosteroids in the symptomatic treatment of many diseases. Due to its potent antiinflammatory activity, prednisolone is present in varying amounts in many products. It is also in the class of materials prohibited by WADA because it increases the performance of athletes from unnatural ways. Prednisolone can be measured by HPLC,GC-MS, LC MS MS. However, these techniques require pre-treatment such as SPE,LLE, derivatization, and expensive equipment. The aim of this work is to develop a molecularly imprinted polymer (MIP) based biosensor system for fast, inexpensive analysis of prednisolone. MATERIALS and METHODS: Prednisolon-MIP sensors were prepared by electropolymerization pyrolle in the presence of a prednisolone molecule on the gold nanoparticle-coated graphite electrode surface. Biosensor responses were monitoredbyFerri/FerrosolutionwithDifferentialPulsemethod.Templatemolecule/ monomer ratio, incubation and extraction duration optimizations were performed. RESULTS: The optimum incubation time of the developed biosensor was found to be 7 minutes and optimum extraction time was found to be 5 minutes. The linear detection range of the Prednisolon MIP sensor is 1-75 $\mu \mathrm{M}$, and the detection limit is $0.35 \mu \mathrm{M}$. the mean, standard deviation and \%variation coefficient values were found as $48.69 \mu \mathrm{M}, \pm 1.06$ and $2.189 \%$ respectively. MIP sensors have been used to test substrate specificity, interference effect, and tank stability. CONCLUSIONS: In addition, the developed MIP sensors were tested for prednisolone in urine and serum samples and compared with LCMSMS method. As a result, a fast, inexpensive, reliable biosensor system for the determination of prednisolone has been developed. Keywords: Prednisolone, MIP, biosensor

\section{OP-098 \\ SYNTHESIS AND APPLICATION OF P (HEMA-MAGA) -CTS NANOPOLIMMER FOR UREASE IMMOBILIZATION}

Hilmiye Deniz Ertuğrul Uygun ${ }^{1}$, Elif Esen ${ }^{1}$, Simge Öztürk ${ }^{1}$, M Nalan Tüzmen Dokuz Eylül University The Graduate School of Natural and Applied Sciences İzmir ${ }^{2}$ Dokuz Eylül University Faculty of Science Chemistry Department İzmir

OBJECTIVES: Urease (urea amidohydrolase, E.C.3.5.1.5) is an enzyme that catalyzes the hydrolysis of urine to form ammonium and carbon dioxide. Most industrial applications of enzymes are carried out using immobilized systems and the immobilization process facilitates the recovery and reuse of the enzyme. In this work, chitosan (CTS), 2-hydroxyethyl methacrylate (HEMA) and N-methacryloyl- (L) -glutamic acid (MAGA) it is aimed to synthesize environmentally friendly nanoscale polymer with high mechanical stability by suspension polymerization and to use it in urease immobilization studies MATERIALS and METHODS: The synthesized p (HEMA-MAGA) -CTS was characterized by Fourier transform infrared spectroscopy (FTIR), scanning electron microscopy (SEM) and particle size analysis tests. The parameters affecting immobilization such as sorbent amount, initial urease concentration, duration, ionic strength are optimized in order to optimize the prepared urease immobilization conditions with sorbent. Measurements were made at $280 \mathrm{~nm}$ using UV spectroscopy. RESULTS: The initial urease concentration was studied at an enzyme concentration of $0.1-2 \mathrm{mg} / \mathrm{ml}$ and was determined as the initial concentration of $0.5 \mathrm{mg} / \mathrm{ml}$. In order to determine the optimum immobilization time, the period of immobilization was $120 \mathrm{~min}$. To determine the amount of sorbent, sorbent was used at 250-2000 $\mu \mathrm{l}$ and sorbent amount was chosen as $500 \mu \mathrm{l}$. For temperature optimization, it was operated at $5-45^{\circ} \mathrm{C}$ and set at $25^{\circ} \mathrm{C}$. As the ionic violence increased, amount of adsorption decreased. CONCLUSIONS: The synthesized nanostructured suspension polymer was used for urease immobilization. The maximum adsorption capacity at optimum conditions was found to be $2.06 \mathrm{mg} / \mathrm{mg}$. Keywords: Urease, Enzyme Immobilization, Nanopolymer

\section{OP-099}

\section{DESIGN OF POLYANILINE BASED UREA BIOSENSOR}

Kezban Kartlașmiș, Umut Kökbaş, Levent Kayrın Department of Medical Biochemistry, Faculty of Medicine, Çukurova University, Adana

OBJECTIVES: Urea is a side effect that can be observed in renal diseases and is a good indicator of the level of uremic toxins. The purpose of this study is to design an electrochemical biosensor that uses polyaniline polymer to provide urea measurement at lower cost and in a shorter time. MATERIALS and METHODS: After the Au work was attached to the electrode surface as a polyaniline-gelatin polymer monolayer, the bioactive layer was prepared by binding urease-glutamate dehydrogenase enzymes to form a specific reaction with urea on the polymer. The measurements were made based on the fact that the NAD + formed at the end of the reaction was directly proportional to the urea concentration. The working range, appropriate buffer-pH and polyaniline concentrations were investigated. The results were confirmed by spectrophotometric method. RESULTS: In the measurements made with polyaniline /urease glutamate dehydrogenase coated bioactive layer, the working range was determined as $0.0-1.4 \mathrm{~V}$ and the scan rate was $0.02 \mathrm{~V} / \mathrm{s}$. Suitable ambient conditions for the study are; Tris buffer $\mathrm{pH} 7.6$ and $20 \mathrm{mmol} / \mathrm{l}$ polyaniline. CONCLUSIONS: It has been determined that the biosensor we have developed responds to the urine specific response. When we looked at the result of correlation analysis, we found that there was a strong and significant correlation between both methods when $r$ value was 0,999 and $\mathrm{p}$ value was $\mathrm{p}<0,01$. Low cost and quick results compared to traditional urea measurement methods show that this technique can be used as an alternative. Keywords: Glutamate dehydrogenase, polyaniline, urease, urea biosensor

\section{OP-100}

\section{DEVELOPMENT OF A REUSABLE MOLECULARLY IMPRINTED} IMPEDIMETRIC SENSOR FOR CORTISOL DETECTION IN SALIVA $\frac{\text { Zihni Onur Uygun }}{1}$, Erhan Canbay ${ }^{1}$, Hilmiye Deniz Ertuğrul Uygun ${ }^{2}$, Ebru

${ }^{1}$ Ege University Faulty of Medicine, Medical Biochemistry Department, Bornova, İzmir

${ }^{2}$ Dokuz Eylül University Center for Electronica Materials Application and Manufacturing Buca İzmir

OBJECTIVES: Molecularly imprinted polymers (MIP) are artificial receptors produced by imprinting unnatural polymers with a target molecule. In this study, we developed an impedimetric sensor modified by molecularly imprinted copolymers (acrylamide-acrylamidophenyl boronic acid) for cortisol detection in saliva. MATERIALS and METHODS: This sensor was developed by the modification of carbon screen printed electrode (CSPE) by acrylamide and acrylamidophenyl boronic acid(AAPBA) monomers to form cortisol selective polymers. This 
polymer layer was formed on the single walled carbon nanotube (SWCNT) modified CSPE surface by using cortisol:acrylamide:AAPBA(2:4:1) ratio. Ammonium persulfate was used to initiate polymerization. The sensor surface was investigated by electrochemical impedance spectroscopy (EIS), Scanning Electron Microscopy (SEM) and X-Ray Photoelectron Spectroscopy (XPS). The performance of the sensor was evaluated by tandem mass spectrometer (MS/MS). Salivary samples were obtained from healthy volunteers, both genders, between the ages 25-32. Time for collection of samples was at least 30 minutes after wake-up. RESULTS: Performances of the electrode was as follows; calibration curve was calculated between $0.8 \mathrm{pM}$ to $10 \mu \mathrm{M}, \quad \mathrm{R} 2=98.92 \pm 0.52$, LOD and LOQ were $0.22 \mathrm{pM}$ and $0.76 \mathrm{pM}$, respectively. The sensor showed good correlation with MS/MS in real samples. CONCLUSIONS: This study revealed the achievement of a resuable, low cost, easy to use and fast cortisol detection sensor. This sensor could therefore be developed to use in point-of-care testing of the stress hormone cortisol. Keywords: sensor, biosensor, cortisol, impedance, molecular imprinting

\section{OP-101 \\ DESIGN OF A NEW BIOSENSOR FOR THE DETERMINATION OF FERROUS IRON IN BLOOD}

Ahmet İlhan, Kezban Kartlaşmış, Umut Kökbaş, Abdullah Tuli, Levent Kayrın Department of Medical Biochemistry, Faculty of Medicine, Çukurova University, Adana

OBJECTIVES: Iron is an element that is necessary for life but can damage the organism if it is present in excess. Metals such as iron are needed for physiological functions of the body. Iron performs many important functions in the body. Iron deficiency is the most common nutritional deficiency and the leading cause of anemia in the world. In this study, we aimed to design a biosensor for the quantitative determination of $\mathrm{Fe}+2$ in a short time and at an affordable cost. MATERIALS and METHODS: The Fenton reaction is based on the reaction of $\mathrm{Fe}+2$ ion with hydrogen peroxide. The bioactive layer was prepared by immobilizing hydrogen peroxidase enzymes on the gold electrode with bovin serum albümin (BSA), gelatin, glutaraldehyde with the help of UV light. This study was carried out with using $10 \mu \mathrm{l}$ of enzyme from stocks at $0.5,1$ and $2 \mathrm{mg} /$ $\mathrm{ml}$ concentrations prepared from horseradish peroxidase. The cyclic voltamogram is used to determine the current range at which the response can be measured. RESULTS: The response current in the range of 0.2 and $1.4 \mathrm{~V}$ was realized in the cyclic voltammogram where the scanning speed was $0.06 \mathrm{~V} / \mathrm{S}$. The rate of the enzymatic reaction was initially increased linearly by increasing the substrate concentration in an environment where all parameters were constant, and the reaction rate decreased after a certain substrate concentration. CONCLUSIONS: In this study, the best measurement was obtained with gold electrode immobilized with an enzyme concentration of $2 \mathrm{mg} / \mathrm{ml}$ was used. Our work continues. Keywords: biosensor, hydrogen perxidase, optimization

\section{Introduction}

Iron is an element that is necessary for life but can damage the organism if it is present in excess [1-2]. Metals such as iron are needed for physiological functions of the body [3]. Iron performs many important functions in the body [4]. It is primarily involved in the transfer of oxygen from the lungs to tissues [5]. However, iron also plays a role in metabolism as a component of some proteins and enzymes [6]. Iron deficiency is the most common nutritional deficiency and the leading cause of anemia in the World [7]. In this study, we aimed to design a biosensor for the quantitative determination of $\mathrm{Fe}+2$ in a short time and at an affordable cost.

Material and Methods

Experimental: Chemicals; All chemicals used in biosensor establishement were purchased from Sigma Chemical Co., USA. All solutions were prepared freshly just before experiment.

Apparatus: PalmSens potentiostat (Holland), and corundum ceramic based screen printed gold electrode (tickness $1.0 \mathrm{~mm}$, BVT Technologies, CZ) combined with the reference $\mathrm{Ag} / \mathrm{AgCl}$ electrode, and the auxiliary AuPd (98/2\%) electrode were used to perform the electrochmeical measurements.

In the experiments, automatic pipets (Gilson, France), a yellow line magnetic stirrer (Germany), and a thermostat (Nuve, Turkey) were used. Ultra-pure water in the preparation of solutions was obtained water purification system (Mili-Q and Milipore RIOS-DI 3 UV, USA).

Preparation of the biosensor: Prior to coating with BSA/Jelatin, the surface of $\mathrm{Au}$ ceramic electrode was polished with alumina slurries on microfiber cloth to obtain a mirror surface. The polished electrode was rinsed with double distilled water. In order to remove undisered absorbable particules, the electrode was sonicated first in pure ethanol and later in double distilled water for 10 minutes. In the next step, the electrochemical cleaning of electrode was accomplished by five successive cyclic voltammetric sweeps between -1.0 and $+1.0 \mathrm{~V}$ in $0.1 \mathrm{M}$ HNO3 solution.

The bioactive layer was prepared by immobilizing hydrogen peroxidase enzymes on the gold electrode with bovin serum albumin (BSA), gelatin, glutaraldehyde with the help of UV light.

All the measurements were executed in a thermostatic reaction cells, contained varying amounts of hydrogen peroxide concentration in the reaction medium (Sodium acetat buffer, $50 \mathrm{mM}$, pH 6.0 and $1 \mathrm{~g} / \mathrm{L} \mathrm{H} 2 \mathrm{O} 2$, at $40{ }^{\circ} \mathrm{C}$.

Principle of measurement is based on the oxidation- reduction reactions by the peroxidase enzymes in reduced form, of which convert $\mathrm{H} 2 \mathrm{O} 2$ to $\mathrm{OH}$ - and than the oxidized enzyme rejenerated by FeSO4 in the media [8]. Finally, the arrised electrochemical potential difference during these reactions was measured by voltammetry.

Results and Discussion

Electrochemical characterisation of the biosensor: After screening for a wide potantial range, cyclic voltammograms were found out at a potential range between 0.2 and $1.4 \mathrm{~V}$ (Fig 1) for measuring $\mathrm{H} 2 \mathrm{O} 2$ concentration. Cyclic voltammograms showed that immobilization of hydrogen peroxidase enzyme brought about prominent oxidation and reduction peaks.

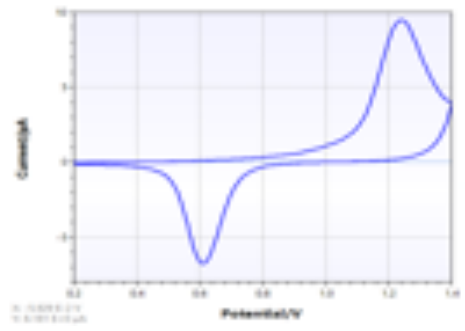

Figure 1. The cyclic voltammograms of the biosensor at different stages in a potential range of $(+0.2)-(+1.4) \mathrm{V}$ at sodium acetat buffer solution at a scan rate of $0.6 \mathrm{Vs}-1$. According to the figure 1 redox peak appeared in the cyclic voltammogram of the Au electrode.

Effect of the enzyme concentration

The amount of enzyme activity used in the biosensor preparation is the key factors for biosensor responses and sensitivity [9]. To determine the effect of the enzyme activity on the biosensor response, the different amount of enzyme concentrations $(0.05,0.1$, and $0.2 \mathrm{mg} / \mathrm{mL})$ were seperatly used for the biosensor preparation. According to the results, when the bioactive layer of biosensor contained the concentrations of hydrogen peroxidase of $0.1 \mathrm{mg} / \mathrm{mL}$, the most meaningfull curve was obtained (Fig 2.).

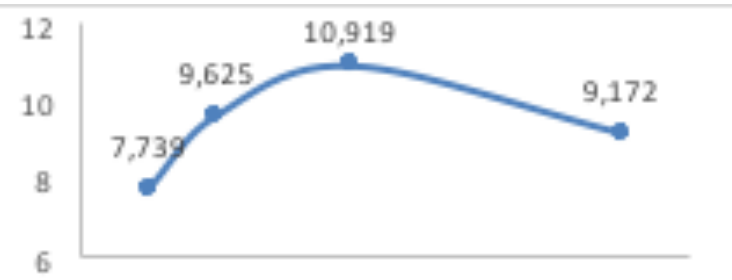

\section{$\begin{array}{llllllllll}0 & 0,25 & 0,5 & 0,75 & 1 & 1,25 & 1,5 & 1,75 & 2 & 2,25\end{array}$}

Concentration of Enzyme (HPOD) mg ml

Figure 2. The effect of hydrogen peroxidase activity on the biosensor response (sodium acetat buffer, $\mathrm{pH} 6.0,50 \mathrm{mM}, \mathrm{T}, 40{ }^{\circ} \mathrm{C}$ ) $.0 .25 \mathrm{mg} / \mathrm{ml} 0.05 \mathrm{mg} / \mathrm{ml}, 1 \mathrm{mg}$ $\mathrm{ml}, 2 \mathrm{mg} / \mathrm{ml}$ of hydrogen peroxidase.

Effect of the cross-linker concentration: To determine the effect of cross-linker concentration on the biosensor, the concentrations of glutaraldehyde of $1,5 \%$, $2,5 \%, 3 \%$ and $3,5 \%$ were used. The optimum value was obtained at $3 \%$. (Fig 3)

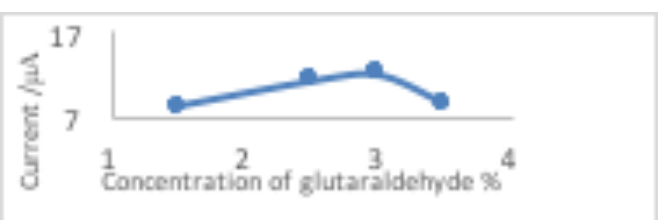

Figure 3. The effect of the cross-linker concentration activity on the biosensor response (sodium acetat buffer, pH $6.0,50 \mathrm{mM}, \mathrm{T}, 40^{\circ} \mathrm{C}$ ). $0.25 \mathrm{mg} / \mathrm{mL} 0.05 \mathrm{mg} /$ $\mathrm{mL}, 1 \mathrm{mg} / \mathrm{mL}, 2 \mathrm{mg} / \mathrm{mL}$ of hydrogen peroxidase.

Effect of $\mathrm{pH}$ on the biosensor response: Biosensors based on an enzyme depends on a suitable buffer system and $\mathrm{pH}$ medium for obtaining the best responses. To detect the effect of the $\mathrm{pH}$ value on the biosensor response, different buffer systems were investigated [10]. For this aim, acetate $(50 \mathrm{mM}, \mathrm{pH} 4.0-5.0-6.0)$ phosphate $(50 \mathrm{mM}, \mathrm{pH} 7.0)$, and Glycine/ $\mathrm{NaOH}(50 \mathrm{mM}, 8.0)$ buffers were used in the experiments. The optimum $\mathrm{pH}$ value was 6.0 due to $100 \%$ activity rate. Below and above $\mathrm{pH} 6.0$ causes a decreases in the biosensor response. Effect of temperature: For the determination of temperature effect on the biosensor response, the assay was performed by different temperature $\left(30-45^{\circ} \mathrm{C}\right)$. Optimum working temperature of the biosensors was detected as $40^{\circ} \mathrm{C}$. According to Fig. 4 , the biosensor response directly increased with temperature until $40{ }^{\circ} \mathrm{C}$, but further increase in temperature caused a decrease on the biosensor response. 


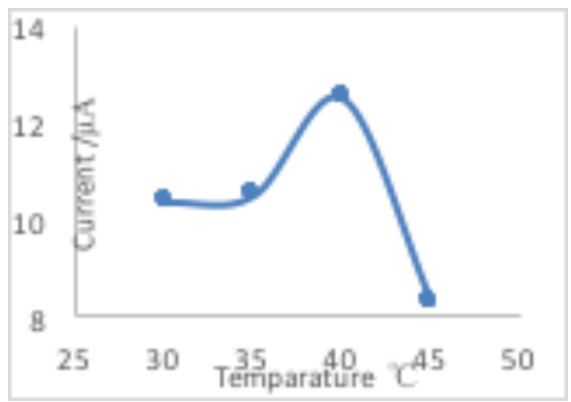

Figure 4. Calibration curve of temperature (Sodyum Acetat buffer, pH 6.0, 50 $\mathrm{mM}$ ).

Effect of scan rate on the biosensor response: In order to determine the effect of scan rate on the biosensor responses, measurements were carried out at 0.04 , 0.05 , and $0.06 \mathrm{~V} \mathrm{~s}-1$. Cyclic voltammograms obtained from the experiments showed that $0.05 \mathrm{~V} \mathrm{~s}^{-} 1$ was the optimum scan rate for the detection of hydrogen peroxide (considering the fastest response and maximum reduction in current).

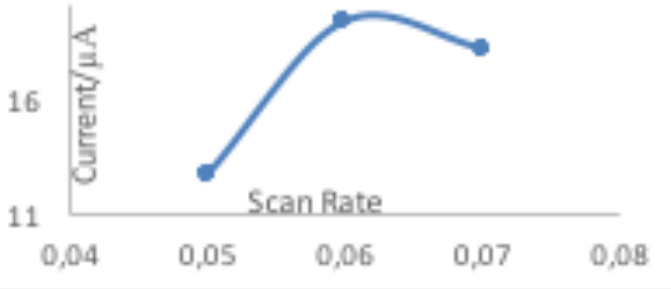

Figure 5. Calibration curve of the electrode scan rate (Sodium acetat buffer, $\mathrm{pH}$ $\left.6.0 ; 50 \mathrm{mM}, \mathrm{T}, 40^{\circ} \mathrm{C}\right)$.

Measurement of different ferrous iron amount: $25,50,75$, and $100 \mu \mathrm{g} / \mathrm{dl}$ of ferrous iron $(\mathrm{Fe}+2)$ concentration were prepared using iron sulphate and measurements were taken under optimized conditions. When the iron concentration increases,

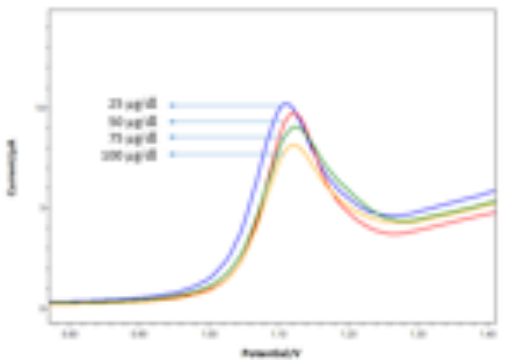

Figure 6. Measurement of different ferrous iron amount (Sodium acetat buffer, $\left.\mathrm{pH} 6.0 ; 50 \mathrm{mM}, \mathrm{T}, 40^{\circ} \mathrm{C}\right)$.

Conclusions

As a result of this work, determination of $\mathrm{Fe}+2$ via hydrogen peroxide by using biosensor method is a new approach. Determination of $\mathrm{Fe}+2$ with this method is also possible at low concentrations. According to literature the enzymatic biosensor studies have known to be very sensitive, specific, simple and less timeconsuming methods [11-12].

Consequently, we can be suggested that development of the method would be an original and useful procedure for hydrogen peroxide determination

Therefore next step towards making the sensor for in vivo studies and more portable involves further miniaturization allowing in situ monitoring of signals. References

1.Kösem A, Haklıgör A, Yücel D. Effects of Calcium (II), Magnesium (II), Copper (II) and Iron (II) Ions on Ischemia Modified Albumin. Turk J Biochem 2008;33:31-4

2.Knutson MD, Walter PB, Ames BN, Viteri FE. Both iron deficiency and daily iron supplements increase lipid peroxidation in rats. J Nutr 2000;130:621-8.

3. Tiwari AK, Mahdi AA, Chandyan S, Zahra F, Godbole MM, Jaiswar SP, et al. Oral iron supplementation leads to oxidative imbalance in anemic women: a prospective study. Clin Nutr 2011;30: 188-93.

4.Kumar N, Chandhiok N, Dhillon BS, Kumar P. Role of oxidative stres while controlling iron deficiency anemia during pregnancy- Indian scenario. Indian J Clin Biochem 2009:24:5-14.

5.Scholl TO, Hediger ML, Fischer RL, Shearer JW. Anemia versus iron deficiency: increased risk of preterm delivery. Am J Clin Nutr 1992;55:985-988. 6.Shatrugna V, Raman L, Kailash U, Balakrishna N, Rao KV. Effect of dose and formulation on iron tolerance in pregnancy. Natl Med J India 1999;12:18-20.

7.Srigiridhar K, Nair KM. Supplementation with alphatocopherol or a combination of alpha-tocopherol and ascorbic acid protects the gastrointestinal tract of iron-deficient rats against iron-induced oxidative damage during iron repletion. Br J Nutr 2000;84:165-73.

8.Srigiridhar K, Nair KM. Iron-deficient intestine is more susceptible to peroxidative damage during iron supplementation in rats. Free Radic Biol Med 1998;25:660-5.

9.Kokbas U, Kayrin L, Tuli A. Biosensors and their medical applications. Archives Medical Review Journal 2013;22: 499-513.

10.Xia Li, Shanshan Liu, Di Cao, Ran Mao, Xu Zhao. Synergetic activation of $\mathrm{H} 2 \mathrm{O} 2$ by photo-generated electrons and cathodic Fenton reaction for enhanced self-driven photoelectrocatalytic degradation of organic pollutants. Applied Catalysis B: Environmental 2018;23:1-8

11.Akkaya A, Altug C, Pazarlioglu NK, Dinckaya E. Determination of 5-Aminosalicylic Acid by Catalase-Peroxidase Based Biosensor. Electroanalysis. 2009;21(16):1805-10.

12.Dündar Yenilmez E, Kökbaș U, Kartlassmıs K, Kayrın L, Tuli A (2018) A new biosensor for noninvasive determination of fetal RHD status in maternal blood of RhD negative pregnant women. PLoS ONE 13(6): e0197855.

\section{OP-102 \\ IN SILICO ANALYSIS OF BETA-SECRETASE GENE (BACE1) WHICH PLAYS A ROLE IN ALZHEIMER'S DISEASE}

Ömer Faruk Karasakal ${ }^{1}$, Ebru Özkan Oktay², Tuğba Kaman ${ }^{3}$, Korkut Ulucan ${ }^{4}$, Muhsin Konuk ${ }^{5}$

${ }^{1}$ Uskudar University, Vocational School of Health Services, Medical Laboratory Techniques, Uskudar, Istanbul

${ }^{2}$ Uskudar University, Vocational School of Health Services, Laboratory Technology, Uskudar, Istanbul

${ }^{3}$ Uskudar University, Vocational School of Health Services, Medical and Aromatic Plants, Uskudar, Istanbul

${ }^{4}$ Marmara University, Faculty of Dentistry, Basic Medical Sciences, Department of Medical Biology and Genetics, Istanbul

${ }^{5}$ Uskudar University, Faculty of Enginering and Natural Sciences, Department of Molecular Biology and Genetics, Istanbul

OBJECTIVES: The BACE1 gene encodes $\beta$-secretase that plays a role in the formation of amyloid beta plaques in the brain that are leading to the Alzheimer's disease. The aim of this study was to determine the single nucleotide polymorphisms (SNPs) in the BACE1 gene via internet based software tools and to predict the SNPs have damaging effects on protein structure and stabilization. MATERIALS and METHODS: The NCBI dbSNP database was used to access missense SNPs in BACE1 gene. Functional effects of SNPs were determined by SIFT and PolyPhen-2 software tools. The I-Mutant 2.0 software tool was used to determine the effect of selected SNPs on protein stabilization. Furthermore, in order to determine the effects of these SNPs on the three-dimensional structure of the protein, modeling was carried out using the Project HOPE software tool. RESULTS: 271 SNPs were determined as missense in the BACE1 gene from NCBI dbSNP database. According to the both SIFT and PolyPhen-2 software tools, a total of 10 SNPs determined to have damaging effects. I-Mutant 2.0 results showed that 9 SNPs decreased protein stabilization while 1 SNP increased. Three-dimensional modeling of protein was performed with Project HOPE software tool and wild and mutant type amino acids were evaluated in terms of size, charge, and hydrophobicity. CONCLUSIONS: In our study, it has been determined that 10 SNPs located in the BACE1 gene may have damaging effects on the structure and stabilization of beta-secretase protein by means of Internet-based software tools. These results are suggested to provide data for further experimental analysis. Keywords: BACE1, Alzheimer's Disease, single nucleotide polymorphism (SNP), in silico

\section{OP-103 \\ DEVELOPMENT OF FUNCTIONALISED QCM BASED BIOSENSORS TO DETECT BREAST CANCER CELLS}

Merve Yılmaz, Ayşe Kevser Pişkin

Department of Medical Biochemistry, Faculty of Medicine, Hacettepe University, Ankara

OBJECTIVES: Transferrin, notch and Her2/neu receptors of breast cancer cells increase parallel to their metastatic potential. Quartz crystal microbalance (QCM) detects molecules by converting mass changes into an electrical signal. Here, receptor-specific ligands and/or antibodies were used to create a QCM-based system toidentifyasmallnumberofcellsviatheirreceptorsinaspecificandsensitivemanner MATERIALS and METHODS: Nanoparticles prepared using HEMA and characterized by FTIR and zeta sizer and adsorbed onto the chip surface to expand surface area. The QCM chip was functionalized by binding Her2/Neu and notch monoclonal antibodies and transferrin. MDA-MB-231, MCF7 and as negative control, mouse fibroblast cells were passed through prepared surface and system activity was investigated and binding kinetics were determined. RESULTS: The average size of the nanoparticles were $40 \mathrm{~nm}$. The contact angle has decreased considerably due to -OH groups in HEMA. QCM sensor measured $96.7 \%$ linearity at the given the range of $500-125,000$ cells $/ \mathrm{mL}$ After competing adsorption experiments and the sensogram signal values were compared. It was found that all there receptors were detected on MDA 
MB 231 cells specifically with high sensitivity by this QCM based biosensor. CONCLUSIONS: In this study, we analyzed the efficacy of functionalized QCM biosensors with three different receptor-specific antibodies and ligands, and found that transferrin, notch and Her2/neu receptor targeted QCM based sensor may offer a highly specific, rapid and sensitive method for detecting cancer cells via their overexpressed receptors. Keywords: Breast cancer, transferrin, notch, HER2/neu, biosensors, quartz cystal microbalance

\section{OP-104 \\ NAD+ DEPENDENT FORMATE DEHYDROGENASE PRODUCTION AND ENHANCEMENT OF ACTIVITY VIA PROTEIN ENGINEERING}

Hurï Bulut ${ }^{1}$, Büsra Yüksel${ }^{2}$, Mehmet Gül ${ }^{2}$, Meryem Eren², Michail Isupov ${ }^{3}$, Berin Yelmazer ${ }^{4}$, Barış Binay ${ }^{4}$, Jennifer Littlechild ${ }^{3}$, Abdürrahim Koçyiğit ${ }^{1}$ ${ }^{1}$ BezmiAlem Vakıf University, Department of Clinic BioChemistry, Istanbul ${ }^{2}$ Istanbul Technical University, Department of Moleculer Biology and Genetics, Istanbul

${ }^{3}$ University of Exeter, College of Life and Environmental Science, Exeter/UK

${ }^{4}$ Gebze Technical University, Department of Bioengineering, Kocaeli

OBJECTIVES: Enzymes have a broad ranges of utility in industries Furthermore, biochemical kits used for diagnostic, therapeutic purposes and research fields depend on enzymes for operating for accurately. Formate is an essential endogenous single-carbon metabolite. Formate levels were shown to increase in human serum, urine and exhaled breathe condensate due to metabolism of different substances in cases of especially methanol intoxication, vitamins B deficiencies, asthma and various psychiatric disorders. MATERIALS and METHODS: In our study, Candida boidinii gene-derived FDH enzyme was cloned by recombinant DNA technology and transferred to E. coli BL21 cells. The His-Trap column was used for purification of the enzyme. Enzyme activity measurements were performed spectrophotometrically at $340 \mathrm{~nm}$. Single and combined mutations were made at positions Gln287-His311-Cys262Lys328-Phe285-Val120-Asn187 using protein modeling and simulation (pymol, Gaussian09) programme in CboFDH enzyme. Optimum temperature, $\mathrm{pH}$ and comparative kinetic activity determinations were made for Wt and Mutant strains. RESULTS: The optimum $\mathrm{pH}$ for the WtFDH enzyme and the mutant FDH obtained after purification was found to be 7.4. Thermal stability studies showed that the mutant FDH activity was stable at $70^{\circ} \mathrm{C}$. The $\mathrm{Km}$ format values were $5.6 \pm 0.4 \mathrm{mM}$ for WtFDH and the values were between $4.3 \pm 0.2471$ and $5.1 \pm 0.326$ for MutFDHs. CONCLUSIONS: In particular, the single and combined mutations of the mutants FDHP285T and FHDV120S showed significantly higher activity than wtFDH in the measurement of low level format levels in serum. The robust properties of the enzymemakeitasuitablecandidateforindustrialandclinicaldiagnosticapplications. Keywords: Candida boidinii, formate, formate dehydrogenase, protein engineering, Recombinant DNA Technology

\section{OP-106 \\ DIABETES MELLITUS RELATIONSHIP WITH VITAMIN D AND VITAMIN B12 LEVELS: A RETROSPECTIVE ANALYSIS}

İlhan Sabancılar ${ }^{1}$, Gülten Toprak ${ }^{1}$, Zafer Pekkolay ${ }^{2}$, Ahmet Dönder $^{3}$, Ömer Satıci ${ }^{4}$ ${ }^{1}$ Dicle University Faculty of Medicine, Department of Biochemistry, Diyarbakir ${ }^{2}$ Dicle University Endocrinology and Metabolic Diseases, Diyarbakir ${ }^{3}$ Dicle University, Department of Medical Services and Technical AD, Diyarbakir

${ }^{4}$ Dicle University Faculty of Medicine, Biostatistics, Diyarbakir

OBJECTIVES: To compare the levels of vitamin D and vitamin B12 in patients with type 2 diabetes mellitus (DM) versus those without diabetes mellitus. MATERIALS and METHODS: Serum hemoglobin A1c (HbA1c), 25-hydroxy vitamin D, vitamin B12, calcium and phosphate levels were studied in 1932 patients (1306 women and $626 \mathrm{men}$ ) who applied to Adult Endocrinology Unit of Dicle University Medical Faculty Hospital between January 2016 and January 2018 the patients were taken to work and the results were retrospectively reviewed. According to HbAlc levels, two groups were categorized as nondiabetic and diabetic, $\leq 6.5 \%$ and $>6.5 \%$. The results were evaluated according to age, gender and seasonal variables as well as biochemical parameters. RESULTS: In the study group, diabetic patients were $41.04 \%$ (female / male: $515 / 278$ ) when as non diabetic and diabetic according to HbAlc values. Non diabetic patients were $58.96 \%$ (Female/ Male: 791/348). Diabetic patients (HbA1c level $>6.5 \%$ ) with D vitamin-B12 and D vitamin-calcium were statistically significant $(\mathrm{p}<0.001)(\mathrm{p}<0.001)$; A negative correlation between vitamin $\mathrm{D}$ and phosphorus and vitamin D HbAlc was statistically significant $(p<0.01)(p<0.01)$. CONCLUSIONS: it was seen that in the group of $\mathrm{HbAlc}>6,5 \%$,vitamin $D$ value was lower in males $(p=0,002)$ than in females $(p=0,093)$ and was meaningful in males.These findings suggest that vitamin $\mathrm{D}$ deficiency in patients with Type 2 diabetes is important in examining vitamin D and B12 levels in such chronic diseases. The statistical significance of vitamin D in male diabetic patients suggests that this may be due to hormonal differences. Keywords: B12 vitamin,type 2 diabetes,Vitamin D

\section{OP-107 \\ ASSESSMENT OF CARDIAC DYSAUTONOMIA AND VITAMIN D LEVELS IN MULTIPLE SCLEROSIS PATIENTS}

Tülin Aktürk ${ }^{1}$, Yașar Turan ${ }^{1}$, Nermin Tanık ${ }^{2}$, Müjgan Ercan Karadağ ${ }^{3}$, Hikmet Saçmac1 ${ }^{1}$, Levent Ertuğrul İnan ${ }^{1}$

${ }^{1}$ Department of Neurology, School of Medicine, Bozok University, Yozgat ${ }^{2}$ Department of Cardiology, School of Medicine, Bozok University, Yozgat ${ }^{3}$ Department of Biochemistry, School of Medicine, Bozok University, Yozgat

OBJECTIVES: Vitamin D deficiency has been described as enviromental risk factor for Multiple Sclerosis (MS). Vitamin D is a neuroactive hormone that modulates the autonomic balance. It is suggested that autonomic nervous system is related to vitamin $\mathrm{D}$ regulation. The aim of this study was investigate the serum levels of vitamin D, Vitamin D Binding protein (VDBP) and Vitamin D Receptor (VDR), as well as the evaluation of cardiac authonomic dysfunction in MS patients. MATERIALS and METHODS: This cross-sectional and prospective study examined 26 patients with relapsing remitting MS and 24 healthy matched controls. 24-hour ambulatory blood pressure measurement were performed and evaluated for orthostatic hypotension. Serum levels of vitamin D, VDBP and VDR were evaluated by taking serum samples of the patients RESULTS: Serum vitamin D levels found to be significantly lower in MS patients than in controls $(\mathrm{p}: 0,044)$ however there was no significant difference VDR ve VDBP levels in both groups. Autonomic dysfunction was detected in $38.4 \%$ of MS patients. Supine hypertension and orthostatic hypotension were found in MS patient group $(\mathrm{p}=0,023$ and $\mathrm{p}=0,023)$. Variable Blood Pressure (BPV) systolic and diastolic significantly lower in MS patients than in controls $(\mathrm{p}=0,005$ and $\mathrm{p}=0,015)$. There were a negative correlation between VDBP and EDSS and a positive correlation between vitamin D and 24-hour diastolic (BPV) in MS patients. $(\mathrm{p}=0,039, \mathrm{r}=-0,406$ and $\mathrm{p}=0,037, \mathrm{r}=0,297)$. CONCLUSIONS: In addition to findings of known cardiac autonomic dysfunction, we found supine hypertension more than control in MS patients for the first time. BPV systolic and diastolic values were lower than control too. Keywords: Multiple Sclerosis,Vitamin D, Vitamin D Binding protein,Vitamin D Receptor

\section{OP-108 \\ COMPARISON OF IMMUNOASSAY METHODS IPTH MEASUREMENT IN HEMODIALYSIS PATIENTS}

Özgür Mehmet Yis ${ }^{1}$, Mine Büșra Pehlivan ${ }^{1}$, Güler Buğgdayc1 ${ }^{1}$, Neslihan Yüce ${ }^{1}$, Rabia Nur Yildiz ${ }^{2}$

${ }^{1}$ Bolu Abant Izzet Baysal University, Department of Biochemistry, Bolu ${ }^{2}$ Izzet Baysal State Hospital, Bolu

OBJECTIVES: Intact parathyroid hormone (iPTH) test is used routinely in diagnosis, treatment and follow-up in patients with bone mineral disorders and chronic renal failure. Accumulation causes analytical problems due to reduced elimination of PTH C fragments in hemodialysis patients. We aimed to evaluate iPTH and analytical performance in hemodialysis patients with two immunoassay systems commonly used in routine laboratories (Abbott Architect i2000SR and Beckman Coulter DxI 800 Access) MATERIALS and METHODS: In analytical performance evaluation for iPTH test, LOD, LOQ and linearity studies were performed. The serum of 45 hemodialysis patients and 41 patients without renal insufficiency was used for accuracy evaluation. The samples were collected on five consecutive days and worked on both devices within the same day. For statistical evaluation of these data, Bland-Altman and regression analysis were used. RESULTS: In our study, inter-assay CV values for the three-level controls were found between $4.37-7.68 \%$ and intra-assay CV values were found between $3.60-4.33 \%$ in the Abbott Architect i2000SR. LoB, LoD and LoQ values were found $0.31 \mathrm{pg} / \mathrm{mL}, 0.85 \mathrm{pg} / \mathrm{mL}$ and $2.4 \mathrm{pg} / \mathrm{mL}$, respectively. For normal and high level controls in Beckman Coulter DxI 800 Access, CV\% inter-assay was found $6.12-7.07 \%$, intra-assay CV\% was found $4.30-4.44 \%$. LoB, LoD and LoQ values were found $0.42 \mathrm{pg} / \mathrm{mL}, 1.04 \mathrm{pg} / \mathrm{mL}$ and $5.0 \mathrm{pg} / \mathrm{mL}$, respectively. In the linear regression analysis, $R 2$ value was calculated as $0.958(\mathrm{y}=0.65 \mathrm{x}-2.32)$ for hemodialysis patients and $0.985(\mathrm{y}=0.55 \mathrm{x}+1.40)$ for the control group. CONCLUSIONS: The acceptability of analytical performance and analytical compliance of these immunoassay tests used in our laboratory for hemodialysis patients have been demonstrated.

Keywords: Immunoassay, chronic kidney disease, luminescent measurements, parathyroid hormon.

\section{OP-109 \\ IS HIGH SENSITIVE TROPONIN I EFFECTED BY EGFR RATE IN ASYMPTOMATIC RENAL FAILURE PATIENTS?}

Zumrut Mïne Isik Saglam, Esma Yucetas, Yasemin Doventas, Cihan Coskun, Ayla Yildiz, Macit Koldas

Haseki Training and Research Hospital, Istanbul

OBJECTIVES: Stably elevated troponin concentrations are commonly observed in renal failure patients in the absence of clinical evidence of myocardial damage. Specificity is even lower if newer, highly sensitive troponin assays are used. Based on the initial level, the overall accuracy for the diagnosis of 
AMI was acceptable for both sensitive and high-sensitive assays, although, depending on the assay, accuracy was lower for patients with renal dysfunction compared with those without. Consensus guidelines do not specify an assay preference. The aim of this study is to investigate the difference between hsTnI and $\mathrm{cTnI}$ assays in four groups of patients separated according to eGFR values. MATERIALS and METHODS: 378 outpatients were divided into 4 groups according to their eGFR values as Group 1:<30, Group 2: 30-60, Group 3: $60-90$ and Group 4: $>90 \mathrm{~mL} / \mathrm{min} / 1.73 \mathrm{~m} 2$. The high-sensitivite troponin I (Access hsTnI) and classic troponin I (Access hsTnI+3) concentrations were measured on Access2 Systems, Beckman Coulter. RESULTS: There was a weak but significant negative relationship between eGFR and hsTnI $[\log (y)=2.7-0.84 \log (x) ; R(2)=0.246]$ whereas there was no significant relationship between eGFR and cTnI $[\log (\mathrm{y})=1.19-0.09 \log (\mathrm{x})$; $\mathrm{R}(2)=0.021]$ when eGFR was taken into consideration as a continuous variable. CONCLUSIONS: Among asemptomatic patients who present with signs and symptoms suspicious for AMI, a change in troponin concentration (ie, rise or fall over three to six hours after presentation) should be used to define AMI, rather than a single value obtained on presentation. In this study, we found that hsTnI weakly increases with decreasing eGFR values, but cTnI is not affected by the change in eGFR values. Keywords: Asymptomatic renal failure, AMI, cTnI, hsTnI, eGFR

\section{OP-110 \\ VITAMIN D LEVELS IN CHILDHOOD AND VITAMIN D SUPPLEMENTATION}

Yasemin Ardiçoğlu Akıșınn' ${ }^{1}$ Nejat Akar ${ }^{2}$

${ }^{1}$ Department of Medical Biochemistry, Faculty of Medicine, TOBB ETU, Ankara

${ }^{2}$ Department of Pediatrics, Faculty of Medicine, TOBB ETU, Ankara

OBJECTIVES: Vitamin D is an essential nutrient that plays an important role in calcium homeostasis and bone health. The infants are at high risk of vitamin D deficiency in the first year of life. Vitamin D supplementation is a daily practice for the children in order to protect bone health. Mainly vitamin D supplementation is stopped at the age of one year; few children continue supplementation until walking, and very few until the age two. WeaimedtoscreenvitaminDlevelsinchildrenlivinginahigheconomicstatushospital. MATERIALS and METHODS: Data was obtained retrospectively between 2013 and 2017. 792 children between the ages 9 months and 24 months who came to TOBB ETU Faculty of Medicine for rutine pediatric control were taken. The groups were divided according to age as 9 months-12 months (Group1; 278 , 35\%); 13-18 months (Group 2; 265, 33\%); 18-24 months (Group 3; 104, $13 \%)$; 25-30 months(Group 4; 76, 10\%) and 31- 36 months (Group5; 69, 9\%). Serum 25(OH)D3 levels were determined by electrochemiluminescence immunoassay (Cobas 6000, Roche Diagnostics Co., Mannheim, Germany). RESULTS: According to the data, when the vitamin $\mathrm{D}$ values under $25 \mathrm{ng} / \mathrm{ml}$ were considered, deficiency rates for groups were $14 \% ; \quad 6,4 \% ; \quad 18,3 \% ; 26,3 \%$ and $34,8 \%$ respectively, CONCLUSIONS:ConsideringthatvitaminDprophylaxislasted for 12 or 18 months, vitamin D deficiency has been observed to increase after 12 months. This indicates that vitamin D levels should be controlled in children who do not continue vitamin D supplementation and, if necessary, vitamin D supplementation should be initiated. Keywords: Vitamin D, childhood, supplementation

\section{OP-111 \\ PROTECTIVE EFFECTS OF NIGELLA SATIVA ON CARBON TETRACHLORIDE-INDUCED HEPATOTOXICITY MODEL IN RATS}

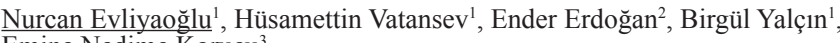
Emine Nedime Korucu

${ }^{1}$ Department of Medical Biochemistry, Faculty of Medicine, Selcuk University, Konya

${ }^{2}$ Department of Histology and Embryology, Faculty of Medicine, Selcuk

University, Konya

${ }^{3}$ Department of Molecular Biology and Genetics, Faculty of Science, Necmettin Erbakan University, Konya

OBJECTIVES: The potential protective effects of Nigella sativa oil (NSO) on carbontetrachloride-induced acute liver injury in rats was investigated in this work. Carbontetrachloride (CCl4) is an organic chemical, which causes tissue damage, especially to the liver. MATERIALS and METHODS: 32 healthy Wistar rats were divided into 4 groups which 200-300 grams of weight. Control group were received $0,4 \mathrm{~mL} /$ $\mathrm{kg}$ olive oil intraperitonealy for 14 days. NSO grup were received $0,4 \mathrm{~mL} / \mathrm{kg}$ NSO intraperitonealy for 14 days. CCl4 group were received $0,4 \mathrm{~mL} / \mathrm{kg}$ olive oil intraperitonealy for 14 days. On 14th day one hour after treatment $\mathrm{CCl} 4$ $1 \mathrm{~mL} / \mathrm{kg}$ (ip.) performed to rats. CCl4+NSO grup were received $0,4 \mathrm{~mL} / \mathrm{kg}$ NSO intraperitonealy for 14 days. On 14th day, one hour after the treatment CCl4 $1 \mathrm{~mL} / \mathrm{kg}$ (ip.) was performed to rats. 24 hour after end of the experiment, blood samples were obtained from the animals. Then the rats were sacrificed and liver tissues were taken. AST, ALT and LDH activities were measured in the blood serum with spectrophotometric method. M 30 were measured with ELISA, 3-NT were measured with HPLC method in tissue homogenates
8-OHdG analysis in nuclear extract with ELISA. Caspase-3 and Caspase-9 activity were determined with immunohistochemical methods in liver tissues. RESULTS: This study has shown that damage occurs enzymatically in the CCl4 group. For M 30 and $8-\mathrm{OHdG}$ levels there wasn't found significance. CCl4 was caused nitrosative damage. It was obtained that apoptotic indexes and 3-NT levels in group CCl4+NSY were lower than group CCl4. This decrease was found significantly $(\mathrm{p}=0,001)$. CONCLUSIONS: Consequently, It was determined that cells towards apoptosis as a result of $\mathrm{CCl} 4$ induced nitrosative damage. NSO has been found to inhibit apoptosis by protecting cells against nitrosative damage. Keywords: Hepatotoxicity, Carbontetrachloride, Nigella Sativa, M 30, 8-OHdG,3-NT

\section{Introduction}

The liver is the largest and most important organ in our body composed of different functional and anatomical structures. It plays a leading role in filtering and clearing blood received from digestive tract prior to passing it to other body tissues and organs. Furthermore, it is involved in detoxifying the body from hazardous substances, including xenobiotics and toxins, and in mediating drug transformations and metabolism. So, the liver is highly susceptible to damage from different toxins, viruses, and reactive oxygen and nitrogen species $(1,2)$. Such damage is often associated with liver metabolic and synthetic dysfunctions which can result in many disorders, ranging from the transient elevation of levels of hepatic enzymes to life-threatening hepatic fibrosis, cirrhosis of the liver, and even hepatocellular carcinoma (3).

There are more than 600 chemicals that cause damage to the liver, one of this is carbon tetrachloride $(\mathrm{CCl} 4)(4,5)$. In experimental studies of liver, higher doses o longer exposure of $\mathrm{CCl} 4$, are more serious, permanent and develop over a longer period of time, such as fatty degeneration, fibrosis, mononuclear cell infiltration, cirrhosis and even cancer $(6,7)$. At low doses, transient effects prevail, such as loss of $\mathrm{Ca}+2$ sequestration, impairment of lipid homeostasis, the release of noxious or beneficial cytokines, and apoptotic events followed by regeneration(5).

Throughout the history of humanity, many diseases have been tried to be treated using plants. Approximately $25 \%$ of prescription drugs in developed countries are active ingredients of herbal origin $(8,9)$. Nigella sativa has been described as a medicinal plant for the treatment of many diseases for more than 2000 years in many Middle Eastern and Far Eastern countries (10). Plants seeds and seed oil are the sources of the active ingradient (11). The seed oil of N. Sativa is well known for its strong antioxidant properties(12). Previous studies have documented that pre-treatment with TQ, the main active constituents in seed oil, protected organs against oxidative damage induced by a variety of free radical generating agents such as carbon tetrachloride. N. Sativa shows positive impacts on the $\mathrm{CCl} 4$ hepatotoxicity have been reported in many studies $(13,14)$. AlGhamdi(15), investigated the effects of a liquid suspension of black cumin at CCl4-derived liver damage in rats and in conclusion, N.sativa shows a protective effect on the CCl4-dependent liver hepatotoxicity has been identified. Essawy et al(16)., in their study CCl4 administered to rats, black cumin seed orally and the effects on blood cells by morpological, cytological and biochemical aspects have been investigated. Research result dedicated the antioxidant properties of black seed and at hematopoietic cells showed significant protection from $\mathrm{CCl} 4$ created damage has been reported. In many studies, N.sativa seed is lethal for various cancer cells and production of tumour-specific antibodies like stimulating properties have been found (17). In our study; The protective effect of Nigella sativa oil against CCl4-induced acute liver injury was determied by measuring 8-OHdG and 3-NT levels and the antiapoptotic effect by M30, caspase-3 and caspase-9 activities.

Materials And Methods

Animals and Treatments:In this study. 32 healthy Wistar rats were divided into 4 groups which 200-300 grams of weight. All rats were separated into four groups. These animals were fed ad libitum a diet including $20 \%$ crude protein, $0.88 \%$ calcium, phosphorus $0.44 \%$ on average, $3.7 \%$ crude fiber, $5.7 \%$ ash and $0.2 \%$ salt.The diet has $2600 \mathrm{~kg} / \mathrm{cal}$ metabolic energy.

The rats in the control group were received $0,4 \mathrm{~mL} / \mathrm{kg}$ olive oil intraperitonealy for 14 days. The rats in the Nigella sativa oil grup were received $0,4 \mathrm{~mL} / \mathrm{kg}$ Nigella sativa oil intraperitonealy for 14 days. The rats in the $\mathrm{CCl} 4$ group were received $0,4 \mathrm{~mL} / \mathrm{kg}$ olive oil intraperitonealy for 14 days. On 14th day one hour after treatment CCl4 $1 \mathrm{~mL} / \mathrm{kg}$ (ip.) performed to rats. The rats in the CCl4t Nigella sativa oil grup were received $0,4 \mathrm{~mL} / \mathrm{kg}$ Nigella sativa oil intraperitonealy for 14 days. On 14th day, one hour after the treatment CCl4 $1 \mathrm{~mL} / \mathrm{kg}$ (ip.) was performed to rats. 24 hour after end of the experiment, blood samples were obtained from the animals under ketamine anesthesia. The rats were sacrificed with ketamine anesthesia after blood collection in all groups. Liver tissues were washed with $0.9 \% \mathrm{NaCl}$ and stored in formaldehyde for immunohistochemical studies and frozen at $-80^{\circ} \mathrm{C}$ in liquid nitrogen for biochemical studies. The blood was centrifuged at $3000 \mathrm{rpm}$ for 5 minutes and the serum was separated. Serum was divided into eppendorf tubes and stored at $-80^{\circ} \mathrm{C}$. (Ethical approval number. NEÜ-2012-090)

Determination of liver functions.

Serums stored at $-80^{\circ} \mathrm{C}$ were dissolved at room temperature and AST, ALT and $\mathrm{LDH}$ levels were measured in the autoanalyser and united as $\mathrm{U} / \mathrm{L}$.

8-OHdG Measurement in Liver Tissue

8-hydroxy-2-deoxyguanosine analysis in DNA extracts obtained from livers, using the appropriate kit (EIA Kit Cayman 589320 USA) and reading at $405 \mathrm{~nm}$. 3-NT Measurement in Liver Tissue

Liver tissues stored at $-80^{\circ} \mathrm{C}$ were frozen in liquid nitrogen and homogenized with potassium phosphate buffer (1:3). $300 \mu \mathrm{L}$ of TCA was added to precipitate 
homogenate proteins. The mixture was centrifuged at 3000 RPM for $5 \mathrm{~min}$. $1 \mathrm{ml}$ of $6 \mathrm{~N} \mathrm{HCl}$ was added to the precipitate for hydrolysis and It was stored at $105^{\circ} \mathrm{C}$ for 24 hours. The supernatant was filtered through a $0.45 \mu \mathrm{m}$ membrane filter to the HPLC (Agilent 1200, UV dedector) system. According to the standard 3-NT values obtained in HPLC, the sample 3-NT concentrations were obtained from the peak areas of the samples as $\mu \mathrm{mol} / \mathrm{L}$. By calculating the 3-NT concentration obtained for $1 \mathrm{~g}$ of tissue, the amount of tissue 3-NT was given in the form of $\mathrm{nmol} / \mathrm{g}$ tissue.

M30 Measurement in Serum

Serum apoptotic M30 antigen level M30 (EIA Kit Eastbiopharm CK-E90547)

was quantitatively determined.

Determination of Caspase 3 and Caspase 9 Activities of Apoptotic Cells in Liver Tissues

Small pieces of liver tissue stored in $10 \%$ formol was taken and stored in $30 \%$ sucrose solution for 3 days and poly-L-lysine coated slides were taken for 5 microns thick caspase 3 and caspase 9 separately. preparations stained with primary antibody caspase 3 (Abcam ab 4051) and caspase 9 (Abcam ab 4053) secondary antibody Texas red (sc-2780)

Slides were covered with DAPI fluorescent closure solution. Prepared preparations were examined with a photo attachment fluorescence microscope with Texas Red and UV filters and evaluations were made. Using the UV filter of the fluorescent microscope; blue fluorescent cells were identified and counted with DAPI. Apopitotic indexes were calculated by positive red cell counts and red fluorescent labeled caspase 3 and caspase 9 positive apoptotic cell counts in the counted 100 cells

Statistical analysis

Statistical analysis was performed with Minitab-14 program. Normal dağllım Kolmogorov Simirnov testi ile belirlendi. Accordingly, the results of M30, 8-OHdG, Caspase 3 and Caspase 9 were not evaluated as normal and nonparametric Krukal-Wallis variance analysis was used and Mann-Whitney U Test and Bonferroni correction were used to determine the difference between the groups. The results of AST, ALT, LDH and 3-Nitrotyrosine were analyzed using the parametric Anova variance analysis. and Post Hoc Tukey HSD test. $\mathrm{p}<0.05$ was considered to be significant.

Results

When the macro images of liver tissues after sacrification are examined, $\mathrm{CCl} 4$ treated group had significant degeneration and lubrication. It was observed that the lubrication decreased in the NSY group with CC14. Only in the NSY group, it was determined that the lubrication started. Liver images of the groups are shown in Figure 1 .

Figure 1. Liver tissues taken from rats A: Liver tissue in control group

$\mathrm{B}$ : NSY group liver tissue C: CCl4 group liver tissue D: CCl4 + NSY group liver tissue

Aspartate Aminotransferase (AST), Alanine Aminotransferase (ALT) and Lactate Dehydrogenase (LDH) Results

Enzyme levels measured by autoanalyser AST values approximately 25 times ALT values were 60 times, and LDH values were increased 2 times in CC14 group compared to the control group. In the group given CCL4 and NSY, these values were found to be close to the control group. The levels and statistical results of these enzymes are given in Table 1.

Table 1. AST, ALT and LDH Results and Statistics

\begin{tabular}{|l|l|l|l}
\hline Gruplar & $\mathrm{n}$ & $\begin{array}{l}\text { AST (U/L) } \\
\text { Mean } \pm \text { SD }\end{array}$ & $\begin{array}{l}\text { ALT (U/L) } \\
\text { Mean } \pm \text { SD }\end{array}$ \\
\hline Kontrol & 6 & $189 \pm 81,221$ & $61,83 \pm 17,371$ \\
\hline $\mathrm{NSY}$ & 6 & $172,33 \pm 58,732^{\mathrm{c}}$ & $68,83 \pm 20^{\mathrm{c}}$ \\
\hline $\mathrm{CCl} 4$ & 10 & $3992,50 \pm 373,901^{\mathrm{a}, \mathrm{b}, \mathrm{c}}$ & $3484,38 \pm 831,364^{\mathrm{a}, \mathrm{b}, \mathrm{c}}$ \\
\hline $\mathrm{CCl}_{4}+\mathrm{NSY}$ & 10 & $353,78 \pm 151,216^{\mathrm{b}}$ & $94,56 \pm 21,755^{\mathrm{b}}$ \\
\hline
\end{tabular}

a: Control- CCl4 : p<0,001 b: CCl4-CCl4 + NSY : $p<0,001 \quad$ c: NSY-

$\mathrm{CCl} 4: \mathrm{p}<0,00$

d: Control- CC14 : p<0,016 e: $\mathrm{CCl} 4-\mathrm{CCl}+\mathrm{NSY}: \mathrm{p}<0,005 \quad$ f: NSY-

$\mathrm{CCl} 4: \mathrm{p}<0,002$

Results of 3-Nitrotyrosine

3-NT results measured in liver tissue by HPLC system were found to increase in CCl4 group. In the CCl4 + NSY group, 3-NT levels were significantly lower. The difference between the groups was statistically significant $(\mathrm{p}<0.001)$. Table 2 .

Table 2. 3-NT, 8OHdG and M30 Results and Statistics

\begin{tabular}{|l|l|l|l}
\hline Gruplar & $\mathrm{n}$ & $\begin{array}{l}3 \mathrm{NT}(\mathrm{nmol} / \mathrm{g}) \\
\text { Mean } \pm \text { SD }\end{array}$ & $\begin{array}{l}\text { MeHdG (pg/ml) } \\
\text { Mean } \pm \text { SD }\end{array}$ \\
\hline Kontrol & 6 & $717,5 \pm 118,76$ & $535,6 \pm 74,7^{\mathrm{x}}$ \\
\hline $\mathrm{NSY}$ & 6 & $1021,83 \pm 32,52^{\mathrm{d}}$ & $541,8 \pm 89,5^{\mathrm{x}}$ \\
\hline $\mathrm{CCl}_{4}$ & 10 & $2257,7 \pm 696,44 \stackrel{\text { a,c,d }}{ }$ & $607,3 \pm 62,8^{\mathrm{x}}$ \\
\hline $\mathrm{CCl}_{4}+\mathrm{NSY}$ & 10 & $1317,8 \pm 211,64 \stackrel{\mathrm{b}, \mathrm{c}}{ }$ & $568,2 \pm 130,7^{\mathrm{x}}$ \\
\hline
\end{tabular}

a : Kontrol- CCl4 :p<0,001 b:Kontrol- CCl4 + NSY:p<0,001 c : CCl4- CCl4 + NSY $: p<0,001$

d: CCl4- NSY :p $<0,001 x: p>0,005$

8-OHdG Results and Statistics

In the DNA samples isolated from liver tissue, $8-\mathrm{OHdG}$ levels increased in $\mathrm{CCl} 4$ group compared to the control group. 8-OHdG levels were increased in the NSY group with $\mathrm{CCl} 4$ but this increase was lower than the $\mathrm{CCl} 4$ group. The difference between the groups was not significant $(\mathrm{p}>0,05)$. 8-OHdG results are given in Table 2.

M30 Results

The M30 levels determined by the ELISA method, was observed that $\mathrm{CCl} 4$ group increased compared to the control group. M30 levels in the group given CCL4 and NSY, was found to be lower than $\mathrm{CCl} 4$ group. The difference between the groups was not significant ( $p>0,05)$. M 30 results are given in Table 2 .

Caspase 3 Results

In liver tissues stained with immunohistochemical methods, Increased Apoptotic cells stained with Caspase 3 in the CCl4 group, Nigella sativa oil application reduces the number of apoptotic cells, In the control group and only Nigella sativa oil groups, apoptotic cells were found to be negligible.

The difference between the groups was significant $(\mathrm{p}=0.001)$. Microscopic images of caspase 3 activities in hepatocytes and apoptotic indices are given in Figüre 2 and Table 3 .
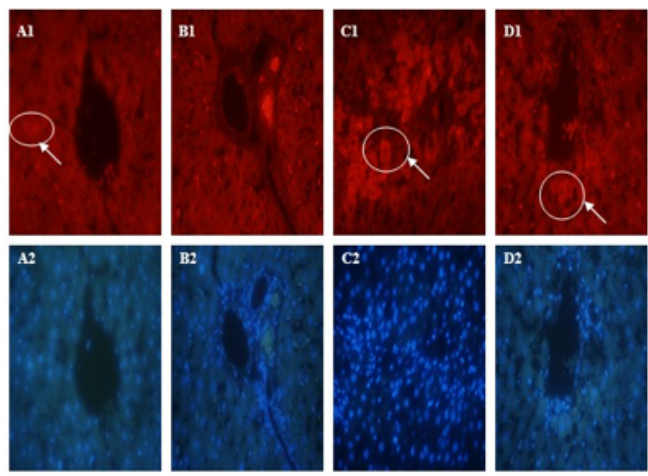

Figure2. Caspase 3 activity results;A1: control group apoptotic cells B1:NSY group apoptotic cells $\mathrm{C} 1: \mathrm{CCl}$ group apoptotic cells $\mathrm{D} 1: \mathrm{CCl}+\mathrm{NSY}$ group apoptotic cells.

A2: Live cell nuclei in the control group B2: Live cell nuclei in the NSY group $\mathrm{C} 2$ : Live cell nuclei in the CCl4 group D2: Live cell nuclei in the CCl4+NSY group.

Caspase 9 Results

In liver tissues stained with immunohistochemical methods, Increased Apoptotic cells stained with Caspase 9 in the $\mathrm{CCl} 4$ group, Nigella sativa oil application reduces the number of apoptotic cells, The control group and only Nigella sativa oil groups were found to have 1-2 apoptotic cells. The difference between the groups was significant $(\mathrm{p}=0.001)$. Microscopic images of caspase 9 activities in hepatocytes and apoptotic indices are given in Figure 3 and Table 3.
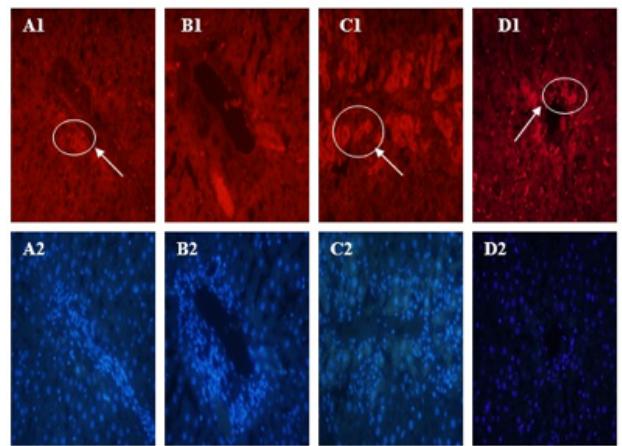
Figure 3. Caspase 9 activity results;A1: control group apoptotic cells B1:NSY group apoptotic cells $\mathrm{C} 1: \mathrm{CCl} 4$ group apoptotic cells D1:CC14+NSY group apoptotic cells.

A2: Live cell nuclei in the control group B2: Live cell nuclei in the NSY group C2: Live cell nuclei in the CC14 group D2: Live cell nuclei in the CC14+NSY group.

Table 3. Caspase-3 and Caspase-9 Apoptotic index and statistics

\begin{tabular}{|c|c|c|c|}
\hline Groups & $\mathrm{n}$ & $\begin{array}{l}\text { CASPASE-3 } \\
\text { Median (min-max) }\end{array}$ & $\begin{array}{l}\text { CASPASE-9 } \\
\text { Median (min-max) }\end{array}$ \\
\hline Control & 6 & $0,25(0-2)$ & $0(0-1)$ \\
\hline NSY & 6 & $0,25(0-2)^{b, d}$ & $1,15(0-2)^{\mathrm{b}, \mathrm{d}}$ \\
\hline $\mathrm{CCl}_{4}$ & 10 & $25(20-\underline{30})^{\mathrm{a}, \mathrm{b}, \mathrm{c}}$ & $22,5(19-\underline{32})^{a, b, c}$ \\
\hline $\mathrm{CCl}_{4}+\mathrm{NSY}$ & 10 & $10(7,2-12)^{\text {c,d,e }}$ & $10(7,5-12)^{\text {c,d,e }}$ \\
\hline
\end{tabular}

a: Control- CCl4 :p=0,001 b:NSY- CCl4 :p=0,001 c:CCl4 - CCl4 + NSY $: p=0,001$

d: NSY- CCl4 + NSY : $=0,001 \quad$ e: Control- CCl4 + NS :p $=0,001$

Discussion

Recently, the effects of many plants on the prevention of liver damage have been investigated. A wide range of research is being carried out in this area regarding the seeds, oil and active ingredients of Nigella sativa. According to present literatüre, many plant sources have been used against the negative effects of carbon tetrachloride for long time(18). Nigella sativa is one of the most known among them, traditionally used against a wide range of diseases. Jaswal and shukla(19). studied therapeutic effects of N.sativa seed extract on carbon tetrachloride induced liver injury, their biochemical and histopathological results showed that the aqueous extract of seed can be used as the hepatoprotective agent. Kanter (20). emphasized that black cumin seeds have been protective effects in rat liver at their study too. CCI4 is applied in a single dose in many studies, AST, ALT and LDH values increased significantly within 24 hours after acute toxicity conducted in Turkey and abroad (21). In our study, acute hepatotoxicity was observed in CCI4 group in accordance with the literature. There was a significant increase in AST, ALT and LDH values only in CCI4 group, Increased levels of AST, ALT and LDH in the Nigella sativa oil group were significantly lower before CCI4 was given and the values in this group were close to the values in the control group.

In the literature, there are publications reporting that CCI4 causes oxidative (22) and nitrosative damage $(23,24)$. In our literature, we did not find any study such as our study investigating the effect of Nigella sativa on liver tissue against stress caused by CCI4. 8-OHdG is formed by the oxidation of the $\mathrm{OH}$ radical to the 8th carbon of the guanine from the DNA bases. $8-\mathrm{OHdG}$ reflects DNA damage in oxidative stress.

From Kadiiska et al and Aksit(24,25) studies, 8-OHdG levels were given to CCl4 dose and depending on the expected time for toxicity After $\mathrm{CCl} 4$ administration, these peaks decrease after a certain time period. Nakamoto et al (26). reported that there was no significant difference between the groups 24 hours after CCl4 administration. In our study, blood samples were taken 24 hours after application of CCl4 (1ml / kg i.p.) to rats and rats were sacrificed and liver tissues were taken. It was observed that 8-OHdG levels increased in liver tissues compared to control group in $\mathrm{CCl} 4$ group. In the $\mathrm{CCl} 4+\mathrm{NSY}$ group, 8-OHdG levels increased and this increase was lower than the $\mathrm{CCl} 4$ group. The difference between the groups was not statistically significant $(\mathrm{p}>0.05)$. The dose $(1 \mathrm{ml} / \mathrm{kg}$ i.p.) $\mathrm{CCl} 4$ given to the rats does not reflect the oxidative stress at the end of 24 hours in terms of 8-OHdG parameters.

3 -nitrotyrosine is a frequently used indicator of nitrosative damage. Soleimani et al. (27), in their study, have proven that CCl4 induced nitrosative stress. Taysi et al. (28) investigated the antioxidant and radioprotective effects of Nigella sativa oil on cataracts induced by ionizing radiation in lenses. Nitrosative stress parameters were significantly decreased in the NSY and TQ groups compared to the IR group. The 3-NT levels we measured as an indirect marker of peroxynitrite were increased only in the CCI4-treated group.In the group with Nigella sativa oil before CCI4 administration, the increase in 3-NT levels was suppressed. The difference between the groups was found to be statistically significant ( $p$ $<0.001)$. In accordance with the literature, $\mathrm{CCl} 4$ produced nitrous damage to the liver. Nigella sativa oil is protected against damage by inhibiting the increase in peroxynitrite by antioxidant effect. Damage cannot be repaired when increased amount of peroxynitrite reaches cellular damage level and cell is directed towards death by apoptosis or necrosis (29).

Cytokeratins released into the serum reflect the stage after the end of cell death. M30 levels are not liver-specific but indicate circulating apoptosis. Serum M30 levels of circulating apoptosis in our study, Increased in CCl4 group compared to control groups, In the NSY group with $\mathrm{CCl} 4$, however, the difference between the experimental groups was found to be statistically insignificant. Apoptosis can be triggered by extracellular or intracellular signals. Apoptotic indices for caspase 8 and caspase 9 antigens in tissues, It can be interpreted that apoptosis is induced by receptor-mediated extrinsic or mitochondrial-mediated intrinsically. Caspase 3 is the intersection of these two pathways. $\mathrm{CCl} 4$ has been reported to increase apoptosis by activating Caspase 3 in the liver (30). In our study, activation of caspase 3 and caspase 9 in liver tissue was investigated. There was almost no apoptosis in the control groups, Apoptosis significantly increased in CCl4 group and CCL4 and Nigella sativa oil were found to be decreased in the given groups. We think that nigella sativa oil inhibits apoptosis by protecting cells against damage.

As a result; Nigella sativa oil inhibits apoptosis by suppressing nitrosative stress and protects the liver from damage caused by toxicity.

References

1. Hong Lu Y. Tian CR, Gao CY, Wang WJ, Yang WY, Kong X, Chen YX and Liu ZZ. Protective effect of free phenolics from Lycopus lucidus Turcz. root on carbon tetrachloride-induced liver injury in vivo and in vitro Citation: Food \& Nutrition Research 2018, 62: 1398.

2.Hoek JB, Pastorino JG. Ethanol, oxidative stress, and cytokine-induced liver cell injury. Alcohol 2002; 27: 63-8.

3.Srivastava A, Shivanandappa T. Hepatoprotective effect of the root extract of Decalepis hamiltonii against carbon tetrachloride-induced oxidative stress in rats. Food Chem 2010; 18: 411-17.

4.Zimmerman HJ. The adverse effects of drugs and other chemicals in the liver Hepatotoxicity.Appleton Century Crofts, New York. 1978

5.Robbins SL,Cotran RS \& Kumar V. Basic Pathology. 6th Ed, WB Saunders Company Philadelphia.2000.516

6.Manibusan MK, Odin M \& Eastmond DA. Postulated carbon tetrachloride mode of action: a rewiev. J Environ Sci Health C Environ Carcinog Ecotoxicol Rev, 25.2007.185.

7.Jadhav VB, Thakare VN, Suralkar AA, Deshpande AD \& Naik SR. Hepatoprotective activity of Luffa acutangula against CCL4 and rifampicin induced liver toxicity in rats.Indian J Exp Biol.,48 2010.822

8.Farnsworth NR, Akerev O. Bingel AS. The Bullettion of WHO.1985;63:986571 .

9.Faydaoğlu E, Sürücüoğlu MS. Geçmisten günümüze tıbbi ve aromatik bitkilerin kullanılması ve ekonomik önemi. Kastamonu Üni. Orman Fakültesi Dergisi. 2011;11(1): 52 - 67 .

10.Baytop T. Türkiye'de Bitkiler ile Tedavi. İstanbul. İ.Ü. Yayınları. 1984;3255. 11.Goreja WG. Black Seed: Nature's Miracle Remedy. Amazing Herbs Press, New York NY7.2003.

12.Badary OA, Taha RA, Gamal el-Din AM\& Abdel-Wahab MH.Thimoquinone is a potent Superoxide Anion Scavenger. Drug and Chemical Toxicology, 26:87. 13.Mansour M.A, Ginawi O. T, El-Hadiyah T, El-Khatib A.S, Al-Shabanah O.A, Al-Sawaf H.A. Effects of volatile oil constituents of nigella sativa on carbon tetrachloride -induced hepatotoxicity in mice: Evidence For Ant1oxidant Effects Of Thymoquinone Res. Commun. Mol. Pathol. Pharmacol.2001;110: (3\&4); 239-251.

14.Meral I, Kanter M. Effects of Nigella sativa L. and Urtica dioica L. on selected mineral status and hematological values in CCl4-treated rats. Biol Trace Elem Res 2003;96(1-3):263-70.

15.Al-Ghamdi MS, Protective Effect of Nigella sativa seeds against carbon tetrachloride-induced Liver Damage. Am. J. Chin. Med.31.2013.721

16.Essawy AE, Hamed SS, Abdel-Moneim Am, Abou-gabal AA \& Alzergy AA

Role of black seeds in ameliorating carbon tetrachloride induced haematotoxicity in Swiss albino mice. Journal of Medicinal Plants Research 4.2010

17.Salem ML \& Hossain MS, Protective effect of black seed oil from Nigella sativa against murine cytomegalovirus infection. Int. J Immunopharmacol,22.2000.729 18. Karaca Ö, Pekmez H, Kuș MA, Akpolat N, Ögetürk M, Kuș İ. Deneysel karbon tetraklorür toksisitesi sonucu karaciğerdeki IŞP70 immünoreaksiyon artışı üzerine melatonin hormonunun etkisi F.U..Sağ.Bil.Tıp Derg. 2011; 25 (2): $73-76$

19.Jaswal A \& Shukla S, Therappeutic efficacy of Nigella sativa Linn. Seed extract against CCl4 induced hepatic injury in Wistar rats. Indian J Exp Biol. 53.2015.44

20. Kanter M, Coskun O, Budancamanak M. Hepatoprotective effects of Nigella sativa $\mathrm{L}$ and Urtica dioica $\mathrm{L}$ on lipid peroxidation, antioxidant enzyme systems and liver enzymes in carbon tetrachloride-treated rats. World J Gastroenterol. 2005 Nov 14;11(42):6684-8.

21. Yılmaz T. Sıçanlarda karbon tetraklorür ile olusturulan karaciğer hasarına amaranthus lividus (a.blitum) bitkisinin antioksidan ve hepatoprotektif etkilerinin incelenmesi. İstanbul Üniversitesi Sağlık Bilimleri Enstitüsü. 2010

22. Bayram İ, Özbek H, Uğraș S, Tuncer İ, Reçber D. Askorbik asit ve alfatokoferolün karbontetraklorürle olusturulmus akut karaciger toksisitesi modelinde karacigeri koruyucu etkisi Van Tip Dergisi 2004; 11 (2):32-38.

23. Slater TF. Free-radical mechanisms in tissue injury. Biochem. J. 1984;222:115 .

24.Kadiiska $\mathrm{MB}$ at al. Biomarkers of oxidative stress study; are oxidation products of lipids, proteins, and DNA markers of $\mathrm{CCl} 4$ poisoning? Free Radic. Biol. Med.2005;38:698-710.

25.Akșit H. Deneysel karaciğer intoksikasyonunda DNA hasarının belirlenmesi Ve N Asetil Sisteinin rolü Adnan Menderes Üniversitesi Sağlık Bilimleri Enstitüsü Biyokimya Anabilim Dalı. Doktora Tezi

26. Nakamoto N, Tada S, Kameyamak, Kitamura K, Kurita S, Saito Y, Saito H, And Ishı1 H. A free radical scavenger, edaravone, attenuates steatosis and cell death via reducing inflammatory cytokine production in rat acute liver injury. Free Radical Research.2003; Volume 37 Number 8:2003, pp. 849-859.

27. Soleimani H, Ranjbar A, Baeeri M, Mohammadirad A, Khorasani R, Yasa N 
and Abdollahi M. Rat Plasma Oxidation Status After Nigella Sativa L.Botanical Treatment in CCL4-Treated Rats Toxicology Mechanisms and Methods. 2008; $18: 725-731$

28. Taysi S, Abdulrahman ZK, Okumuş S, Demir E, Demir T, Akan M, Sarıçicek E, Sarıçicek V, Aksoy A, and Tarakcıoğlu M. The radioprotective effect of Nigella sativa on nitrosative stress in lens tissue in radiation-induced cataract in rat Cutan Ocul Toxicol.2014;Early Online:1-6.

29.Erdal N,Gürgül S,Tamer L ve Ayaz L. Effect of long-term exposure of extremely low frequency magnetic field on oxidative/nitrosative stres in rat liver.J. Rdiat. Res.2008;49:181-7

30.Sun F, Hamagawa E, Tsutsui C, ve ark. Evaluation of oxidative stres during apoptosis and necrosis caused by carbon tetrachloride in rat liver. Biochimica at Biophysica Acta, 2001;1535:186-191

\section{OP-112}

\section{INVESTIGATION OF LITHIUM CARBONATE'S EFFECT ON HUMAN} BLOOD LYMPHOCYTES IN IN VITRO ENVIRONMENT

Bülent Adar ${ }^{1}$, Selçuk Akın², Ahmet Kaymaz

${ }^{1}$ Department of Clinical Biochemistry, University of Health Sciences Van Education and Research Hospital, Van

${ }^{2}$ Department of Clinical Biochemistry, Batman State Hospital, Batman ${ }^{3}$ Department of Clinical Biochemistry, Sanlıurfa Education and Research Hospital, Şanlıurfa

OBJECTIVES: Lithium is an important drug which is used in the treatment and prophylaxis of depression and manic-depressive illness. Lithium has the narrow therapeutic treatment range and it has too much potential side effects. In this study we aimed to investigate cytotoxicity, genotoxicity and oxidative effects of lithium at different concentrations on lymphocytes in in vitro environment. MATERIALS and METHODS: Different concentrations of LiCO3 (lithium carbonate) solutions, Negative and Positive control groups were prepared. After 24 hours of incubation MTT((3-[4,5-dimethylthiazol-2-yl]-2,5 diphenyl tetrazolium bromide)) assay was performed. After 36 hours the genotoxicity investigated with the comet assay method, the oxidativeantioxidative effects were investigated with a colorimetric method. RESULTS: $1 \mathrm{mM}$ lithium almost had no cytotoxic effect on cells by the MTT assay but with increasing concentrations of lithium this cytotoxic effect found to be increased. When groups were compared in terms of TAS (total antioxidant status) levels; $1 \mathrm{mM}$ Lithium carbonate containing group was higher than the other groups and significantly higher than negative control group $(p<0.05)$. When groups were compared in terms of the DNA damage and TOS (total oxidant status) level, lithium-treated groups had no significant difference compared with the negative control group ( $p>0.05)$. CONCLUSIONS: Based on our findings, lithium carbonate can be used as a reliable drug at the mean therapeutic concentration of $1 \mathrm{mM}$ because of the antioxidant properties at these doses, we can say that these doses may have protective effect against oxidative damage and cytotoxic effect due to its antioxidant property and the therapeutic effect may be related to this antioxidant property. Keywords: Antioxidant, Cytotoxicity, Genotoxicity, Lithium, Oxidant

\section{OP-114 \\ IN ACUTE DISTAL COLITIC RATS; HEALING EFFECT OF MEDICAL OZONE THERAPY}

Feyza Yağmur Tekeli ${ }^{1}$, Seçkin Özgür Tekeli ${ }^{1}$, Tuğrul Çakır², Arif Aslaner ${ }^{2}$, Sema $\mathrm{Avc1}^{3}$, Uğur Doğan ${ }^{2}$, Hakan Soylu ${ }^{3}$, Cebrail Akyüz ${ }^{4}$, Süleyman Koç ${ }^{4}$, İsmail Üstünel ${ }^{5}$, Necat Yilmaz

${ }^{1}$ Department of Biochemistry, Antalya Training and Research Hospital, Antalya. ${ }^{2}$ Department of General Surgery, Antalya Training and Research Hospital, Antalya.

${ }^{3}$. Department of Histology and Embryology, Akdeniz University, Antalya ${ }^{4}$ Department of Gastroenterology, Haydarpaşa Training and Research Hospital, Istanbul

${ }^{5}$ Department of General Surgery, Inonü University Faculty of Medicine, Malatya. Scientific content of the study.

OBJECTIVES: To investigate the effect of medical ozone treatment on the experimental acute distal colitis in rats.

MATERIALS and METHODS: Eighteen rats were randomly distributed into three equal groups; control, acute distal colitis (ADC) without and with medical ozone treatment. Rats in the control group were taken saline. ADC was performed by rectal way with $4 \%$ acetic acid in groups 2 and 3 , and the group 3 was treated with medical ozone for three weeks both rectally and intraperitoneally. At the twenty second day the distal colons samples were obtained for malondialdehyde and myeloperoxidase, blood samples were obtained to measure the levels of TNF- $\alpha$ and IL-1 $\beta$ levels. Histolopatological examination was evaluated with Ki-67, IL-1 $\beta$ and VEGF immunostaining densities.

RESULTS: There was significant increase in tissue MDA, MPO activity, TNF- $\alpha$ and IL-1 $\beta$ after ozone administration. There was also a significant difference at immunostaining densities of histopathological examination CONCLUSIONS: Medical ozone treatment ameliorated the experimental acute distalcolitis induced by aceticacid in rats. Its possibleeffect is by means ofdecreasing inflammation, edema, and affecting the proliferation and the vascularization
Keywords: Ozone, Acetic Acid, Colitis, Rats

\section{OP-115 \\ ANTIPROLIFERATIVE EFFECTS OF THYMOQUINONE IN HEPG2 CELLS INVOLVE INCREASED CERAMIDE AND CASPASE 3}

Ebru Afșar ${ }^{1}$, Özlem Yilmaz², Sabriye Kaya ${ }^{1}$, Mutay Aslan ${ }^{1}$ Department of Medical Biochemistry, Akdeniz University Faculty of Medicine, Antalya,

${ }^{2}$ Human Gene and Cell Therapy Center, Akdeniz University Faculty of Medicine, Antalya

OBJECTIVES: Previous studies have shown that thymoquinone (TQ), an active compound of black seed, has anticancer properties. However, the antiproliferative mechanisms of TQ on cancer cells is unclear. Our study aimed to investigate the impact of TQ on neutral sphingomyelinase activity (N-SMase), ceramide levels and apoptotic pathways in HepG2 human liver cancer cell line. MATERIALS and METHODS: Antiproliferative effect was exerted in HepG2 liver cancer cells via TQ incubation at different doses and durations. Cell viability was measured by MTT assay. Levels of C16-C24 sphingomyelins (SM) and C16-C24 ceramides (CER) were determined in cell lysates by an optimized multiple reaction monitoring (MRM) method using ultra fast-liquid chromatography (UFLC) coupled with tandem mass spectrometry (MS/MS). Neutral sphingomyelinase enzyme activity was measured by a colorimetric assay. Caspase -3 activity in cell lysates was measured via a fluorometric method RESULTS: Incubation with $100-200 \mu \mathrm{M}$ TQ for 18 hours significantly decreased cell viability when compared to control. A significant increase was observed in N-SMase activity, cellular levels of C16-C24 CERs and caspase-3 enzyme activity in cells treated with $100-200 \mu \mathrm{M}$ TQ for 24 hours compared to controls. A significant decrease was found in C16 SM levels in cells treated with $200 \mu \mathrm{M}$ TQ for 24 hours compared to controls. CONCLUSIONS: Our data suggests that N-SMase, caspase-3 and CER levels can be regulated in HepG2 human liver cancer cells by TQ treatment and that TQ can potentially be a pharmaceutical agent in the treatment of liver cancer Keywords: Liver cancer, thymoquinone, neutral sphingomyelinase, ceramide

OP-116

THYMOQUINONE UPREGULATES NEUTRAL SPHINGOMYELINASE ACTIVITY AND CERAMIDE LEVELS IN MCF7 CELLS

Sabriye Kaya $^{1}$, Ebru Afşar ${ }^{1}$, Mutay Aslan $^{1}$, Özlem Y1lmaz

${ }^{1}$ Department of Medical Biochemistry, Akdeniz University Medical Faculty, Antalya

${ }^{2}$ Human Gene and Cell Therapy Center, Akdeniz University Faculty of

Medicine, Antalya

OBJECTIVES: Previous studies have shown that thymoquinone (TQ), an active compound of black seed, has anticancer properties. However, the antiproliferative mechanisms of TQ on cancer cells is unclear. Our study aimed to investigate the impact of TQ on neutral sphingomyelinase activity (N-SMase), ceramide levels and apoptotic pathways in MCF-7 human breast cancer cell line. MATERIALS and METHODS: Antiproliferative effect was exerted in MCF7 breast cancer cells via TQ incubation at different doses and durations. Cell viability was measured by MTT assay. Levels of C16-C24 sphingomyelins (SM) and C16-C24 ceramides (CER) were determined in cell lysates by an optimized multiple reaction monitoring (MRM) method using ultra fast-liquid chromatography (UFLC) coupled with tandem mass spectrometry (MS/MS) Neutral sphingomyelinase enzyme activity was measured by a colorimetric assay. Caspase -3 activity in cell lysates was measured via a fluorometric method. RESULTS: Incubation with $100 \mu \mathrm{M}$ TQ for 18 hours significantly decreased cell viability when compared to control. 24 hour treatment of cells with equal amount of TQ caused a more pronounced decrease in cell viability. A significant increase was observed in N-SMase activity and cellular levels of C16-C24 CERs in cells treated with $100 \mu \mathrm{M}$ TQ for 24 hours compared to controls. A significant decrease was found in C16 SM levels in cells treated with $100 \mu \mathrm{M}$ TQ for 24 hours compared to controls CONCLUSIONS: Our data suggests that N-SMase and CER levels can be regulated in MCF-7 human breast cancer cells by TQ treatment and that TQ can potentially be a pharmaceutical agent in the treatment of breast cancer. Keywords: Breast cancer, ceramide, neutral sphingomyelinase, thymoquinone,

\section{OP-117 \\ THE PREVALENCE OF ILLEGAL SUBSTANCE USE IN BALIKESIR REGION; A LABORATORY DATA MINING STUDY}

Medine Alpdemir, Mehmet Fatih Alpdemir

Clinical Biochemistry Laboratory, Balıkesir State Hospital, Balıkesir

OBJECTIVES: Drug abuse screening test is performed clinical toxicology, forensic toxicology and social toxicology (start of work, sport and school) areas. The purpose of this study is showed the prevalence of illegal substance use in our region according to drug abuse screening test results of our laboratory. MATERIALS and METHODS: In this study, the data of urine specimens 
accepted to the Balikesir State Hospital Clinical Biochemistry Laboratory for substance analysis between July 2016 and July 2018 was retrospectively analyzed from the laboratory information system. Substance screening was performed for the tests of amphetamine, benzodiazepine, opiate, cocaine, cannabis, buprenorphine, barbiturate, ecstasy, and bonzai-1, 2, 3. After the sample was delivered, the characteristics of urine (quantity, temperature, appearance) and urine composition (creatinine, $\mathrm{pH}$, density, nitrite, oxidant) were analyzed for suitability. Inappropriate samples were rejected. RESULTS: During this period, 3422 samples were accepted for urine analysis in 2771 patients ( $\mathrm{E}: 97.4 \%, \mathrm{~K}: 2.6 \%$ ). 95.6\% of the cases were of probation, $1.2 \%$ of the clinics (emergency and intensive care) and $3.2 \%$ of came for the job application. According to the number of patients, the positivity rate was $5.6 \%$ and the positivity rate was $12.6 \%$ according to the total number of samples analyzed. The most commonly used substance in our study was cannabis. This was followed by ecstasy, amphetamine, bonzai 3 and benzodiazepine. CONCLUSIONS: In conclusion, analysis of the substance use profile based on the laboratory data of the region, information on substance use prevalence and profile is thought to be useful for preventive studies. Keywords: Probation, Drug Abuse Screening Test, Urine

\section{OP-118 \\ 25-OH VITAMIN D3 DEPENDENT INTACT PARATHYROID HORMONE REFERENCE VALUE STUDY}

Fatih Özçelik ${ }^{1}$, Büssra Efem Toy ${ }^{2}$, Halime Hanım Pençe ${ }^{3}$

${ }^{1}$ University of Health Sciences, Sultan Abdulhamid Han Training Hospital

Medical Biochemistry, İstanbul

${ }^{2}$ University of Health Sciences, Haydarpaşa Numune Training Hospital

Medical Biochemistry, İstanbul

${ }^{3}$ University of Health Sciences, Department of Medical Biochemistry, İstanbul

OBJECTIVES: We aimed to determine the reference range for intact$\mathrm{PTH}$ relative to different levels of vitamin $\mathrm{D}$ for our population in order to provide more effective diagnostic and therapeutic results in accordance with IFCC standards in line with our clinical needs. MATERIALS and METHODS: Healthy 513 subjects included in the study were divided into 3 groups according to $25-\mathrm{OHVitD} 3$ levels(25-OHVitD3 $<20 \mathrm{ng} /$ $\mathrm{ml}=$ Group I, $20 \mathrm{ng} / \mathrm{ml} \leq 25$-OH Vit D $3<30 \mathrm{ng} / \mathrm{ml}=$ Group II,25-OH Vit D3 $\geq 30 \mathrm{ng} /$ $\mathrm{ml}=$ Group III). Calcium, magnesium, phosphorus,25-OHVitD3,Abbott I-PTH were studied in serum samples;eGFR values were calculated.The I-PTH reference interval was calculated according to different 25-OHVitD3 levels.I-PTH levels in Roche and Siemens instruments were measured in 472 of populations to determine the relationship between different methods. RESULTS: 154 of the population were in group I,111 were in group II,248 were in group III.I-PTH levels of all populations were found to moderately correlate with 25-OHVitD3 levels(Spearman $r=-0.568, \mathrm{P}<0.001)$. The Abbott I-PTH values were highly correlated with Siemens and Roche I-PTH values $(r=0.941, r=0.957, \mathrm{P}<0.0001$; respectively $)$, the I-PTH median/ mean values were statistically different from each other(56.2/62.7 \pm 26.0 , $44.7 / 50.3 \pm 20.9, \quad 33.6 / 37.1 \pm 14.8, \mathrm{P}<0.0001)$. The widest reference interval belonged to the Abbott method.As Abbott I-PTH levels were influenced by $25-\mathrm{OH}$ Vit D3 levels, the reference interval value meeting the clinical need for Group III reference population was determined to be $17.7-90.9 \mathrm{pg} / \mathrm{ml}$. CONCLUSIONS: Each laboratory should determine the reference interval for each method that doesn't have absolute compliance,considering its clinical needs according to its own population. As the D vitamin affects the parathormone level,I-PTH reference range study should also be determine to be different $25-\mathrm{OHVitD} 3$ levels and I-PTH reference intervals should be reported according to 25-OHVitD3 level if possible. Keywords: Parathyroid hormone, Vitamine D, Reference value

\section{OP-119 \\ BIOCHEMICAL EVALUATION OF A NOVEL ANTI-CANCER DRUG CANDIDATE}

Selvi Durmuș Erim ${ }^{1}$, Engin Ulukaya ${ }^{1}$, Özgür Şahin ${ }^{2}$

'Department of Medical Biochemistry, Faculty of Medicine, İstinye University, Istanbul

${ }^{2}$ Department of Molecular Biology and Genetics, Bilkent University, Ankara

OBJECTIVES: In this study, we aimed to evaluate anti-cancer drug candidacy of a novel palladium(II) barbiturate complex with a comparison to cisplatin side-by-side, becauseitisalsoaheavy-metal-basedcompoundandanestablishedanti-cancerdrug. MATERIALS and METHODS: We analyzed the cytotoxic effects of palladium compound in various breasct cancer cells, analyzed cell death mode and serum biochemistry profile after injections into mice. RESULTS: We found that our compound has 14-fold lower IC50 values with an apoptotic cell death via cleaved PARP, cleaved caspase 3, bax, bid and bcl2 in MDA-MB-231 cells. Serum biochemistry analysis in mice showed that palladium compound was superior to cisplatin in terms of kidney damage. The serum urea, but not creatinine levels were significantly increased cisplatin, but not after any of palladium dose groups suggesting that the cisplatin-induced nephrotoxicity is probably not a risk for our compound. On the other hand, only $2.5 \mathrm{mg} / \mathrm{kg}$ palladium dose increased the serum AST levels, but not ALT or ALP parameters suggesting for a possibility of liver damage. Cisplatin also increased AST levels, but this was not significant. Serum albumin, total protein and cholesterol levels generally remained the same in all treatment groups. These results were also supported by histological analyses of the relevant organs. CONCLUSIONS: Altogether, our results suggest that we may have a more potent anti-cancer drug candidate than cisplatin in terms of in vitro anti-cancer activity found by more cytotoxicity and apoptotic cell death and in vivo drug candidacy shown by a more preferrable serum biochemistry profile for tissue damage. Keywords: kanser, ilaç, serum biyokimyası, cisplatin, palladyum

\section{OP-120 \\ INVESTIGATION OF ANTICANCER POTENTIAL OF SILICON (IV) PHTHALOCYANINE AND NAPTHALOCYANINE}

Burak Barut ${ }^{1}$, Arzu Özel ${ }^{1}$, Turgut Keleş², Zekeriya Bıyıklığlu ${ }^{2}$ 'Karadeniz Technical University Faculty of Pharmacy, Biochemistry, Trabzon ${ }^{2}$ Karadeniz Technical University Faculty of Science, Chemistry, Trabzon

OBJECTIVES: Cancer is the second most common cause of death after cardiovascular diseases in worldwide. Silicon (IV) phthalocyanines and naphthalocyanines are promising molecules for diagnostic and therapy usage in cancer. In this study, anticancer potential of two water soluble novel silicon (IV) phthalocyanine and napthalocyanine bearing pyridine group using different techniques were investigated. MATERIALS and METHODS: The binding properties of two water soluble novel silicon(IV) phthalocyanine and napthalocyanine bearing pyridine groups (1a and 2a) with CT-DNA were investigated absorption titration, competitive ethidium bromide and electrophoresis experiments. The DNA cleavage activities and topoisomerase I and II inhibition properties of compounds were investigated using pBR322DNAonagarosegelelectrophoresis. The cytotoxiceffects of the compounds were tested against human lung (A549), breast (BT-20), liver (SNU-398), prostate (DU-145) cancer and melanoma (SK-MEL 128) cell lines using MTT assay. RESULTS: The DNA binding studies showed that compounds interacted with CT-DNA strongly. The compounds showed low cleavage activities in the dark whereas they had remarkable photocleavage effects via singlet oxygen pathways under irradiation. The compounds showed moderate topoisomerases inhibition compared to irinotecan and doxorubicin which are used as positive controls. The CC50 values of compounds $1 \mathrm{a} / 2 \mathrm{a}$ were determined as $6.06 / 6.05,15.02 / 19.04,2.15 / 40.23,15.61 / 35.19$ and 7.78/7.46 $\mu \mathrm{M}$ toward A549, BT-20, SNU-398, DU-145 and SK-MEL 128 CONCLUSIONS: The results suggested that the compounds are a very promising candidate as an anticancer agent compared to cis-platin as a positive control. This study was supported by The Scientific \& Technological Research Council of Turkey (TÜBİTAK, project no: 116Z364). Keywords: CT-DNA, cytotoxicity, pBR322, topoisomerase.

\section{OP-121 \\ A NEW APPROACH FOR TARGETED CANCER THERAPY:} SYNTHESIS AND CHARACTERIZATION OF NANOPARTICLE

\section{Ümmühan Fulden Bozkaya ${ }^{1}$, Güliz $\mathrm{Ak}^{2}$, Şenay Şanlıer ${ }^{2}$}

${ }^{1}$ Cukurova University Faculty of Medicine, Medicinal Biochemistry Deparment, Adana

${ }^{2}$ Ege University Faculty of Science, Biochemistry Department, İzmir

OBJECTIVES: According to the World Health Organization's data, cancer is the second cause of deaths worldwide. The adverse effects and limitations caused by current cancer therapies require the development of new treatment modalities. The aim of this study was developing a drug delivery system to reduce the limitations and adverse effects caused by conventional cancer therapies. MATERIALS and METHODS: Chitosan-hyaluronic acid nanoparticles (CSHA-NPs) formed by ionic gelation method were loaded with doxorubicin. Amount of the drug to be loaded and of hyaluronic acid and the drug adsorption yield at different $\mathrm{pHs}$ were determined by SEM and spectrophotometer. ZetaSize, FTIR analyses, and in vitro drug release experiments of doxorubicinloaded CS-HA-NPs prepared under optimal conditions were performed. RESULTS: The most efficient amount of HA was determined to be 10 mg. The optimal $\mathrm{pH}$ of the drug loading by the adsorption method to the nanoparticulate structure was determined to be 8 . Optimum drug concentration was determined as $1.5 \mathrm{mg} / \mathrm{mL}$ with $89.8 \%$ of adsorption yield. At the end of 6 hours, the nanoparticular drug delivery system releases $44.6 \%$ of the drug at $\mathrm{pH} 7.4$ while it is released $61.5 \%$ at $\mathrm{pH} 5.5$. CONCLUSIONS: Nanoparticular structure wasn't formed with low amount of HA, but extreme HA amount caused large-sized nanoparticles. It is seen from in vitro drug release studies that carrier system released the drug in controlled manner. Moreover, the system released the drug more at acidic $\mathrm{pH}$ than physiological $\mathrm{pH}$. When considered all data, it is considered that prepared carrier system has a potential for targeted cancer therapy. Keywords: Drug Delivery System, Doxorubicin, Hyaluronic Acid Nanoparticle, Targeted Cancer Therapy

\section{Introduction}

According to World Health Organization's (WHO) data, cancer is the second leading cause of death and is a large group of diseases characterized by the growth 
of abnormal cells that can invade neighbor organs and spread to body. Tumor blood vessels have some abnormalities such as high proportion of proliferating endothelial cells, deficiency of pericyte and atypic membrane formation leading to an enhanced vascular permeability. Endothelial pores have size varying from 10- $1000 \mathrm{~nm}$. Additionally, lymphatic vessels are absent or non-functional in tumor. These features of tumor have been called "Enhanced Permeability and Retention Effect". While normal tissues and blood $\mathrm{pH}$ is 7.4, extracellular tumor $\mathrm{pH}$ is between 6 to 7 [1]. WHO stated the cancer therapies as surgery, radiotherapy and systemic therapy. These conventional cancer treatment strategies are nonspecific to the cancer cells causing undesirable adverse effects to the healty tissues. Cytotoxic agents are commonly used for cancer therapy, however, that agents can have some limitations such as poor aqueous solubility, non-specific biodistribution, severe toxicity to normal cells, inadequate drug concenration to cancer cells. Nanomedicine can help to solve these limitations via increasing aqueous solubility and drug efficiacy and improving the therapeutic index. Nanoparticles are used in cancer therapy and their size varies between 1-1000 $\mathrm{nm}$. Delivery of nanoparticles to the tumor tissue can be performed via active and/or passive targeting [2]. Polymeric nanoparticles can be formed with natural or synthetic polymers. Drugs could be entrapped within polymer or adsorbed to nanoparticle surface [3]. Hyaluronic acid is a natural polymer composed of $\mathrm{N}$-acetyl-D-glucosamine and D-glucuronic acid. It can be used in biomedical applications because of its biodegredable, bicompatible, non-toxic and nonimmunogenic features [4]. Chitosan is a natural, non-toxic, biodegredable and polycationic polysaccharide [5] which is produced via deacetylation of chitin [6]. Hyaluronic acid and chitosan can be used together to produce polyelectrolyte complexes for drug delivery thanks to polyanionic character of hyaluronic acid and polycationic feature of chitosan [4]. Doxorubicin is an intercalation agent and anthracycline antibiotic with antineoplastic activity [7]. Doxorubisin causes severe toxic side-effects such as cardiotoxicity, vomiting, leucopenia and stomatitis, thus, it is loaded to drug delivery system to reduce that side-effects [8]. The aim of this study was developing a drug delivery system to reduce the limitations and adverse effects caused by conventional cancer therapies and evaluation of cytotoxic efficiency of the system.

Materials and Methods

Hyaluronic acid-chitosan nanoparticles (HA-CS NPs) were synthesized via ionic gelation method. $0.11 \%(\mathrm{w} / \mathrm{v})$ chitosan solution is prepared in acetic acid solution. After $\mathrm{pH}$ of chitosan solution was adjusted to 4.7-4.8, $14 \mathrm{~mL}$ of varying concentrations of low molecular weight (LMW) HA and $0.44 \mathrm{mg} / \mathrm{mL}$ tripolyphospate (TPP) containing solution was added dropwise into equal volume of chitosan solution and reaction medium were incubated at $25 \square \mathrm{C}$ and for 20 minutes. Nanoparticles were seperated via centrifugation. Doxorubicin (Dox) was loaded into HA-CS NPs by using adsorption method. HA-CS NPs were dispersed in $2 \mathrm{~mL}$ of Dox solution and incubated for 16 hours at $37 \square \mathrm{C}$. To optimize adsorption $\mathrm{pH}$, HA-CS NPs were dispersed in doxorubicin solutions prepared in pH 6 acetate buffer; 7 and 7.4 phosphate buffered saline; $8 ; 8.5$ and 9 tris buffers. Moreover optimization study of drug quantity to be loaded was carried out by incubation of HA-CS NPs with varying concentrations of Dox solutions in $\mathrm{pH}$ 8 tris buffer. Loaded drug amount and loading yield was determined via visible spectroscopy. FTIR, Zeta-Size and SEM analysis of both empty and Dox loaded HA-CS NPs were carried out. In vitro drug release studies of Dox loaded HA-CS NPs prepared in optimum conditions and of free drug were performed in asidic (5.5) and physiological (7.4) $\mathrm{pH}$

Results and Discussion

The most efficient HA concentration to form HA-CS NPs was determined as 0.1 $\mathrm{mg} / \mathrm{mL}$ via SEM analysis. While under $0.1 \mathrm{mg} / \mathrm{mL}$ HA concentration, HA-CS NPs were not formed, HA-CS NPs formed with $0.2 \mathrm{mg} / \mathrm{mL} H A$ were seen bigger. According to Zeta-Size anaylsis HA-CS NPs were measured as $327.6 \mathrm{~nm}$. In addition, FTIR analysis showed that HA-CS NPs were comprised both HA and $\mathrm{CS}$ as expected. Although adsorption yield was increased during $\mathrm{pH}$ rises, optimal adsorbtion $\mathrm{pH}$ was selected as 8 due to changes of Dox's character at $\mathrm{pH} 8.5$ and 9. In drug absorbtion study, after $1.5 \mathrm{mg} / \mathrm{mL}$, Dox adsorption yield decreased from $89.8 \%$ to $75.7 \%$, thus, optimum drug quantity was selected $1.5 \mathrm{mg} / \mathrm{mL}$. Dox loaded HA-CS NPs were spherical in shape, $286.6 \mathrm{~nm}$ in size according to SEM and Zeta-Size analyses respectively. According to in vitro drug release studies, at the end of the 6 hours Dox loaded HA-CS NPs released $44.6 \%$ of drug at $\mathrm{pH} 7.4$ and released $61.5 \%$ at $\mathrm{pH} 5.5$. However free drug was released $37.3 \%$ at $\mathrm{pH} 7.4$ and $74 \%$ at $\mathrm{pH} 5.5$ at the end of the 1.5 hours. These results indicated that HA$\mathrm{CS}$ NPs released the drug in controlled manner at more asidic $\mathrm{pH}$ which is alike tumor microenvironment.

Conclusion

According to all data, it is seen that Dox loaded HA-CS NPs were synthesized properly. The synthesized drug delivery system had controlled drug release profile and released the drug at asidic $\mathrm{pH}$ than physiological $\mathrm{pH}$. As a result, Dox loaded HA-CS NPs could have a potential for the targeted cancer treatment to reduce the toxicity and to increase the therapeutic index.

Acknowledgements

This study was supported by Ege University Scientific Research Project. (Project ID: 17 FEN 004)

Thanks to Ege University Center for Drug Research \& Development and Pharmacokinetic Applications.

References

1. Danhier, F., Feron, O., Preat, V., 2010, To exploit the tumor microenvironment: Passive and active tumor targeting of nanocarriers for anti-cancer drug delivery, Journal of Controlled Release, 148, 135-146 p.

2. Kumari, P., Ghosh, B., and Biswas, S., 2015, Nanocarriers for Cancer-targeted Drug Delivery, Journal of Drug Targeting, early online: 1-13 p.
3. Khodabandehloo, H., Zahednasab, H., and Hafez, A. A., 2016, Nanocarriers Usage for Drug Delivery in Cancer Therapy, Iran Journal of Cancer Previews, 9(2):3966

4. Tripodo, G., Trapani, A., Torre, M. L., Giammona, G., Trapani, G., and Mandracchia, D., 2015, Hyaluronic Acid and Its Derivatives in Drug Delivery and Imaging: Recent Advances and Challenges, European Journal of Pharmaceutics and Biopharmaceutics, 97, 400-416 p.

5. Gwak, S. J., Jung, J. K., An, S. S., Kim, H. J., Oh, J. S., Pennant, W. A., Lee, H. Y., Kong, M. H., Kim, K. N., Yoon, D. H., and Ha, Y., 2012, Chitosan/TPPHyaluronic Acid Nanoparticles: A New Vehicle for Gene Delivery to the Spinal Cord, Journal of Biomaterials Science, 23, 1437-1450 p.

6. Almalik, A., Donno, R., Cadman, C. J., Cellesi, F., Day, P. J., Tirelli, N., 2013, Hyaluronic acid-coated Chitosan Nanoparticles: Molecular Weight-dependen Effects on Morphology and Hyaluronic Acid Presentation, Journal of Controlled Release, 172, 1142-1150 p.

7. https://pubchem.ncbi.nlm.nih.gov/compound/Doxorubicin

Hydrochloride\#section=Top, last accesed date: 30th August 2018.

[8] Wu, S., Zhao, X., Du, Q., Sun, J., Wang, Y., Xia, Y., Wang., Z., and Xia, L., 2013, Adsorption Properties of Doxorubicin Hydrochloride onto Graphene Oxide: Equilibrium, Kinetic and Thermodynamic Studies, Materials, 6, 20262042

\section{OP-122 \\ BIOCHECMICAL AND MOLECULAR RESPONSE TO PERSONALIZED RADIOLIGAND THERAPY AT METASTATIC PROSTATE CANCER}

Emine Acar ${ }^{1,2}$, Ender Berat Ellidokuz ${ }^{2,3}$, Gamze Capa Kaya İzmir Kâtip Celebi University, Ataturk Training and Research Hospital, Department of Nuclear Medicine, Izmir

Dokuz Eylul University, Graduate School of Health Sciences, Department of Translational Oncology, Izmir

${ }^{3}$ Dokuz Eylul University, School of Medicine, Department of Gastroentorology, Izmir

${ }^{4}$ Dokuz Eylul University, School of Medicine, Department of Nuclear

Medicine, Izmir

OBJECTIVES: In this study, we aimed to assess the anatomical and molecular response with Gallium(Ga)-68 PSMA Positron Emission Tomography/Computed Tomography (PET/CT) and prostate specific antigen (PSA) response to applied Lutetium(Lu)-177 prostate specific membrane antigen in patients who were diagnosed with castration resistant metastatic prostate cancer and progression developed despite all treatments with survival advantage.

Materials and Methods: The data of fifteen male patients to whom applied 3 or 4 circle of Lu-177 PSMA treatment was analysed retrospectively. Serum PSA values and Ga-68 PSMA PET/CT images were compared before and after the therapy.

Results: Fifteen male patients with mean $64 \pm 8$ age had mean 8 (6-10) Gleason score. While serum PSA values were mean $204 \mathrm{ng} / \mathrm{ml}$ before therapy, it was calculated as $49 \mathrm{ng} / \mathrm{ml}$ after treatment (p:0.027). When PET/CT images before and after the therapy were compared, regression in five patients $(33 \%)$, progression in three $(20 \%)$ patients and mix response in seven $(47 \%)$ patients were observed molecular and anatomically. PSA response was observed in all patients with regression, beside PSA progression were observed in all patients with progression. On the other hand, four of seven patients who had mix response showed PSA regression, in one patient the PSA value was stable while other two patients were showing PSA progression. After the therapy, PSA regression was observed in nine of fifteen $(60 \%)$ patients, progression was determined in five $(33 \%)$ and the rest one $(7 \%)$ was stable.

Conclusions: Regression in metastasis was observed via Lu-177 PSMA treatment, in patients with castration resistant metastatic prostate cancer which was progressed despite all therapies having survival advantages. This was thought as the therapy is successful. After the therapy, PSA response in $60 \%$ patients and molecular and anatomic response was observed in $1 / 3$ patients. In follow up, in addition to serum PSA response, it is thought that assessment of anatomical and molecular response via Ga-68 PSMA PET/BT has also a great importance. Key words: prostate cancer, PSMA, radyoligand therapy

INTRODUCTION: Prostate cancer is the second most common type of cancer in males. Prostate cancer prevalence increases simultaneously with age [1] Routine serum PSA monitoring is performed in many countries because of high prostate cancer prevalence. Despite to differentiation of incidence of countries which PSA monitoring performed and non-performed; $1-2 \%$ of male deaths are due to prostate cancer on both type of countries [2]. The most important reasons of death due to prostate cancer are metastatic disease and $>100 \mathrm{ng} / \mathrm{ml}$ PSA value [3]. During diagnosis, PSA $>20 \mathrm{ng} / \mathrm{ml}$, Gleason score is $>7$, on presence of clinical T2c-3a disease, evaluation of all body with Ga-68 PSMA Positron Emission Tomography/Computerized Tomography (PET/CT) is important on early detection of possible metastatic disease [4]. Treatment choices on metastatic disease are; chemotherapy, alpha particle therapy, hormonothreapy and vaccines [5]. Many studies showed that Lu-177 PSMA treatments succeeded on metastatic prostate cancer patients [6-8]

In this study; serum prostate specific antigen (PSA) response and anatomic/ molecular response evaluation with Ga-68 PSMA PET/CT is studied on patients with castration resistant metastatic prostate cancer which still has progression after treatment of all therapies with survival advantage. 
MATERIAL METHOD: Patient Selection: This treatment was applied to patients with the diagnosis of prostate cancer. The data of 15 patients with a mean age of $64 \pm 8$ years and mean of Gleason score is $8(6-10)$ of who were treated with Lu177 PSMA I\&T were retrospectively reviewed. Two patients had prostatectomy history. 14 patients had chemotherapy and all patients had hormonotherapy history. Ethics committee was not applied because of the retrospective design of study.

Treatment Process: $200 \mathrm{mCi} \mathrm{Lu}-177$ PSMA treatment is applied intravenously. A $>25 \%$ reduction of PSA value was evaluated as treatment response, $>25 \%$ increase was progression and $\pm 25 \%$ was stabile PSA. $30 \%$ reduction of SUVmax value in Ga-68 PSMA PET / CT was defined as regression. None of these lesions were decreased in SUVmax value even though increase of 30\% SUVmax value and observation of new lesion is accepted as progression. $\pm 30 \%$ change in SUVmax value was accepted as stable disease. Due to the comparison of each lesion individually before and after the treatment; such cases who had regression in some lesions while other some expressed pregression or cases with new lesions which were not exist in previous imaging despite in presence of regression his/her all other lesions were accepted as mixed response.

Statistics: Data were evaluated using IBM SPSS 22 (Armonk, NY) program. Mean, median values and range were used in various variables. Non-parametric testes are used on comparison of pre-treatment and post-treatment PSA values. $\mathrm{P}<0,05$ is accepted as significant result.

RESULTS: Bone metastasis on 11 patients, lymph nodes metastasis on 9 patients, lung metastasis on 3 patients and adrenal gland metastasis on 1 are detected on Ga-68 PSMA PET/CT images before treatment.

The mean pre-treatment serum PSA value of patient was $204 \mathrm{ng} / \mathrm{ml}$ and this value decreased to $49 \mathrm{ng} / \mathrm{ml}$ after treatment (p:0.027). Serum PSA values of patients in pre-treatment and post-treatment is given in Table 1. Nine of 15 patients $(60 \%)$ had PSA regression, 5 of them $(33 \%)$ had PSA progression and 1 of them $(7 \%)$ had stabile PSA at post-treatment period. All of 9 patients which had PSA regression showed $>50 \%$ decrease.

There was anatomical and molecular regression on $5(33 \%)$ patients ( 2 of them had complete response), progression on $3(20 \%)$ patients, mix response on 7 (47\%) patients. Four of that 7 mixed responded patients had PSA regression, 2 of them had PSA progression and 1 patient was stable. Mixed response of patient to treatment can be seen on Image 1 .

Grade 3 anemia was observed in 1 patient at post-treatment period, meanwhile grade 1-2 anemia was observed at pre-treatment on 8 patients. However, there was no grade 3 leukopenia, thrombocytopenia and GFR/creatinine decrease at post-treatment period.

DISCUSSION: We are presenting Lu-177 PSMA treatment efficiency on prostate cancer metastasis. $60 \%$ of patients showed serum PSA regression and $33 \%$ of them showed PET/CT response on post-treatment period. Serum PSA value of 2 patients were $<1 \mathrm{ng} / \mathrm{ml}$ is accepted as biochemical and molecular complete response. $>50 \%$ serum PSA decrease on $30-71 \%$ patients after Lu-177 PSMA treatment is reported in the literature [9]. Ahmadzadehfar et al. [6] reported that there is $>25 \%$ serum PSA decrease on $58 \%$ patients with 1 cure of Lu- 177 PSMA treatment and $70 \%$ patients with 2 cures. Consistent with the literature, we observed a regression in $60 \%$ patients of who had taken 3 or 4 cures of treatment in our study. Although, grade 3 anemia was reported on $8 \%$ in aforementioned study, this rate was found as $7 \%$ in our study. In the literature, another study has reported that hematological toxicity did not increase even tough Lu-177 PSMA therapy after Ra-223 therapy which used to treat bone metastasis [8].

In the study of Fendler et al. [10] they showed that there is $45 \%$ treatment response to Ga-68 PSMA PET/CT, as well as our results approximately $33 \%$. In addition to these, with a rate of $50 \%$ molecular response was shown by Kulkarini et al [11]. Yadav et al. [12] reported that there is no monitored molecular and anatomical response via PET/CT images in their serial including six patients. Progression occurred patient group on literature was named as mixed group in our study. In the literature these studies utilized RECIST and PERCIST criterias for CT and F-18 FDG. In this case, ambiguity is occurred owing to absence of criteria belongs to Ga-68 PSMA PET/CT monitoring evaluation. We are in opinion that a group of patient, who's most of lesions have been regressed and has response in PSA values up to $90-95 \%$ shouldn't be characterized as progression as in Image 2. We want to represent again that there is serum PSA regression on $57 \%$ of this group. Therefore, we recommend that mixed treatment response term should be used on Ga-68 PSMA PET/CT evaluations besides to regression, stabile disease and progression terms.

Anemia may occur among these patients because of metastasis of prostate cancer to bone or seconder type anemia to past treatments. Brauer et al. [13] reported that grade 3 anemia occurred on $19 \%$ and grade 3 leukopenia and thrombocytopenia is occurred on $3 \%$ of patients who received Lu-177 PSMA treatment. In our study, hematological toxicity rates found lower than study of Brauer et al. [13], even though our results are similar to other studies in the literature [6]. Lu-177 PSMA treatment can be accepted as reliable in terms of bone marrow toxicity, hematological and nephrological toxicity according to dosimetry results $[14,15]$. Theoretically, seconder nephrological response to treatment could occur as a result of excretion of Lu-177 PSMA from kidneys. However, there is no study in the literature about Lu-177 has nephrotoxicity. Similarly, there was no nephrotoxicity in our study either.

CONCLUSION: Regression and complete response was determined via Lu-177 PSMA treatment in patients with progression and castration resisted metastatic prostate cancer even all received treatments which have survival advantage. This condition may be approved in favor of treatment success. $60 \%$ of patients has serum PSA response and 33\% of them had molecular and anatomical response on post-treatment period. In addition to serum PSA response, evaluation of molecular and anatomical response with Ga-68 PSMA PET/CT has great importance on monitoring the process.

REFERENCES

1. Mottet N, Bellmunt J, Briers E, Bolla M, Bourke L, et al. EAU-ESTRO-ESURSIOG Guidelines on Prostate Cancer 2017.

2. Attard G, Parker C, Eeles RA, Schroder F, Tomlins SA, et al. Prostate cancer. Lancet 2016;387: 70-82.

3. Caicoya M. Prostate cancer screening in Europe. Lancet. 2015;385: 1507 4. Fendler WP, Eiber M, Beheshti M, Bomanji J, Ceci F, et al. (68)Ga-PSMA PET/ CT: Joint EANM and SNMMI procedure guideline for prostate cancer imaging: version 1.0. Eur J Nucl Med Mol Imaging 2017;44: 1014-1024.

5. Lindenberg ML, Turkbey B, Mena E, Choyke PL. Imaging Locally Advanced, Recurrent, and Metastatic Prostate Cancer: A Review. JAMA Oncol 2017;3: 14151422.

6. Ahmadzadehfar H, Eppard E, Kurpig S, Fimmers R, Yordanova A. Therapeutic response and side effects of repeated radioligand therapy with 177Lu-PSMADKFZ-617 of castrate-resistant metastatic prostate cancer. Oncotarget 2016;7: $12477-12488$.

7. Ahmadzadehfar H, Wegen S, Yordanova A, Fimmers R, Kurpig S, et al. Overall survival and response pattern of castration-resistant metastatic prostate cancer to multiple cycles of radioligand therapy using [(177)Lu]Lu-PSMA-617. Eur J Nucl Med Mol Imaging 2017;44: 1448-1454.

8. Ahmadzadehfar H, Zimbelmann S, Yordanova A, Fimmers R, Kurpig S, et al. Radioligand therapy of metastatic prostate cancer using (177)Lu-PSMA-617 after radiation exposure to (223)Ra-dichloride. Oncotarget 2017;8: 55567-55574.

9. Kratochwil C, Giesel FL, Stefanova M, Benesova M, Bronzel M, et al. PSMATargeted Radionuclide Therapy of Metastatic Castration-Resistant Prostate Cancer with 177Lu-Labeled PSMA-617. J Nucl Med 2016;57: 1170-1176.

10. Fendler WP, Rahbar K, Herrmann K, Kratochwil C, Eiber M. (177)Lu-PSMA Radioligand Therapy for Prostate Cancer. J Nucl Med 2017;58: 1196-1200. 11. Kulkarni HR, Singh A, Schuchardt C, Niepsch K, Sayeg M, et al. PSMA-Based Radioligand Therapy for Metastatic Castration-Resistant Prostate Cancer: The Bad Berka Experience Since 2013. J Nucl Med 2016;57: 97s-104s.

12. Yadav MP, Ballal S, Tripathi M, Damle NA, Sahoo RK, et al. (177)Lu-DKFZ PSMA-617 therapy in metastatic castration resistant prostate cancer: safety, efficacy, and quality of life assessment. Eur J Nucl Med Mol Imaging 2017;44: 81-91.

13. Brauer A, Grubert LS, Roll W, Schrader AJ, Schafers M, et al. (177)Lu-PSMA-617 radioligand therapy and outcome in patients with metastasized castration-resistant prostate cancer. Eur J Nucl Med Mol Imaging 2017;44: 1663-1670.

14. Baum RP, Kulkarni HR, Schuchardt C, Singh A, Wirtz M, et al. 177Lu-Labeled Prostate-Specific Membrane Antigen Radioligand Therapy of Metastatic CastrationResistant Prostate Cancer: Safety and Efficacy. J Nucl Med 2016;57: 1006-1013. 15. Delker A, Fendler WP, Kratochwil C, Brunegraf A, Gosewisch A, et al. Dosimetry for (177)Lu-DKFZ-PSMA-617: a new radiopharmaceutical for the treatment of metastatic prostate cancer. Eur J Nucl Med Mol Imaging 2016;43: 42-51.

IMAGES

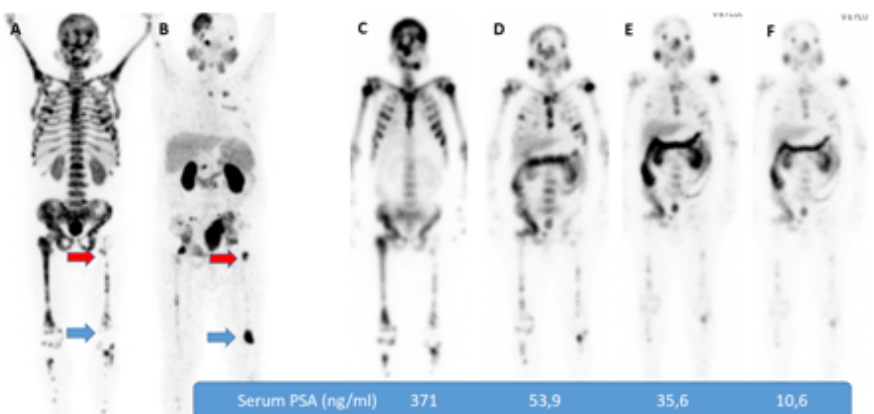

Image 1: 52 years old, male patient, has bone metastasis and imaging with $\mathrm{Ga}$ 68 PSMA PET/CT MIP (A). Four cure of Lu-177 PSMA received to the patient and scintigraphy images are shown at C,D,E,F respectively. Activity decrease of lesions (response to treatment) and decrease of serum PSA value clearly can be seen on these images. A large part of bone metastasis is diminished at Ga-68 PSMA PET/CT image (monitored at post-treatment) (B). Progression of size and activity of bone metastasis at left femur proximal (red arrow) is remarkable. A brand new lesion can be seen on distal of left lemur (blue arrow) which there wasn't before treatment. Besides to significant regression and serum PSA response, these new lesions causes that this treatment response should evaluate as mixed response.

\section{OP-123}

\section{THE COMPARISON OF GENE EXPRESSION OF INDIVIDUALS WITH} LOWER G6PD ENZYME ACTIVITY

Bașak Günaștı, Ebru Dündar Yenilmez, Abdullah Tuli Department of Medical Biochemistry, Faculty of Medicine, Çukurova University, Adana

OBJECTIVES: Glucose 6-phosphate dehydrogenase is the key enzyme which catalyzes first step of pentose phosphate metabolic pathway. The deficiency 
of G6PD deficiency may result in hemolytic anemia due to drug toxication, infections during the neonatal period, consumption of beans and stress conditions. Reported that if exposed to these conditions, while some case has been affected, some of which has not been affected. In order to clarify this situation G6PD enzyme kinetics were studied from cases G6PD activity below the reference values. The aim of this study was to evaluate the relationship between G6PD gene expression and G6PD enzyme kinetics parameters and genotype. MATERIALS and METHODS: Ten cases ( 7 male and 3 female) of low or null G6PD enzyme activity were enrolled in this study. Enzyme activity was determined with the Beutler method. G6PD was partially purified DE52 anion exchange resin and then enzyme kinetics were studied. G6PD Mediterranean mutation was genotyped by sequencing analysis and MboII restriction enzyme. G6PD gene expression levels were analyzed by using the $2-\Delta \Delta \mathrm{Ct}$ formula. Variables were evaluated by correlation test. RESULTS: In this study G6PD Mediterranean mutation were identified in 4 cases two of hemizygote and two of heterozygot. We evaluated relationship of G6PD gene expression with other variables. CONCLUSIONS: There was statistically significant high positive correlation with G6PD gene expression levels and KmNADP, statistically significant moderate positive correlation with G6PD gene expression levels and KmG6P. This case is suggested to have different specifications in the substrate binding site as a result of post-translational or post-transcriptional modifications. Keywords: Glucose-6-phosphate Dehydrogenase, Gene Expression, Enzyme Kinetic

\section{OP-124 \\ ESTIMATION OF FUNCTIONAL SNPS IN APH1B GENE BY USING COMPUTER BASED SOFTWARE TOOLS}

Tuğba Kaman ${ }^{1}$, Ömer Faruk Karasakal², Ebru Özkan Oktay ${ }^{3}$, Korkut Ulucan ${ }^{4}$, Muhsin Konuk $^{5}$

${ }^{1}$ Uskudar University, Vocational School of Health Services, Medical and Aromatic Plants, Uskudar, Istanbul

${ }^{2}$ Uskudar University, Vocational School of Health Services, Medical Laboratory Techniques, Uskudar, Istanbul

${ }^{3}$ Uskudar University, Vocational School of Health Services, Laboratory

Technology, Uskudar, Istanbul

${ }^{4}$ Marmara University, Faculty of Dentistry, Basic Medical Sciences, Department of Medical Biology and Genetics, Istanbul

${ }^{5}$ Uskudar University, Faculty of Enginering and Natural Sciences, Department of Molecular Biology and Genetics, Istanbul

OBJECTIVES: Amyloid beta peptide produced by gamma secretase complex is known to be one of the reasons of Alzheimer's disease. The APH1B gene encodes a component of the gamma secretase complex which is effective in the formation of the disease. The aim of this study is to identify single nucleotide polymorphisms (SNPs) in the APH1B gene and to predict SNPs which have damaging effects on the structure and function of the protein by computer-based software tools. MATERIALS and METHODS: SNPs in the APH1B gene were obtained from the NCBI dbSNP database in June-July, 2018. The functional effects of these SNPs which known to cause amino acid substitutions are predicted using SIFT (Sorting Intolerant From Tolerant) and PolyPhen-2 software tools. I-Mutant 2.0 software tool was used to determine the effect of damaging SNPs on the protein stabilization and Project HOPE software tool were used to construct three-dimensional models. RESULTS: 216 missense SNPs were found in APH1B gene. 24 SNPs were determined to be damaging by both SIFT and PolyPhen-2 software tools. I-Mutant 2.0 results showed that 19 SNPs decreased and 5 SNPs increased the protein stabilization. Three-dimensional modelling was not obtained from the databases of Project HOPE software due to the lack of structural information of the protein. CONCLUSIONS: The results of the study showed that 24 SNPs in APH1B gene had deleterious effects on the protein structure and stabilization by in silico methods. It is envisaged that theresults obtained will providedata for furtherexperimentalanalysis. Keywords: APH1B, Alzheimer's Disease, single nucleotide polymorphism (SNP), In silico

\section{OP-125 \\ INVESTIGATION OF VASPIN, VISFATIN, CHEMERIN AND IL-18 LEVELS IN PATIENTS WITH MIGRAINE}

Ahmet Dönder ${ }^{1}$, Vugar Cafer $^{2}$

${ }^{1}$ Mardin Artuklu U,niversity, Healthy and Vocational High School, Department of Medical Services, Mardin

${ }^{2}$ Dicle University, Faculty of Medicine, Department of Nörology, Diyarbakır

OBJECTIVES: Migraine is a type of primary headache which is caused by the alterations in trigeminovascular system. Migraine attacks are associated with neurovascular inflammation of the cerebral and extracerebral vessels, but its pathophysiological mechanisms have not still been fully delineated. Also, migraine has been found to be associated with higher risks for various metabolic disorders. Thus, we aimed to investigate the matrix metalloproteinases (MMP), fetuin-A, ghrelin, and omentin levels which have important roles in metabolic disorders and inflammation, and to examine their relationship with migraine subtypes and attack frequency. MATERIALS and METHODS: 100 migraine patients and 50 age- and sex- matched healthy control subjects were enrolled. Migraine diagnosis was confirmed according to the International Classification of Headache DisordersII diagnostic criteria. Analyses of Vaspin, visfatin, chemerin and IL-18 RESULTS: Vaspin, visfatin, chemerin and IL-18 levels were significantly increased inmigraine than controls $(p<0.05)$. In migrainepatients, serum vaspin, visfatinlevels were positively correlated with Vaspin, visfatin, chemerin ve IL-18 levels did not correlate with age, disease duration, or frequency of migraine headache $(\mathrm{p}>0.05)$. CONCLUSIONS: Vaspin, visfatin, chemerin and IL-18 levels were significantly higher in migraine than controls $(\mathrm{p}<0.05)$. Migraine patients have high vaspin, visfatin, chemerin and IL-18 levels levels, which may be related to the pathogenesis of migraine. The importance and impact of our findings on the pathogenesis, characteristics, and treatment of migraine needs to be investigated in further detailed studies. Keywords: vaspin, visfatin, IL 18, chemerin, migraine,

\section{OP-126 \\ INVESTIGATION OF COPEPTIN/GHRELIN LEVELS IN INDIVIDUALS WITH RESPIRATORY DISEASES}

Emre Avci ${ }^{1}$, Sertac Arslan 2 , Gamze Cagatay ${ }^{1}$, Gulcin Avci ${ }^{1}$, Muhsin Akbaba 'Department Molecular Biology and Genetics, Hitit University, Corum ${ }^{2}$ Department of Pulmonary Diseases, Faculty of Medicine, Corum ${ }^{3}$ Department of Public Health, Faculty of Medicine, Cukurova University, Adana

OBJECTIVES: Respiratory disease is a common disease that increases in certain periods. Significant increases have been observed in chronic respiratory diseases such as chronic obstructive pulmonary disease (COPD), asthma and bronchitis, especially in seasonal migrations. In these patients, there is evidence of systemic inflammation, measured by increased circulating cytokine, chemokine and acute phase proteins, or abnormalities of circulating cells, particularly when the disease is severe and during exacerbations. Studies have shown that serum copeptin and ghrelin levels are associated with prognosis in many diseases. Therefore, in this study, it was aimed to evaluate the levels of copeptin and ghrelin in the prognosis of patients with respiratory disease (asthma and COPD). MATERIALS and METHODS: Materials used in the study were obtained with serum samples taken for clinical diagnosis during routine investigations without any additional intervention, and to be discarded after routine work. According to the power analysis, a minimum 40 (COPD: 20, asthma: 20) were determined and a control group was established with 20 healthy individuals. Copeptin and Ghrelin levels were determined by ELISA method. RESULTS: It was found that serum copeptin and gheralin levels of respiratory tract patients (STP) were significantly increased compared to healthy subjects. However, copeptin and ghrelin levels of COPD patients were found to be higher than those of asthmatic patients. CONCLUSIONS: The frequency of regional respiratory diseases was determined according to our results and the parameters of copeptin and ghrelin were analyzed in order to better manage the prognosis. In addition, the obtained data contributed to the epidemiological data of our country. Keywords: Respiratory Diseases, Copeptin, Ghrelin

\section{OP-127 \\ THE EFFECTS OF DIET AND EXERCISE TREATMENT IN IRISIN, ADIPONECTIN, INTERLEUKIN-6 LEVELS IN OBESES}

$\underline{\text { Gülay Sezgin }}^{1}$, Fatih $\mathrm{Kar}^{1}$, Sema Uslu ${ }^{1}$, Kevser Setenay Dinçer Öner ${ }^{2}$ ${ }^{1}$ Eskisehir Osmangazi University, Faculty of Medicine, Department of Medical Biochemistry, Eskisehir

${ }^{2}$ Eskisehir Osmangazi University, Faculty of Medicine, Department of Bioistatistics, Eskisehir

OBJECTIVES: In this study, we aimed to investigate the effects of diet and exercise therapy on iris, adiponectin and IL-6 levels in obese subjects. MATERIALS and METHODS: 37 patients who applied for Eskisehir Private Fora Physical Therapy and Rehabilitation Center between 01.11.201730.05.2018 were included in the study. Patients were divided into 3 groups according to body mass index (BMI) and diet and exercise therapy were applied for 8 weeks. Adiponectin, IL-6 serum levels and irisin plasma levels were measured by enzyme-linked immunosorbent assay (ELISA) in Eskisehir Osmangazi University Clinical Biochemistry Laboratory Anthropometric characteristics of 37 individuals participating in the study were recorded. All values were evaluated before and after treatment RESULTS: As a result of 8-week diet and exercise treatment, body weight decreased by $4 \%$. There was a statistically significant difference between IL-6 levels and adiponectin levels measured at the beginning of the study and the values measured at the end of the 8-week diet and exercise treatment respectively $(p<0.05),(p<0.01)$. However there wasn't a statistically significant difference in the measured IL- 6 and adiponectin values between the groups separated according to BMI values ( $p>0.05$ ). There wasn't statistically significant difference between the beginning of the study and the measured values of irisin at the end of the 8 -week diet and exercise treatment $(p>0.05)$ CONCLUSIONS: IL-6 and adiponectin, which play a role in obesity metabolism, showed statistically significant changes with 8-week diet and exercise treatment. The irisin, which is thought to increase the level 
with exercise, didn't show a statistically significant change in our study. Keywords: obesity, irisin, adiponectin, interleukin-6

Introduction

The World Health Organization (WHO) defines obesity as abnormal and excessive fat accumulation in the adipose tissue that will impair human health [1]. Adipose tissue is an energy store and actively acts as an endocrine organ [23]. Adipose tissue is considered to be an endocrine organ because of the secretion of many substances from adipose tissue such as leptin, resistin, tumor necrosis factor-a(TNF-a), adiponectin, interleukin-6 (IL-6) [4].

Adiponectin

Adiponectin is an antidiabetic and antiatherogenic adipokine that is secreted from adipose tissue [5-6]. Adiponectin improves insulin sensitivity, glucose tolerance and lipid profile. It shows the beneficial effect on the metabolism by reducing atherosclerosis and inflammation [7]. Exercise can improve insulin resistance and reduce the risk of cardiovascular disease by increasing adiponectin levels as well as a range of benefits [8]. Dietary measures such as dietary calorie restriction or fat reduction have been shown to increase serum adiponectin levels [9]. Interleukin-6

Interleukin IL-6 is a cytokine that is involved in obesity and insulin resistance and is secreted by many cells as well as adipocytes and adipose stromal cells [10-11]. Subcutaneous adipose tissue has been shown to secrete IL-6, and this secretion is proportional to BMI. With the increase in body mass index, the release of inflammation mediators increases and this silent inflammation causes undesirable consequences of obesity [12].

Irisin

In 2012, Boström et al. discovered a protein that, when exercised systematically, protects the person from metabolic diseases and released from the skeletal muscle after exercise. This protein is the protein of irisin [13]. Irisin is released by exercise and cold and causes UCP1 increase in white adipose tissue cell. When UCP1 pumps increase in mitochondria of white adipose tissue cells, these cells are called beige fat tissue. These cells work like brown fatty tissue cells and provide thermogenesis [14]. Increased expression of UCP1 enhances heat production, so it is a lucrative event that increases energy expenditure in individuals with insulin resistance and in obese patients [15]. Although there are studies showing that the release of irisin is increased by exercise, there are still question marks on the regulation of irisin in human skeletal muscles [16].

The aim of this study was to investigate the effects of 8-week diet and exercise therapy on plasma irisin, serum adiponectin, serum interleukin-6 and HOMA-IR values.

Material and Methods

Subjects and study protocol

The study included 37 female patients aged between 25-65 years who applied to Eskişehir Fora Physiotherapy and Rehabilitation Center for obesity treatment between 01.10.2017 and 30.04.2018. The participants were given a "Volunteer Information Form' before the study and written approval was obtained from the volunteers. Individuals who have undergone cancer treatment or who have previously had cancer, those with any kidney disease, those with Type 1 or Type 2 diabetes, and those with severe cardiovascular disease are excluded from the study.

Three experimental groups were formed according to the BMI, each group consisting of 13 people. All 3 groups were given 8-week diet and exercise therapy. Group 1 (Control) $(\mathrm{n}=13)$ : Individuals with a body mass index of $18.5 \leq \mathrm{BMI} \leq$ $29.99 \mathrm{~kg} / \mathrm{m}^{2}$ (normal or slightly overweight)

Group $2(n=11)$ : Individuals with a body mass index of $30 \leq \mathrm{BMI} \leq 34,99 \mathrm{~kg}$ / $\mathrm{m}^{2}$ (grade I obese)

Group $3(\mathrm{n}=13)$ : Individuals whose body mass index is between $35 \leq \mathrm{BMI}$ $\leq 39,99 \mathrm{~kg} / \mathrm{m}^{2}$ (grade II obese)

Patients were examined by an internal diseases specialist and the patients eligible for the study were identified. Patients were then examined by a physical medicine and rehabilitation specialist to determine the physical competence of the patients and to plan the exercise program. The diet programs of the patients were arranged by the dietitian individually and nutrition training was provided to the patients. Patients who did not participate in exercise therapy more than 2 times were excluded from the study. Similarly, daily food consumption records were recorded. Individuals who did not diet were also excluded.

Biochemical Analysis

After 12- 14 hours fasting, $2 \mathrm{ml}$ blood samples from antecubital veins of participants were taken to EDTA tubes and $5 \mathrm{ml}$ blood samples were taken into biochemistry tubes. Blood samples taken into EDTA tubes were centrifuged at $1000 \mathrm{rpm}$ for 15 minutes with NF400 model centrifuge to obtain plasma samples. Blood samples were taken from biochemistry tubes by centrifugation at $4000 \mathrm{rpm}$ with NF400 centrifugal device for 5 minutes to obtain serum samples.

Fasting blood glucose and fasting insulin levels were measured with Rosche COBAS C501 autoanalyzer in Eskisehir Osmangazi University Clinical Biochemistry Laboratory and a Homeostasis Model Assessment (HOMA) was used to evaluate insulin resistance [17]. Serum adiponectin and interleukin-6 levels and plasma irisin levels were determined by enzyme-linked immunosorbent assay (ELISA). All values were evaluated before and after treatment.

Serum adiponectin measurement: Adiponectin measurement in serum was measured by the Cloud-Clone Corp. human adiponectin Elisa kit. Results were given in $\mu \mathrm{g} / \mathrm{ml}$.

Serum interleukin-6 measurement: IL-6 measurement in serum was measured by the Dia-source human adiponectin Elisa kit. Results were given in pg/ml.

Plasma irisin measurement: Irisin measurement in plasma was measured by the BioVendor human adiponectin Elisa kit. Results were given in $\mathrm{ng} / \mathrm{ml}$.
Anthropometric Measurements

Height $(\mathrm{cm})$, body weight $(\mathrm{kg})$, BMI, body fat content, fat-free mass $(\%)$, body water body $(\%)$, basal metabolic rate (BMR) (kcal), waist - hip circumference $(\mathrm{cm})$ at the beginning and end of the study. The body composition of the individuals was analyzed by the TANITA BC-418 device.

Statistical Analysis

Continuous data are expressed as mean \pm standard deviation, and categorical data as percentage (\%). The Shapiro Wilk test was used to investigate the appropriateness of data to normal distribution. Two-way repetitive measurements for repeated measurements ANOVA (One Factor Repetitive) "Two-way reapeated mesasures ANOVA (One Factor Repetition)" test was used.

Spearman correlation coefficients were calculated for variables that did not conform to normal distribution. IBM SPSS Statistics 21.0 (IBM Corp. Released 2013. IBM SPSS Statistics for Windows, Version 22.0. Armonk, NY: IBM Corp.) package was used in the implementation of the analyzes. $P$ value of $<0.05$ was considered as a criterion for statistical significance.

Result

The mean age of the participants was $47,91 \pm 13,16$. The median values of the variables examined in the study, the differences between the pre-treatment and post-treatment and the differences between the groups are expressed in Table 1 and Table 2 .

Table 1 . Differences in physical parameters before and after obesity treatment and comparison between groups

\begin{tabular}{|c|c|c|c|c|c|c|c|}
\hline \multirow{2}{*}{$\begin{array}{l} \\
\text { Physical } \\
\text { Parameters }\end{array}$} & \multicolumn{7}{|c|}{ Experimental Groups } \\
\hline & & & $\begin{array}{c}\text { Group 1 } \\
(\mathrm{n}=13)\end{array}$ & $\begin{array}{c}\text { Group 2 } \\
(\mathrm{n}=11)\end{array}$ & $\begin{array}{c}\text { Group } 3 \\
(\mathrm{n}=13)\end{array}$ & $\begin{array}{c}\text { Total } \\
(\mathrm{n}=37)\end{array}$ & P values \\
\hline \multirow{3}{*}{$\begin{array}{l}\text { Fasting glucose, } \\
\mathrm{mg} / \mathrm{dL}\end{array}$} & Pre - T & & $84,84 \pm 8,07$ & $92,63 \pm 16,12$ & $94,92 \pm 10,25$ & & \\
\hline & Post-T & & $80,76 \pm 6,45$ & $84,00 \pm 12,88$ & $96,53 \pm 14,65$ & $87,27 \pm 13,45$ & 0.03 \\
\hline & & $\mathbf{p}$ & 0.11 & 0.00 & 0.5 & 0.03 & - \\
\hline Fasting insüline & Pre - T & & $10,72 \pm 4,19$ & $13,36 \pm 6,78$ & $15,17 \pm 6,72$ & $35,47 \pm 10,26$ & \\
\hline \multirow[t]{2}{*}{$\mathrm{mg} / \mathrm{dL}$} & Post-T & & $6,62 \pm 2,98$ & $8,55 \pm 4,82$ & $13,26 \pm 6,93$ & $32,55 \pm 9,53$ & 0.30 \\
\hline & & $\mathbf{p}$ & 0.00 & 0.00 & 0.14 & 0.00 & - \\
\hline \multirow[t]{3}{*}{ HOMA-IR } & Pre - T & & $2,29 \pm 1,05$ & $3,10 \pm 1,75$ & $3,58 \pm 1,84$ & $2,98 \pm 1,63$ & \\
\hline & Post-T & & $1,32 \pm 0,63$ & $1,82 \pm 1,17$ & $3,25 \pm 2.07$ & $2,15 \pm 1,63$ & 0.15 \\
\hline & & $\mathbf{p}$ & 0.00 & 0.00 & 0.29 & 0.00 & . \\
\hline Adiponectin & Pre - $T$ & & $11,48 \pm 2,25$ & $8,93 \pm 1,86$ & $6,04 \pm 2,14$ & $8,81 \pm 3,08$ & \\
\hline \multirow[t]{2}{*}{$(\mu \mathrm{g} / \mathrm{ml})$} & Post-T & & $12,21 \pm 1,86$ & $9,94 \pm 1,85$ & $7,26 \pm 2,27$ & $9,80 \pm 2,87$ & 0.69 \\
\hline & & p & 0.00 & 0.00 & 0.00 & 0.00 & - \\
\hline IL-6 & Pre - T & & $8,48 \pm 4,47$ & $12,48 \pm 5,13$ & $13,49 \pm 6,41$ & $11,43 \pm 5,66$ & \\
\hline \multirow[t]{2}{*}{$(\mathrm{pg} / \mathrm{ml})$} & Post-T & & $10,85 \pm 5,86$ & $14,91 \pm 5,11$ & $15,65 \pm 10,63$ & $13,74 \pm 7,82$ & 0.99 \\
\hline & & p & 0.16 & 0.19 & 0.20 & 0.02 & - \\
\hline Irisin & Pre - T & & $8,83 \pm 3,15$ & $12,18 \pm 5,43$ & $15,62 \pm 8,11$ & $12,21 \pm 6,46$ & \\
\hline \multirow[t]{2}{*}{ (ng/ml) } & Post-T & & $9,50 \pm 3,99$ & $12,45 \pm 5,69$ & $16,73 \pm 9,56$ & $12,92 \pm 7,37$ & 0.75 \\
\hline & & p & 0.38 & 0.74 & 0.15 & 0.13 & . \\
\hline
\end{tabular}

$\begin{array}{lc}\text { BMR } & \text { : Basal metabolic rate } \\ \text { Pre-T } & \text { : Pre-treatment } \\ \text { Post-T } & \text { : Post- Treatment }\end{array}$

Table 2. Differences in biochemical parameters before and after obesity treatment and comparison between groups

\begin{tabular}{|c|c|c|c|c|c|c|}
\hline \multirow{2}{*}{ Physical Parameters } & \multicolumn{5}{|c|}{ Experimental Groups } & \multirow[b]{2}{*}{$P$ values } \\
\hline & & Group $1(n=13)$ & Group 2 (n=11) & $\begin{array}{c}\text { Group } 3 \\
(\mathrm{n}=13)\end{array}$ & $\begin{array}{c}\text { Total } \\
(\mathrm{n}=37)\end{array}$ & \\
\hline \multirow[t]{3}{*}{ Body weight(kg) } & Pre - $T$ & $70,66 \pm 7,16$ & $86,08 \pm 8,80$ & $97,52 \pm 10,32$ & $84,68+14,32$ & \\
\hline & Post-T & $67,62 \pm 6,41$ & $81,88 \pm 8,07$ & $93,64 \pm 10,10$ & $81,00 \pm 13,72$ & 0.04 \\
\hline & $\mathbf{p}$ & 0.00 & 0.00 & 0.00 & 0.00 & - \\
\hline \multirow[t]{3}{*}{ Fat Mass(kg) } & Pre - T & $25,34 \pm 4,88$ & $36,41 \pm 7,35$ & $44,80 \pm 6,39$ & $35,47 \pm 10,26$ & \\
\hline & Post-T & $23,60 \pm 4,25$ & $33,24 \pm 6,82$ & $40,92 \pm 7,28$ & $32,55 \pm 9,53$ & 0.02 \\
\hline & $\mathbf{p}$ & $0.00^{*}$ & 0.00 & 0.00 & 0.00 & - \\
\hline \multirow{3}{*}{$\begin{array}{l}\text { Waist circumference } \\
\text { (cm) }\end{array}$} & Pre - T & $91,23 \pm 5,52$ & $100,63 \pm 7,07$ & $112,84 \pm 6,30$ & $101,62 \pm 11,05$ & \\
\hline & Post-T & $87,23 \pm 5,27$ & $95,00 \pm 6,04$ & $108,38 \pm 6,35$ & $96,97 \pm 10,74$ & 0.23 \\
\hline & $\mathbf{p}$ & 0.00 & $0.00^{* *}$ & 0.00 & 0.00 & \\
\hline \multirow{3}{*}{$\begin{array}{l}\text { Hip } \\
\text { circumference } \\
\text { (cm) }\end{array}$} & Pre-T & $107,30 \pm 6,39$ & $115,81 \pm 4,30$ & $126,23 \pm 7,79$ & $116,48 \pm 10,18$ & \\
\hline & Post-T & $104,00 \pm 5,44$ & $111,45 \pm 3,95$ & $123,15 \pm 8,16$ & $112,94 \pm 10,18$ & 0.21 \\
\hline & $\mathbf{p}$ & 0.00 & 0.00 & 0.00 & 0.00 & - \\
\hline \multirow[t]{3}{*}{ Waist/Hip ratio(cm) } & Pre - T & $0,85 \pm 0,05$ & $0,85 \pm 0,06$ & $0,85 \pm 0,07$ & $0,87 \pm 0,5$ & \\
\hline & Post-T & $0,84 \pm 0,05$ & $0,84 \pm \mathbf{0 , 0 6}$ & $0,84 \pm 0,07$ & $0,85 \pm 0,6$ & 0.80 \\
\hline & $\mathbf{p}$ & 0.05 & 0.06 & 0.07 & 0.00 & - \\
\hline \multirow[t]{3}{*}{ BMR(kcal) } & Pre-T & $0,85 \pm 0,06$ & $0,85 \pm 0,07$ & $0,85 \pm 0,08$ & $1519,35 \pm 175,68$ & \\
\hline & Post-T & $0,84 \pm 0,06$ & $0,84 \pm \mathbf{0 , 0 7}$ & $0,84 \pm 0,08$ & $1485,4 \pm 173,33$ & 0.86 \\
\hline & p & 0.01 & 0.00 & 0.03 & 0.00 & - \\
\hline
\end{tabular}

Pre- $\mathrm{T}$

: Pre-treatment

Post-T

Post- treatment

As a result of 8 -week diet and exercise treatment, body weight decreased by $4 \%$. There was a statistically significant difference between IL-6 levels and adiponectin levels measured at the beginning of the study and the values measured at the end of the 8-week diet and exercise treatment respectively $(p<0.05),(p<0.01)$. However there wasn't a statistically significant difference in the measured IL-6 and adiponectin values between the groups separated according to BMI values 
( $p>0.05)$. There wasn't statistically significant difference between the beginning of the study and the measured values of irisin at the end of the 8-week diet and exercise treatment $(\mathrm{p}>0.05)$

Discussion

In recent years, fat tissue has been shown to actively affect insulin sensitivity by secreting various adipocytokines. In many independent studies, increased IL-6 and decreased adiponectin have been shown to play a role in the development of insulin resistance, obesity and type 2 diabetes in humans [18]. While many studies showed that exercise could significantly alter adiponectin levels [19-21], other studies did not support these results [22-24].

Although an earlier study showed that at least $10 \%$ weight loss was needed to increase serum adiponectin levels [25], we found that 8-week diet and exercise therapy decreased the insulin resistance and increased adiponectin levels in our study.

IL-6 production with human adipose tissue increases with obesity [26]. Bastard et al. showed that IL-6 levels decrease in serum and adipose tissue after weight loss in obese women [27]. However, there was a statistically significant decrease in the IL-6 levels measured at the beginning of our study and the values measured at the end of the 8-week diet and exercise therapy. The increase in IL-6 levels despite weight loss may be due to the fact that individuals are given exercise in addition to diet therapy. The circulating levels of IL-6 are very low at a healthy rest, but levels increase rapidly during exercise in both humans and mice. This is mainly due to increased IL-6 production by operating the skeletal muscle [28]. Ikeda et al. found that increased IL-6 after exercise increased GLUT4 expression in muscle. As a result, the increase of IL-6 in skeletal muscle may play a role in increasing insulin sensitivity [29].

Recent studies in mice and humans have demonstrated that enhancing brown fat thermogenesis may lead to improved glucose tolerance, increased insulin sensitivity, lower body weight, and decreased fat mass [30-31]. Irisin is a protein that activates thermogenesis in brown fat tissue [13]. Although there are studies showing that plasma levels of irisin increase as a result of exercise, there are still contradictions in the regulation of irisin in human skeletal muscles [32]. In our study, the levels of irisin did not change significantly as a result of diet and exercise therapy.

As a result, even 8 weeks of diet and exercise therapy has changed the levels of adiponectin and IL-6, which play an important role in the obesity metabolism. However, there is no difference in response to treatment between all 3 groups. In our study, diet and exercise therapy were applied together. Further studies are needed to determine whether the release of irisin may be affected by diet or exercise.

Acknowledgement: This study was supported by Eskişehir Osmangazi University Scientific Researc Projets Commission as a project(Project No:2017-1776).

Conflict of interest statement: The authors report no conflict of interest.

Ethical Considerations: This study was approved by the Clinical Research Committee of the Eskişehir Osmangazi University (Project No:2017-1776).

References

1. Özen, G., \& Pehlivan, E. (2013). Malatya il merkezinde sağllk ocaklarına başvuran obez hastalarda idrarda mikroalbuminüri sıklığı ve etkileyen faktörler. Turgut Özal Tıp Merkezi Dergisi, 20(3).

2.Steppan, C. M., \& Lazar, M. A. (2002). Resistin and obesity-associated insulin resistance. Trends in endocrinology \& Metabolism, 13(1), 18-23.

3. Montague, C. T., \& O'rahilly, S. (2000). The perils of portliness: causes and consequences of visceral adiposity. Diabetes, 49(6), 883-888.

4. ERGÜN, A. (2005). Yağ Dokusu ve Yağ Hücresi. Turkiye Klinikleri Journal of Medical Sciences, 25(3), 412-420.

5. Deepa, S. S., \& Dong, L. Q. (2009). APPL1: role in adiponectin signaling and beyond. American Journal of Physiology-Endocrinology and Metabolism, 296(1), E22-E36.

6. Mao, X., Kikani, C. K., Riojas, R. A., Langlais, P., Wang, L., Ramos, F. J.,

\& Liu, F. (2006). APPL1 binds to adiponectin receptors and mediates adiponectin signalling and function. Nature cell biology, 8(5), 516.

7. Kadowaki, T., Hara, K., Yamauchi, T., Terauchi, Y., Tobe, K., \& Nagai, R. (2003). Molecular mechanism of insulin resistance and obesity. Experimental Biology and Medicine, 228(10), 1111-1117.

8. Gondim, O. S., de Camargo, V. T. N., Gutierrez, F. A., de Oliveira Martins, P. F., Passos, M. E. P., Momesso, C. M., ... \& Cury-Boaventura, M. F. (2015). Benefits of regular exercise on inflammatory and cardiovascular risk markers in normal weight, overweight and obese adults. PLoS One, 10(10), e0140596

9. Salehi-Abargouei, A., Izadi, V., \& Azadbakht, L. (2015). The effect of low calorie diet on adiponectin concentration: a systematic review and meta-analysis. Hormone and Metabolic Research, 47(08), 549-555.

10. Crichton, M. B., Nichols, J. E., Zhao, Y., Bulun, S. E., \& Simpson, E. R. (1996). Expression of transcripts of interleukin-6 and related cytokines by human breast tumors, breast cancer cells, and adipose stromal cells. Molecular and cellular endocrinology, 118(1-2), 215-220.

11. Fried, S. K., Bunkin, D. A., \& Greenberg, A. S. (1998). Omental and subcutaneous adipose tissues of obese subjects release interleukin-6: depot difference and regulation by glucocorticoid. The Journal of Clinical Endocrinology \& Metabolism, 83(3), 847-850.

12. Jazet, I. M., Pijl, H., \& Meinders, A. E. (2003). Adipose tissue as an endocrine organ: impact on insulin resistance. Insulin, $51,6$.

13. Boström, P., Wu, J., Jedrychowski, M. P., Korde, A., Ye, L., Lo, J. C., ... \& Kajimura, S. (2012). A PGC1- $\alpha$-dependent myokine that drives brown-fat-like development of white fat and thermogenesis. Nature, 481(7382), 463.

14. Ferrer $\square$ Martínez, A., Ruiz $\square$ Lozano, P., \& Chien, K. R. (2002). Mouse PeP. a novel peroxisomal protein linked to myoblast differentiation and development.
Developmental dynamics: an official publication of the American Association of Anatomists, 224(2), 154-167.

15. Teufel, A., Malik, N., Mukhopadhyay, M., \& Westphal, H. (2002). Frcp1 and Frcp2, two novel fibronectin type III repeat containing genes. Gene, 297(1), 79 83

16. Scharhag-Rosenberger, F., Meyer, T., Wegmann, M., Ruppenthal, S., Kaestner, L., Morsch, A., \& Hecksteden, A. (2014). Irisin does not mediate resistance training-induced alterations in resting metabolic rate. Medicine and science in sports and exercise, 46(9), 1736-1743.

17. Matthews, D. R., Hosker, J. P., Rudenski, A. S., Naylor, B. A., Treacher, D. F., \& Turner, R. C. (1985). Homeostasis model assessment: insulin resistance and $\beta$-cell function from fasting plasma glucose and insulin concentrations in man. Diabetologia, 28(7), 412-419.

18. EMRAL, R. (2006). Adiponektin ve Diğer Sitokinler. Turkiye Klinikleri Journal of Medical Sciences, 26(4), 409-420.

19. Auerbach, P., Nordby, P., Bendtsen, L. Q., Mehlsen, J. L., Basnet, S. K., Vestergaard, H., ... \& Stallknecht, B. (2013). Differential effects of endurance training and weight loss on plasma adiponectin multimers and adipose tissue macrophages in younger, moderately overweight men. American Journal of Physiology-Regulatory, Integrative and Comparative Physiology, 305(5), R490-R498.

20. Kim, Y. S., Nam, J. S., Yeo, D. W., Kim, K. R., Suh, S. H., \& Ahn, C. W. (2015) The effects of aerobic exercise training on serum osteocalcin, adipocytokines and insulin resistance on obese young males. Clinical endocrinology, 82(5), 686-694. 21. Lee, J. A., Kim, J. W., \& Kim, D. Y. (2012). Effects of yoga exercise on serum adiponectin and metabolic syndrome factors in obese postmenopausal women. Menopause, 19(3), 296-301

22. Bhutani, S., Klempel, M. C., Kroeger, C. M., Trepanowski, J. F., Phillips, S. A., Norkeviciute, E., \& Varady, K. A. (2013). Alternate day fasting with or without exercise: effects on endothelial function and adipokines in obese humans. e-SPEN Journal, 8(5), e205-e209.

23. Abbenhardt, C., McTiernan, A., Alfano, C. M., Wener, M. H., Campbell, K. L., Duggan, C., ... \& Mason, C. (2013). Effects of individual and combined dietary weight loss and exercise interventions in postmenopausal women on adiponectin and leptin levels. Journal of internal medicine, 274(2), 163-175. 24. Beavers, K. M., Ambrosius, W. T., Nicklas, B. J., \& Rejeski, W. J. (2013) Independent and combined effects of physical activity and weight loss on inflammatory biomarkers in overweight and obese older adults. Journal of the American Geriatrics Society, 61(7), 1089-1094.

25 . Weight loss larger than $10 \%$ is needed for general improvement of levels of circulating adiponectin and markers of inflammation in obese subjects: a 3-year weight loss study

26. Bastard, J. P., Maachi, M., Lagathu, C., Kim, M. J., Caron, M., Vidal, H., \& Feve, B. (2006). Recent advances in the relationship between obesity, inflammation, and insulin resistance. European cytokine network, 17(1), 4-12. 27. Bastard, J. P., Jardel, C., Bruckert, E., Blondy, P., Capeau, J., Laville, M., \& Hainque, B. (2000). Elevated levels of interleukin 6 are reduced in serum and subcutaneous adipose tissue of obese women after weight loss. The Journal of Clinical Endocrinology \& Metabolism, 85(9), 3338-3342.

28. Benrick, A., Wallenius, V., \& Asterholm, I. W. (2012). Interleukin $\square 6$ mediates exercise $\square$ induced increase in insulin sensitivity in mice. Experimental physiology, 97(11), 1224-1235

29. Ikeda, S. I., Tamura, Y., Kakehi, S., Sanada, H., Kawamori, R., \& Watada, H. (2016). Exercise-induced increase in IL-6 level enhances GLUT4 expression and insulin sensitivity in mouse skeletal muscle. Biochemical and biophysical research communications, 473(4), 947-952.

30. Stanford, K. I., Middelbeek, R. J., Townsend, K. L., An, D., Nygaard, E. B., Hitchcox, K. M., ... \& Goodyear, L. J. (2012). Brown adipose tissue regulates glucose homeostasis and insulin sensitivity. The Journal of clinical investigation, 123(1).

31. Lowell, B. B., Vedrana, S., Hamann, A., Lawitts, J. A., Himms-Hagen, J. Boyer, B. B., ... \& Flier, J. S. (1993). Development of obesity in transgenic mice after genetic ablation of brown adipose tissue. Nature, 366(6457), 740. 32. Kurdiova, T., Balaz, M., Mayer, A., Maderova, D., Belan, V., Wolfrum, C., \& Ukropcova, B. (2014). Exercise-mimicking treatment fails to increase Fndc5 mRNA \& irisin secretion in primary human myotubes. Peptides, 56, 1-7.

\section{OP-128}

\section{RELATIONSHIP BETWEEN ALBUMINURIA LEVELS AND PAF-AH E} IN PATIENTS WITH DIABETIC NEPHROPATHY

Özlem Özge Sezgin, Özlem Özbaş Demirel, Murat Duranay, Cavit Çulha Doğan Yücel

Health Sciences University Ankara Health Training and Research Center, Department of Medical Biochemistry, Ankara

OBJECTIVES: We aimed to assess the association of PAF-AH with renal function and metabolic parameters in patients with DN that we have classified according to albuminuria(alb) levels and with diabetic patients without nephropathy.We also aimed to apply the PAF-AH activity measurement method to automated chemistry analyzer and determine basic performance characteristics of the method. MATERIALS and METHODS: $67 \mathrm{DN}$ patients and 41 non-nephropathy diabetic patients were included in the study.DN patients were assigned to 3 groups according to their alb/creatinine levels; Group1(<30), Group 2(30-300) and Group3 $(>300)$. The mean age of the DN and diabetes groups were Group 1 
65,Group2 57.2,Group3 61.5, and controls 55,respectively.PAF-AH activity as well as cholesterol, HDL-K,LDL-K,eGFR,folic acid,HOMA-IR,B12,Ca,P,hom ocysteine,fibrinogen,urea,uric acid,creatinine,ALT,AST,APO B,mg,TG levels were determined in patient sera, and vit.B12, urine,protein,creatinine and alb levels in patient urines.PAF-AH activity was determined by kinetic reading at 412 $\mathrm{nm}$ of the discoloration of free thiols formed by hydrolysis of the substrate 2-thiol PAF with DTNB.The method was applied to the Roche Cobas c501 analyzer RESULTS: No significant difference was found in the study between the PAF$\mathrm{AH}$ activities of $\mathrm{DN}$ and control groups( $\mathrm{p}>0.05)$. There was a strong correlation between PAF-AH activity and atherogenic parameters such as cholesterol,LDL $-\mathrm{K}$ and Apo B: Group1,(cholesterol $\mathrm{r}=0.700, \mathrm{p}=0.002 ; \mathrm{LDL}-\mathrm{K} \mathrm{r}=$ $0.760, \mathrm{p}=0.001$; APO B r $=0.874, \mathrm{p}=0.001$ ) Group 2, (LDL-K r=0.738, $\mathrm{p}=0.001$;APO $\mathrm{B} r=0.785, \mathrm{p}=0.001)$. Apo B showed a positive correlation with PAF-AH when all study groups were combined $(\mathrm{r}=0.593, \mathrm{p}=0.001))$.In group 3 , there was a moderate correlation between PAF-AH activity and creatinine $(\mathrm{r}=0.439, \mathrm{p}=0.015)$. CONCLUSIONS: Findings in our study have shown that PAF-AH activity in patients with DN is higher than diabetic patients. The increased PAF$\mathrm{AH}$ activity may be interpreted as an increased risk of plac rupture. However, this risk is independent from the albuminuria or proteinuria level. Keywords: Platelet activating factor - Acetyl hydrolase, diabetes, nephropathy, renal function

\section{OP-129 \\ TRANSFORMATION OF WHITE ADIPOSE TISSUE TO BROWN ADIPOSE TISSUE: IRISIN AND ITS METABOLIC EFFECTS}

Zerrin Kutlu ${ }^{1}$, Murat Ozan ${ }^{2}$, Erdinc Sıktar ${ }^{2}$, Zafer Bayraktutan $^{3}$, Mehmet Ali Gul $^{3}$, Ebubekir Bakan ${ }^{3}$, Fatma Zuhal Umudum ${ }^{3}$, Nurcan Kilıc Baygutalp ${ }^{1}$ ${ }^{1}$ Department of Biochemistry, School of Pharmacy, Ataturk University, Erzurum ${ }^{2}$ Department of Motion and Training Sciences, School of Sports Sciences, Ataturk University, Erzurum

${ }^{3}$ Department of Medical Biochemistry, School of Medicine, Ataturk University, Erzurum

OBJECTIVES: Irisin is a thermogenic protein that reduces the production of ATP over the UCP protein by turning white adipose tissue to brown adipose tissue and has been considered as an alternative for the treatment of diseases such as obesity, Type II diabetes. This study was aimed to measure circulating irisin levels after 4 weeks of exercise and to evaluate relationships between irisin levels and many biochemical/metabolic parameters. MATERIALS and METHODS: 30 elite boxers were randomly divided into 3 groups and different exercise programs were applied. Serum irisin, glucose, insulin levels and hemogram parameters were measured in venous blood samples taken from boxers at the end of 1st week, 2nd week, 3rd week and 4th week. Serum irisin levels were measured by ELISA method using commercial kit RESULTS: Serum irisin levels were $4.03 \pm 2,86 \mathrm{ng} / \mathrm{ml}$ at the beginning of the study, $4.13 \pm 2.67 \mathrm{ng} / \mathrm{ml}$ at the end of the first week, $4.67 \pm 3.76 \mathrm{ng} /$ $\mathrm{ml}$ at the end of the second week, $47.26 \pm 54.73 \mathrm{ng} / \mathrm{ml}$ at the end of the third week and $47.49 \pm 54.21 \mathrm{ng} / \mathrm{ml}$ at the end of the fourth week following exercise. The increment of serum irisin levels was statistically significant CONCLUSIONS: Considering the changes in serum irisin levels and other biochemical parameters, it was observed that 3 weeks of regular exercise showed positive effects on metabolism. Further studies are needed to evaluate the use of irisin, a promising compound discovered recently, in the treatment of many diseases, especially cancer. We intend to continue our researchs on irisin with further studies to investigate mRNA expression of the FNDC5 protein Keywords: irisin, exercise, brown adipose tissue

\section{OP-130
SERUM HYALURONIDASE ACTIVITY IN PATIENTS WITH BLADDER CANCER}

Tuba Özgün${ }^{1}$, Elmas Öğüș ${ }^{1}$, Ali Ayyıldı², Demirhan Örsan Demir², Doğan Yücel $^{1}$

'Department of Medical Biochemistry, Ankara Health Research and Training Center, Health Sciences University, Ankara

${ }^{2}$ Department of Medical Urology, Ankara Health Research and Training Center, Health Sciences University, Ankara

OBJECTIVES: Bladder cancer (BC) is the most common malignancy of the urinary system. Hyaluronidase (HYAL) degrades hyaluronic acid (HA), one of the structural components of the extracellular matrix. Our aim is to investigate the relationship between $\mathrm{BC}$ and HYAL activity and to evaluate the clinical and analytical performance of serum HYAL activity measurement method. MATERIALS and METHODS: Our study consisted $43 \mathrm{BC}$ patients and 43 control groups with the same symptoms but without $\mathrm{BC}$. After the removal of outliers of the age data of the groups, remained $39 \mathrm{BC}$ patients and 38 control patients in the study. The association between $\mathrm{BC}$ and prognostic parameters was obtained from $43 \mathrm{BC}$ patient data. All parameters were compared between age- and sex matched MK and control groups. HYAL activity was measured by Morgan-Elson colorimetric method. In this method, HA is degraded with HYAL, chromogen 1 and 2 are formed. Addition of dimethylamino benzaldehyde solution was allowed to form chromogen 3 . The resulting color change was measured spectrophotometrically at $585 \mathrm{~nm}$.
RESULTS: Serum HYAL activity in BC patients was found to be significantly higher than control group $(\mathrm{p}<0.05)$. Serum HYAL activity was found to be significantly increased proportionally with the clinical and / or pathologica stage of BC $(p<0.05)$. Serum HYAL activity was significantly higher in smokers than non-smokers $(\mathrm{p}<0.05)$. When we combined the patient and control groups $(\mathrm{n}=86)$, serum HYAL activity was no significant difference in participants younger than 55 years old than those older than 55 years old $(\mathrm{p}>0.05)$ CONCLUSIONS: The clinical performance of the method may be useful in the evaluation of $\mathrm{BC}$ patients. The method is also sufficient in terms of analytical performance caharacteristics. Keywords: Hyaluronic acid, Hyaluronidase, Bladder cancer

\section{OP-131}

\section{INFLAMMATORY RESPONSE EVALUATION OF SLEEP APNEA}

Ercan Saruhan $^{1}$, Yasemin Ünal ${ }^{2}$, Gülnihal Kutlu ${ }^{2}$

${ }^{1}$ Department of Medical Biochemistry, Faculty of Medicine, Muğla Sitk

Koçman University, Muğla

${ }^{2}$ Department of Neurology, Faculty of Medicine, Muğla Sitkı Koçman

University, Muğla

OBJECTIVES: Obstructive sleep apnea syndrome (OSAS), a disease characterized by recurrent obstructions of the upper airway during sleep, is one of the common health problems in the community. In this study, AHI (Apnea Hypopnea Index) values and C-reactive protein (CRP) levels were compared to show that the inflammatory response in obstructive sleep apnea syndrome is more intense in the REM and NREM sleep phases. MATERIALS and METHODS: Between 25 April and 20 July 2018 , 100 volunteer patients (74 males, 26 females) who were diagnosed as OSAS in the Sleep Laboratory of Muğla Sitkı Koçman University were included in the study. CRP levels were studied by immunoturbidimetric method and correlated with Total AHI, REM AHI and NREM AHI values. RESULTS:Themean CRPvalue was $3.545 \pm 3.82 \mathrm{mg} / \mathrm{L}$, TotalAHI was $38.45 \pm 27.21$, REMAHI was $39.64 \pm 27.31$, and NREMAHI was $37.65 \pm 28.95$. Positive correlation between REM AHI and CRP levels $(r=0.332)$ was statistically significant $(\mathrm{p}<0.05)$. CONCLUSIONS: Apnea and hypopnea occurring during REM sleep period cause more hypoxia and accompanying inflammatory response compared to NREM. Because REM sleep duration covers a smaller proportion of total sleep duration, lower AHI scores are obtained in REM-associated OSAS patients. In our study, there was no correlation between CRP levels and total AHI values, but statistically significant correlation between CRP and REM AHI values was found. Since the effects of REM and NREM sleep periods are different, it is very important to follow apnea evaluation according to sleep stages as well as apnea during the whole sleep period and to plan treatment accordingly. Keywords: Sleep apnea, inflammation, C-reactive protein

\section{OP-132}

\section{ZINC ANALYSIS IN MULTIPL SKLEROSIS (MS) PATIENTS: KONYA} EXAMPLES

Mustafa Fatih Hayïrlioğlu ${ }^{1}$, Ali Ulvi Uca ${ }^{2}$, Mehmet Gürbilek

${ }^{1}$ Necmettin Erbakan University Meram Medical Faculty Medical Biochemistry Department, Konya

${ }^{2}$ Necmettin Erbakan University Meram Medical Faculty Neurology Department, Konya

OBJECTIVES: Multiple sclerosis (MS) is an autoimmune disease characterized by inflammation and demyelination in many parts of the central nervous system (CNS), which usually begins in young adulthood. A wide variety of studies on MS etiology, pathogenesis and treatment are ongoing. In this study, it was investigated that decreased zinc levels may increase the susceptibility to immune system disorders in MS and alter the activity of the disease MATERIALS and METHODS: The study was carried out in N.E.Ü Meram Medical Faculty Hospital. The study consisted of 20 individuals with MS findings and 20 healthy controls with radiological findings. Zinc study was carried out in Atomic Absorption Spectrophotometer T-test was applied in the statistical analysis of the results. RESULTS: As a result of the study, the zinc levels of MS patients were found to be $9.33 \pm 1.13$ and the zinc average of healthy controls was found to be 11.63 \pm 1.01 . The mean age of MSI individuals is 34.1 and the healthy controls are 33.5. The age at onset of MS patients is between $20-30 \%$ in $48 \%$ of cases. The number of patients with MS was $17(85 \%)$ and the male ratio was $3(15 \%)$. CONCLUSIONS: It has been observed that zinc deficiency in MS patients with autoimmune disease is lower than normal values. Zinc, which is very important for increasing the immunity of the immune system, may be followed in nutritional and food supplements in MS patients by strengthening the immune systems of natural persons with MS and decreasing the effect of the disease. Keywords: zinc, multiple sclerosis, the immune system 


\section{OP-133 \\ CIRCULATING OF MIRNA-521 AND OXIDANT/ANTIOXIDANT STATUS AFTER RADIATION IN PROSTATE CANCER}

Selim Öğ̈̈t ${ }^{1}$, Behice Cinemre ${ }^{2}$, Didem Karaçetin ${ }^{3}$, Hakan Cinemre ${ }^{4}$, Alev Kural $^{5}$, Birsen Aydemir ${ }^{6}$

${ }^{1}$ Department of Radiotherapy, School of Health, Istanbul Gelişim University, Istanbul

${ }^{2}$ Department of Biochemistry, Faculty of Medicine, Sakarya University, Sakarya ${ }^{3}$ Dr. Sadi Konuk Education and Research Hospital, Radiation Oncology Clinic, Istanbul

${ }^{4}$ Department of Internal Medicine, Faculty of Medicine, Sakarya Univesity, Sakarya

${ }^{5}$ İstanbul Dr. Sadi Konuk Education and Research Hospital, Medical Biochemistry Clinic, Istanbul

${ }^{6}$ Department of Biophysics, Faculty of Medicine, Sakarya University, Sakarya

OBJECTIVES: Radiotherapy is a therapeutic strategy in the prostate cancer (PCa). As some tumor cells can be radio-resistant, tumors may relapse and metastases. After radiotherapy some genes in cancer cells are effected directly from radiation. MicroRNAs (miRNAs) are the molecules which regulate gene expression related with tumorigenesis, metastatic progression and therapeutic responses. In recent studies, the roles of miRNAs in radiation response in prostate cancer cell lines have been investigated. However, the roles of miRNA, and its integration into the radiation signaling pathways are largely unknown. Our aim was to investigate expression levels of miR-521, total antioxidant status (TAS), which is a marker of all of the antioxidants, and 8-hydroxy2'-deoxyguanosine (8-OHdG) levels, which is a marker of DNA oxidative damage, in patients with $\mathrm{PCa}$, before, after radiation therapy. MATERIALS and METHODS: 30 patients who admitted to Radiation Oncology Department for PCa radiotherapy were included in study. Blood samples for the miRNA were obtained before and after initiation of radiotherapy. miR521 expressions were analyzed by using quantitative reverse-transcription polymerase chain reaction.. TAS and 8-OHdG were measured by ELÍSA. RESULTS: We found that miR-521 expression levels increased in the group after radiotherapy. 8-OHdG levels were found to be higher in the after radiotherapy patients group when compared to before radiotherapy patient group. Additionally, no significant differences were found between the groups as TAS levels were taken into consideration. CONCLUSIONS: Expression of miRNAs, such as miR-521 effected by radiation therapy in patient with $\mathrm{PCa}$ showing that they might be related with treatment efficacy of radiotherapy of the cancer patients. Keywords: Prostat Cancer, miR-521, TAS, 8-OH dG

\section{OP-134 \\ EVALUATION OF ANALYTICAL PERFORMANCE IN CLINICAL} CHEMISTRY LABORATORY VIA MEASUREMENT UNCERTAINTY

Ömer Kaya, Hüseyin Kurku

Konya Research and Training Hospital, Clinical Biochemistry, Konya

OBJECTIVES: Measurement uncertainty is a quantitative indicator of the quality of the result produced in a laboratory. We aimed to compare the values obtained by the measurement uncertainty of twenty two parameters from two different devices of the same brand and model used in the laboratory calculated by using the internal and external quality control results for the biochemistry with the total allowable error (\%TEa) values of CLIA. MATERIALS and METHODS: Our laboratory's external quality control data for the years 2016, 2017 and 2018 and internal quality control data for the year 2018 were analyzed retrospectively. Two Beckman Coulter AU5800 (Beckman Coulter, Mishima, Japan) autoanalyzers were used in this study. In the calculation of measurementuncertainty, the6-stepmodeldescribedintheNordestmanualwasused. RESULTS: The measurement uncertainty values of Sodium and Chloride tests obtained from both autoanalyzers were found to be higher than the \%TEa values. The measurement uncertainty values calculated for Albumin, ALP AST, ALT, Amylase, Calcium, Total Cholesterol, CK, Creatinine, Iron, Glucose, HDLCholesterol, Potassium, LDH, Magnesium, Total Bilirubin, Triglycerides, Uric Acid, Blood Urea Nitrogen from both autoanalyzers were within the limits of CLIA. CONCLUSIONS: Measurement uncertainty is a good evaluation model for the analytical performance of clinical laboratories. However, each laboratory should determine which of the analytical error calculation models to use according to its own dynamics. The analytical difference between autoanalyzers must be monitored and minimized. Also in the patient outcomet format, test and device specific measurement uncertainty values must be declared. Keywords: Analytical performance, measurement uncertainty, total allowable error, CLIA

\section{OP-135 \\ A DISCUSSION STUDY FOR LABORATORY PROCESS EDUCATION DEMANDS AND NEEDS OF OUR TECHNICIANS}

Saliha Aksun ${ }^{1}$, Candeğer Avşarr ${ }^{1}$, Hayat Özkanay ${ }^{1}$, Tuğba Öncel ${ }^{1}$, Leyla Demir ${ }^{1}$, Huriye Erbak Yilmaz ${ }^{2}$, Ayşenur Atay ${ }^{2}$, Figen Narin

${ }^{1}$ Department of Medical Biochemistry, Faculty of Medicine, Izmir Katip Celebi University, Izmir, Turkey

${ }^{2}$ Izmir Katip Celebi University Atatürk Training and Research Hospital, Medical Biochemistry Laboratory, Izmir, Turkey

OBJECTIVES: Laboratory technicians have a role in the continuous functioning of preanalytical, analytical and postanalytical phases.

Sample acceptance, rejection, the correct description of the sample, proper management, storage, true preparation of analytical instruments, the meaning of the tests in the post analytical process, panic values, interfering substances. it is necessary for good laboratory practices that all laboratory staff have adequate knowledge in the matter of correct pre-approval of results.

Our technicians have theoretical information requests.It is planned to conduct a survey with the aim of analyzing the needs and determining the training programs. MATERIALS and METHODS: 20 question and multiple choice options were created, reflect about the most common preanalytical and analytical issues. The questionnaire has been directed into 36 laboratory technicians in IKÇÜ Atatürk Education and Research hospital.

General statements were related to sample quality, correctly samples collecting, blood-taking errors

sample storage conditions, frequent preanalytical errors. Specific questions were related to impact of hemolysis interferences, relation of hematocrit with hemoglobin, calculated biochemical tests, markers, laboratory tests that require urgent work.

RESULTS: Since $70 \%$ of the respondents do not know the concept of full clot retraction, the blood is centrifuged early and fibrin formation in the serum continues. It was not known by the $50 \%$ participants that calcium and potassium could be affected in EDTA-induced calorie.

CONCLUSIONS: It is necessary to education to all laboratory technicians In the course of our work, laboratory quality studies and the effect of training would be evaluated by indicators.as sample rejection rate, time to yield, accurate sample storage etc.

Keywords: laboratory education, survey study, good laboratory practices

\section{OP-136}

\section{INVESTIGATION OF THE READABILITY OF NOTIFICATION TEXTS OF THE DOUBLE TEST IN THE INTERNET}

\section{Ciğdem Damla Deniz ${ }^{1}$, Mahmut Sami Tutar², Betül Kozanhan², Oğuzhan} Günenç

${ }^{1}$ Department of Clinical Biochemistry, Konya Training and Research Hospital, Konya

${ }^{2}$ Department of Anesthesiology and Reanimation, Konya Training and Research Hospital, Konya

${ }^{3}$ Department of Gynecology and Obstetrics, Konya Training and Research Hospital, Konya

OBJECTIVES: The first trimester screening test, also known as the double test or the 11-14 test, is a test to detect infants with chromosomal anomalies. Internet is a resource that patients often use in order to better understand medical procedures. With this study, it is aimed to determine the readability levels of web sites. MATERIALS and METHODS: A total of $200 \mathrm{web}$ sites were reached by the web search engine Google using the keywords such as 'double test', '11 -14 week test'. Sites with less information than ten sentences, chat, forum and commercial blog sites were excluded from the study. The average readability level was analyzed using Ateşman and Bezirci-Yilmaz readability formulas RESULTS: Following the application of the exclusion criteria, 48 web sites were eligible for evaluation. Of these, $62,5 \%$ were private clinics, $18,5 \%$ were private hospitals and $8,3 \%$ were private laboratory sites. The readability of the web sites was moderate to severe according to the Atesman formula, and it was very difficult according to the Bezirci-Yilmaz formula. Most of the texts contained information about the definition of the double test. However, in these texts, it has been seen that there is not enough mention of the interpretation of the double test results. CONCLUSIONS: It has been determined that the readability level of informative texts related to double test on web sites was low. It has been concluded that the cooperation of the effective biochemical societies and health care institutions is necessary for the revision of existing information texts. Keywords: DoubleTest, Readibility, Understandability

\section{OP-137}

\section{EVALUATION OF ANTAGONISTIC AND SINERGISTIC PAIR-WISE} ANTIBIOTIC DRUG INTERACTIONS

$\frac{\text { Kaan Y1lancioğlu }}{\text { Uskudar University }}$

OBJECTIVES: Antibiotic resistance in pathogenic bacteria is a major health problem. The long-term efforts of the emergence of new antibiotics and of 
treatment methods make this problem more difficult to be solved in the near future. Clinicians currently use combinatorial antibiotics as the most effective method of treatment. However, antibiotics can show synergistic interactions when used together, as well as antagonistic interactions. For this reason, understanding of antibiotic interactions is important. In our study, it is aimed to investigate the interactions of antibiotics with different mechanisms of actions. MATERIALS and METHODS: Antibiotics, which act as protein synthesis inhibitor (PRO) and DNA synthesis inhibitor (DNA), were used in our study. 108 DNA-PRO, 30 DNA-DNA and 112 PRO-PRO drug pairs were tested on the Escherichia coli strain and the interactions of the pair-wise combinations of drugs were analyzed. The Loewe additivity model was used statistically and alpha scores were calculated. Drug interactions are categorized as synergistic and antagonistic. RESULTS: Accordingly, it has been found that combinations of protein synthesis inhibitors have showed more synergistic and stronger synergistic effects than combinations of DNA synthesis inhibitors and DNA synthesis-protein synthesis inhibitors. CONCLUSIONS: As a result of the study, The importance of the mechanisms of action of drugs is emphasized in the selection of synergistic drug combinations. It is likely that such studies on screening of pair-wise combinations of DNA synthesis and protein synthesis inhibitors will shed light on finding effective pairs in therapy. Keywords: Antagonism, Antibiotic interactions, Synergy

\section{OP-138 \\ DETERMINATION OF PHYSIOLOGICAL IMPACTS OF HEAVY METALS IN DIFFERENT CROPS THROUGH HYDROPONIC STUDIES}

\section{Elif Öztetik \\ Anadolu University}

OBJECTIVES: Rapid population growth on earth increases the needs for the healthy food. However, so called development of the industrial activities and related sectors with increased traffic load and household wastes cause heavy metal (HM) accumulations in soil, air and waters dramatically. Increased HMs can easily transfer from original sources to other organisms via food chain and this begins with plants. As final scheme of this transportation can cause some serious health problems in humans, therefore we examined the HM effects on some of the most commonly consumed crop varieties. MATERIALS and METHODS: In this study, toxic effects of HMs on germination percentage, root and shoot length, water, pigment and MDA contents of wheat (Triticum aestivum cv. Bezostaja) and barley (Hordeum vulgare cv. Erginel) varieties were investigated through selected concentrations $(0,1.5,3.0$ $\mathrm{mM})$ of $\mathrm{PbCl} 2$ and $\mathrm{CdCl} 2$ together with their combinations $(\mathrm{PbCl} 2+\mathrm{CdCl} 2)$. RESULTS:According to our results, application ofHMs to plants caused differences in their physiological parameters by comparing to control groups. Except carotenoid and MDA contents, all other parameters decreased after HM treatments dramatically. Detailed observations have shown that, Erginel (barley) variety were found to be more tolerant to HM stress by comparing to Bezostaya (wheat). CONCLUSIONS: It is clear that, the initiation of oxidative stress in examined crop varieties were caused by the application of HMs. Consequently, to determine more tolerant species / varieties, onward studies should recruite different HM applications along with their range of concentrations on other most commonly cultivated crop species. Keywords: Crops (Barley and Wheat), Germination, Heavy metals (Cd and Pb), MDA, Pigment

\section{OP-139 \\ PEROXIDASE-LIKE ACTIVITY OF MAGNETIC POROUS SILICA MICROSPHERES AND THEIR INTERACTION WITH DNA}

$\underline{\text { Sevim Eda Öğ̈̈t }}{ }^{1}$, Burcu Gökçal ${ }^{2}$, Çiğdem Kip ${ }^{2}$, Ali Tuncel ${ }^{2}$

${ }^{1}$ Hacettepe University, Bioengineering Division, Ankara

${ }^{2}$ Hacettepe University, Chemical Engineering Department, Ankara

OBJECTIVES: This study was to test the peroxidase activity of the monodispersporous silica microspheres. The use of synthesized microspheres as a support material reveals a linear increase in peroxidase activity with increased concentration of genomic DNA.The results facilitate the development of a new diagnostic kit. MATERIALS and METHODS: The monodisperse-porous silica microspheres were $5 \mathrm{~mm}$ in size and with a coefficient of variation for size distribution less than $5 \%$.The morphological investigation performed by SEM showed that the surface of microspheres was porous. The devleoped synthetic protocol of the magnetic silica microspheres allowed strong immobilization of magnetic $\mathrm{Fe} 3 \mathrm{O} 4$ nanoparticles on the surface of the pore found within the microspheres. The presence of tightly immobilized Fe3O4 nanoparticles having an ability to interact with the enviroment should be probably the main reason of peroxidase-like activity of magnetic silica microspheres. RESULTS: In order to test the peroxidase-like activity of magnetic silica microspheres, tetramethylbenzidine (TMB) was used as the substrate.The effect of concentration of magnetic silica microspheres on the peroxidaselike activity was investigated in TE buffer medium using TMB as the synthetic substrate and a linear increase in the peroxidase-like activity with the increasing microsphere concentration.Besides, the effect of human genomic DNA concentration on the peroxidase-like activity of magnetic silica microspheres was investigated.The results showed that a linear increase occurred in the activity with the increasing DNA concentration. CONCLUSIONS: The results of presented study also allow the development of new diagnostic methods worked based on peroxidase-activity. The magnetic silica microspheres have a significant potential as support material for various biological molecules.Hence, the use of magnetic silica microspheres with this property instead of an expensive enzyme-peroxidase may provide serious advantages in the studies on the development of diagnostic test kits. Keywords: peroxidase-like activity, microspheres, genomic DNA

\section{OP-140 \\ EVALUATION OF SUSPICIOUS POSITIVE HLA B27 RESULTS IN FLOW CYTOMETRY}

Bagnu Orhan, Derya Sonmez, Birsen Cigdem Topkaya, Berrin Bercik Inal Istanbul Training and Research Hospital, Medical Biochemistry Laboratory, Istanbul

OBJECTIVES: We aimed to investigate how suspicious positive results obtained by flow cytometry turned out in the verification tests conducted in the genetic laboratory and to evaluate the reference range of the test.

MATERIALS and METHODS: In the Medical Biochemistry Laboratory of Istanbul Training and Research Hospital, between January 27 th 2017 and October 16 th 2018, 1949 HLA B27 flow cytometry (Beckman Coulter Navios 10 Color $3 / \mathrm{L}$ ) screening results were analyzed retrospectively. Seven suspected positive samples were sent to the genetic laboratory for verification and the results were compared.

RESULTS: Of the 1949 patients, 1747 were reported as negative, 30 as positive, and 172 as suspicious positive. It was observed that the suspicious positive results were positive for all of the samples directed to the genetic laboratory for verification by the clinician.

CONCLUSIONS: Genetic validation of all suspicious positive results was positive and it is suggested that recommended reference range for flow cytometry should be reviewed.

Keywords: HLA B27, flow cytometry, reference range

\section{OP-141 \\ DETECTION OF AFP VALUES IN PATIENT WITH ATAXIA TELANGIECTASIA}

Oytun Portakal

Hacettepe University, Medical School, Department of Biochemstry, Ankara

OBJECTIVES: Ataxia telangiectasia (A-T) is a rare disease, characterized by cerebellar ataxia, telangiectasia immunodeficiency, radiation sensitivity, and cancer predisposition. A-T is a genome instability disorder, and associated with elevated serum alpha fetoprotein (AFP) and hipogamaglobulinemia. The purpose of this study to determine serum AFP levels in patients with A-T, and to get attention to the importance of this disease

MATERIALS and METHODS: Retrospectively serum AFP levels in patient with A-T were investigated. Median and IQR were calculated. The change in immunoglobulin values were investigated.

RESULTS: Total 51 subject diagnosed as A-T, in whom 22 were boys, were included into the study. The mean age was $8,8 \pm 5,7$ Median AFP value was found to be $147,12 \mathrm{ng} / \mathrm{mL}$ (IQR 28,03 -357,12). There was a positive correlation between age and AFP levels with a 0,81 of correlation coefficient.

CONCLUSIONS: Elevated serum AFP is important biomarker in diagnosis of A-T.

Keywords: Alpha fetoprotein, Ataxia telangiectasia, Rare disease 